\title{
Rheumatoide Arthritis: Proteomische Analyse von Serum und synovialen Fibroblasten zur Detektion von Biomarkern
}

\author{
Dissertation \\ zur Erlangung des Doktorgrades \\ der Mathematisch-Naturwissenschaftlichen Fakultäten \\ der Georg-August-Universität zu Göttingen
}

vorgelegt von

Jan-Hendrik Streich

aus Oldenburg i.O. 
Referent: Prof. Dr. Sigrid Hoyer-Fender

Korreferent: Prof. Dr. Uwe Groß

Tag der mündlichen Prüfung: 22.04.2009 
Der Fortgang der wissenschaftlichen Entwicklung ist im Endeffekt eine ständige Flucht vor dem Staunen.

Albert Einstein 



\section{Inhaltsverzeichnis}

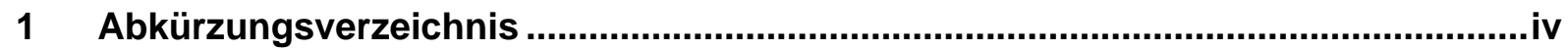

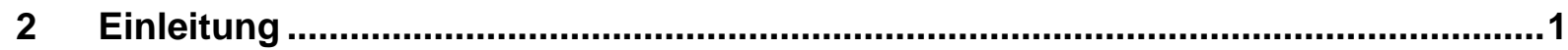

2.1 Krankheiten des rheumatischen Formenkreises ...........................................

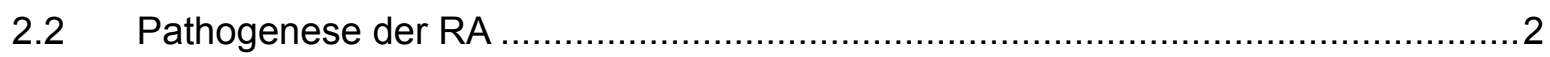

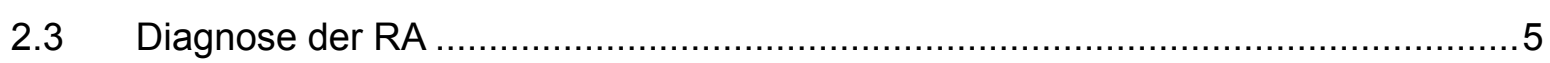

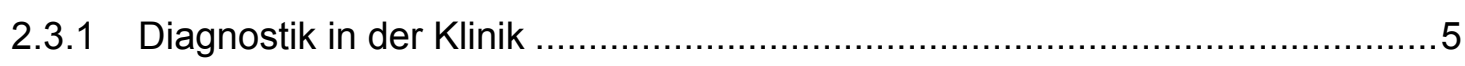

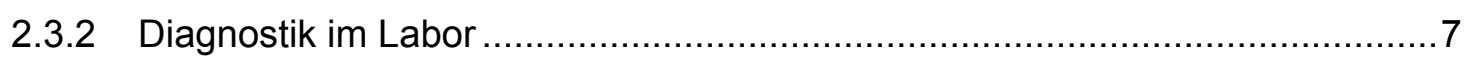

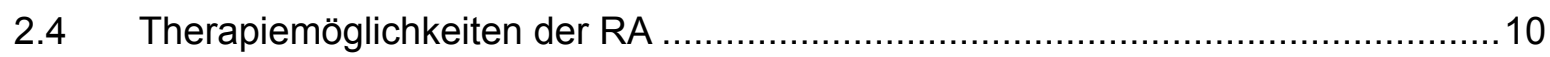

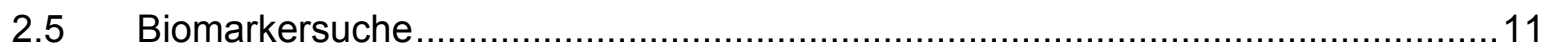

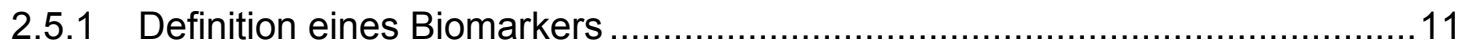

2.5.2 Biomarkersuche durch 2D-SDS-Page ............................................... 12

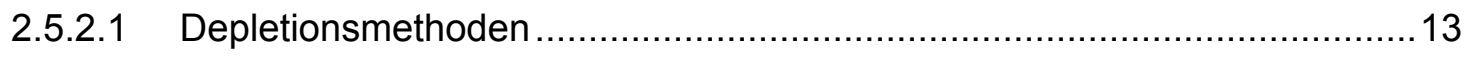

2.5.3 Weitere Methoden zur Biomarkersuche ............................................. 14

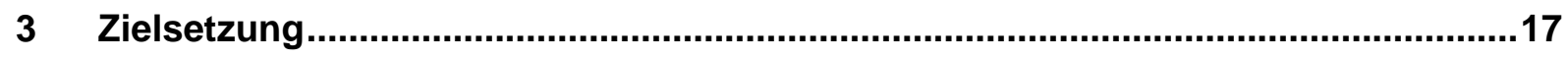

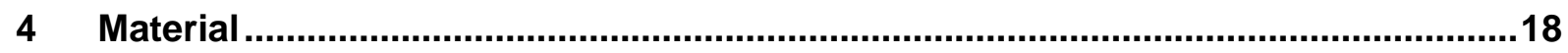

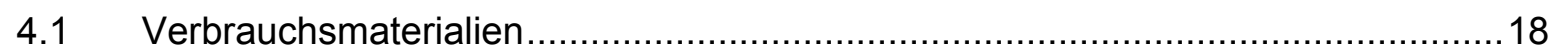

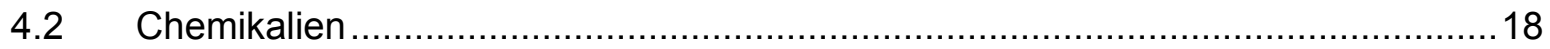

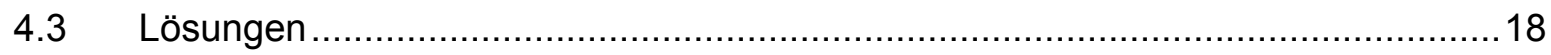

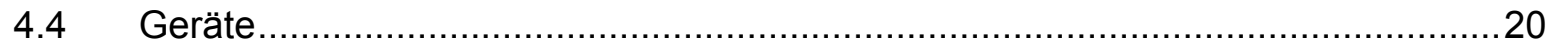

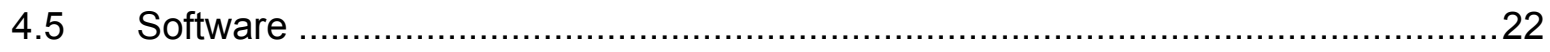

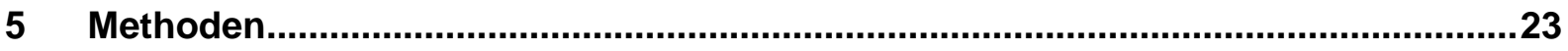

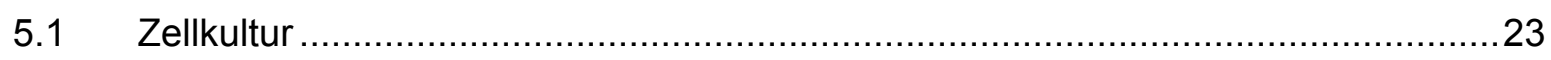

5.1.1 Isolierung synovialer Fibroblasten aus Synovia ......................................23

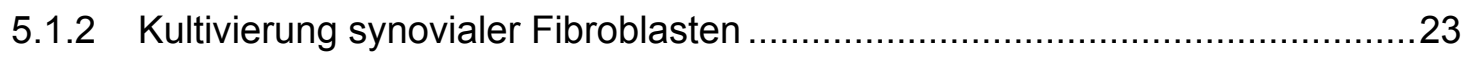

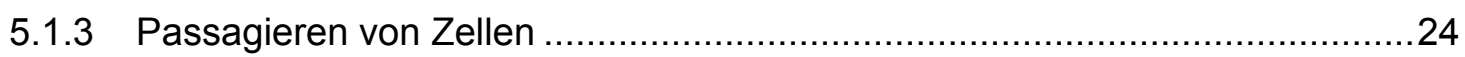

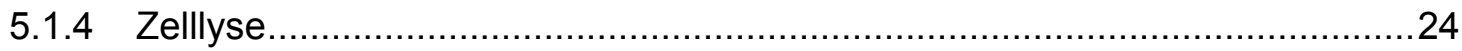

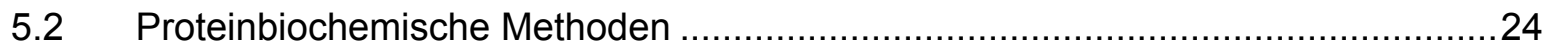

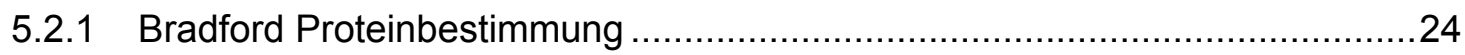

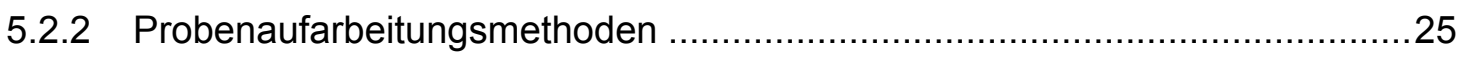

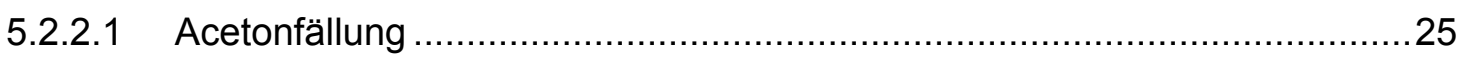

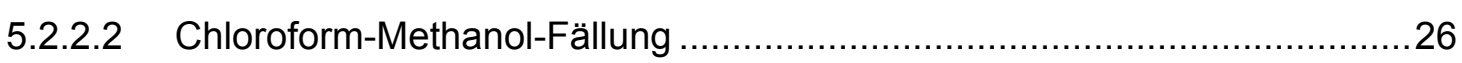

5.2.2.3 Ankonzentrierung und Entsalzung mittels Vivaspin ${ }^{\circledR}$-Konzentratoren ........26

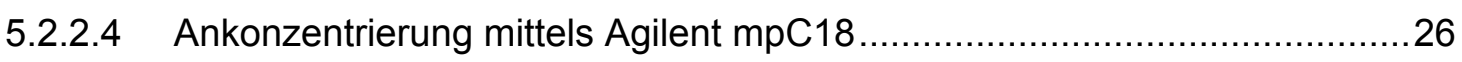

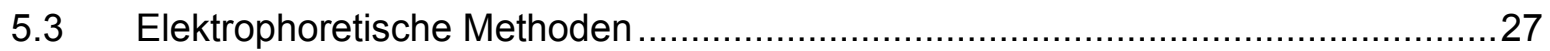

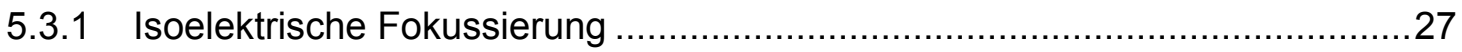

5.3.2 Proteinelektrophorese im SDS-Polyacrylamidgel ......................................28 


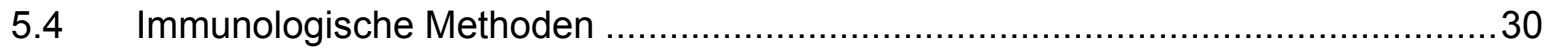

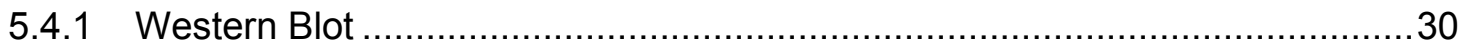

5.4.2 Immunoblot: Citrullin Detektionskit ...................................................... 31

5.5 DIGE (Differentielle In-Gel Elektrophorese) ............................................. 32

5.5.1 Probenvorbereitung und Kopplung der Farbstoffe ....................................33

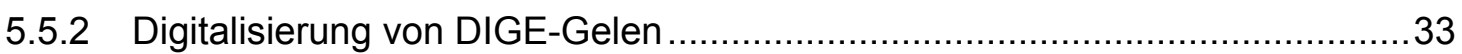

5.5.3 Statistische Auswertung von DIGE-Gelen ................................................. 35

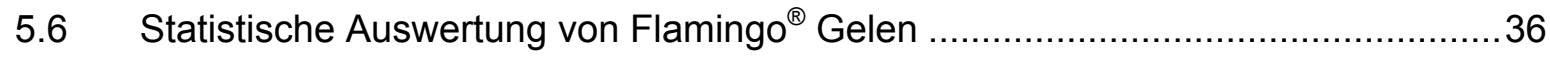

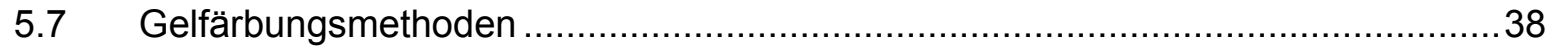

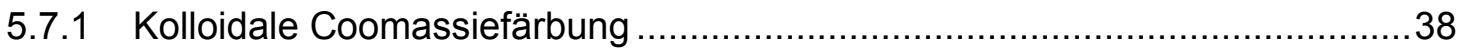

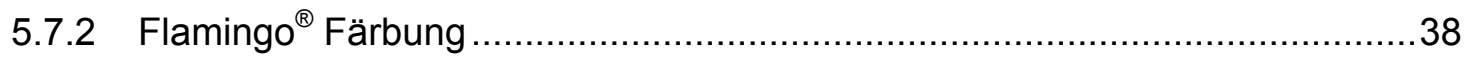

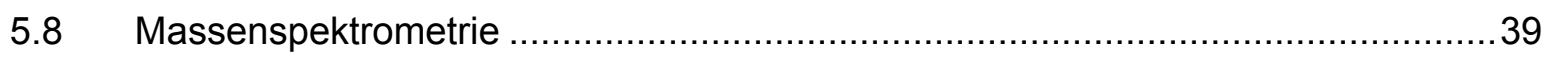

5.8.1 Tryptischer Verdau von Proteinen im SDS-Polyacrylamidgel........................41

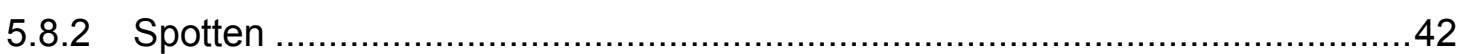

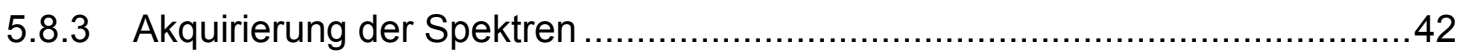

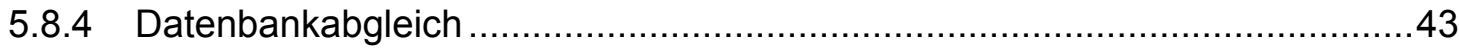

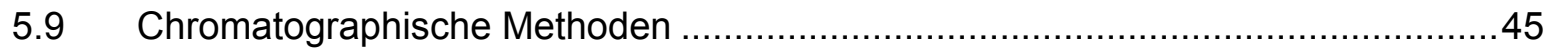

5.9.1 Funktionsprinzip der Immunodepletion ..................................................... 45

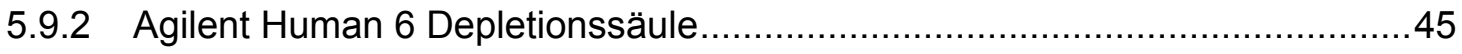

5.9.3 Beckman-Coulter Proteome Lab IgY-12 LC2 Depletionssäule.......................46

5.9.4 Entsalzungs- und Fraktionierungsmethoden ........................................47

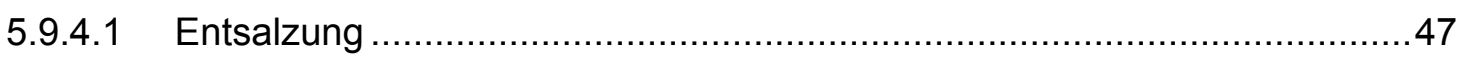

5.9.4.2 Fraktionierung durch eine Gradiententrennung ....................................47

5.9.4.3 Fraktionierung durch einen Stufengradienten ........................................48

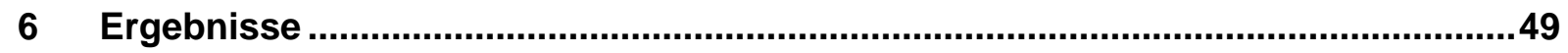

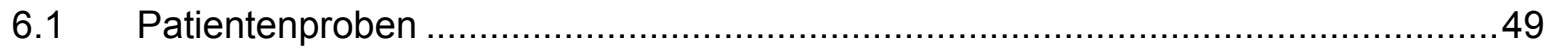

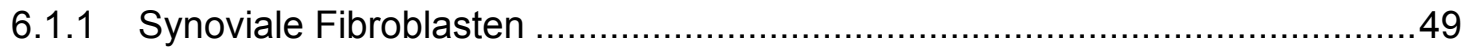

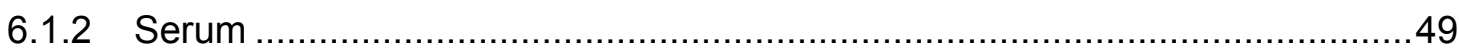

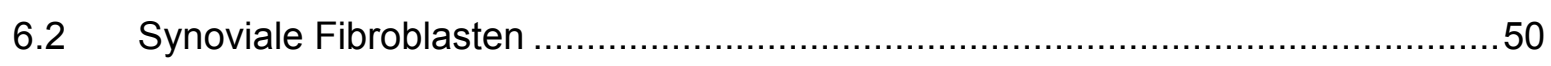

6.2.1 Kultivierung synovialer Fibroblasten ................................................ 50

6.2.2 Gelelektrophoretische Analyse der synovialen Fibroblasten ........................51

6.2.3 Validierung der Expressionsunterschiede durch Western Blot .......................54

6.2.4 Nachweis citrullierter Proteine in Zelllysaten synovialer Fibroblasten ............55

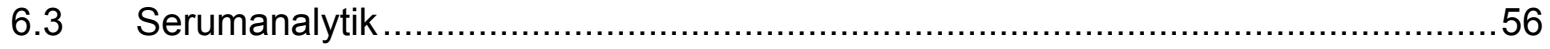

6.3.1 Elektrophoretische Auftrennung von Serumproteinen .................................56

6.3.2 Optimierung der depletierten Serumproben für die 2D-SDS-PAGE ..............59

6.3.3 Vergleich der Depletionssäulen .............................................................62 
6.3.4 Identifizierungen im humanen depletierten Serum ..................................64

6.3.5 Fraktionierung von depletiertem Serum ..................................................66

6.3.5.1 Fraktionierung durch eine Gradiententrennung ....................................66

6.3.5.2 Fraktionierung durch eine Stufenelution ..............................................69

6.3.6 DIGE-Vergleich der depletierten Seren ................................................ 74

6.3.7 Nachweis von citrullierten Proteinen im humanen Serum ............................. 78

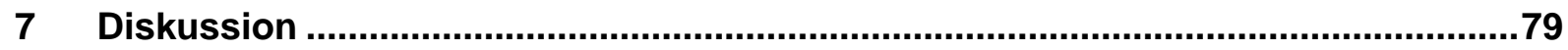

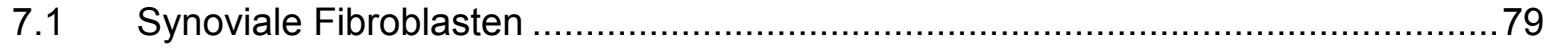

7.1.1 Methodische Einflüsse auf die Analysen ................................................

7.1.2 Diskussion der Expressionsunterschiede von HSPB1 und Destrin in RASF..80

7.1.3 Vimentinfragmente als spezifische Gewebemarker der RA .........................81

7.1.4 Die Bedeutung von Vimentin bei Apoptose der RASF ...............................83

7.1.4.1 Vimentin als anti-apoptotisches Protein................................................. 83

7.1.4.2 Vimentin als pro-apoptotisches Protein ................................................ 85

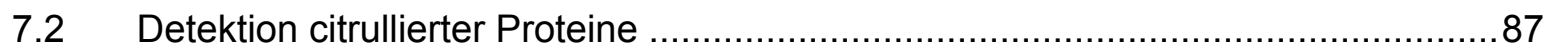

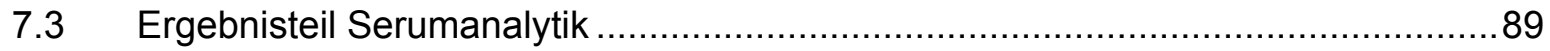

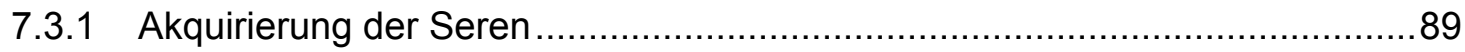

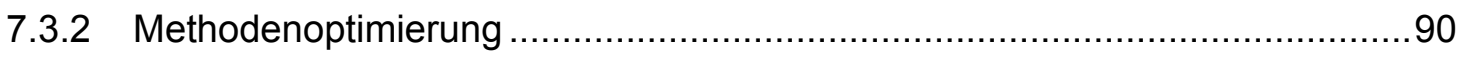

7.3.3 Identifizierungen der Proteine im depletierten Serum und deren Rolle in der

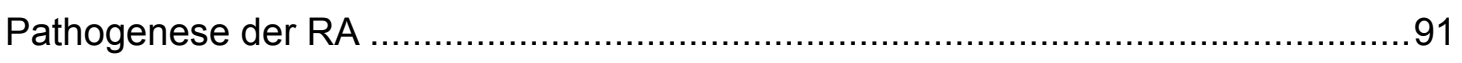

7.3.4 Untersuchung des depletierten und fraktionierten Serums ..........................92

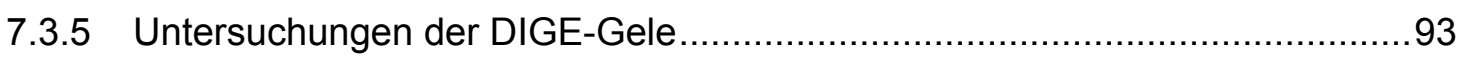

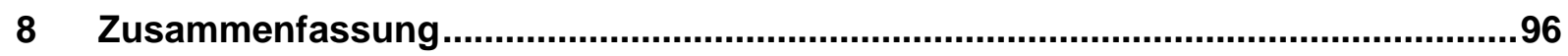

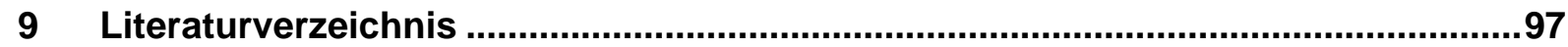

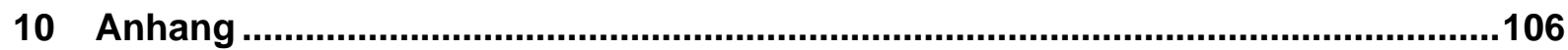

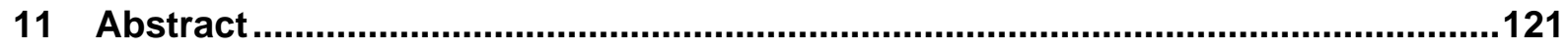

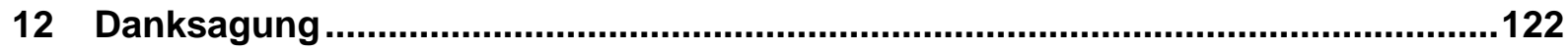

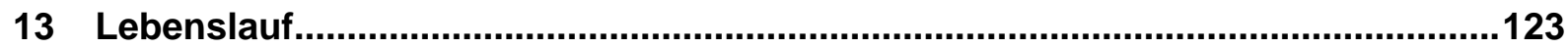




\section{Abkürzungsverzeichnis}

\begin{tabular}{|c|c|c|c|}
\hline $\mathrm{ACN}$ & Acetonitril & MCV & Mutiertes citrulliertes Vimentin \\
\hline ACPA & $\begin{array}{l}\text { Anti-citrulliertes Protein/Peptid } \\
\text { Antikörper }\end{array}$ & MALDI & $\begin{array}{l}\text { Matrix-unterstützte-Laser- } \\
\text { Desorption/Ionisation }\end{array}$ \\
\hline ad & auf & MS & Massenspektrometrie \\
\hline AK & Antikörper & MS/MS & Tandemmassenspektrometrie \\
\hline APS & Ammoniumpersulfat & OA & Osteoarthritis \\
\hline BSA & Bovines Serum Albumin & OASF & Synovialer Fibroblast OA \\
\hline BSG & Blutsenkungsgeschwindigkeit & PAD & Peptidylarginindeiminase \\
\hline CCP & Cyclisch citrulliertes Peptid & PAGE & Polyacrylamid-Gelelektrophorese \\
\hline CRP & C-reaktives Protein & pl & Isoelektrischer Punkt \\
\hline $\mathrm{Da}$ & Dalton & PMF & Peptide Mass Fingerprint \\
\hline DHB & Dihydroxybenzoesäure & PVDF & Polyvinylidenfluorid \\
\hline DIGE & Differentielle In-Gel-Elektrophorese & RA & rheumatoide Arthritis \\
\hline DTT & 1,4-Dithiothreitol & RASF & Synovialer Fibroblast RA \\
\hline ECM & Extrazelluläre Matrix & Ratio & Relativer Expressionsunterschied \\
\hline ESI & Elektrospray-Ionisation & RF & Rheumafaktor \\
\hline FFE & Free Flow Electrophoresis & RP & Umkehrphase \\
\hline g & Erdbeschleunigung & SC & Sequenzabdeckung \\
\hline GES & gesund & SD & Standardabweichung \\
\hline HPLC & Hochleistungsflüssigkeitschromatografie & SDS & Natriumdodecylsulfat \\
\hline IEF & Isoelektrische Fokussierung & SELDI & $\begin{array}{l}\text { Surface enhanced laser desorption } \\
\text { ionisation }\end{array}$ \\
\hline IEX & Ionenaustauscher & TEMED & Tetramethylethylendiamin \\
\hline IFN & Interferon & TFA & Trifluoressigsäure \\
\hline IL & Interleukin & TNF & Tumornekrosefaktor \\
\hline IPG & Immobilisierter pH-Gradient & Tris & Tris(hydroxymethyl)-aminomethan \\
\hline kDa & Kilodalton & $v / v$ & Volumen pro Volumen \\
\hline LC & Liquid Chromatography & $w / v$ & Gewicht pro Volumen \\
\hline m & Masse & $\mathbf{z}$ & Ladung \\
\hline
\end{tabular}

In dieser Arbeit wurden die gebräuchlichen SI-Einheiten verwendet. 


\section{Einleitung}

\subsection{Krankheiten des rheumatischen Formenkreises}

„Was man nicht erklären kann, das sieht man gern als Rheuma an.“ Dieses volkstümliche Sprichwort verdeutlicht die Problematik der Definition von Rheuma, denn zu den Krankheiten des rheumatischen Formenkreises gehören alle chronisch schmerzhaften und mit dauerhaften Bewegungseinschränkungen verbundenen Störungen des Stütz- und Bewegungsapparates. Die Internationale Klassifikation der Krankheiten (ICD, International Classification of Diseases) unterscheidet mittlerweile 450 verschiedene Erkrankungen des Muskel-SkelettSystems und des Bindegewebes, welche sich in Beschwerdebild, Verlauf und Prognose sehr unterscheiden. Eine kurze schematische Übersicht der Systematik rheumatischer Erkrankungen, die vorrangig die Gelenke betreffen, ist in Abbildung 1 dargestellt. Laut Angaben des DRFZ (ㅁeutsches $\underline{R}$ heuma $\underline{F}$ orschungszzentrum) begeben sich schätzungsweise $15 \%$ der Bevölkerung mindestens ein Mal im Jahr in ärztliche Behandlung wegen rheumatischer Beschwerden. Überdies verursachen Erkrankungen von Skelett, Muskeln und Bindegewebe ca. $15 \%$ aller verlorenen Erwerbsjahre.

Somit haben die Krankheiten des rheumatischen Formenkreises nicht nur eine sozialmedizinische Bedeutung, sondern stellen wegen der ätiologischen, pathogenetischen und klinischen Heterogenität eine Herausforderung für die Diagnostik dar.

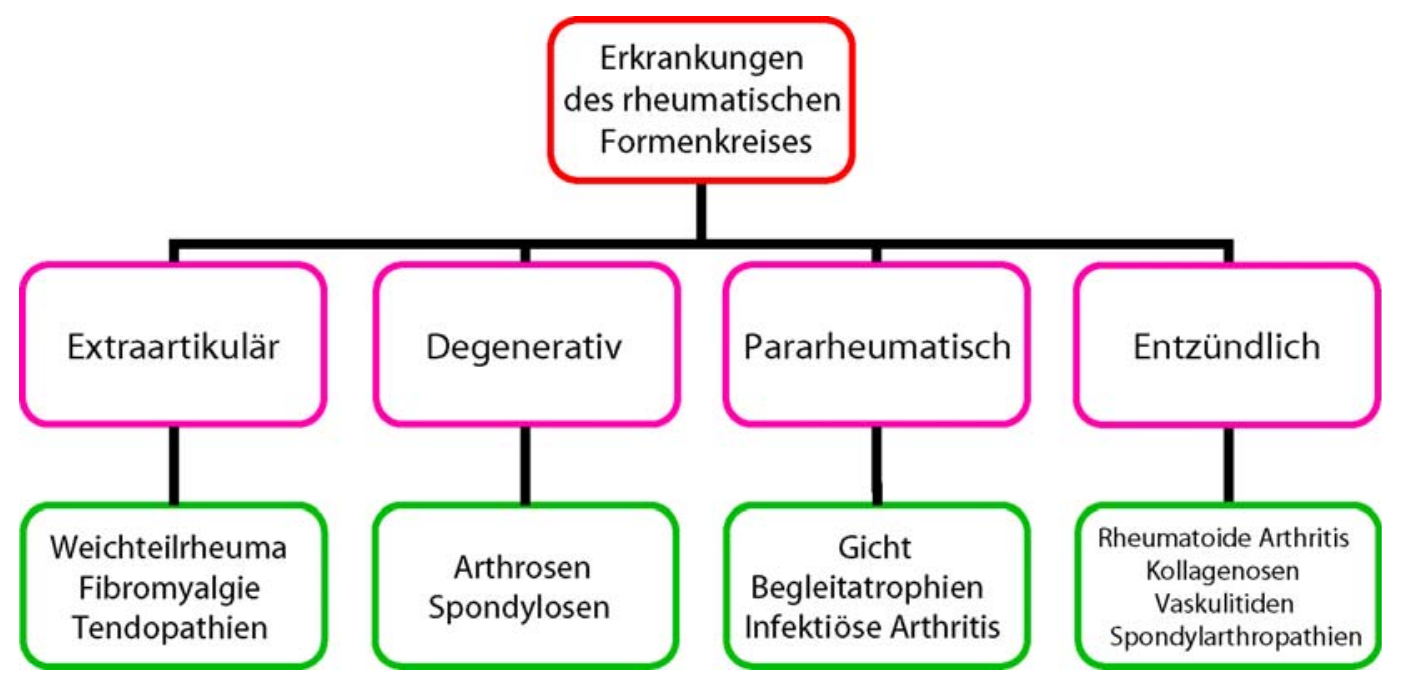

Abbildung 1: Systematik rheumatischer Erkrankungen.

Doch gerade wegen der Diversität rheumatischer Erkrankungen wird eine Frühdiagnose selten rechtzeitig gestellt. Laut Angaben der Deutschen Rheuma-Liga (Stand 2001) vergehen bei Morbus Bechterew durchschnittlich sieben Jahre vom Auftreten der ersten Symptome bis zur Diagnosestellung, bei der Fibromyalgie bis zu zehn und beim Lupus erythemato- 
des (SLE) zwei Jahre. Nur durch eine exakte Artdiagnose des Rheumas kann eine gezielte Therapie erfolgen und Folgeschäden vermindert werden.

Unter den entzündlich rheumatischen Erkrankungen ist die rheumatoide Arthritis (RA), die auch als chronische Polyarthritis (cP) bezeichnet wird, die häufigste systematische Autoimmunkrankheit, deren Krankheitsbild am häufigsten mit dem einer rheumatischen Erkrankung in Verbindung gebracht wird. Sie beginnt in der Regel mit einem Befall der Gelenke, jedoch zeigen sich im Verlauf der Krankheit auch pathologische Veränderungen anderer Organe. Ihre Prävalenz liegt bei $1 \%$ der Bevölkerung und die Inzidenz in Deutschland bei 2000 neuen Fällen pro Jahr. Dabei ist die Inzidenz bei Personen im Alter von 30 bis 55 am höchsten und betrifft Frauen fast drei Mal häufiger als Männer (Quelle: Deutsche RheumaLiga, Stand 2001).

Weitere entzündlich-rheumatische Erkrankungen sind Spondylarthropathien wie z.B. Morbus Bechterew und reaktive Arthritiden, die neben peripheren Gelenken hauptsächlich entzündliche Erkrankungen der Wirbelsäule darstellen. Die Prävalenz dieser Spondylarthropathien beträgt $1 \%$ und hat im Fall des Morbus Bechterew ein Manifestationsalter von 20 - 35 Jahren.

Kollagenosen, wie z.B. Lupus erythematodes oder das Sjögren-Syndrom, sind entzündliche Erkrankungen des Bindegewebes und haben eine Prävalenz von 0,2 \%.Sie zählen neben den Immunvaskulitiden (entzündliche Erkrankungen der Blutgefäße) ebenfalls zu den entzündlich rheumatischen Erkrankungen.

Bei den degenerativen rheumatischen Erkrankungen handelt es sich um Arthrosen (Osteoarthrose, OA, Verschleißrheuma), die auch mit einem Abbau von Knorpelgewebe einhergehen. Als Ursache werden neben einem erhöhten Lebensalter, Gelenküberlastungen durch Fehlstellungen, körperliche Überlastungen, Verletzungen und Übergewicht auch Hypermobilität angegeben. Mit einer Prävalenz von ca. 5 Millionen Betroffenen ist es die häufigste Gelenkkrankheit in Deutschland überhaupt. Genau wie bei allen anderen Arten rheumatischer Erkrankungen kann der Verlauf schleichend sein und sich die Krankheit über Jahre langsam entwickeln. Die häufige Prävalenz und die Chronifizierung schaffen eine klare Abgrenzung gegenüber den entzündlich rheumatischen Erkrankungen meist schwierig und erfordern eine genaue Differentialdiagnose und Labordiagnostik.

\subsection{Pathogenese der RA}

Die gängige Arbeitshypothese geht davon aus, dass ein unbekanntes Antigen mit einem Topismus für Gelenke auf dem Blutweg in die Synovialis gelangt oder direkt dort entsteht. Durch Antigen präsentierende Zellen (APC) wird das Antigen aufgenommen und mit Hilfe des HLA-Systems den T-Lymphozyten präsentiert. Die Struktur des HLA-Systems scheint hierbei für die Entstehung und Ausprägung der RA eine Rolle zu spielen. Die Allele HLA- 
DRB $1{ }^{*} 0401$ und HLA-DRB1*0404 sind bei Kaukasiern mit dem Auftreten der Krankheit assoziiert (Gonzalez-Gay et al. 2002; Roudier 2006). Die Allele ähneln sich sehr in ihren Aminosäuresequenzen, weswegen von einem shared epitope gesprochen wird (KhaniHanjani et al. 2002).

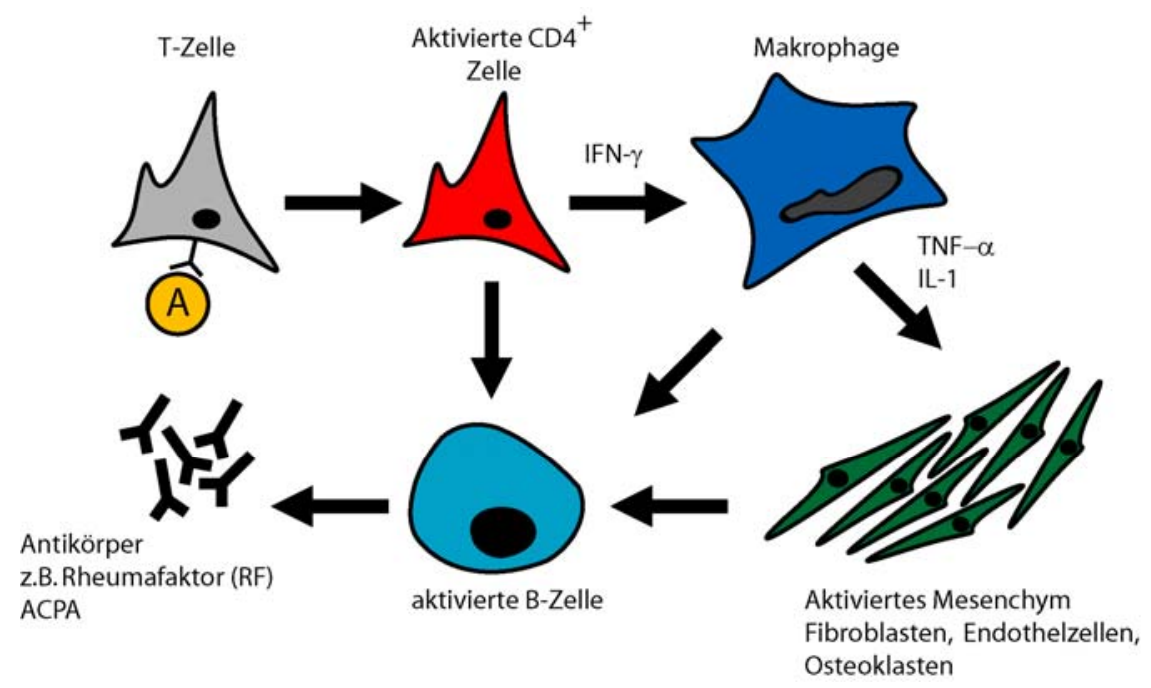

Abbildung 2: Zelluläre Interaktionen der Pathogenese der rheumatoiden Arthritis (Bernhard 2001). Durch ein bisher unbekanntes Antigen wird über die Ausschüttung von Zytokinen (vorrangig TNF- $\alpha$, Interleukin-1 und Interferon- $\gamma$ ) ein Entzündungsprozess in Gang gesetzt, der neben der Autoantikörperproduktion die Aktivierung des mesenchymalen Gewebes bewirkt.

Als Folge dieser Antigenpräsentation kommt es zur Aktivierung von Immunzellen und zur Ausschüttung verschiedener proinflammatorischer Zytokine (vorrangig IL-1 und TNF $\alpha$ ) und zur Infiltration des betroffenen Gewebes durch aktivierte Monozyten, Makrophagen, BLymphozyten und T-Lymphozyten. Durch die Infiltration und dem vermehrten Blutfluss in das Gewebe kommt es zu einer Verdickung der Synovia, was im Allgemeinen als Ausbildung eines Pannus bezeichnet wird. Die lokal frei gesetzten Mediatoren führen nicht nur zur Infiltration des Gewebes, sondern stimulieren darüber hinaus andere mesenchymale Zellen, wie Synovialzellen, Endothelzellen, Fibroblasten und Osteoklasten, die im Allgemeinen als Pannuzyten zusammengefasst werden. Dies bewirkt eine Sezernierung so genannter MatrixMetalloproteasen (MMP-1, MMP-2, MMP-3, MMP-9, MMP-13), die maßgeblich zur Zerstörung des Gelenk umgebenden Gewebes beitragen (Fernandes et al. 2002; Burrage et al. 2006). Im Insertionsbereich des Gelenks kommt es durch invasiv-destruktives Wachstum der Pannozyten zu Knochenerosionen. Die gleichzeitige Aktivierung von Chondrozyten im hyalinen Knorpel resultiert in einer Hemmung der Kollagen- und Proteoglykansynthese und bewirkt letztendlich den Knochen- und Knorpelabbau. In Abbildung 3 sind neben dem gesunden Zustand eines Gelenks schematisch das frühe und späte Stadium der RA dargestellt. Im frühen, entzündlichen Stadium der RA kommt es im Rahmen der Entzündungsreaktion zu einer massiven Verdickung der Synovia, die eine Verschmälerung des Gelenkspalts 
bewirkt. Des Weiteren kommt es aufgrund der erhöhten Osteoklastenaktivität zur Knochendemineralisation. Im späten Stadium ist die Bewegungsfähigkeit des Gelenks stark beeinträchtigt, die Synovia aufgrund persistierender entzündlicher Prozesse nahezu vollständig abgebaut und der Insertionsbereich des Gelenks stark verschmälert und knöchern deformiert. Diese destruktiven progressiven Gelenkveränderungen lassen sich radiologisch erkennen und werden in fünf LDE-Stadien unterteilt.

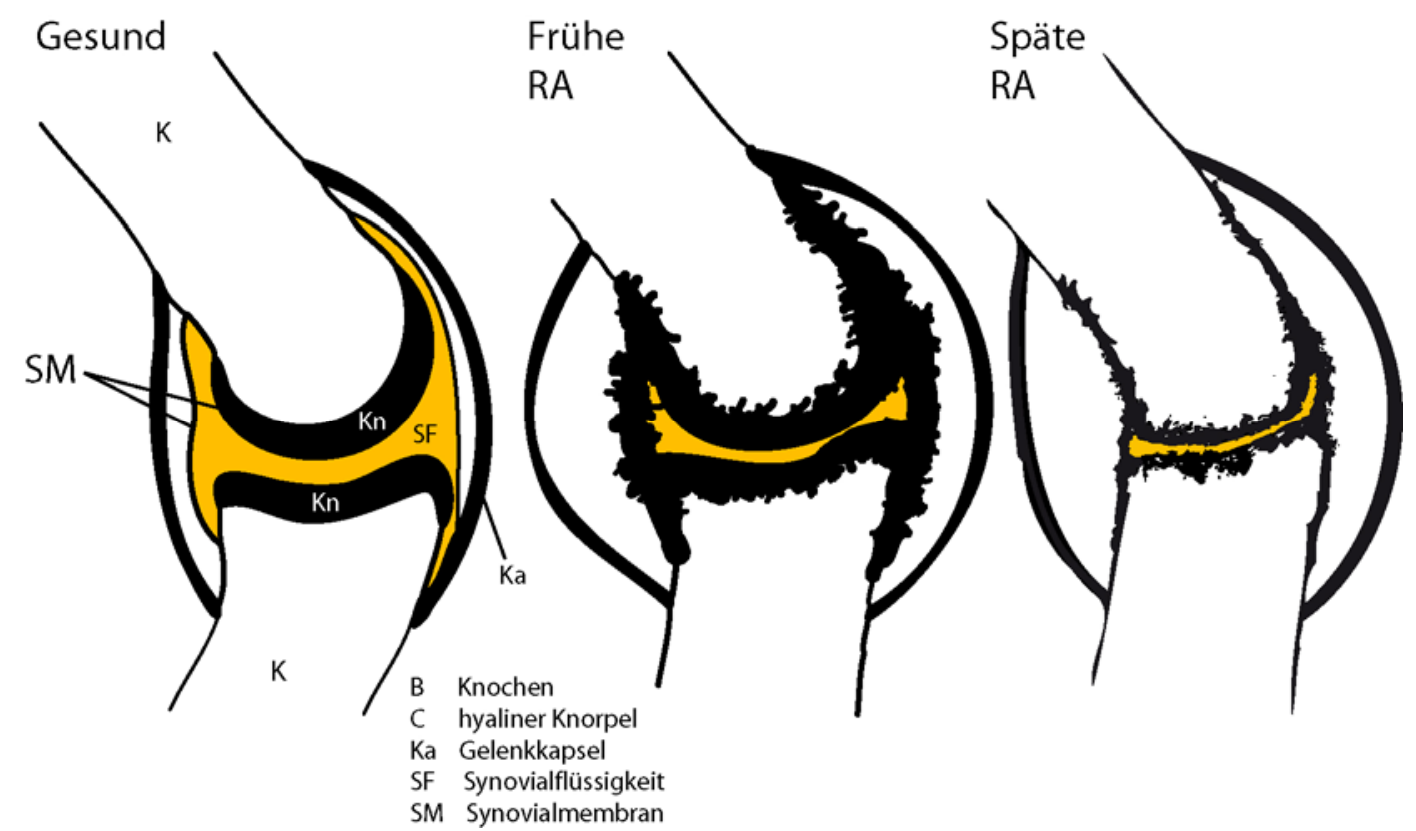

Abbildung 3: Gelenksveränderungen im Verlauf einer rheumatoiden Arthritis. Im frühen Stadium kommt es im Rahmen einer Entzündungsreaktion zu einer starken Verdickung der Synovia (Pannusbildung). Durch Chronifizierung und Aktivierung des mesenchymalen Gewebes kommt es im späten Stadium zu starken Knochenerosionen und nahezu vollständigem Verlust der Synovia sowie der Bewegungsfähigkeit des Gelenks. Radiologisch werden die verschiedenen Zustände in die LDE-Stadien eins bis fünf eingeteilt.

Die Frage, warum es jedoch bei der RA im Vergleich zur OA zu solch einem aggressiven und chronischen Verlauf kommt, ist bis heute unklar. Das Antigen könnte persistent vorliegen, was die Zahl an T-Lymphozyten in der Synovialmembran, die vermehrte HLA-DRExpression und die Aktivierung Antikörper produzierender B-Lymphozyten erklären würde (Muller-Ladner et al. 2000; Ospelt et al. 2008). Des Weiteren wird der Einfluss eines viralen Infektes auf die RA diskutiert, der eine Expression von HLA-Klasse-II-Molkekülen auch auf nicht Antigen präsentierenden Zellen induzieren könnte. (Depper et al. 1981; Fox et al. 1985; Bonneville et al. 1998). Dadurch wären diese Zellen ihrerseits ebenfalls Zielobjekte der Immunantwort und beim Epitop könnte es sich um ein zelleigenes Protein handeln, das bis zu diesem Punkt nicht in Erscheinung getreten ist (hidden epitope). Dieser Prozess würde ebenfalls die Infiltration von T-Zellen in das Gelenk und die damit verbundenen Entzündungsvorgänge erklären. 


\subsection{Diagnose der RA}

Das typische Erscheinungsbild der RA ist polyartikulär mit Schmerzen, Steifheit und Schwellungen. Der Ausbruch der Krankheit ist nur schwer auszumachen, da sich die Schwellungen und Schmerzen über Wochen bis Monate entwickeln. Typische Begleiterscheinungen sind Anorexie, Schwäche und Müdigkeit.

Neben den Gelenken zeigen sich Anzeichen einer rheumatischen Erkrankung auch in anderen Organen. Diese so genannten extraartikulären Manifestationen betreffen das Auge (Skleritis, Episkleritis, Trockenheit, Sjögren Syndrom), die Lunge (Pleuritis, Pleuraerguss, Interstitielle Lungenfibrose, Subpleurale Rheumaknoten), die Haut (Rheumaknoten, Hautulcera, Neutrophile Dermatitis), die Muskeln (Synovitis, Myositis, Vaskulitis), das Skelett (Osteopenie), die Niere (sekundäre Amyloidose, Medikamenten-Toxizität), die Milz (Splenomegalie) und das Herz (Perikarditis, Myokarditis). Des Weiteren sind eine Reihe hämatologischer Veränderungen (Anämie, Leukozytose, Trombozytose) möglich.

Die Krankheitsaktivität und Progredienz der RA werden unter anderem durch den DAS 28 und radiologische Veränderungen in der Klinik bestimmt und durch die Erfassung spezifischer Laborparameter (CRP, BSG, Rheumafaktor, Anti-CCP, Anti-MCV, siehe Abschnitt 2.3.2) bekräftigt.

\subsubsection{Diagnostik in der Klinik}

Für die Feststellung der Krankheitsaktivität eines RA-Patienten kommt in der Klinik der so genannte DAS 28 (disease a ctivity score) zum Einsatz. Der DAS 28 wurde empirisch anhand der Daten von RA-Patienten 1983 in der Abteilung für Rheumatologie des University Medical Centre in Nijmegen entwickelt und wird auch bei der Beurteilung der Wirksamkeit einer Therapie angewendet. Wie aus Formel 1 ersichtlich ist, handelt es sich um einen numerischen Wert, der sich aus der Betrachtung und Klassifikation von 28 definierten Gelenken in Hinblick auf Schwellungen und Schmerzen errechnet und Werte von 0 bis 10 annehmen kann. Da insbesondere die Gelenke der Finger und des Handgelenks bei der RA betroffen sind, werden diesen besondere Betrachtung zugemessen (vgl. Abbildung 4).

Neben der Klassifikation der Gelenke, wird des Weiteren die Blutsenkungsgeschwindigkeit (BSG, allgemeiner Marker für Entzündungsreaktionen) und der subjektive gesamte Gesundheitszustand $(\mathrm{GH}$, general health) des Patienten in der Formel mit eingerechnet.

$$
\text { DAS28 }=0,56 \cdot \sqrt{\text { Gelenke SCHMERZ }}+0,28 \cdot \sqrt{\text { Gelenke SCHWELLUNG }}+0,70 \text { BSG }+0,014 \text { GH }
$$

Formel 1: $\quad$ Berechnung des DAS 28. 


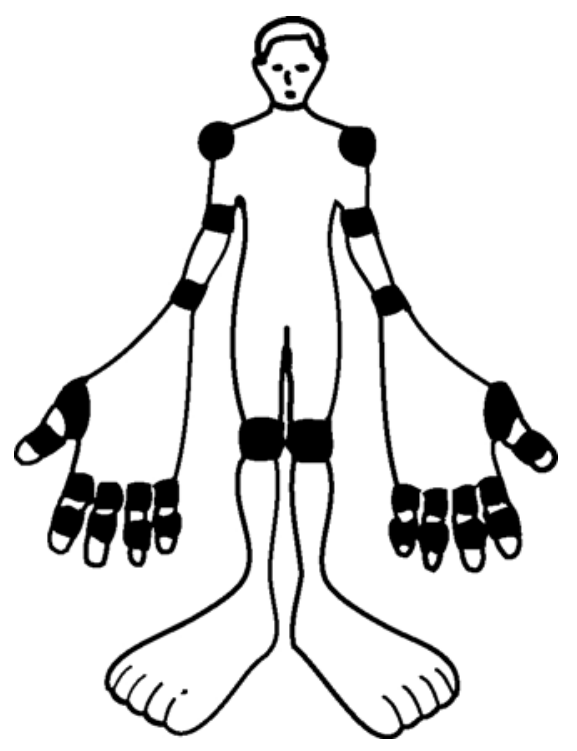

Abbildung 4: Die 28 Gelenke, die zur Erstellung des DAS 28 untersucht und klassifiziert werden.

Ein DAS von 0 bis 3.2 gibt eine geringe, ein DAS von 3.2 und 5.1 eine mittlere und Werte von 5.1 bis 10 eine hohe Krankheitsaktivität an.

Neben der Krankheitseinstufung mittels DAS werden radiologische Veränderungen, die sich im Krankheitsverlauf abzeichnen, in sechs Abstufungen (LDE-Stadien) aufgeteilt. Stadium 0 beschreibt die normalen gesunden Gelenkverhältnisse und Stadium 5 einen vollkommen aufgebrauchten Gelenkspalt mit einer knöchernen Deformität (vgl. Abbildung 3).

Weitere Kriterien zur Sicherung der Diagnose der RA wurden durch die Europäische Rheuma-Liga (EULAR, european league against rheumatism) vorgegeben und sind in Tabelle 1 dargestellt. Dabei stellt die Betrachtung der Gelenkveränderungen und deren Verteilung ein Hauptkriterium bei der Beurteilung des Krankheitszustands dar. Von den insgesamt sieben vorgegebenen Kriterien müssen vier erfüllt sein, um die Diagnose der RA zu bekräftigen.

Tabelle 1: Diagnosekriterien der EULAR für die rheumatoide Arthritis (Arnett et al. 1988). Mindestens vier Kriterien müssen für die Diagnose der RA erfüllt sein.

\begin{tabular}{|ll|}
\hline \multicolumn{2}{|c|}{ Diagnosekriterien der rheumatoiden Arthritis } \\
$\mathbf{1}$ & Morgensteifigkeit der Gelenke von mehr als einer Stunde \\
$\mathbf{2}$ & Arthritis an 3 oder mehr Gelenkarealen (Hand-, Fuß- und \\
& Fingergelenke, Ellenbogen, Knie, Sprunggelenk) \\
$\mathbf{3}$ & Arthritis an den Gelenken der Finger und des Handgelenks \\
$\mathbf{4}$ & Symmetrische Verteilung der betroffenen Gelenke \\
$\mathbf{5}$ & Subkutane Rheumaknoten \\
$\mathbf{6}$ & Positiver Rheumafaktor \\
$\mathbf{7}$ & Radiologische Veränderungen (Finger- oder Handgelenk) \\
\hline
\end{tabular}

Die Diagnostik der Klinik wird durch eine umfangreiche Analytik im Labor assistiert. Dabei werden neben den reinen Entzündungsparametern Blutsenkungsgeschwindigkeit (BSG) und 
C-Reaktives Protein (CRP, diagnostisch wichtigstes Akutphase Protein der Leber) auch spezifische Tests auf die RA durchgeführt. Diese werden im Abschnitt 2.3.2 vorgestellt.

\subsubsection{Diagnostik im Labor}

Die Labordiagnostik bietet eine Reihe hochspezifischer Parameter zur Erkennung einer RA. Viele dieser Faktoren haben einen geschichtlichen Hintergrund und fanden erst Jahrzehnte nach ihrer Entdeckung und Modifizierung als Biomarker ihren Weg in die klinische Routineanalytik.

Die Qualität dieser Marker wird durch ihre Sensitivität und Spezifität bestimmt. Dabei gibt die Sensitivität den prozentualen Anteil an Patienten wieder, bei dem eine entzündliche Gelenkserkrankung mit Hilfe der Marker zu messen war. Die Spezifität beschreibt hingegen nur den Anteil der RA-Patienten, bei dem der Marker zu detektieren war.

Der erste rheumatologische Biomarker war der Rheumafaktor (rheumatoid factor, RF). Der RF geht in seinen Ursprüngen auf das Jahr 1937 zurück. Erik Waaler vermischte menschliches Blut mit dem von Schafen, die vorher mit humanem Immunglobulinen immunisiert wurden. Es konnte eine Hämagglutinationsreaktion beobachtet werden, die spezifisch bei Blut von Patienten mit Krankheiten des rheumatischen Formenkreises eintrat (Waaler 2007). Gleiche Beobachtungen wurden 1948 von den Amerikanern Charles Regan und Harry Rose gemacht (Rose et al. 1948). Diese Experimente prägten den bis heute gebräuchlichen Namen des RF.

Mit der Weiterentwicklung immunologischer Techniken konnte gezeigt werden, dass es sich beim RF um Autoantikörper der Subklassen IgM, IgG und IgA handelt, die gegen die Epitope des $F_{c}$-Teils von polyklonalem IgG gerichtet sind (Torrigiani et al. 1967; Bennett 1973; Silvestris et al. 1985; Kleveland et al. 1988; Teitsson 1988).

Ein positiver RF ist aufgrund der großen Anzahl verschiedener Subklassen der Autoantikörper und des ubiquitären Epitops bei einer Vielzahl rheumatischer und nichtrheumatischer Erkrankungen zu detektieren, die in Tabelle 2 aufgelistet sind.

Tabelle 2: $\quad$ Rheumatische und nichtrheumatische Krankheiten, die einen seropositiven Rheumafaktor verursachen können, sowie deren prozentualer Anteil (Shmerling et al. 1991).

\begin{tabular}{|lr|}
\hline \multicolumn{2}{|c|}{ Ursachen seropositiven Rheumafaktors } \\
\hline Rheumatische Erkrankungen & RF \% \\
Rheumatoide Arthritis & $26-90$ \\
Sjögrens Syndrom & $75-95$ \\
Kollagenosen & $50-60$ \\
Kryoglobulinämie & $40-100$ \\
Lupus erythematodes (SLE) & $15-35$ \\
Polymyositis/Dermatomyositis & $5-10$ \\
\hline
\end{tabular}




\begin{tabular}{|lr|}
\hline \multicolumn{2}{|c|}{ Ursachen seropositiven Rheumafaktors } \\
\hline Nichtrheumatische Erkrankungen & $\%$ \\
Alter (> 60 Jahre) & $5-25$ \\
Bakterielle Endokarditis & $25-50$ \\
Hepatitis B oder C & $20-75$ \\
Syphilis & $1-13$ \\
Parasitäre Infektionen & $20-90$ \\
Lepra & $5-60$ \\
Allgemeine Virusinfektion & $15-65$ \\
Sarkoidose & $3-33$ \\
Pulmonale Fibrose & $10-50$ \\
Silikose/Asbestosis & $30-50$ \\
Primäre biliäre Zirrhose (PBZ) & $45-70$ \\
Krebs & $5-25$ \\
Nach Impfungen & $10-15$ \\
\hline
\end{tabular}

ACPA (anti citrullinated protein/peptide antibodies) sind deutlich spezifischer für die RA als der RF. Nach dem Stand heutiger Forschung sind sie gegen eine Vielzahl von Proteinen gerichtet, in denen Arginin durch posttranslationale Modifikation der Peptidylarginindeiminase (PAD) in Citrullin katalysiert wurde. Diese Reaktion ist in Abbildung 5 dargestellt (Schellekens et al. 1998; Girbal-Neuhauser et al. 1999).<smiles>N=C(N)NCCCC(N)C(=O)O</smiles>

Arginin<smiles>NC(=O)NCCCC(N)C(=O)O</smiles>

Citrullin

Abbildung 5: Reaktionsschema der Deaminierung von Arginin durch die Peptidylarginindeiminase.

Diese Autoantikörper sind hochspezifisch für die rheumatoide Arthritis (Cantaert et al. 2006). Der Grund für die Citrullierung von Proteinen und die Produktion dieser Autoantikörper ist bisher jedoch unklar. Der Einsatz in der klinischen Diagnostik basiert auf empirisch erworbenen Erfahrungen und soll daher im Folgenden dargestellt werden.

Die Geschichte der ACPA begann 1964 mit der Entdeckung eines Autoantikörpers, der als Antiperinuclear Factor (APF) bezeichnet wurde. Als Antigen erkannte dieser Antikörper die keratohyaline Granula um den Zellkern bei humanen Mundschleimhautzellen (Hijmans et al. 1964; Nienhuis et al. 1964). Dieser neu entdeckte Autoantikörper wurde in Seren von 78 \% der untersuchten RA - Patienten mit einer Spezifität von 70 \% gefunden (Sondag-Tschroots et al. 1979).

15 Jahre später wurde der Anti-Keratin-Antikörper (AKA) entdeckt, der durch Immunfluoreszenz auf Gewebeschnitten von Speiseröhren von Ratten gefunden wurde (Scott et al. 1981). Mit einer Sensitivität von 36 - 59 \% und einer Spezifität von 80 - 90 \% wurde spezifisch von Autoantikörpern im Serum von RA-Patienten ein Epitop erkannt, das von Serumproben 
gesunder Personen nicht erkannt wurde (Ordeig et al. 1984; Hajiroussou et al. 1985). Die klinische Anwendbarkeit dieser Tests war jedoch wegen der Übertragbarkeit des Immunfluoreszenzprofils eingeschränkt und fand daher nur wenig Anwendung.

1995 wurde nachgewiesen, dass sowohl der APF als auch der AKA citrulliertes Filaggrin als Epitop erkannten (Sebbag et al. 1995; Youinou et al. 1995). Durch diese genauere Spezifikation war es möglich, die Analysen mittels Immunoblot und ELISA (enzyme-linked immunosorbent assay) auf Basis eines Anti-Filaggrin-Antikörpers durchzuführen (Nogueira et al. 2001; Vincent et al. 2002). Im Gegensatz zur bisher durchgeführten Detektion auf Basis von Immunfluoreszenz bietet ein Testsystem auf Basis eines ELISAs deutliche Vorteile in der Quantifizierung und Reproduzierbarkeit. In den Analysen wurde eine Sensitivität von $52 \%$ und eine Spezifität von 95-100 \% festgestellt. Es konnte somit erstmalig in einer großen Studie belegt werden, dass die Präsenz von Citrullin für die Antigenität bei der RA verantwortlich ist.

1998 wurden die Versuche mit einem spezifischen Fragment des Filaggrin ausgeweitet. Es wurde ein synthetisch hergestelltes, citrulliertes Peptid generiert, welches mit einer Sensitivität von ca. 50 \% und in einer Spezifität von $97 \%$ ausschließlich von Antikörpern in Seren von RA-Patienten erkannt wurde (Schellekens et al. 1998).

In einem weiteren Schritt wurde die Peptidsequenz des Filaggrins zyklisiert (cyclic citrullinated peptide), um die Struktur des Antigens weiter zu optimieren. Dies war der erste erhältliche ELISA CCP-Kit (CCP1) und resultierte in Sensitivitäten von 41 - 68 \% und Spezifitäten von 98 \% (Schellekens et al. 2000). In den letzten Jahren konnte durch Änderungen der Aminosäurensequenz der Peptide und Mischen der synthetischen Peptide die Sensitivität und Spezifität erhöht werden. Dieser so genannte CCP-ELISA der zweiten Generation wird als CCP2 bezeichnet. In weiteren Studien konnten Sensitivitäten von $80 \%$ und Spezifitäten von 98 - 99 \% für den CCP2 erreicht werden (Fernandez-Suarez et al. 2005; van Gaalen et al. 2005).

Obwohl Studien zeigten, dass die ermittelten CCP-Titer eine spezifische Korrelation mit dem Krankheitsverlauf zeigen und sogar einen Ausbruch einer RA in gesunden Personen voraussagen können (Rantapaa-Dahlqvist et al. 2003; Vencovsky et al. 2003; Agrawal et al. 2007), bleibt dieser Punkt umstritten. Serdaroglu et al. konnten keine Korrelation zwischen der Progredienz und dem Anti-CCP-Titer nachweisen (Serdaroglu et al. 2008).

Sehr aktuell und ebenfalls zur Gruppe der ACPA gehörend wurde in den letzten Jahren der Anti-MCV-Antikörper (anti-modified citrullinated vimentin) zur Frühdiagnostik eingeführt. Auch in diesem Fall hat die Identifizierung des Epitops einen geschichtlichen Hintergrund.

1994 wurde in Gewebeextrakten von humaner Plazenta und Milz durch Western Blot mit Serum von Patienten mit RA ein spezifisches Doppelbandenmuster bei ca. $50 \mathrm{kDa}$ entdeckt (Despres et al. 1994), das als SA-Antigen bezeichnet wurde. Die Identität des Antigens war 
zu jenem Zeitpunkt unklar, jedoch konnte eine hohe Sensitivität von 51 - $92 \%$ und Spezifität von bis zu 98 \% nachgewiesen werden (Hayem et al. 1999; Hueber et al. 1999). 2004 wurde dieses Antigen als citrulliertes Vimentin beschrieben (Vossenaar et al. 2004). In der Gegenüberstellung mit CCP1 und CCP2 zeigte dieser Autoantikörper eine nahezu vergleichbare Sensitivität und Spezifität (Keskin et al. 2008; Sghiri et al. 2008). Der Anti-MCV-Test zeigte jedoch in einer Studie von Mathsson et al. eine deutlich bessere Korrelierung des radiologischen Krankheitsbildes im Vergleich zum CCP (Mathsson et al. 2008). Der Anti-MCV findet neben dem CCP1 und CCP2 Anwendung in der klinischen Routineanalytik.

Trotz der hohen Spezifitäten der vorgestellten Tests bleibt die genaue Definiton des Epitops unklar. Beide Tests erkennen spezifisch modifizierte Formen von Intermediärelementen des Zytoskeletts (Vimentin und Filaggrin). Ungeklärt bleibt jedoch, ob und wenn ja, warum eine Modifikation durch die PAD stattfindet und an welchen Stellen die Proteine des Zytoskeletts modifiziert werden. Ferner bleibt unklar, welche Rolle diese modifizierten Formen in der Pathogenese der RA haben.

Die Diagnose der RA ist zur Zeit durch die Anwendung klinischer Tests (radiologische Befunde, DAS 28) und der unterstützenden Labordiagnostik (RF, CCP, anti-SA, anti-MCV) recht zuverlässig und durch viele Studien hinreichend validiert. Dennoch bleibt die RA eine systematische Autoimmunerkrankung, die meist spät erkannt wird. Aus diesem Grund ist die Suche nach neuen Biomarkern für die Frühdiagnose, entweder allein oder in Kombination mit den bereits bestehenden Markern, ein hoch aktuelles Forschungsgebiet.

\subsection{Therapiemöglichkeiten der RA}

Bei der Therapie der RA kommen viele verschiedene Ansätze zum Tragen. Es soll im folgenden Absatz ein kurzer Überblick über die medikamentöse Therapie der RA gegeben werden.

Grundsätzlich kommen nichtsteroide analgetische Antirheumatika (NSARDs, nnon steroidal antirheumatic drugs) zum Einsatz, wie z.B. Paracetamol und Diclofenac, die oral oder topisch gegeben werden. Diese Medikamente wirken schmerzlindernd, ändern jedoch nicht den Verlauf der Krankheit.

RA-Patienten sollten so schnell wie möglich nach der Diagnose mit so genannten DMARDs

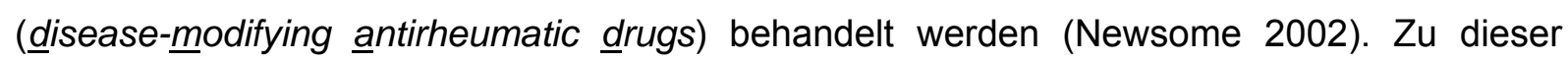
Gruppe gehören z. B. Methotrexat und Chloroquin. Diese Medikamente haben im Gegensatz zu den NSARDs eine modulierende Wirkung auf den Krankheitsverlauf.

Des Weiteren kommen bei der Behandlung so genannte TNF-Antagonisten zum Einsatz (Adalimumab, Infliximab, Etanercept). Hierbei handelt es sich um Moleküle biologischen Ursprungs, die in die Freisetzung und Wirkung des proinflammatorischen Zytokins TNF- $\alpha$ eingreifen. Zum einen kommen Fragmente von rekombinanten humanisierten monoklonalen 
Antikörpern (Adalimumab, Infliximab) oder Rezeptorantagonisten (Etanercept) auf Basis von rekombinanten Proteinen zum Einsatz, die durch kompetitive Bindungen mit dem jeweiligen Liganden (TNF- $\alpha$-Rezeptor oder TNF- $\alpha$ ) gezielt den TNF $\alpha$-Spiegel im Serum senken. Diese so genannten Biologika kommen bei schwerer progressiver RA und anderen chronischentzündlichen Krankheiten zum Einsatz. Ein weiteres Biologikum ist das Anakinra, bei dem es sich um einen Interleukin-1 Rezeptorantagonisten handelt, der die proinflammatorische Wirkung des Interleukin-1 hemmt.

Zur Zeit erscheint die Therapie mit einer Kombination von beiden Arten von Biologika als sehr aussichtsreich (Mertens et al. 2009). Die Therapiemöglichkeiten der RA und deren Nebenwirkungen sind in Tabelle 3 dargestellt.

Tabelle 3: $\quad$ Pharmaka, die bei der Behandlung der RA zum Einsatz kommen sowie deren unerwünschte Nebenwirkungen (vgl. Deutsches Ärzteblatt, Jg 1003;1-2; Jan. 2006).

\begin{tabular}{|c|c|}
\hline Pharmakon & Nebenwirkungen \\
\hline Methotrexat (MTX) & $\begin{array}{l}\text { Knochenmarkssuppression, Leberfibrose, Zirrhose, Alopezie, } \\
\text { Pneumonie, Aleolitis, Stomatitis, hämatologische Malignome }\end{array}$ \\
\hline Hxdroxychoroquin & Makulaschädigung, Diarrhö, Katarakt \\
\hline Sulfasalazin & Knochenmarkssuppression \\
\hline Lelunomid & Diarrhö, Alopezie, Exanthem, Immunsuppression \\
\hline \multicolumn{2}{|l|}{ Biologika } \\
\hline Etanercept $^{\circledR}$ & Immunsuppression (Infektion) \\
\hline Infliximab ${ }^{\circledR}$ & $\begin{array}{l}\text { Nur in Kombination mit MTX, daher siehe MTX. Immunsup- } \\
\text { pression, Lymphome }\end{array}$ \\
\hline Adalimumab $^{\circledR}$ & Immunsuppression (Infektion) \\
\hline Anakinra $^{\circledR}$ & Immunsuppression \\
\hline
\end{tabular}

Trotz der hier kurz vorgestellten Therapiemöglichkeiten ist bisher nur eine Verlangsamung der Krankheit erreicht worden. Obwohl gerade die Biologika große Hoffnungen auf eine verlängerte Beschwerdefreiheit geben, ist eine direkte Heilung und natürliche Rückbildung der Gelenkerosionen nur eingeschränkt gegeben. Insbesondere durch die massiven Nebenwirkungen der Therapien einerseits und den guten Erfolgsaussichten bei frühzeitiger Behandlung andererseits ist damit der Druck auf eine möglichst frühzeitige und sichere Diagnostik nochmals verstärkt.

\subsection{Biomarkersuche}

\subsubsection{Definition eines Biomarkers}

Ein biologischer Marker, der auch in der Klinik Anwendung finden soll, muss neben einem robusten und spezifischen Testsystem auch Proben verarbeiten, die von einem Patienten ohne große Umstände abgenommen werden können und einfach zu verarbeiten sind. Obwohl die meisten Krankheiten von einem Organ ausgehen, ist die Abnahme einer Probe 
mittels Biopsie mit großem Aufwand und Risiken verbunden. Aus diesem Grund erscheint die Analyse einer Körperflüssigkeit (Blut, Urin, Speichel) deutlich attraktiver für die routinierte Analytik zu sein. Die klinische Routinediagnostik greift bereits seit Jahrzehnten auf dieses Medium zurück und es werden die unterschiedlichsten Tests im Rahmen einer Behandlung durchgeführt.

Die gewählten Parameter einer Blutanalytik sind jeweils auf die Faktoren ausgerichtet, die entweder einen Einfluss haben könnten, oder sich stark verändern. Im Fall der RA werden eine Reihe entzündungsspezifischer Parameter (BSG, CRP, RF, CCP) ermittelt und deren Verlauf über Jahre dokumentiert, um so die Progression der Krankheit verfolgen und darauf reagieren zu können. Es handelt sich also um messbare Produkte oder Indikatoren von pathologischen Veränderungen. Diese Indikatoren werden als Biomarker bezeichnet. Im Zentrum der Biomarkerforschung stehen zur Zeit Biomarker auf Proteinbasis und deren frühzeitiger Nachweis in Plasma, Serum oder Urin.

Wie schon im Abschnitt 2.3.2 gezeigt, sind bei der Früherkennung der RA einige Marker beschrieben, die aufgrund ihrer hohen Spezifität und Sensitivität für die Diagnostizierung ein unverzichtbares Mittel darstellen. Durch das Finden neuer Marker sowie einer Kombination mit bestehenden könnte die Diagnostik so weit vorangetrieben werden, dass weiterführende Aussagen über den Verlauf oder die Frühentstehung dieser Krankheit getroffen werden können.

Durch den enormen Wissenszuwachs und die schnelle Entwicklung im Bereich der Massenspektrometrie ist die Biomarkerfindung mittlerweile eines der Hauptaufgabengebiete der klinischen Proteomics geworden. Dabei stellt die Analyse des Proteoms von humanen

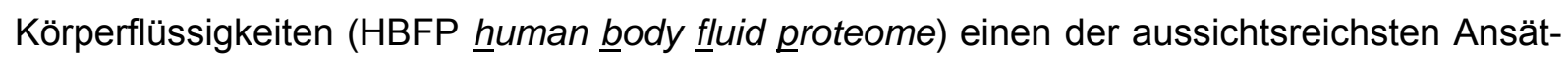
ze in der Entdeckung neuer, Protein basierender Biomarker dar (Aebersold et al. 2003; Yates 2004; Veenstra et al. 2005).

\subsubsection{Biomarkersuche durch 2D-SDS-Page}

Methodisch gibt es mittlerweile viele Ansätze zur Auffindung von Biomarkern durch Proteomics. Klassische 2D-SDS-PAGE mit anschließendem tryptischen Verdau der Proteine und Identifizierung mittels PMF MALDI-TOF-MS, so wie es auch in dieser Arbeit zum Einsatz kam (vgl. Aschnitt 5.8, Seite 39), wird häufig bei der Auffindung von Proteinmarkern eingesetzt. Es konnte beispielsweise die Phosphoglycerinkinase 1 als serologischer Marker beim Lungenkarzinom ermittelt werden (Chen et al. 2003), ein Fragment vom Komplement Faktor C3 und eine Isoform des Apolipoproteins A1 für das Leberkarzinom (Steel et al. 2003), das Hitzeschockprotein 27 (HSPB1) als Frühmarker beim Mammakarzinom (Rui et al. 2003) und Haptoglobin und Serum Amyloid A Protein beim Magenkarzinom (Juan et al. 2004). 
Die Auftrennung humanen Serums mittels elektrophoretischer Methoden erweist sich allerdings als ein umfangreiches Unterfangen mit mehreren Arbeitsschritten. Das Blut übernimmt neben der Versorgung der Organe mit Sauerstoff auch den Transport von Nährstoffen und enthält daher Lipide, Salze und freie Aminosäuren. Es birgt somit neben den zu untersuchenden Proteinen eine Vielzahl geladener und ungeladener Moleküle, die mit der elektrophoretischen Auftrennung interferieren. Erst durch die Abreicherung dieser Substanzen durch Dialyse oder Fällung ist es möglich, das Proteom zu untersuchen. Doch neben der Abreicherung dieser Substanzen stellt Serum an sich ein sehr schwierig zu analysierendes Gemisch an Proteinen dar. Serum enthält eine sehr große Anzahl von Proteinen, die sich in ihren Konzentrationsbereichen um 6-9 Potenzen unterscheiden. Albumin, die Immunglobuline $G$ und A, Transferrin, Antitrypsin und Haptoglobin machen fast $75 \%$ der sich im Serum befindlichen Proteine aus (Anderson et al. 2002) und ihre Konzentrationen liegen im Bereich von Milligramm pro Milliliter Serum $\left(10^{-3} \mathrm{~g} / \mathrm{ml}\right)$. Neben diesen so genannten high abundant Proteinen enthält das Serum auch Proteine, die sich nur in Spuren nachweisen lassen. Diese so genanten low abundant Proteine, wie z.B. Zytokine liegen im Konzentrationsbereich von $10^{-9}-10^{-12} \mathrm{mg} / \mathrm{ml}$ vor und können an high abundant Proteine gebunden sein (Anderson 2005). Durch die Entfernung dieser Proteine (Depletion) konnte gezeigt werden, dass eine deutliche Verbesserung der Detektion von low abundant Proteinen möglich ist (Georgiou et al. 2001; Ahmed et al. 2003; Greenough et al. 2004; Bjorhall et al. 2005).

\subsubsection{Depletionsmethoden}

In der Literatur sind unterschiedliche Methoden zur Entfernung der high abundant Proteine beschrieben, von denen im Folgenden einige vorgestellt werden.

Ahmed et al. konnten durch den Farbstoff Cibracon Blue den Anteil an Albumin in humanen Seren spezifisch verringern (Ahmed et al. 2003). Des Weiteren wurde eine Abreicherung der Immunglobuline mittels Protein A oder G beschrieben (Fu et al. 2005). Durch diese Methoden werden jedoch nur wenige Proteine abgereichert. Den aussichtsreichsten Ansatz stellen

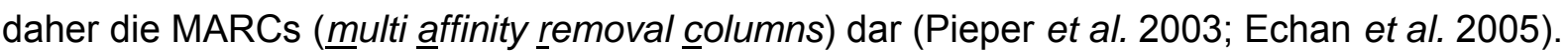
Die Funktionsweise einer MARC ist in Abschnitt 5.9.1 exemplarisch dargestellt.

MARCs werden von vielen kommerziellen Herstellern angeboten und unterscheiden sich in der Beladung mit verschiedenen polyklonalen Antikörpern, die die Abreicherung der high abundant Proteine vermitteln. Neben Agilent (Human 6, Human 7, Human 14), Beckman Coulter (Proteome Lab ${ }^{\circledR} \lg$ 12) und Sigma Aldrich (ProteoPrep ${ }^{\circledR} 20$ ) gibt es eine Vielzahl von Kits zum Entfernen von high abundant Proteinen, deren Vergleich untereinander unter anderem Gegenstand heutiger Forschung ist (Bjorhall et al. 2005). Dabei ist die Depletion von humanen Proteinen durch die Funktionalisierung des Säulenmaterials mit polyklonalen 
Antikörpern, deren Immunisierung im Huhn erfolgte (IgY), besonders spezifisch (Hinerfeld et al. 2004).

Da jedoch alle MARCs eine Restunklarheit darüber lassen, welche Epitope speziell erkannt werden, besteht bei der Depletion stets die Gefahr der Abreicherung von potentiellen Biomarkern. Es gibt daher proteomische Untersuchungen nur derer Proteine, die an high abundant Proteine wie das Albumin binden. Dieser Forschungsansatz wird in dem Begriff Albuminome beschrieben (Gundry et al. 2007).

Des Weiteren ist die Arbeit mit Immunaffinitätssäulen mit dem Risiko verbunden, dass bei mehrmaliger Benutzung ein Kapazitätsverlust durch Verlust der Affinitätspartner (Antikörper) eintritt (bleeding). Dies könnte sich, neben der Verunreinigung der Probe mit den Antikörpern der Säule, bei der Betrachtung des Serumproteoms in einem geänderten Spotpattern auf einem 2D-Gel niederschlagen.

Diese Probleme sind bei der Verwendung von Peptiden anstelle von Antikörpern als Ligationspartner deutlich verringert. Beim ProteomeMiner ${ }^{\circledR}$ (Biorad) wurde das Säulenmaterial mit einer Vielzahl kombinatorisch erzeugter Hexapeptide funktionalisiert (CPLL, combinatorial peptide ligand libraries). Diese Permutation unterschiedlichster Liganden weist ähnliche Eigenschaften wie eine Depletion mittels Immunoaffinität auf (Boschetti et al. 2008; Boschetti et al. 2008; Righetti et al. 2008). Die Leistungsfähigkeit dieser Depletionstechnik wurde bei den Untersuchungen von Cerebrospinalflüssigkeit (Shores et al. 2008) und Urin (Castagna et al. 2005) unter Beweis gestellt. Die Methode fokussiert sich dabei hauptsächlich auf die Proteine im unteren Molekulargewichtsbereich (Mr 600 - 8000 Da) (Boschetti et al. 2007).

\subsubsection{Weitere Methoden zur Biomarkersuche}

Neben der 2D-SDS-PAGE mit anschließender Identifizierung regulierter Proteine gibt es eine Reihe anderer Methoden, die zur Zeit im Bereich der Biomarkerfoschung Anwendung finden und durch die rasanten Fortschritte im Bereich der Massenspektrometrie begünstigt werden. Der Aufbau dieser multiplexed proteomics plattforms besteht aus einer Vorfraktionierung, einer multidimensionalen Trennungsmethode und der Proteinidentifizierung mittels TandemMassenspektrometrie (MS/MS-Technik) und wird unter dem Begriff shotgun proteomics zusammengefasst. Bei der Vorfraktionierung kommen neben der Depletion diverse Trenntechniken zum Tragen: Umkehrphasenchromatographie (reversed phase liquid chromatography, RP-LC) (Martosella et al. 2005), lonenaustauschchromatographie (strong cation exchange chromatography, SCX oder anion-exchange-chromatography, AEC) (Pieper et al. 2003), Größenausschlusschromatographie (size exclusion chromatography, SEC) (Horn et al. 2006), FFE (free flow electrophoresis) (Cho et al. 2005) und das Ausschneiden von Banden aus einem 1D-Gel (Thulasiraman et al. 2005). Die Fraktionen aus den jeweiligen Trenntechniken können auch aus der Kombination der verschiedenen Trenntechniken 
resultieren. Letztendlich werden die Proteine der Fraktionen anschließend mittels Trypsin verdaut und die resultierenden Peptide chromatographisch separiert (RP-LC). Es erfolgt eine Analyse ihrer Größe durch Tandem-Massenspektrometrie (ESI-MS/MS) und Identifizierung des ursprünglichen Proteins durch bioinformatische Suchalgorithmen (datamining).

Das PPP (plasma proteome project) der HUPO (human proteome organization) hat die Ergebnisse dieser Studien zusammengefasst. Es wurden durch die verschiedenen multiplexed proteomics plattforms 9504 Proteine im humanen Plasma nachgewiesen, die mit einem oder mehreren Peptiden identifiziert wurden. 3020 Proteine wurden mit mehr als zwei Peptiden identifiziert, wovon nach einem spezifischen Datenbankabgleich mit codierenden Gensequenzen insgesamt 889 Proteine mit einer Irrtumswahrscheinlichkeit von 0,05\% nachgewiesen wurden (States et al. 2006). Die Separationsleistung dieser Plattformen liegt damit weit höher als die Möglichkeiten der Trennung mittels 2D-SDS-PAGE. Jedoch ist die Standardisierung der Suchalgorithmen und die Quantifizierbarkeit noch Gegenstand momentaner Optimierungsarbeiten. Dieser so genannte Ansatz der gel free proteomics und deren Einfluss auf die Entdeckung neuer Biomarker wird in den kommenden Jahren immer mehr an Einfluss gewinnen (Baggerman et al. 2005). Eine schematische Übersicht der hier behandelten Strategien der Proteomanalyse ist in Abbildung 6 dargestellt.

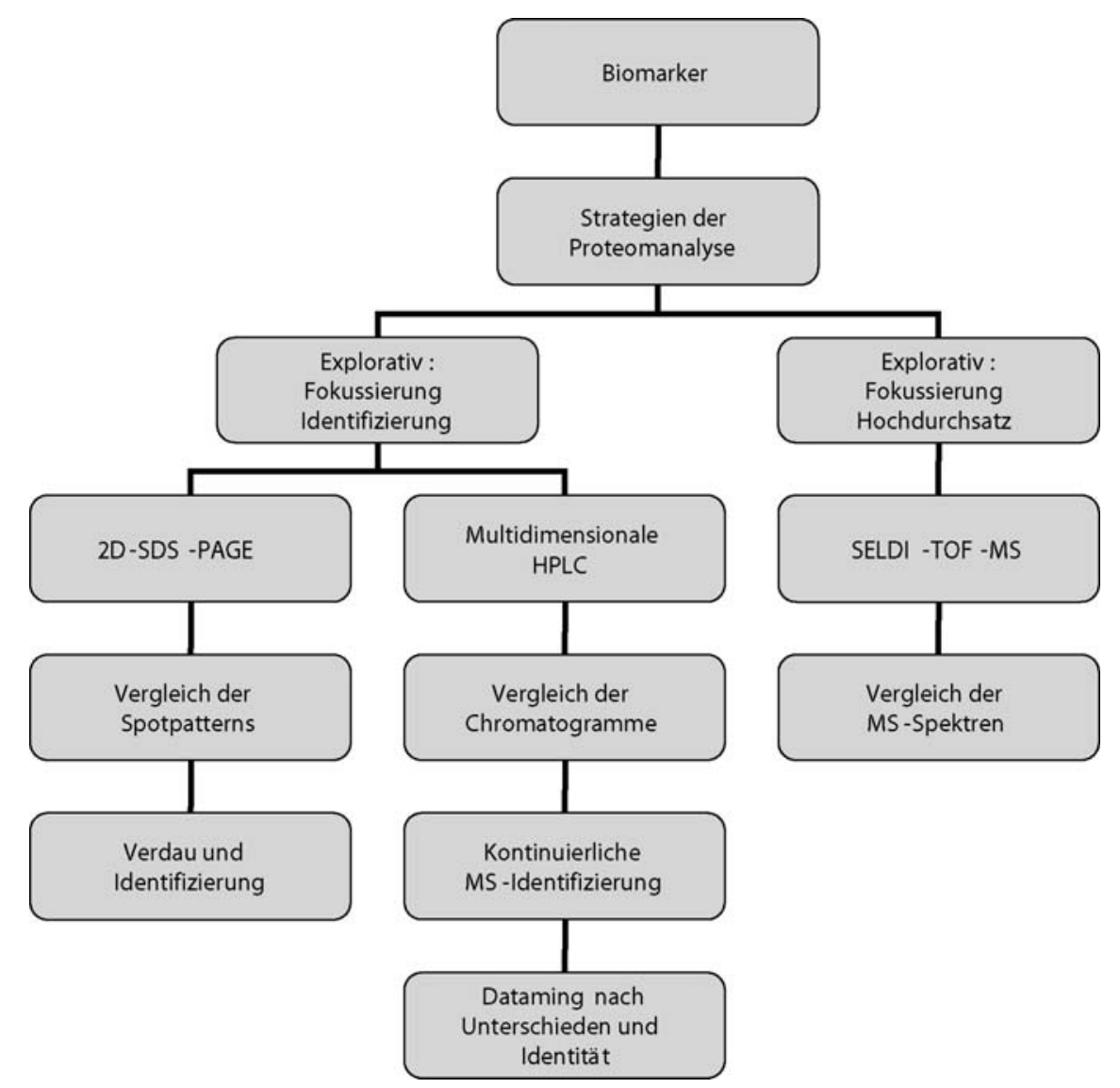

Abbildung 6: Strategien der Proteomanalyse bei der Biomarkersuche. 
Unter den gelfreien Systemen der Biomarkerforschung ist SELDI (ㅁurface enhanced laser desorption/ ionization) ebenfalls eine bedeutende Technik, die in den letzten Jahren ihre gute Anwendbarkeit bei Studien mit hohen Patientenzahlen unter Beweis gestellt hat. Es handelt sich um eine Variation von MALDI, bei dem die Oberfläche des Targets durch verschiedene Liganden funktionalisiert wurde. Gebräuchliche Oberflächen sind schwache und starke Anionen- und Kationenaustauscher, hydrophobe reverse-phased Liganden (Phenyl, C18) oder die Möglichkeit, spezifische Antikörper auf der Oberfläche zu koppeln. Nach Auftragen der Probe (Urin, Serum, Plasma) und spezifischen Waschschritten wird die gebundene Probe mit einer Matrix (Sinapinsäure) versetzt und durch Akquirierung eines MS-Spektrums ein spezifisches Peakmuster generiert. Diese Methode ist für den Hochdurchsatz konzipiert In Biomarkerstudien, die durch SELDI durchgeführt wurden, sind daher nur die $\mathrm{m} / \mathrm{z}$-Werte als spezifische Marker angegeben. Es bedarf dann anderer Methoden zur Identifizierung der Proteinidentität.

Trotz der hier genannten Vorzüge der klinischen Protoemics gibt es Kritikpunkte gegenüber den aktuellen Arbeiten. Gegenüber den groß angelegten Studien, die auf Messwerte der Routineanalytik zurückgreifen, sind die bisher in proteomischen Studien untersuchten Kollektive sehr klein.

Ein weiteres großes Problem ist die Standardisierung der Analysemethoden. Im Fall der 2DSDS-PAGE konnte durch die Einführung von DIGE (differential in gel electrophoresis) ein großer Schritt in Richtung Standardisierung getan werden. Im Bereich der multidimensionalen HPLC mit anschließender Identifizierung durch Tandem-Massenspektrometrie wird durch die Einführung von labelfreien Quantifizierungsmethoden versucht, die Genauigkeit, Reproduzierbarkeit und Quantifizierung zu verbessern (America et al. 2008; Negishi et al. 2008). 


\section{Zielsetzung}

Ziel der Arbeit ist das Auffinden eines Biomarkers, der die Früherkennung der rheumatoiden Arthritis ermöglichen könnte. Es werden bei der Ausführung des Projektes zwei unterschiedliche Strategien verfolgt.

Im ersten Ansatz erfolgt eine proteomische Betrachtung der Zellen, die im Gelenk als Initiatoren der Entzündungsreaktion vermutet werden. Es handelt sich hierbei um die fibroblastenähnlichen Zellen der Membrana Synovialis (RASF = rheumatoid arthritis synovial fibroblast, OASF = osteoarthritis synovial fibroblast). Die Fibroblasten der Patientenkollektive RA und OA sollen auf Basis der 2D-SDS-PAGE untersucht werden. Unterschiedlich exprimierte Proteine werden identifiziert und hinsichtlich ihrer Funktion klassifiziert, um Informationen über die Pathogenese auf molekularer Ebene zu gewinnen. Des Weiteren soll das Vorkommen citrullierter Proteine untersucht werde und somit geklärt werden, ob pathogene Veränderungen der synovialen Fibroblasten der Grund für die Produktion der Autoantikörper (ACPA) sind.

Ferner wird im zweiten Ansatz dieser Arbeit auf Basis der 2D-SDS-PAGE eine Serumanalytik etabliert. Zur Visualisierung von low abundant Proteinen werden die high abundant Proteine des humanen Serums der Patientenkollektive mittels Immunaffinitätchromatographie (Agilent Human 6 und Beckman Coulter Proteome Lab IgY12 LC2, Abschnitt 5.9.1, Seite 45) spezifisch abgereichert. Nach dieser Vorbereitung der Serumproben werden die Patientenpools auf Basis der DIGE-Technologie analysiert. Im Idealfall lassen sich die auffälligen Proteine der Analyse der RASF nachweisen.

Methodisch wird des Weiteren erörtert, ob eine Fraktionierung des depletierten humanen Serums mittels RP-Chromatographie die Separationsleistung von 2D-Gelen erhöhen kann.

Durch den Vergleich der Proteinspotpatterns des Serum von Patienten mit RA und OA mit gesunden Spendern soll ein serologischer Marker identifiziert werden, der zusammen mit den bestehenden Markern (Rheumafaktor, Anti-CCP, Anti-MCV) zur Frühdiagnostizierung eingesetzt werden kann. 


\section{Material}

\subsection{Verbrauchsmaterialien}

Alle Verbrauchsmaterialien wurden aufgrund der Sicherstellung von Sterilität, Kontaminationsgefahr oder Reinheit als Einwegartikel verwendet. Falls nicht anders angegeben, wurden sie vorher bei einem Wasserdampfdruck von 2 bar bei $121^{\circ} \mathrm{C}$ für $1 \mathrm{~h}$ in einem Autoklaven sterilisiert.

Alle Verbrauchsmaterialien wurden von den Firmen Nunc, Sarstedt, Greiner Bio-One, Biozym, Heraeus, Biorad, Carl Roth, Sigma-Aldrich, B.Braun, BD, Mettler-Toledo, Sartorius, Applied Biosystems, Sigma und Eppendorf verwendet.

\subsection{Chemikalien}

Die Chemikalien wurden von den Firmen Merck KGaA (Darmstadt), Roche AG (Mannheim), Sigma-Aldrich GmbH (Steinheim), Bio-Rad GmbH (München), Serva GmbH (Heidelberg) und Carl Roth $\mathrm{GmbH} \&$ Co. KG (Karlsruhe) bezogen und hatten den -Reiheitsgrad p.a. oder reinst. $96 \%$, vergällt mit $1 \%$ (v/v) MEK Ethanol wurde aus der Klinikumsapotheke bezogen. Reinstwasser (Milli-Q) wurde aus einer Reinstwasseranlage der Firma Millipore (Billerica, USA) bezogen und hatte eine Leitfähigkeit von mehr als $18 \mathrm{M} \Omega \mathrm{cm}$.

\subsection{Lösungen}

\section{Zellkultur}

DMEM „high Glucose“ FCS (hitzeinaktiviert) Glutamin 200 mM (100 x) Penicillin/Streptomycin (100 x)

MEM-Vitamins $(100 \mathrm{x})$ Trypsin / EDTA (1:250) Kollagenase (lyophilisiert)

E.C. Nummer 3.4.2.4.3. Dispase (lyophilisiert) E.C. Nummer 3.4.24.2 PBS (ohne $\mathrm{Ca}^{2+}$ und $\mathrm{Mg}^{2+}$ )

Kollagenase Dispase Verdaupuffer Lysepuffer
Invitrogen, Karlsruhe Invitrogen, Karlsruhe Invitrogen, Karlsruhe PAA Laboratorien, Pasching PAA Laboratorien, Pasching PAA Laboratorien, Pasching Invitrogen, Karlsruhe

Invitrogen, Karlsruhe

8,0 $\mathrm{g} / \mathrm{l}$ Natriumchlorid $(\mathrm{NaCl})$ $0,2 \mathrm{~g} / \mathrm{l}$ Kaliumchlorid $(\mathrm{KCl})$

$1,44 \mathrm{~g} /$ Dinatriumhydrogenphosphat $\left(\mathrm{Na}_{2} \mathrm{HPO}_{4}\right)$ $0,24 \mathrm{~g} / \mathrm{l}$ Kaliumdihydrogenphosphat $\left(\mathrm{KH}_{2} \mathrm{PO}_{4}\right)$ Auf $\mathrm{pH} 7,4$ eingestellt 20 Minuten $121^{\circ} \mathrm{C}$ autoklaviert $0,05 \%$ (w/v) Kollagenase $0,05 \%(w / v)$ Dispase in PBS 9,5 M Urea, 4 \% (w/v) CHAPS, 50 mM DTT Proteaseinhibitoren Complete ${ }^{\circledR}$ EDTA Free (Roche) 


\section{Proteinbiochemische Methoden}

Bradford-Reagenz

BSA-Standard

Rehydratationspuffer

Equilibrierungspuffer I (DTT)

Equilibrierungspuffer II (IAA)

Ampholyte-Stammlösung

1,5 M Tris- $\mathrm{HCl} \mathrm{pH} \mathrm{8,8}$

0,5 M Tris-HCl pH 6,8

Rotiphorese Gel 30 (37,5:1)

Reinstwasser

APS-Lösung

TEMED

$5 \times$ Tris-Glycin Elektrophoresepuffer $20 \times$ MOPS-Puffer

Transferpuffer

TBS

TBS-T

ECl-Reagenz

Western Lighning ${ }^{\circledR}$ Plus ECL

Fixierlösung

Coomassie Färbelösung

Lysepuffer
Bio-Rad, München

$1 \mathrm{mg} / \mathrm{ml}$ in Milli-Q

6,0 M Urea, $2 \%$ (w/v) CHAPS, 25 mM DTT, 0,2 \%

Ampholyte, 0,001\% Bromphenolblau

$6 \mathrm{M}$ Urea, 0,375 M Tris-HCl, pH 8,8 $2 \%$ (w/v) SDS, $20 \%(w / v)$ Glycerin, $2 \%$ (w/v) DTT , 0,001 \% Bromphenolblau

6 M Urea, 0,375 M Tris-HCl, $\mathrm{pH} 8,82 \%$ (w/v) SDS, $20 \%$ (v/v) Glycerin, 2,5 \% (w/v) lodacetamid , $0,001 \%$ Bromphenolblau

Bio-Lyte ${ }^{\circledR} \mathrm{pH} 3-10$, Bio-Rad, München

Bio-Lyte ${ }^{\circledR}$ pH 5-8, Bio-Rad, München

$181,71 \mathrm{~g} / \mathrm{l} \mathrm{Tirs}-\mathrm{HCl}$

$\mathrm{mt}$ rauchender Salzsäure auf $\mathrm{pH}$ 8,8 einstellen

$60,57 \mathrm{~g} / \mathrm{l} \mathrm{Tris}-\mathrm{HCl}$

Mit rauchender Salzsäure auf pH 6,8 einstellen

Carl Roth, Karlsruhe

Ampuwa $^{\circledR}$, Wasser für Injektionszwecke

$10 \%$ (w/v) Ammoniumpersulfat

Sigma-Aldrich, Steinheim

$125 \mathrm{mM}$ Tris, 1,25 M Glycin, 0,5 \% (w/v) SDS

Bio-Rad, München

$25 \mathrm{mM}$ Tris- $\mathrm{HCl}, 186 \mathrm{mM}$ Glycin, $20 \%$ (v/v) Methanol $20 \mathrm{mM}$ Tris- $\mathrm{HCl}, 150 \mathrm{mM} \mathrm{NaCl}$

Mit rauchender Salzsäure auf $\mathrm{pH} 7,4$ einstellen

TBS + 0,02\% Tween-20

Perkin Elmer, Waltham

$40 \%(v / v)$ Ethanol, $10 \%(v / v)$ Essigsäure

Roti ${ }^{\circledR}$-Blue (5x Konzentrat)

9,5 M Urea, 4 \% (w/v) CHAPS, 50 mM DTT

Proteaseinhibitoren Complete ${ }^{\circledR}$ EDTA Free (Roche)

\section{Antikörper}

Name

Anti-HSP27

Katalog-Nr. AF 1580

Anti-Citrullin

Katalog-Nr. C5806

Anti-Citrullin Detection KIT

Katalog-Nr. C5806-03

Anti-Vimentin

Katalog Nr. HPA001762

Anti-Destrin

Katalog-Nr. D8940

Anti-Rabbit HRP-konjugiert

$\begin{array}{ll}\begin{array}{ll}\text { Host } \\ \text { Kaninchen }\end{array} & \begin{array}{l}\text { Hersteller } \\ \text { R\&D, Wiesbaden }\end{array} \\ \text { Kaninchen } & \text { Biomol AG, Hamburg } \\ \text { Kaninchen } & \text { Biomol AG, Hamburg } \\ \text { Kaninchen } & \text { Sigma-Aldrich, Steinheim } \\ \text { Kaninchen } & \text { Sigma-Aldrich, Steinheim } \\ \text { Maus } & \text { GE Healthcare }\end{array}$




\section{Marker}

Marker 1

(Immunoblot)

Marker 2

(Elektrophorese)

\section{Chromatographie}

Depletionspuffer A $(10 \mathrm{x})$

Depletionspuffer B $(10 \mathrm{x})$

Neutralisationspuffer C (10 x)

RP Laufmittel A

RP Laufmittel B

Lysepuffer

\section{Massenspektrometrie}

Procines modifiziertes Trypsin

Trypsinpuffer

Verdaupuffer

Entfärbelösung

Entwässerung

Extraktionslösung

Matrix

\subsection{Geräte}

\section{Zellkultur}

Zellkulturflasche

Zellkulturflasche

Zellsieb

Serologische Pipetten

Kühlzentrifugen

Brutbegasungsschrank

Sterilwerkbank

pH-Meter

Wasserbad

Mikroskop
Bio-Rad, München

Fermentas Vilnius
Precision Plus Protein Kaleidoscope Standard

Page Ruler ${ }^{\mathrm{TM}}$ Unstained

Protein Ladder

$100 \mathrm{mM}$ Tris- $\mathrm{HCl}, \mathrm{pH} 7,4,1,5 \mathrm{M} \mathrm{NaCl}$

$1 \mathrm{M}$ Glycine $\mathrm{HCl}, \mathrm{pH} 2,5$

$1 \mathrm{M}$ Tris- $\mathrm{HCl}, \mathrm{pH} 8,0$

$\mathrm{H}_{2} \mathrm{O}+0,05(\mathrm{v} / \mathrm{v})$ TFA

$\mathrm{ACN}+0,05(\mathrm{v} / \mathrm{v}) \mathrm{TFA}$

9,5 M Urea, 4 \% (w/v) CHAPS, $50 \mathrm{mM}$ DTT

Proteaseinhibitoren Complete ${ }^{\circledR}$ EDTA Free (Roche)

Promega, Mannheim

$1 \mathrm{mM} \mathrm{HCl}$

$10 \% \mathrm{ACN}(\mathrm{v} / \mathrm{v})$ in $10 \mathrm{mM} \mathrm{NH}_{4} \mathrm{HCO}_{3}$

$50 \%(\mathrm{v} / \mathrm{v}) \mathrm{ACN}$ in $\mathrm{H}_{2} \mathrm{O}$

$100 \% \mathrm{ACN}$

$60 \%$ (v/v) ACN, 0,1\% (v/v) TFA in $\mathrm{H}_{2} \mathrm{O}$

Gesättigte 2,5-Dihydroxybenzoesäurelösung

Sigma-Aldrich, Steinheim

\section{Proteinbiochemische Methoden}

Küvetten

Photometer

Kühlbare Tischzentrifuge

Ultrafiltrationskonzentratoren

Isoelektrisches Fokussiersystem IPG-Streifen
Nunc, Langenselbold

BD, Heidelberg

BD, Heidelberg

Sarstedt, Nürmbrecht

Sigma, Osterode

Heraeus, Hanau

Clean Air, Woerden

Sartorius, Göttingen

GFL, Burgwedel

Carl Zeiss, Göttingen
Nunclon ${ }^{\mathrm{TM}}$ Surface $75 \mathrm{~cm}^{2}$

BD Falcon ${ }^{\mathrm{TM}} 75 \mathrm{~cm}^{2}$

BD Zellsieb $100 \mu \mathrm{m}$

2, 5, 10, $25 \mathrm{ml}$

Sigma 3-18K

Heraeus BB6220

Typ CA/R

Basic $\mathrm{pH}$ Meter pB-11

GFL 1083

Axiovert 40
Sarstedt, Nürmbrecht

Perkin Elmer, Waltham

Sigma, Osterode

Sartorius Stedim, Göttingen

Bio-Rad, München

Bio-Rad, München
Halb-Mikroküvetten

Lambda 25

Sigma 1-15PK

Rotor 12132-H

Vivaspin 155000 MWCO

Vivaspin 45000 MWCO

Protean IEF Cell

Ready Strip ${ }^{\mathrm{TM}}$ IPG-Streifen

$11 \mathrm{~cm} \& 17 \mathrm{~cm}$

$\mathrm{pH} 3-10, \mathrm{pH} 3-10 \mathrm{NL}$,

pH 5-8, pH 4-7 


Elektrophoresesystem
$20 \mathrm{~cm} \times 20 \mathrm{~cm}$
$13 \mathrm{~cm} \times 8 \mathrm{~cm}$
$8 \mathrm{~cm} \times 6 \mathrm{~cm}$
Fertiggele Criterion $^{\circledR}$
Immunoblotsystem
Immunblotmembran
Filterpapier
Temperiereinheit
Spannungsquellen
Gelfärbeschalen
Rotationsschüttler
Ungekühlte Tischzentrifuge
Kühlbare Tischzentrifuge
Geldokumentationssystem
pH-Meter

Elektrophoresesystem

$20 \mathrm{~cm} \times 20 \mathrm{~cm}$

$\mathrm{cm} \times 8 \mathrm{~cm}$

$8 \mathrm{~cm} \times 6 \mathrm{~cm}$

Fertiggele Criterion $^{\circledR}$

Immunoblotsystem

Immunblotmembran

Temperiereinheit

Spannungsquellen

$\mathrm{pH}$-Meter

\section{Chromatographie}

HPLC-System 1

Äkta Purifier

HPLC-System 2

Shimadzu LC-10-Serie

Depletionssäule 1

Entsalzungs- und

Fraktionierungssäule

Depletionssäule 2

Ultrafiltrationskonzentratoren

Lyophilisator

Ultraschallbad
Bio-Rad, München

Bio-Rad, München

Bio-Rad, München

Bio-Rad, München

Bio-Rad, München

Bio-Rad, München

Millipore

GE Healthcare,

München

Uniequip, Meadowpine

Bio-Rad, München

Gibco, Karlsruhe

LBB, Uppsala

Pharmacia, Uppsala

Nalgene, Rochester

Nalgene, Rochester

Roth, Karlsruhe

GFL, Burgwedel

Eppendorf, Hamburg

Sigma, Osterode

Fujifilm, Düsseldorf

Sartorius, Göttingen
Protean $\|^{\circledR}$

Criterion ${ }^{\circledR}$

Mini-Protean ${ }^{\circledR}$

$12 \%$ Bis-Tris IPG

$10 \%$ Bis-Tris IPG

$12 \%$ Bis-Tris 18-well

Mini Trans Blot Cell

Immobilon- $P^{S Q}$ Membran

Whatman, Standard

Unijet 2

Power-Pack 1000

Power Supply PS3002

2301 Macrodrive 1

ECPS $2000 / 300$

$22,5 \times 22,5 \mathrm{~cm}$

$12,5 \times 12,5 \mathrm{~cm}$

$14,3 \times 10 \mathrm{~cm}$

GFL 3005

Centrifuge 5415D

Rotor 14198

Sigma 1-15PK

Rotor 12132-H

Fuji FLA 5100

Basic $\mathrm{pH}$ Meter pB-11
GE Healthcare,

München

Shimadzu, Duisburg

Agilent, Böblingen

Agilent, Böblingen

Beckman-Coulter,

Krefeld

Sartorius Stedim,

Göttingen

Heraeus-Christ, Hanau

Bradelin, Berlin
A-900

P-900

UV-900

Frac-950

$\mathrm{LpH} / \mathrm{C}-900$

LC-10 AS

SIL-10 A

FRC-10A

CTO-10A

CBM-10A

SPD-MC10A

Agilent Human $6 \mathrm{HC}$

4,6 $\times 10 \mathrm{~mm}$

Agilent mpCP HI-Recovery

Protein Column

$4,6 \times 50 \mathrm{~mm}$

Proteome Lab IgY-12 LC2

$6,4 \times 63 \mathrm{~mm}$

Vivaspin 155000 MWCO

Vivaspin 45000 MWCO

Christ Alpha 1-4

Sonorex Super 


\section{Geldigitalisierung}

Laserscanner

Fuji, Europa

FLA-5100

Massenspektrometrie

MALDI-TOF

Massenflugzeitanalysator

Applied Biosystems Voyager-DE STR

\subsection{Software}

\section{Gelbearbeitung und Auswertung}

Delta 2-D Version 3.4

Decodon AG, Greifswald

Image $J$

Adobe Photoshop

National Institutes of Health

Adobe Illustrator

Adobe Systems $\mathrm{GmbH}$

Adobe Systems GmbH

\section{Statistische Auswertungen}

Delta 2-D Version 3.4

GraphPad Prism

Decodon AG

Microsoft Excel

GraphPad Software Inc.

Microsoft Access

Microsoft Deutschland $\mathrm{GmbH}$ 


\section{Methoden}

\subsection{Zellkultur}

\subsubsection{Isolierung synovialer Fibroblasten aus Synovia}

Die extrazelluläre Matrix in Geweben ist eine komplexe Mischung aus Kollagenen und anderen extrazellulären Matrixproteinen (Glykoproteine, Proteoglykane). Für die Isolierung synovialer Fibroblasten muss die Matrix schonend aufgelöst werden, während die zellulären Strukturen nicht beschädigt werden dürfen. Für die Gewebedisaggregation wird daher eine Kombination aus proteolytischen Enzymen benötigt. Neben der reinen kollagenolytischen Eigenschaften wird durch die milde Wirkung der Dispase eine proteolytische Komponente hinzugefügt.

Das Gewebe, aus denen die synovialen Fibroblasten gewonnen wurde, stammt aus Synovektomien der Knie-, Hüft-, Sprunggelenks- und Schultergelenke von Patienten mit rheumatoider Arthritis (RA) oder Osteoarthritispatienten (OA). Die Operationen wurden unter Reinraumbedingungen in den Orthopädischen Kliniken Kassel gGmbH von Herrn Dr. B. Mai durchgeführt. Direkt nach Entnahme wurde das erkrankte Gewebe bis zu weiteren Bearbeitungsschritten in ein Gefäß mit sterilen PBS überführt und bei $4{ }^{\circ} \mathrm{C}$ gelagert.

Nach Erhalt wurde das Gewebe zunächst intensiv mit PBS gewaschen bis keine Blutbestandteile mehr in der Waschlösung und im Gewebe auszumachen waren. Anschließend wurde das Gewebe makroskopisch untersucht und mit einem Skalpell die pathologisch durch Zottenbildung verdickte Membrana Synovialis von der Membrana Fibrosa getrennt. Nach erneutem Waschen des herauspräparierten Gewebes wurde es mit $35 \mathrm{ml}$ Kollagenase-Dispase-Verdaulösung versetzt und unter leichtem Schütteln für $3 \mathrm{~h}$ bei $37^{\circ} \mathrm{C}$ inkubiert. Anschließend wurde der Verdauansatz mittels eines $100 \mu \mathrm{m}$ Zellsiebs gefiltert, um unverdaute Gewebestücke zu entfernen. Der Durchlauf wurde aufgefangen und zwei Mal mit $25 \mathrm{ml}$ PBS gewaschen. Zwischen den Waschschritten fand eine Zentrifugation bei $400 \mathrm{~g}$ und $4{ }^{\circ} \mathrm{C}$ statt. Das resultierende Zellpellet wurde in $20 \mathrm{ml}$ Zellkulturmedium aufgenommen und gleichmäßig auf zwei $75 \mathrm{~cm}^{2}$ Zellkulturflaschen verteilt.

\subsubsection{Kultivierung synovialer Fibroblasten}

Die Kultivierung erfolgte anhand der von Doyle et. al. beschriebenen Grundlagen der Zellkulturtechnik (Doyle et al. 1996). Die Zellen wurden in Dulbecco's modified Eagle Medium (DMEM) mit einer Glucosekonzentration von 4,5 g/l unter Zusatz von $10 \%$ hitzeinaktiviertem fötalen Kälberserum (FCS) sowie von $1 \%$ (v/v) $200 \mathrm{mM}$ Glutaminlösung und $1 \%(\mathrm{v} / \mathrm{v})$ Penicillin/Streptomycin in einem Brutschrank bei $37{ }^{\circ} \mathrm{C}, 95 \%$ relativer Luftfeuchte und $5 \%$ $\mathrm{CO}_{2}$ kultiviert. 
Nach 12 h, 24 h, 48 h und 72 h wurde ein Mediumswechsel durchgeführt. Zuvor wurden die Gewebekulturflaschen mit 25 ml PBS gespült, um nicht adhärente Zellen, Gewebe- und Zelldebris, tote Zellen und Zellen des periphären Blutsystems (vorzugsweise Monozyten) zu entfernen. In den anschließenden Wochen der Kultivierung wurde alle $72 \mathrm{~h}$ ein Mediumswechsel durchgeführt und die Zellpopulation mikroskopisch auf Kontaminationen und Dichte untersucht. Bei ca. 80 \% Konfluenz wurden die Zellen passagiert.

\subsubsection{Passagieren von Zellen}

Zum Passagieren wurden die Zellen mit $10 \mathrm{ml}$ PBS gewaschen und anschließend mit $2 \mathrm{ml}$ Trypsin-EDTA-Lösung inkubiert. Das Ablösen der Zellen wurde mikroskopisch verfolgt und nach zwei Minuten wurden die Zellen durch Abklopfen vom Boden der Zellkulturflasche gelöst. Gestoppt wurde die Reaktion durch Zugabe von $18 \mathrm{ml}$ Zellkulturmedium. Anschließend wurde die Zellsuspension auf zwei neue $75 \mathrm{~cm}^{2}$ Zellkulturflaschen verteilt.

\subsubsection{Zelllyse}

Die Analyse der synovialen Fibroblasten erfolgte stets nach der dritten Passage. Anfänglich wurden die adhärent wachsenden Zellen durch Abschaben abgelöst. Jedoch resultierte diese Methode in einer sehr geringen Proteinausbeute. Das Ablösen der Zellen durch einen Zellschaber zerstörte ein Großteil der Zellen, so dass beim Waschen die zytosolischen Proteine weggewaschen wurden. Aus diesem Grund wurden die Zellen abtrypsiniert.

Vor der Zugabe der Trypsin-EDTA-Lösung wurde die Grundfläche der Zellkulturflasche gründlich mit sterilen PBS gespült. Nach dem Abtrypsinieren wurden die Zellen in sterilem PBS aufgefangen und zwei Mal mit 25 ml PBS gewaschen. Zwischen den Waschschritten fand eine Zentrifugation mit $400 \mathrm{~g}$ bei $4{ }^{\circ} \mathrm{C}$ statt. Das Zellpellet wurde anschließend mit Lysepuffer (50 $\mu \mathrm{l}$ pro eingesetzter $75 \mathrm{~cm}^{2}$ Zellkulturflasche) bis zur vollständigen Klärung des Lysates auf Eis gelagert und alle 10 Minuten leicht durchmischt.

Nach vollständiger Klärung wurde das Zelllysat mit $21.000 \mathrm{~g} 30 \mathrm{~min}$ bei $4{ }^{\circ} \mathrm{C}$ zentrifugiert und der Überstand in Aliquots bei $-25{ }^{\circ} \mathrm{C}$ eingefroren. Die Proteinbestimmung fand stets nach einmaligem Einfrieren statt.

\subsection{Proteinbiochemische Methoden}

\subsubsection{Bradford Proteinbestimmung}

Der Triphenylmethanfarbstoff Coomassie Brilliant Blau G-250 bildet in saurer Lösung mit den kationischen, nichtpolaren und hydrophoben Seitenketten der Aminosäuren der Proteine 
Komplexe. Durch die Komplexbildung verschiebt sich das Absorptionsspektrum des Farbstoffes von 470 nm zu 595 nm (Bradford 1976).

Durch die Korrelation der Zunahme der Absorption des Protein-Farbstoffgemisches mittels eines Standardproteins bekannter Konzentration kann eine Kalibrierungskurve erstellt werden. Diese Kalibrierungskurve ist nur in großer Verdünnung linear ansteigend und von Protein zu Protein verschieden. Je nach Anwendungszweck können Standardproteine wie Chymotrypsin, Lysozym, IgG oder BSA zum Einsatz kommen.

Der Test wurde in Küvettenform durchgeführt. Nach Verdünnung des Bradford-Reagenzes im Verhältnis 1:5 wurde jeweils $1 \mathrm{ml}$ in die Halb-Mikroküvetten vorgelegt und 2, 4, 6, 8, $10 \mu \mathrm{l}$ einer $1 \mathrm{mg} / \mathrm{ml}$ BSA-Stammlösung zugegeben. Aus der Auftragung der Absorptionswerte gegen die BSA-Konzentration wurde eine Kalibrierungskurve erstellt. Anhand der Steigung, der Verdünnung der Probe, dem Probenvolumen und dem Leerwert des Probenpuffers errechnete sich die Konzentration.

\subsubsection{Probenaufarbeitungsmethoden}

\subsubsection{Acetonfällung}

Die Löslichkeit eines Proteins in wässrigen Lösungen hängt von der Zusammensetzung der Aminosäureseitenketten des jeweiligen Proteins ab. Handelt es sich bei den Seitenketten vorrangig um hydrophobe, unpolare Residuen, ist die Löslichkeit in wässrigen Lösungen eher schwach. Bei polaren, hydrophilen Residuen ist sie hingegen gut.

Bei der Zugabe eines kurzkettigen organischen Lösungsmittels (Methanol, Ethanol, Aceton, Acetonitril u. a.) wird die Hydratationskraft der Lösung herabgesetzt und die Proteine können aufgrund ihrer freigelegten Seitenketten über Van-der-Waals- oder elektrostatische Kräfte miteinander interagieren und aggregieren. Diese Aggregate können durch Zentrifugation getrennt werden.

Bei der Acetonfällung wird die zu fällende Probe im Verhältnis von 1:3 mit eiskaltem Aceton vermischt und bei $-20{ }^{\circ} \mathrm{C}$ über Nacht inkubiert. Der anschließende Zentrifugationsschritt richtet sich nach dem Probenvolumen. Bei Proben mit einem Volumen über $2 \mathrm{ml}$ wurde bei $5000 \mathrm{~g}$ und $4{ }^{\circ} \mathrm{C}$ für 60 Minuten, bei einem Volumen bis $2 \mathrm{ml}$ wurde bei $21.000 \mathrm{~g}$ bei $4{ }^{\circ} \mathrm{C}$ für 10 Minuten zentrifugiert

Nach Sedimentation wird der Überstand dekantiert und die Probe bei Raumtemperatur für 30 Minuten getrocknet. Das Pellet wird anschließend in Lysepuffer aufgenommen und bis zur späteren Verarbeitung bei $-20^{\circ} \mathrm{C}$ gelagert. 


\subsubsection{Chloroform-Methanol-Fällung}

Die Extraktion wurde gemäß dem Protokoll von Wessel et al. durchgeführt (Wessel et al. 1984). Sie ist nur für Proben bis zu einem Gesamtvolumen von $100 \mu \mathrm{l}$ anwendbar.

$100 \mu$ einer Proteinprobe werden mit $400 \mu$ l eiskaltem Methanol vermischt. Anschließend werden $100 \mu$ l Chloroform hinzugegeben und erneut vermischt. Nach der Zugabe von $300 \mu \mathrm{l}$ Milli-Q und Durchmischung erfolgt ein Zentrifugationsschritt bei $14.000 \mathrm{~g}$ mit $4{ }^{\circ} \mathrm{C}$ für eine Minute. Es bildet sich ein 2-Phasensystem aus, bei dem sich das präzipitierte Protein zwischen den beiden Phasen befindet. Die obere wässrige Phase wird abgenommen und verworfen. Es werden $600 \mu \mathrm{l}$ Methanol zugegeben und gut durchmischt. Nach einem weiteren Zentrifugationsschritt bei $14.000 \mathrm{~g}$ mit $4{ }^{\circ} \mathrm{C}$ für eine Minute wird der Überstand verworfen und das erhaltene Zellpellet nach Trocknung mittels Stickstoff in Lysepuffer aufgenommen und bis zur späteren Verarbeitung bei $-20^{\circ} \mathrm{C}$ gelagert.

\subsubsection{Ankonzentrierung und Entsalzung mittels Vivaspin ${ }^{\circledR}$-Konzentratoren}

Bei der Konzentration durch Vivaspin 15 bzw. Vivaspin 4 Konzentratoren handelt es sich um eine Ultrafiltration mit einer 5000 Da MWCO-Membran im Kleinmaßstab. Mit den Vivaspin-15 können Probenvolumen bis zu $20 \mathrm{ml}$ eingeengt werden, bei den Vivaspin 4 bis zu $5 \mathrm{ml}$. Durch Zentrifugalkräfte wird die Probe durch die Membran gepresst und man erhält ein Retentat, in dem sich mit einer hohen Wiederfindungsrate alle Proteine befinden sollen, die größer als 5000 Da sein. Durch sukzessives Addieren eines Puffers kann die Probe entsalzt und ankonzentriert werden.

In dieser Arbeit wurden Proben unterschiedlicher Volumina mit $4000 \mathrm{~g}$ bei $4{ }^{\circ} \mathrm{C}$ so weit wie möglich eingeengt. Je nach Probenbeschaffenheit und Proteinkonzentration dauerte die Zentrifugation bis zu $4 \mathrm{~h}$.

\subsubsection{Ankonzentrierung mittels Agilent mpC18}

Die Methode ist aufgrund ihrer Zugehörigkeit zum chromatographischen Methodenteil unter Abschnitt 5.9.4.1 (Seite 47) ausführlich in beschrieben. 


\subsection{Elektrophoretische Methoden}

\subsubsection{Isoelektrische Fokussierung}

Bei der isoelektrischen Fokussierung werden die Proteine aus der zu untersuchenden Probe gemäß ihrer Nettoladung aufgetrennt. Die Nettoladung eines Proteins setzt sich dabei aus dem relativen Gehalt saurer und basischer Aminosäureseitenketten und dem umgebenden $\mathrm{pH}-$ Wert zusammen. An einem definierten $\mathrm{pH}-$ Wert heben sich die Ladungen eines Proteins auf, so dass sich das Molekül nach außen hin ladungsneutral verhält. Dieser Zustand, bei dem die Nettoladung eines Proteins gleich null ist, bezeichnet man als isoelektrischen Punkt eines Proteins (Westermeier 2004).

Im dem hier benutzten System der Firma Bio-Rad erfolgte die Trennung über einen gelbasierten, immobilisierten $\mathrm{pH}-$ Gradienten. Der $\mathrm{pH}-\mathrm{Gradient}$ wird durch amphotere Substanzen (bifunktionelle Immobilene) erzeugt, die kovalent an die Gelmatrix gebunden sind (Westermeier et al. 1983). Die Gelmatrix ist auf eine Trägerfolie aufpolymerisiert und wird im getrockneten und gefrorenen Zustand geliefert (IPG-Streifen).

Das aufzutrennende Proteingemisch wird zum Auftragen direkt in die Fokussierungswanne gegeben, in der es von den IPG-Streifen aufgenommen wird. Nach 30 Minuten wird der IPGStreifen mit Öl überschichtet, um das Austrocknen der Streifen zu verhindern. Dieser Vorgang (Rehydratation) wird in der Regel mit 12 Stunden bei einer Temperatur von $20^{\circ} \mathrm{C}$ angegeben.

Je nach Länge des IPG-Streifens werden zur Fokussierung unterschiedliche Spannungen angelegt, die man aus den Tabellen 4 und 5 entnehmen kann.

Tabelle 4: $\quad$ Fokussierungsprogramm IPG-Streifen $17 \mathrm{~cm}$ für Protean $\|^{\circledR}-$ Kammer

\begin{tabular}{|c|c|c|c|c|}
\hline Schritt & $\begin{array}{c}\text { Voltstärke } \\
\text { [V] }\end{array}$ & Gradient & $\begin{array}{l}\text { Zeit } \\
\text { [h] }\end{array}$ & Funktion \\
\hline 1 & 500 & Rapid & 1 & Proteineintritt \\
\hline 2 & 1000 & Rapid & 1 & Proteineintritt \\
\hline 3 & $1000-10000$ & Linear & 4 & Fokussierung \\
\hline 4 & 10000 & Rapid & $50.000 \mathrm{Vh}$ & Fokussierung \\
\hline 5 & 500 & Rapid & 12 & Step and Hold \\
\hline
\end{tabular}

Tabelle 5: $\quad$ Fokussierungsprogramm IPG-Streifen $11 \mathrm{~cm}$ für Criterion ${ }^{\circledR}$-Kammer

\begin{tabular}{|cllll|}
\hline Schritt & $\begin{array}{c}\text { Voltstärke } \\
\text { [V] }\end{array}$ & $\begin{array}{l}\text { Gradient } \\
\text { [h] }\end{array}$ & $\begin{array}{c}\text { Zeit } \\
\text { [h] }\end{array}$ & Funktion \\
$\mathbf{1}$ & $500 \mathrm{~V}$ & Rapid & 1 & Proteineintritt \\
$\mathbf{2}$ & $1000 \mathrm{~V}$ & Rapid & 1 & Proteineintritt \\
$\mathbf{3}$ & $1000-8000 \mathrm{~V}$ & Linear & 4 & Fokussierung \\
$\mathbf{4}$ & $10000 \mathrm{~V}$ & Rapid & $30.000 \mathrm{Vh}$ & Fokussierung \\
$\mathbf{5}$ & $500 \mathrm{~V}$ & Rapid & 12 & Step and Hold \\
\hline
\end{tabular}


Die Proteinmengen sind je nach Probentyp und der anschließenden Färbemethode zu wählen und sind in der Tabelle 6 aufgeführt:

Tabelle 6: Maximale Proteinmengen für die isoelektrische Fokussierung je nach Färbungstechnik

\begin{tabular}{|ccc|}
\hline IPG-Streifen & Flamingo $^{\circledR}$ & Coomassie \\
$\mathbf{1 7} \mathbf{~ c m ~ P r o t e a n ~ I I ~}$ & $150 \mu \mathrm{g}$ & $500 \mu \mathrm{g}$ \\
$\mathbf{1 1} \mathbf{~ c m}$ Criterion $^{\circledR}$ & $100 \mu \mathrm{g}$ & $150 \mu \mathrm{g}$ \\
\hline
\end{tabular}

Das maximale Rehydratationsvolumen (Probe + Rehapuffer) beträgt bei den $17 \mathrm{~cm}$ IPGStreifen $300 \mu \mathrm{l}$, bei den $11 \mathrm{~cm}$ IPG-Streifen $215 \mu \mathrm{l}$.

Nach erfolgreicher isoelektrischer Fokussierung werden die Streifen aus der Fokussierwanne genommen und vom Öl befreit. Anschließend werden sie für jeweils 20 Minuten in Equilibrierpuffer I \& II inkubiert. Während der Inkubation mit DTT werden die Cysteine der Proteine reduziert und anschließend im zweiten Equilibrierschritt mittels lodacetamid carbamidomethyliert. Dies ist erforderlich, damit sich reduzierte Disulfidbrücken während der 2. Dimension (SDS-PAGE) nicht wieder verbinden. Allerdings werden die Cysteine während dieses Schrittes irreversibel modifiziert, wodurch es zu einem Masseschift von 57,034 Da (monoisotopische Masse) kommt. Dieser Masseschift muss bei der Identifizierung der Proteine berücksichtigt werden.

\subsubsection{Proteinelektrophorese im SDS-Polyacrylamidgel}

Die Natriumdodecylsulfat-Polyacrylamidgelelektrophorese (kurz: SDS-PAGE für engl. sodium dodecylsulfate polyacrylamide gel electrophoresis) ist eine Methode zum auftrennen von Proteinen nach ihrer Größe im elektrischen Feld. Dabei bindet das anionische Detergenz SDS an die Proteine und überdeckt die Eigenladung der Proteine. Die Trennung im elektrischen Feld erfolgt daher ausschließlich nach der Größe des Proteins (Laemmli 1970). Durch Zugabe eines reduzierenden Agens (DTT; TCEP, Mercaptoethanol) werden die Disulfidbrücken aufgespalten und die Sekundär- und Tertiärstruktur eines Proteins aufgebrochen.

Zur Auftrennung werden die denaturierten Proben auf ein Gel aus Polyacrylamid aufgetragen, an das eine Spannung angelegt wird. Das Gel fungiert dabei wie ein Sieb. Kleine Proteine wandern schnell durch die Matrixstruktur des Gels, während große Proteine deutlich länger benötigen. Die Siebwirkung des Gels hängt dabei maßgeblich von der Konzentration des Acrylamids und dessen Quervernetzung ab.

Als Elektrolyt werden in dieser Arbeit zwei verschiedene Puffersysteme verwendet. Bei großen Gele der Protean ${ }^{\circledR}{ }^{\circledR}$ Kammer kommt das Tris-Glycin-Puffersystem zum Einsatz. Die Gele haben $\mathrm{pH} 8,8$, was zu einer Deamininierung, Alkylierung und Reoxidierung der Disul- 
fidbrücken von Proteinen führt, da die Proteine im elektrischen Feld vom reduzierenden Agens getrennt werden.

Dieser Nachteil ist bei den kommerziell verfügbaren Neutralgelen (Criterion ${ }^{\circledR}$ ) mit Bis-TrisPuffersystem verbessert worden. Da diese Gele über ein gelinternes Reduktionsmittel verfügen und unter neutralen Bedingungen gegossen werden $(\mathrm{pH} \mathrm{6,5-pH} \mathrm{6,8)} \mathrm{fördert} \mathrm{dies}$ die Protonierung der Cysteinresiduen und verhindert so eine Reoxidierung (Graham et al. 2005).

Die beiden Gelsysteme unterscheiden sich in ihrer Größe. Die Protean II ${ }^{\circledR}$-Gele sind mit 22,5 $\mathrm{cm} \times 22,5 \mathrm{~cm}$ im Vergleich zu den Criterion ${ }^{\circledR}$-Gelen mit $13 \mathrm{~cm} \times 8 \mathrm{~cm}$ doppelt so groß. Die Laufzeit ist mit ca. $6 \mathrm{~h}$ (15 Minuten bei konstant $100 \mathrm{~V} ; 5,5 \mathrm{~h}$ bei konstant $200 \mathrm{~V}$ ) bei den Protean ${ }{ }^{\circledR}$-Gelen im Vergleich zu Criterion ${ }^{\circledR}$-Gelen $(1-1,5 \mathrm{~h}$ bei konstant $200 \mathrm{~V})$ deutlich länger. Es wurden in dieser Arbeit zur Optimierung der Methoden 12,5\% Protean $\|^{\circledR}$-Gele mit einer Dicke von $1 \mathrm{~mm}$ verwendet, dessen Zusammensetzung der Tabelle $7 \mathrm{zu}$ entnehmen ist.

Tabelle 7: $\quad$ Zusammensetzung der Protean $\mathrm{II}^{(\mathrm{R})}$-Gele

\begin{tabular}{|c|c|c|c|c|}
\hline \multirow[b]{2}{*}{ Protean II Gel } & \multicolumn{4}{|c|}{ Konzentration } \\
\hline & $10 \%$ & $12 \%$ & $\begin{array}{l}12,5 \% \\
\mathrm{ml}]\end{array}$ & $15 \%$ \\
\hline Ampuwa & 16.67 & 14.00 & 13.33 & 10.00 \\
\hline 1,5 M Tris pH 8,8 & 10.00 & 10.00 & 10.00 & 10.00 \\
\hline Rothiphorese Gel 30 & 13.33 & 16.00 & 16.67 & 20.00 \\
\hline 10 \% APS-Lösung & 0.20 & 0.20 & 0.20 & 0.20 \\
\hline TEMED & 0.02 & 0.02 & 0.02 & 0.02 \\
\hline
\end{tabular}

Für Western Blots kamen Mini-Protean ${ }^{\circledR}$-Kammern zum Einsatz, dessen Bestandteile und Volumina in der Tabelle 8 abgebildet sind. Die Dicke der Gele betrug $1 \mathrm{~mm}$.

Tabelle 8: Zusammensetzung der Mini-Protean ${ }^{(\mathrm{R})}$-Gele

\begin{tabular}{|r|rrrr|}
\hline & \multicolumn{4}{c|}{ Konzentration } \\
Mini-Protean Gel & $\mathbf{1 0} \%$ & $\mathbf{1 2} \% \begin{array}{c}\text { 12,5 \% } \\
\text { [ml] }\end{array}$ & $\mathbf{1 5} \%$ \\
Ampuwa & 3.125 & 2.625 & 2.5 & 1.875 \\
1,5 M Tris pH 8,8 & 1.875 & 1.875 & 1.875 & 1.875 \\
Rothiphorese Gel 30 & 2.5 & 3 & 3.125 & 3.75 \\
10\% APS-Lösung & 0.075 & 0.075 & 0.075 & 0.075 \\
TEMED & 0.0375 & 0.0375 & 0.0375 & 0.0375 \\
\hline
\end{tabular}

Bei den kleineren Criterion ${ }^{\circledR}$ Neutralgelen kamen die $10 \%$ bzw. $12 \%$ Bis-Tris-Gele mit Vertiefung für IPG-Streifen und Marker, sowie die $12 \%$ Bis-Tris Gele mit 18 Spuren zum Einsatz. Auch hier beträgt die Dicke der Gele $1 \mathrm{~mm}$. 
Zum Molekulargewichtsabgleich wurde vorrangig der Marker 2 verwendet, da alle Banden mittels Flamingo ${ }^{\circledR}$ visualisiert werden konnten. Bei allen Western Blots kam der Marker 1 wegen seiner vorgefärbten Banden zum Einsatz.

\subsection{Immunologische Methoden}

\subsubsection{Western Blot}

Der Transferprozess von Proteinen auf eine Membran unter Beibehaltung der relativen Position und der Auflösung nennt man blotten. Dabei bezeichnet der Western Blot (auch Immunblot genannt) explizit den Transfer von Proteinen aus einer Gelmatrix auf eine Trägermembran (Towbin et al. 1979). Der schematische Ablauf eines Western Blots ist in Abbildung 7 dargestellt.

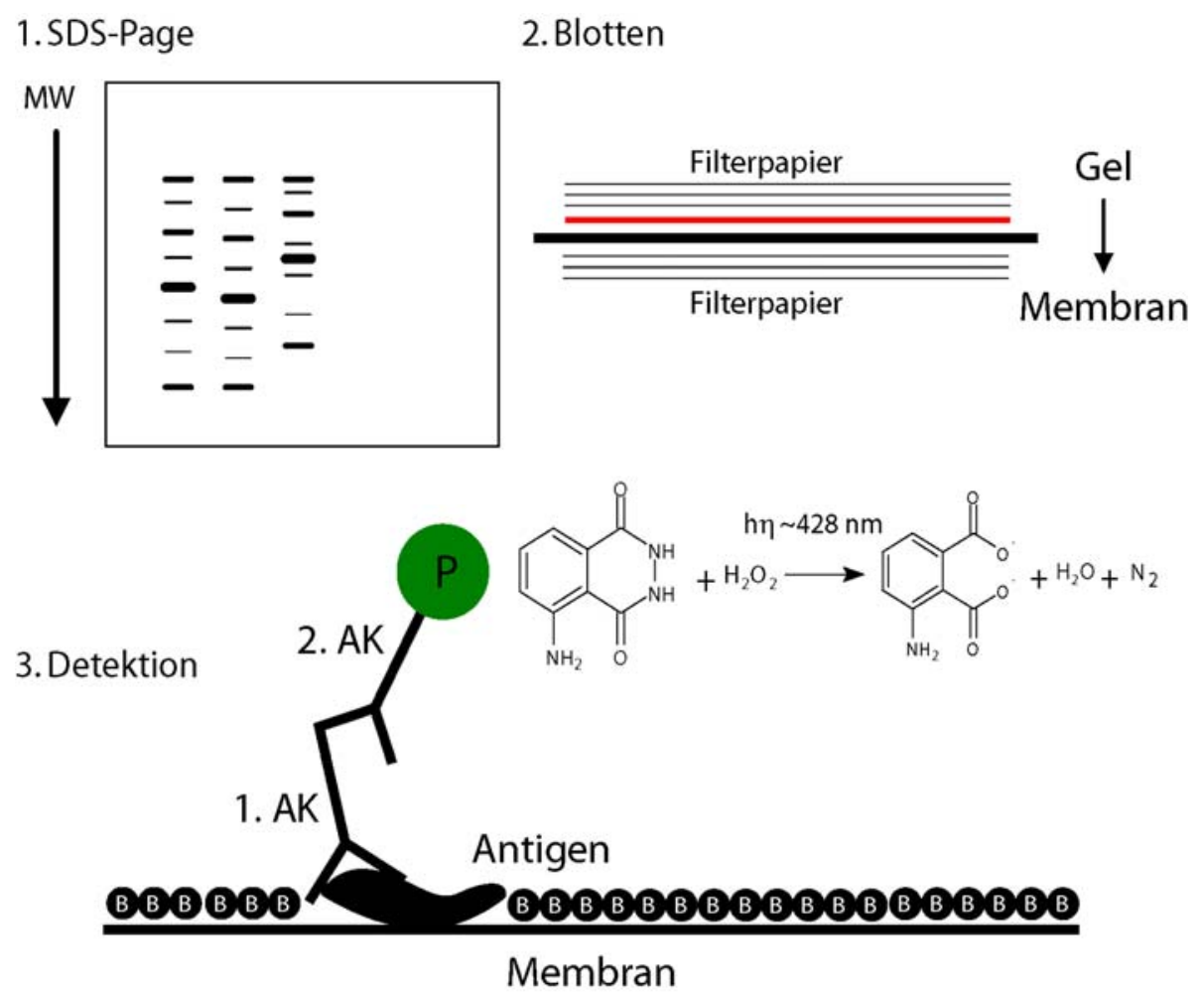

\footnotetext{
Abbildung 7: Schematische Darstellung des Aufbaus und der Detektion eines Immunoblots. (1) Auftrennung der Proteine nach Größe durch SDS-PAGE (2) Elektrotransfer der im Gel aufgetrennten Proteine auf eine PVDF-Membran (3) Nach dem Absättigen der Membran mit BSA (B) erfolgt die Detektion des spezifischen Erstantikörpers (1.AK) durch einen peroxidasegekoppelten $(P)$ Sekundärantikörper (2.AK) und die Umsetzung von Luminol unter Freisetzung von Licht.
} 
In dieser Arbeit wurde ausschließlich ein Elektrotransfer nach einer SDS-PAGE durchgeführt. Zum Einsatz kam eine Mini-Trans-Blot Cell (Bio-Rad, München), die den Transfer in einem Tank-System ermöglicht. Es wurde für den Transfer eine Polyvinylidenmembran (PVDF) mit einer Porengröße von 0,2 $\mu \mathrm{m}$ verwendet (Immobilon- $\mathrm{P}^{\mathrm{SQ}}$, Millipore), die vor Gebrauch 10 Sekunden in 100 \% Methanol aktiviert, danach in Transferpuffer für 10 Minuten equilibriert und dann auf das Gel gelegt wurde (Gultekin et al. 1988). Gel und Membran wurden zwischen zwei Filterpapiere und zwei Schwämme gelegt, die mit Transferpuffer gesättigt waren. Das erhaltene Packet aus Gel, Membran, Filterpapier und Schwämmen wurde in die Mini-Trans-Blot Kammer eingesetzt, mit Transferpuffer aufgefüllt und bei maximal $100 \mathrm{~V}$ für $500 \mathrm{mAh}$ geblottet. Nach dem Transfer wurde die Membran für 30 Minuten getrocknet. Dieser Schritt kann alternativ für die Absättigung der Membran mit BSA eingesetzt werden und ist für die Inaktivierung der Membran verantwortlich, um in kommenden Schritten unspezifische Proteinbindung zu vermeiden.

Es erfolgte eine Inkubation mit einem spezifischen Erstantikörper (1. AK) in geeigneter Verdünnung in TBS-T mit $1 \%$ (w/v) BSA über Nacht im Kühlraum (ca. $8{ }^{\circ} \mathrm{C}$ ) unter leichtem Schütteln. Nicht gebundener Antikörper wurde anschließend durch dreimaliges Waschen mit TBS-T entfernt ( $3 \times 5$ Minuten). Es erfolgte im Anschluss eine Inkubation mit einem peroxidasegekoppelten Sekundärantikörper (2. AK) für eine Stunde, der spezifisch an den $\mathrm{F}_{\mathrm{C}}$-Teil des Erstantikörpers bindet.

Durch Zugabe des durch $\mathrm{H}_{2} \mathrm{O}_{2}$-aktivierten ECL-Reagenzes kommt es zu einer Umsetzung des enthaltenen Luminols unter Freisetzung von Wasser und Licht (Chemoluminescence), das durch das Auflegen eines Films photosensitiv visualisiert wird. Das Filmmaterial mit dem spezifischen Bandenmuster kann nach Digitalisierung densitometrisch semi-quantitativ ausgewertet werden.

\subsubsection{Immunoblot: Citrullin Detektionskit}

Der Kit detektiert Citrullin-Residuen in einem dreistufigen Verfahren. Im ersten Schritt werden die Proteine nach dem Blocken durch 4 \% Paraformaldehydlösung für 20 Minuten irreversibel auf der Membran immobilisiert. Im zweiten Schritt erfolgt die Modifizierung der CitrullinResiduen durch 2,3-butadione monoxim und Antipyrin in stark saurem Milieu. Dazu wird die Membran in einer 1:1-Mischung von Lösung A (0,5 \% (w/v) 2,3-Butadione monoxime, 0,25 \% (w/v) Antipyrine, 0,5 M Essigsäure) und Lösung B (0,025 \% (w/v) $\mathrm{FeCl}_{3} ; 55 \%$ (v/v) Milli-Q, $25 \%(\mathrm{v} / \mathrm{v}) 98 \% \mathrm{H}_{2} \mathrm{SO}_{4} ; 20 \%(\mathrm{v} / \mathrm{v}) 85 \% \mathrm{H}_{3} \mathrm{PO}_{4}$ ) für mindestens $3 \mathrm{~h}$ bei $37^{\circ} \mathrm{C}$ inkubiert.

Nach mehrmaligem Waschen werden im dritten Schritt die modifizierten Citrullin-Residuen mit Hilfe eines polyklonalen Antikörpers spezifisch erkannt. Die Visualisierung erfolgte durch der in Abschnitt 5.4.1 beschriebenen Detektion. 


\subsection{DIGE (Differentielle In-Gel Elektrophorese)}

Durch die Differenzielle In-Gel Elektrophorese (DIGE) können die individuellen Zustände des Proteoms eines Systems durch den quantitativen Vergleich ihrer Spotmuster erörtert werden. Bei dieser Technik werden die Proteinproben vor der Elektrophorese mit spektral voneinander getrennten Fluoreszenzfarbstoffen ( $\mathrm{Cy}^{\mathrm{TM}}$ Dyes) gekoppelt. Anschließend werden die Proben vor der isoelektrischen Fokussierung zusammengemischt und auf einem einzelnen 2D-Gel aufgetrennt (Minden 2007; Westermeier et al. 2008). Die Strukturen der Fluoreszenzfarbstoffe und deren Fluoreszensspektren sind in Abbildung 8 dargestellt.

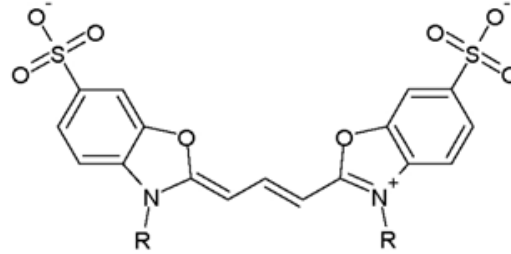

Cy2

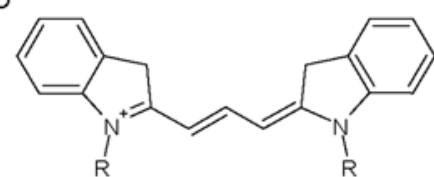

Cy3

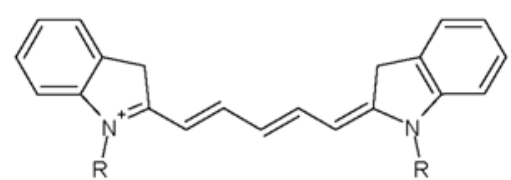

Cy5
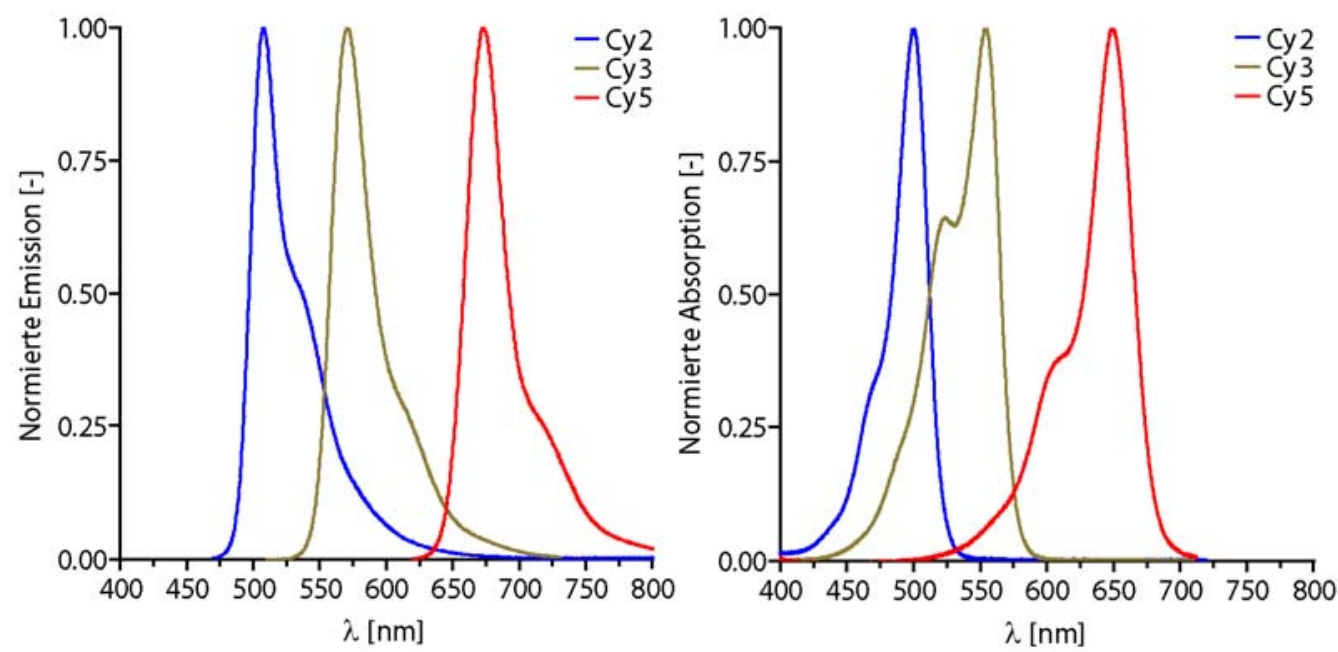

Abbildung 8: Strukturisomerie der Cy-Dyes und deren spektrale Eigenschaften.

Grundvoraussetzung für ein DIGE-Experiment ist, dass die Fluorophore strukturell ähnlich aufgebaut und spektral von einander getrennt sind, um drei distinktive Quantifizierungssignale zu erhalten. Während der elektrophoretischen Auftrennung dürfen sie des Weiteren das Laufverhalten der Proteine nicht zu beeinflussen.

Die Polarität der Farbstoffe spielt eine entscheidende Rolle. Bei der nukleophilen Substitution der $\varepsilon$-Aminogruppe eines Lysinrestes mit der NHS-Esther-Gruppe (R) der Farbstoffe kommt es unter Bildung eines Amides zu einer kovalenten Bindung des Fluorophores an das Protein und, im Falle einer fehlenden Polarität des Fluorophores, zum Wegfall einer positiven Partialladung. Dies würde in einer Änderung der elektrophoretischen Mobilität des Proteins während der isoelektrischen Fokussierung resultieren und das Proteinpattern verfälschen. 


\subsubsection{Probenvorbereitung und Kopplung der Farbstoffe}

Durch DIGE wurden ausschließlich mit Hilfe von Aceton gefällte, depletierte Serumproben analysiert. Da für die Kopplungsreaktionen ein Maximalvolumen von $10 \mu \mathrm{l}$ vorgeschrieben ist, sollte beim Lösen der Proteine das Volumen klein gehalten werden, damit die Proteinkonzentration der Proben mindestens $5 \mu \mathrm{g} / \mu \mathrm{l}$ ergibt.

Die Farbstoffe wurden zunächst in DMF gelöst auf eine Konzentration von $400 \mathrm{pmol} / \mu \mathrm{l}$ verdünnt. Die Kopplung erfolgte in einem Verhältnis von 400 pmol Farbstoff auf $50 \mu \mathrm{g}$ Protein. Der pH-Wert wurde durch die Zugabe von $1 \mu \mathrm{l} 1,5 \mathrm{M}$ Tris- $\mathrm{HCl} \mathrm{pH}$ 8,8 eingestellt. Nach einer 30-minütigen Inkubation auf Eis im Dunkeln wurde $1 \mu \mathrm{l}$ einer $10 \mathrm{mM}$ Lysinlösung zum Abstoppen der Reaktion pro Kopplungsansatz zugegeben. Nach 10 Minuten wurde mit Rehydratationspuffer auf das Maximalrehydratationsvolumen (Abschnitt 5.3.1) aufgefüllt und die Proben vermischt. Die nachfolgenden Bearbeitungsschritte sind identisch zu denen einer regulären 2D-SDS-PAGE.

In einem Kopplungsansatz wurden jeweils die Proben für den Lauf von. 4 DIGE-Gelen vorbereitet. Es wurde in das experimentelle Layout ein dye-shift integriert, der bei der Nutzung des Farbstoffes Cy2 als interner Standard unbedingt von Nöten ist. Die spektrale Trennung der Farbstoffe Cy2 und Cy3 ist nicht optimal. Bei der Akquisition der Bilddaten durch einen Laser der Wellenlänge $473 \mathrm{~nm}$ oder $532 \mathrm{~nm}$ kommt es zu Überschneidungen der Bilddaten. Durch den dye-shift werden diese Abweichungen der Spotintensitäten ausgeglichen.

Tabelle 9: Experimentelles Layout eines DIGE-Experiments mit dye-shift

\begin{tabular}{|cccc|}
\hline Gel & Cy2 & Cy3 & Cy5 \\
$\mathbf{1}$ & Interner Standard (IS) & Probe A & Probe B \\
$\mathbf{2}$ & Interner Standard (IS) & Probe A & Probe B \\
$\mathbf{3}$ & Interner Standard (IS) & Probe B & Probe A \\
$\mathbf{4}$ & Interner Standard (IS) & Probe B & Probe A \\
\hline
\end{tabular}

\subsubsection{Digitalisierung von DIGE-Gelen}

Die Digitalisierung der Gele erfolgte mit einem Fuji FLA-5100 Fluoreszenz-Laser-Scanner. Dieses modular aufgebaute System ist mit vier Laserlinien $(473 \mathrm{~nm}, 532 \mathrm{~nm}, 635 \mathrm{~nm}$ und $650 \mathrm{~nm}$ ) und zwei Detektoren ausgestattet. Die Empfindlichkeit des Systems wird über die Spannung (250 V - 1000 V) der Photomultiplier (PMT 1 und PMT 2) variiert und nicht über die Abstrahlleistung der Laserlinien. Dabei besitzt der PMT des zweiten Kanals eine erhöhte Empfindlichkeit im langwelligeren, roten Bereich.

Die Akquisition der Bilddateien erfolgte bei DIGE-Experimenten im 2Laser2Image-Modus. Dabei werden die drei Kanäle eines Gels (Probe, Kontrolle und interner Standard) in nur 
zwei Lesezyklen ermittelt. Während eines Lesevorgangs können die Bilder von zwei unterschiedlichen Fluorophoren aufgenommen werden. Dies ist möglich durch den Einsatz eines dichroitischen Spiegels (530 DF 20 und 570 DF 20) möglich, der die Signale auf die unterschiedlichen Detektoren aufteilt (PMT1 und PMT2).

Die Einstellung der Spannung der PMTs richtete sich nach der Intensität der Gele. Dabei ist die Spannung so gering wie möglich zu wählen, um ein gutes Signal- zu Rauschverhältnis (S/N-Ratio) zu bekommen. Im Falle der Übersättigung des Signals werden die betroffenen Pixel in der Software rot eingefärbt und das resultierende Bild ist für eine quantitative Betrachtung nicht mehr verwendbar. In diesem Fall muss die Spannung herabgesetzt und der Lesevorgang wiederholt werden. In den Experimenten genügte eine Spannung von 400-500 V für beide Kanäle.

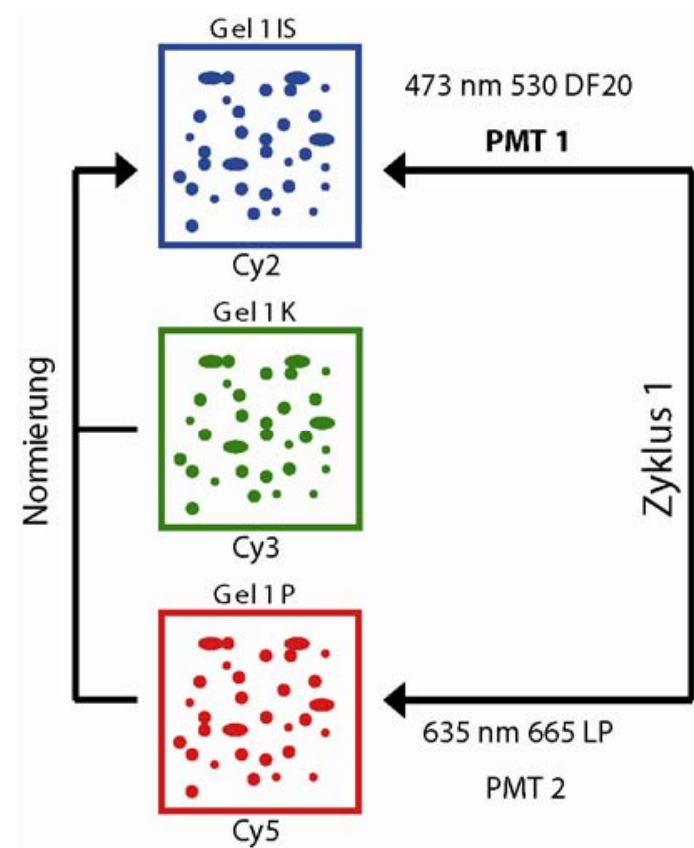

$532 \mathrm{~nm} 570$ DF20

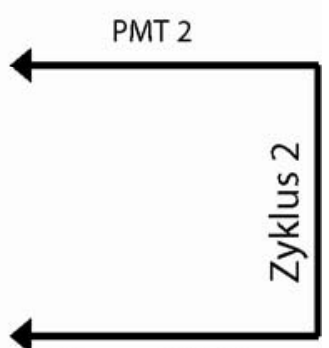

$635 \mathrm{~nm} 665 \mathrm{LP}$

PMT 2

Abbildung 9: Digitalisierungseinstellungen der DIGE-Gele im Lesemodus 2Laser2Image.

Je nach Einsatz und Größe der Gele (gesamte Darstellung bzw. nur einen Ausschnitt) wurde mit einer Auflösung von $100 \mu \mathrm{m} /$ Pixel für Protean II-Gele und $50 \mu \mathrm{m} /$ Pixel für Criterion-Gele in 16-bit Farbtiefe gescannt. Es wurde, für qualitative Analysen das TIFF-Format gewählt. Bei quantitativen Analysen wurde auf das IMG-Format (Ohyama et al. 1983) zurückgegriffen. Dieses Format, das auch als image-save-and-carry-Format bekannt ist, bietet einen kallibrierten Farbraum an und vermag es, durch Tonwertspreizung, die physikalischen Limitierungen des Laserscanners in Bezug auf Signaldynamik zu verbessern. Damit unterscheidet es sich wegen seiner adaptiven Farbraumkalibrierung zur herkömmlichen TIFF-Datei. 


\subsubsection{Statistische Auswertung von DIGE-Gelen}

Zur Auswertung von DIGE-Gelen wurde die Software Delta2D der Decodon AG in der Version 3.4 verwendet.

Für die Auswertung sind nur Gele zulässig, die keine digitale Nachbearbeitung erfahren haben. Nur die Operationen wie Spiegeln, Beschneiden und das Drehen um $90^{\circ}, 180^{\circ}$ und $270^{\circ}$ sind zulässig. Aus diesem Grund ist das korrekte Ausrichten der Bilder während des Scannens empfehlenswert.

Die Vorgehensweise der quantitativen Auswertung von 2D-Gelen ist in Abbildung 10 dargestellt und orientiert sich an dem consensus spot pattern -Algorithmus (Luhn et al. 2003; Berth et al. 2007), der Gegenüber der separate spot detection deutlich mehr Expressionsunterschiede in deutlich kürzerer Zeit ermöglicht (Eravci et al. 2007).

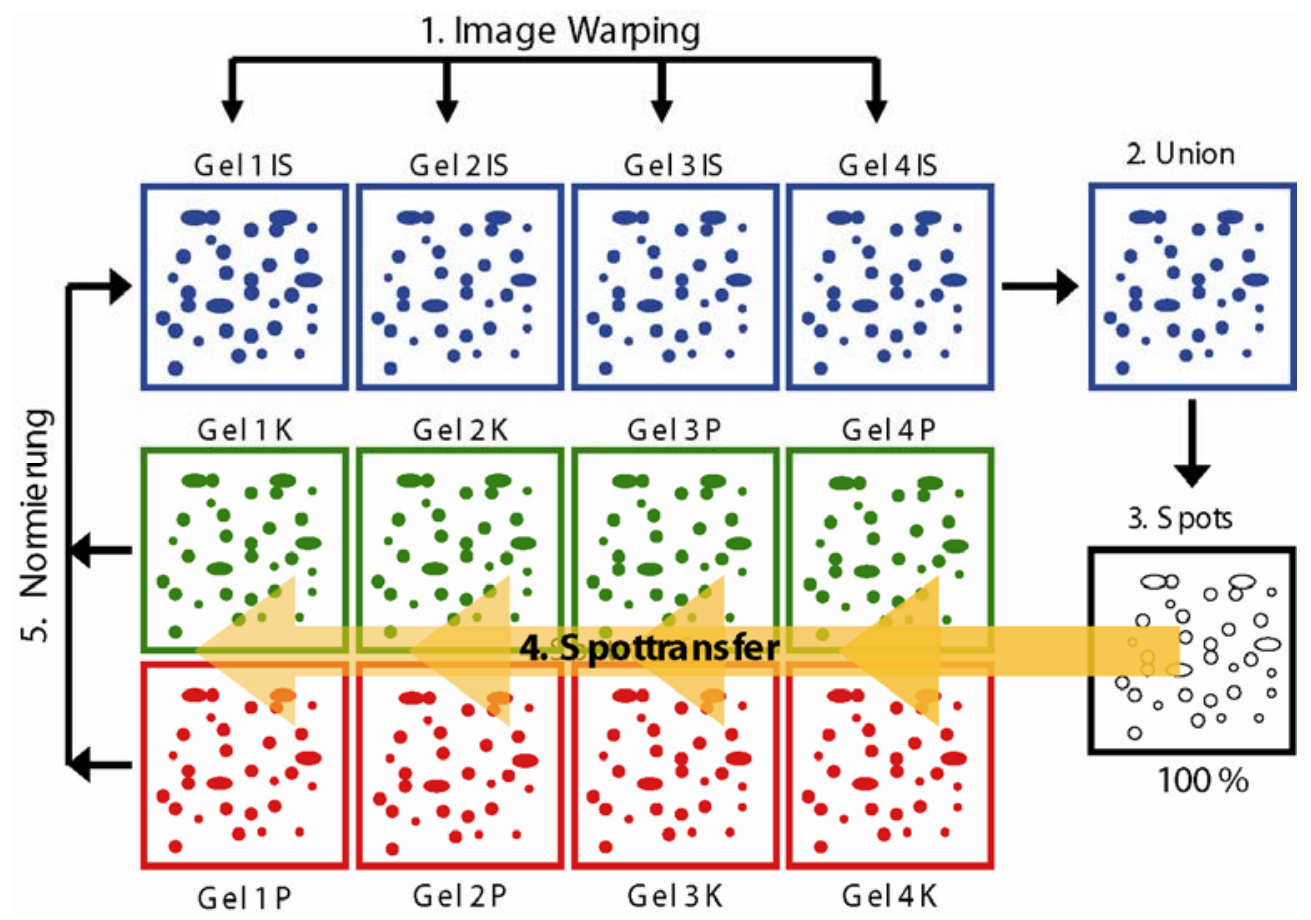

Abbildung 10: Gelauswertungsstrategie von DIGE Gelen nach Consensus Spot Patterns.Der Prozess unterteilt sich in 5 Schritte; (1) Angleichung der Internen Standards (Cy2) durch image warping (2) Erstellung eins Mastergels durch image fusion (3) Erstellung einer proteome map und (4) Spottransfer der in der proteome map festgelegten Spotgrenzen. Die Auswertung der Gele erfolgte durch Delta2D.

1. Im ersten Schritt werden die Positionsunterschiede der Spots durch so genanntes image warping ausgeglichen. Dies geschieht durch das Setzen so genannter matchvectors, die die Positionsunterschiede der Spots quantifizieren. Die aus diesem Schritt gewonnenen Informationen werden für die anschließende Erstellung eines Mastergels und die Übertragung des consensus spot patterns verwendet 
2. Im zweiten Schritt wird aus den übereinander gelegten Bildern ein artifizielles Mastergel durch Bildfusionierung erstellt. Dabei wird die Funktion „union“ als Fusionsalgorithmus gewählt und es entsteht ein Mastergel, das sämtliche Spots und Intensitäten der Einzelgele besitzt. Da dieses Gel keine quantitative Aussage besitzt, kann man es durch wiederholte Hintergrundreduzierung und Farbraumnormierung digital verbessern.

3. Im dritten Schritt wird anhand des artifiziellen Mastergels eine Spotkarte (Proteome Map) erstellt. Dabei werden auf diesem Gel nur die Spotumrisse festgelegt, die sich aus den Parametern Hintergrund, mittlere Spotgröße und Sensitivität errechnen. Es findet eine Festlegung statt, ab welcher Stärke des Graustufenüberganges ein Spot erkannt wird. Dieser Faktor kann durch den Parameter „Sensitivität“ und „Hintergrund“ beeinflusst werden. Der Parameter „mittlere Spotgröße“ dient daneben zur besseren Trennung von Spotclustern.

4. Im vierten Schritt wird die Spotkarte des Mastergels auf alle anderen Gele übertragen. Durch das Setzen der Match Vectors wird garantiert, dass das consensus pattern auf die richtige Position der anderen Gele übertragen wird. Die Intensitäten der Spots werden anhand der Rohdaten der einzelnen Gele (interner Standard, Probe, Kontrolle) errechnet, zusammenaddiert und auf $100 \%$ normiert. Die Angabe der Spotintensitäten erfolgt daher als prozentualer Anteil und nicht als gemittelter Graustufenwert.

5. Im fünften Schritt werden die auf $100 \%$ normierten Intensitäten der Probe und der Kontrolle mit den Intensitäten des Internen Standards verrechnet.

Für die Darstellung der Regulationsunterschiede und deren statistische Signifikanz werden für jeden Spot das relative Verhältnis der normierten Intensität, die Standardabweichung und ein $\mathrm{t}$-Test berechnet.

Ein Protein gilt als signifikant in seiner Expression geregelt, wenn der errechnete Quotient aus dem Vergleich Probe zu Kontrolle einen Wert von 2 für eine Hochregulierung, oder einen Wert von 0,6 für eine Herunterregulierung bei einer Irrtumswahrscheinlichkeit ( $p$-Wert) von $p<0,05$ aufweist.

\subsection{Statistische Auswertung von Flamingo ${ }^{\circledR}$ Gelen}

Neben DIGE-Gelen wurden im Rahmen dieser Arbeit auch 2D-Gele ausgewertet, bei denen die Visualisierung der Proteine durch Flamingo ${ }^{\circledR}$ Pink (Biorad) erfolgte. Im Vergleich zur kolloidalen Coomassiefärbung hat die Anfärbung durch Flamingo ${ }^{\circledR}$ eine deutlich bessere Signaldynamik. 
Das Vorgehen der Analyse greift auf die Grundlagen des image warpings, die Erstellung eines consensus spot patterns auf einem Mastergel und identischer Quantifizierungalgorithmen zurück, die zuvor in der Analyse der DIGE-Gele gezeigt wurden (vgl. Abschnitt 5.5.3).

Eine schematische Übersicht der Auswertungsstrategie ist in Abbildung 11 dargestellt und erfolgte beispielhaft an Hand der Gele, die bei der Proteomanalyse der synovialen Fibroblasten erstellt wurden.
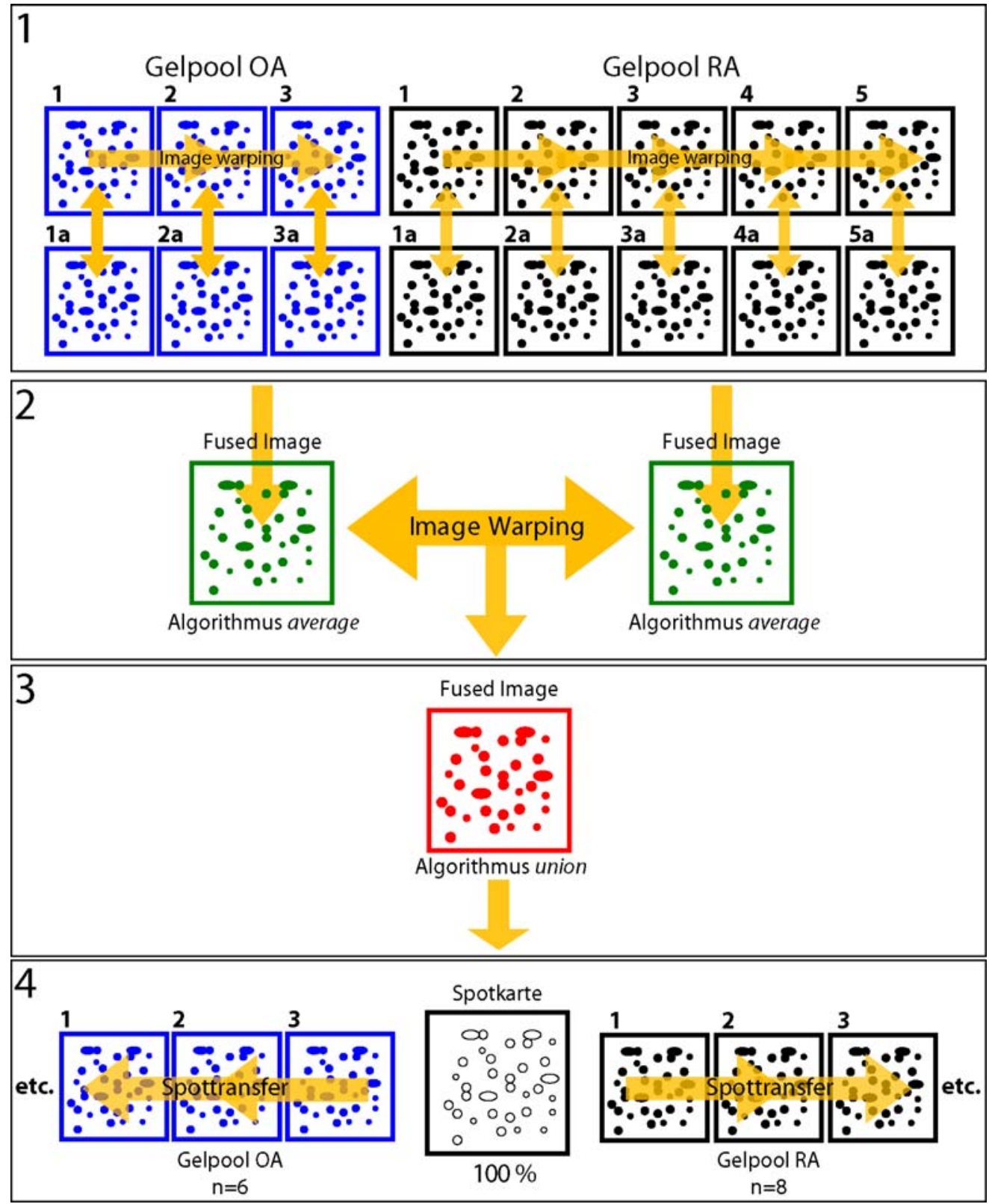

Abbildung 11: Gelauswertungsstrategie von Flamingo ${ }^{\circledR}$-gefärbten Gelen. Beispielhaft gezeigt an den Gelen der Zelllysate der synovialen Fibroblasten. (1) Gele werden durch image warping einander angeglichen (2) Erstellung der Mastergele (Fusionsalgorithmus average) der beiden Patientengruppen und Angleichung (3) Erstellung einer proteome map durch image fusion (Fusionsalgorithmus union) und (4) Spottransfer der in der proteome map festgelegten Spotgrenzen. 
Die Gele der fünf Patienten der Gruppe RA und die drei in der Gruppe OA, jeweils in einer Doppelbestimmung, wurden im ersten Schritt durch image warping einander angeglichen (Schritt 1). Dabei wurde jeweils die Replikatsgele untereinander und alle anderen Gele einer Gruppe auf das erste jeweilige Gruppengel angeglichen. Auf diese Weise war es möglich, durch image fusion mit dem Fusionsalgorithmus average ein virtuelles Mastergel für die Gruppen zu erlangen (Schritt 2). Die Mastergele der beiden Gruppen wurden durch image warping einander angeglichen und eine proteome map durch Fusionierung mit dem Algorithmus union (vgl. 5.5.3) erstellt (Schritt 3). Die im Mastergel determinierten Spotgrenzen werden anschließend auf alle Gele übertragen (Schritt 4).

Für die Darstellung der Regulationsunterschiede und deren statistische Signifikanz werden für jeden Spot das relative Verhältnis der normierten Intensität, die Standardabweichung und ein T-Test berechnet.

Ein Protein gilt als signifikant in seiner Expression geregelt, wenn der errechnete Quotient aus dem Vergleich Probe zu Kontrolle einen Wert von 2 für eine Hochregulierung, oder einen Wert von 0,6 für eine Herunterregulierung bei einer Irrtumswahrscheinlichkeit ( $p$-Wert) von $p<0,05$ aufweist.

\subsection{Gelfärbungsmethoden}

\subsubsection{Kolloidale Coomassiefärbung}

Nach dem Gellauf wird das Gel für mindestens 2 Stunden in Fixierlösung (40 \% (v/v) Ethanol, $10 \%$ (v/v) Essigsäure) fixiert und anschließend für 2 x 20 Minuten in Milli-Q gewaschen. Anschließend erfolgt eine Inkubation von mindestens $12 \mathrm{~h}$ in Coomassie-Färbelösung. Zum Entfärben des Gels wird das Gel mehrmals in 1 \% (v/v) Essigsäure gewaschen und die Färbeschale gewechselt. Die Coomassiefärbung kam vorrangig nach der Färbung der Gele mittels Flamingo zum Einsatz, um Spots auszuschneiden und zu identifizieren.

\subsubsection{Flamingo ${ }^{\circledR}$ Färbung}

Bei der Flamingo ${ }^{\circledR}$-Färbung handelt es sich um eine fluoreszenzbasierte Proteinfärbungsmethode der Firma Bio-Rad. Die genaue Zusammensetzung des Produktes ist nicht erhältlich.

Das Protokoll der Färbung ist vergleichbar mit der Coomassiefärbung. Nach dem Gellauf wird das Gel mindestens zwei Stunden fixiert und anschließend für mindestens drei Stunden in der Färbelösung inkubiert. Weitere Waschschritte sind nicht erforderlich. Die Gele lassen sich entweder mit der $473 \mathrm{~nm}$ oder der $532 \mathrm{~nm}$ Laserlinie bei mittlerer Sensitivität (PMT 1 400-600 V) digitalisieren 


\subsection{Massenspektrometrie}

Die Massenspektrometrie ist eine analytische Technik, die zur chemischen Komponentenanalyse benutzt wird. Das Messprinzip beruht auf der Detektion der unterschiedlichen Masse-Ladungs-Verhältnissen von Substanzen.

Grundsätzlich besteht ein Massenspektrometer aus den folgenden Hauptkomponenten: die Ionenquelle, die die Moleküle in geladene Ionen transformiert, den Masseanalysator, der die Ionen unter Einwirkung eines elektrischen Feldes in ihre Massen aufteilt und dem Detektor, der die lonen detektiert und in ein messbares elektrisches Signal umwandelt. Eine schematische Übersicht ist in Abbildung 12 dargestellt.

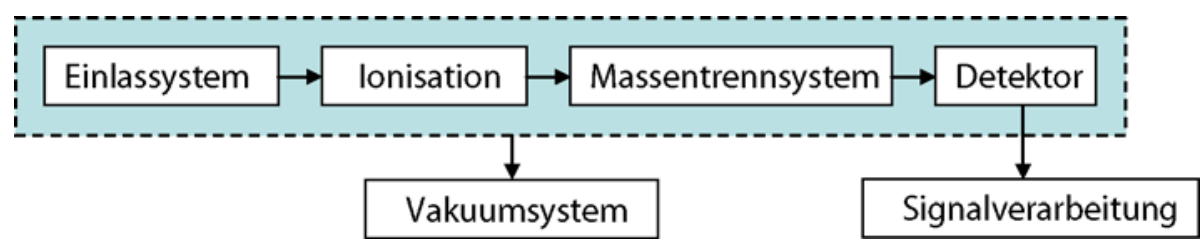

Abbildung 12 Schematischer Aufbau eines Massenspektrometers.

Die Massenspektrometrie diente in dieser Arbeit zur Identifikation von Proteinen mittels peptide mass fingerprinting (PMF) durch MALDI-TOF MS Analyse (Matrix Assisted Laser Desorption Ionisation Time-Of-Flight Mss Spectrometry). Diese von Franz Hillenkamp und Michael Karas (Hillenkamp et al. 1990) begründete Analysetechnik wird oft zur Identifizierung von Proteinen in heutigen Proteomanalysen angewendet.

Methodisch unterteilt sich der Identifizierungsvorgang in vier Teilschritte, die in einer schematischen Übersicht in Abbildung 13 dargestellt sind. In den folgenden Absätzen werden die einzelnen Schritte näher erläutert und die zu Grunde liegenden Parameter spezifiziert.

1

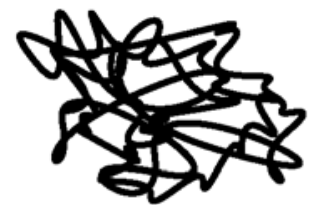

Protein

\section{Trypsin}

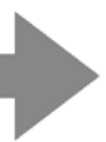

1.

Peptide Matrix (DHB)

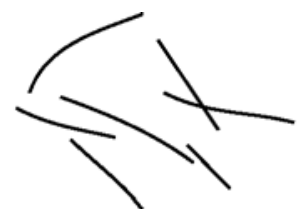

Peptide

MALDI-Target

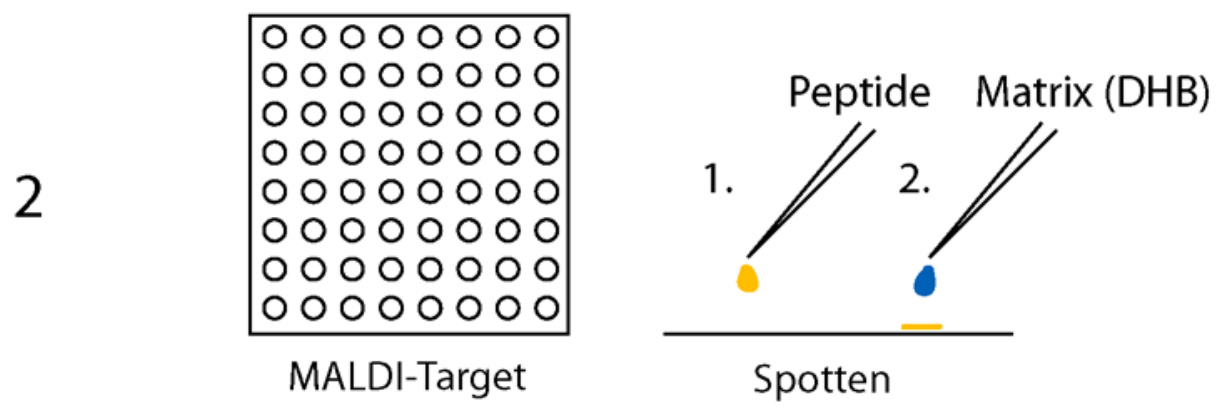


3
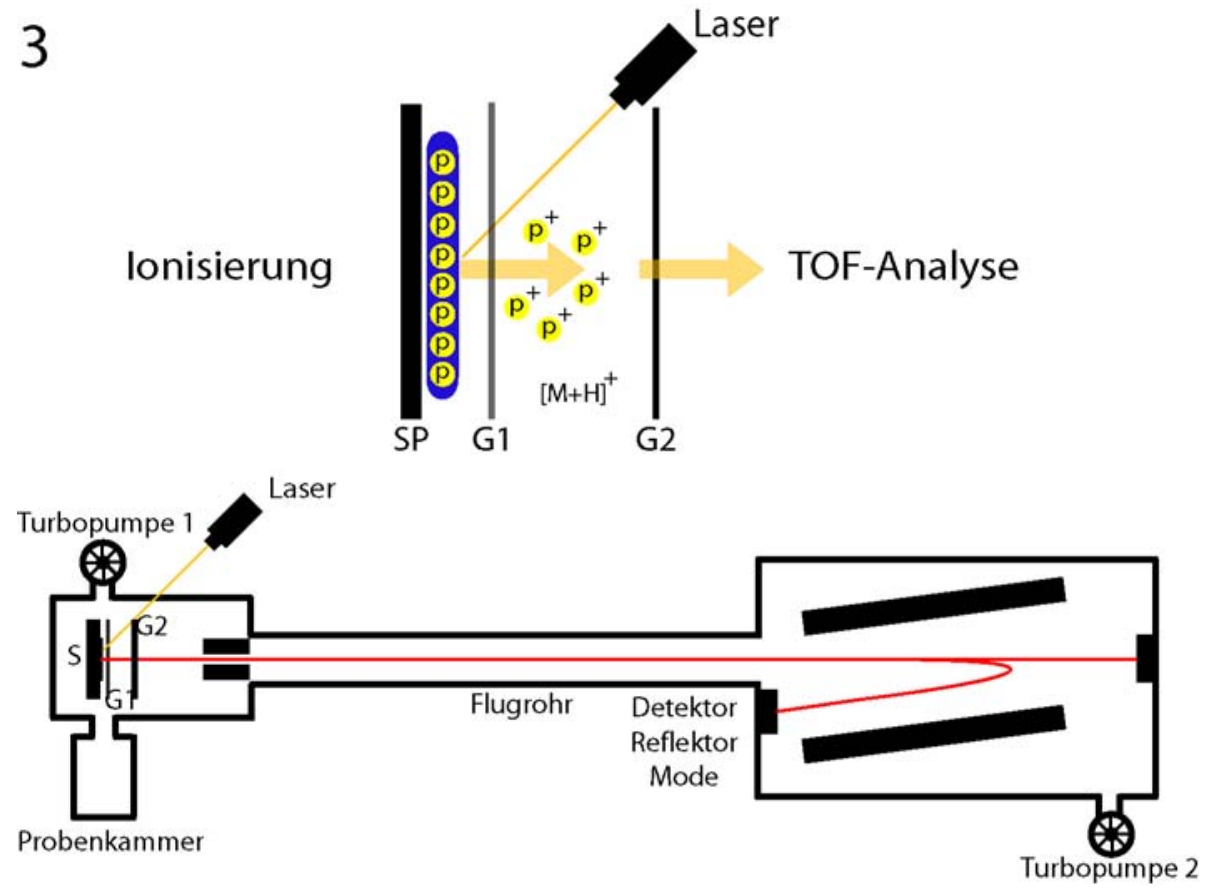

4

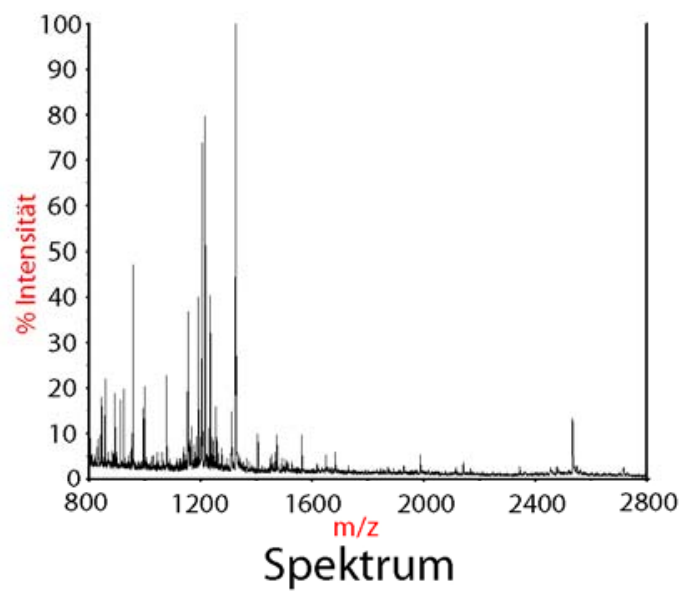

Peakdetektion

Monoisotrophierung

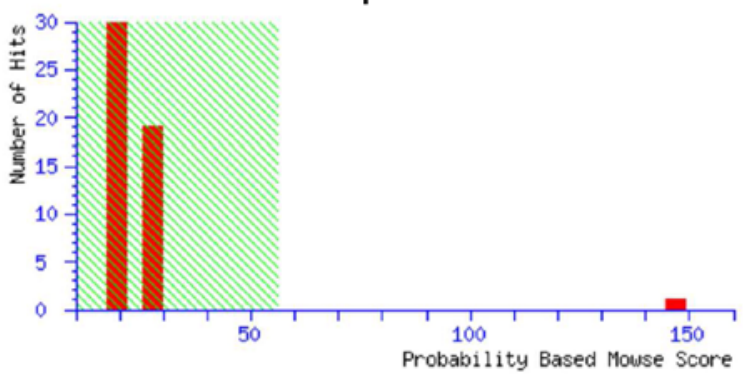

Datenbankabgleich

$\begin{array}{lll}\text { Accession } & \text { Mass } & \text { Score } \\ \text { RET4_HUMAN } & 23337 & 147 \\ \text { TCEA3_HUMAN } & 39688 & 29 \\ \text { IF_HUMAN } & 45729 & 28 \\ \text { TRM1_HUMAN } & 73386 & 28\end{array}$

Abbildung 13: Schematische Darstellung der Identifikation eines Proteins mittels MALDI-TOF MS Peptid Fingerprint-Analyse. Nach erfolgter Auftrennung des Proteingemischs durch 2D-SDS-PAGE und Herausschneiden der Proteinspots erfolgt in Schritt (1) der Verdau durch Trypsin (vgl. Abschnitt 5.8.1.) Anschließend werden die Peptide mit 2,5-Dihydroxybenzoesäure (DHB) vermischt und auf ein MALDI-Target gespottet (2). Es kommt zur Kokristallisation von Matrix (DHB) und Peptiden. Durch den Beschuss des Lasers werden die Peptide ionisiert und deren Massen in einem Flugzeitmassenspektrometer (TOF-Analysator) analysiert (vgl. Abschnitt 5.8.3) (3). Es ergibt sich aus den Massen der Peptide ein für das Protein charakteristisches Spektrum, das mit einer Datenbank (SWISS-PROT) abgeglichen werden kann (4). Die Wahrscheinlichkeit des korrekten Datenbankabgleichs wird in Form des sog. MOWSE-Score quantifiziert (vgl. Abschnitt 5.8.4). 


\subsubsection{Tryptischer Verdau von Proteinen im SDS-Polyacrylamidgel}

Um Proteine aus 2D-Gelen identifizieren zu können, müssen sie zunächst punktuell genau aus dem Gel herausgeschnitten werden. Zu diesem Zweck wird eine Pipettenspitze mit einem Skalpell so weit abgeschnitten, dass die Spitze einen Durchmesser von $2 \mathrm{~mm}$ hat. Mit Hilfe dieser Hohlnadel werden die Proteinspots aus dem Gel gestochen und anschließend tryptisch verdaut.

Es wurden in dieser Arbeit ausschließlich Proteinspots aus Gelen bearbeitet, die mit kolloidalem Coomassie angefärbt wurden. Die Methodik ist im Vergleich zu anderen manuellen Verdauprotokollen (Rosenfeld et al. 1992; Hellman et al. 1995) deutlich abgekürzt. Die Bearbeitungsschritte wurden auf ein minimales Maß gekürzt, um Kontaminationen mit Keratin zu vermeiden. Das Protokoll unterteilt sich in insgesamt fünf Teilbereiche, die im Folgenden Beschrieben sind:

Tabelle 10: Arbeitsschritte des tryptischen Verdaus von Proteinspots zur Identifizierung durch PMF.

\begin{tabular}{|c|c|c|}
\hline 1 & Entsalzung & $\begin{array}{l}\text { Nach dem Ausschneiden werden die } 2 \mathrm{~mm} \text { großen Gelstücke in ein } \\
0,5 \mathrm{ml} \text { Reaktionsgefäß überführt. Je nach Verunreinigungsgrad mit } \\
\text { Gelfragmenten und Coomassierückständen wird das Gelstück zwei } \\
\text { Mal mit jeweils } 100 \mu \mathrm{l} \text { Milli-Q gewaschen. }\end{array}$ \\
\hline 2 & Entfärbung & $\begin{array}{l}\text { Die entsalzen Gelstücke werden mit } 100 \mu \mathrm{l} 50 \%(\mathrm{v} / \mathrm{v}) \text { Aceto- } \\
\text { nitril/Milli-Q für mind. } 60 \text { Minuten inkubiert, bis keine Blaufärbung } \\
\text { mehr zu erkennen ist. }\end{array}$ \\
\hline 3 & Entwässern & $\begin{array}{l}\text { Nach dem Entfärben werden die Gelstücke durch Zugabe von } 50 \mu l \\
100 \% \text { Acetonitril vollständig entwässert. Nach } 30 \text { Minuten wird das } \\
\text { Acetonitril abgezogen und die Gelstücke unter der Reinraumwerk- } \\
\text { bank getrocknet. }\end{array}$ \\
\hline 4 & Verdau & $\begin{array}{l}\text { Modifiziertes porcines Trypsin (Promega) in } 1 \mathrm{mM} \mathrm{HCl} \text { auf eine } \\
\text { Konzentration von } 0,1 \mu \mathrm{g} / \mu \mathrm{l} \text { verdünnen. Diese Trypsin- } \\
\text { Stammlösung ist so für } 3 \mathrm{Monate} \text { bei }-20^{\circ} \mathrm{C} \text { lagerfähig. } 10 \mu \mathrm{l} \text { dieser } \\
\text { Stammlösung werden mit } 90 \mu \mathrm{l} \text { Trypsin Verdaupuffer ( } 10 \% \text { Aceto- } \\
\text { nitril (v/v) } 10 \mathrm{mM} \mathrm{NH}_{4} \mathrm{HCO}_{3} \text { ) vermischt. Die Gelstücke werden mit } \\
3 \mu \mathrm{l} \text { dieser Trypsinlösung überschichtet. Es erfolgt eine Inkubation } \\
\text { von mind. } 3 \mathrm{~h} \text { bei } 45^{\circ} \mathrm{C} \text {. }\end{array}$ \\
\hline 5 & Extraktion & $\begin{array}{l}\text { Nach dem Verdau werden die Gelstücke mit } 15 \mu \mathrm{l} \text { Extraktionslö- } \\
\text { sung (60\% (v/v) Acetronitril/Milli-Q, 0,1\% (v/v) TFA) für } 30 \text { Minuten } \\
\text { versetzt. Die Probe kann direkt gespottet werden. }\end{array}$ \\
\hline
\end{tabular}




\subsubsection{Spotten}

In dieser Arbeit wurde ausschließlich durch die dried droplet-Methode gespottet. Dazu wurde $1 \mu \mathrm{l}$ des Peptidextraktes mit $0,5 \mu$ l einer gesättigten 2,5-Dihydroxybenzoesäure-Lösung (DHB) auf einem MALDI-Target aus Edelstahl pipettiert und vermischt.

Im Falle geringer Signalintensitäten wurden die eingesetzten Peptidmengen des Extraktes variiert. Kokristallisation findet nur in einem engen Konzentrations- sowie Analyten zu MatrixVerhältnis statt. Daher wurden Peptidextrakte aus besonders intensiv gefärbten Gelstücken mit $0,1 \%(v / v)$ TFA in Milli-Q $1: 20$ verdünnt und anschließend gespottet. Bei sehr gering gefärbten oder kleinen Spots wurde durch Aufkonzentrieren in einem Vakuumkonzentrator und das Resuspendieren in einem geringeren Volumen (2-10 $\mu \mathrm{l})$ versucht, die Kriterien der Kokristallisation zu treffen.

\subsubsection{Akquirierung der Spektren}

Die Messung der verdauten und gespotteten Peptide erfolgte an einem Voyager-DE-STR Massenspektrometer der Firma Applied Biosystems.

Es wurde im positive mode mit einer Beschleunigungsspannung von $20.000 \mathrm{~V}$ in der Summe gemessen. Davon verteilten sich $80 \%$ auf das der Gitter G2, 19,98\% auf Gitter G1 und $0,02 \%$ auf den guide wire. Durch das Anlegen der unterschiedlichen Spannungen werden die mittels Laser ionisierten Peptide beschleunigt, während der Führungsdraht (guide wire) die freigesetzten lonen führt und gebündelt auf den Detektor bringt. Zur Intensitätsverbesserung wird die entstandene lonenwolke periodisch abgeführt (delayed extraction). Die so genannte delay time (Verzögerungszeit) betrug $180 \mathrm{~ms}$.

Es wurde im reflector mode gemessen, der für den verwendeten m/z-Bereich von 700-3000 Da ein erhöhtes Auflösungsvermögen besitzt. Dies ist durch die verlängerte Flugdauer der Ionen durch die unterschiedliche Ablenkung zu erklären, die sie im Reflektor erfahren. Technisch wird die Ablenkung durch eine Kaskade unterschiedlicher Ringelektroden realisiert, die je nach Spannung die freigesetzten lonen unterschiedlich stark beeinflussen.

Ein Spektrum wurden durch 50 Schüsse mit einer Pulsrate von $3 \mathrm{~Hz}\left(\mathrm{~N}_{2}\right.$-Laser / $\left.337 \mathrm{~nm}\right)$ akquiriert. Es wurden jeweils zwei Spektren pro Messung akkumuliert.

Das lonisierungsprinzip beruht auf der primären Absorption der Lichtenergie des Lasers durch die Matrix und die gleichzeitige Übertragung eines Energieteils auf den Analyten. Durch den Energietransfer werden entweder Protonen hinzugefügt $[\mathrm{M}+\mathrm{H}]^{+}$oder abgezogen $[\mathrm{M}-\mathrm{H}]^{-}$und der Analyt somit in ein geladenes Teichen überführt, das durch das Anlegen einer Spannung beschleunigt werden kann. Damit das lon detektiert und nicht vorher durch den Zusammenprall mit einem anderen Teilchen abgebremst wird, muss seine Flugbahn in einem Hochvakuum liegen $\left(10^{-7}-10^{-9} \mathrm{mbar}\right)$. 
Die Kalibrierung der Messungen erfolgte mittels des Sequazyme ${ }^{\mathrm{TM}}$ Peptide Mass Standards Kit (Applied Biosystems), das eine Mixtur hochreiner Peptide mit den folgenden bekannten Massen enthält. Die monoisotopischen Massen $(\mathrm{M}+\mathrm{nH}) \mathrm{n}^{+}$sind wie folgt: des-Arg ${ }^{1}-$ Bradykinin $(904,4681 \mathrm{~m} / \mathrm{z})$, Angiotensin I $(1296,6853 \mathrm{~m} / \mathrm{z})$, Glu'-Fibrinopeptid B $(1672,9175 \mathrm{~m} / \mathrm{z})$, Neurotensin $(1672,9175 \mathrm{~m} / \mathrm{z})$, ACTH (clip 1-17) $(2093,0867 \mathrm{~m} / \mathrm{z})$ und ACTH (clip 18-390) $(2465,1989 \mathrm{~m} / \mathrm{z})$. Da sich schon kleinste Feldinhomogenitäten und Oberflächenunebenheiten des Targets auf die Flugdauer auswirken, erfolgt die Kalibrationsmessung so räumlich dicht wie möglich an der Messung des unbekannten Analyten.

\subsubsection{Datenbankabgleich}

Um das Protein anhand seines Peptide-Fingerprints zu identifizieren wurde ein Datenbankabgleich mit der Swiss-Prot Proteindatenbank durchgeführt. Dazu wurde das halbautomatische Tool Mascot Wizzard benutzt, welches makrogesteuert die Vorverarbeitung der akquirierten Spektren übernimmt. Es werden hier auf die Programmbibliotheken des Mascot Distillers zurückgegriffen, um aus den Rohspektren die Peaklisten der einzelnen Messungen zu generieren. Im Zentrum der Peakdetektion und Anisotrophierung steht die Anpassung der experimentellen Elementarverteilung mit der idealen errechneten Verteilung. Diese Idealverteilung ist vorherberechnet für das Peptid oder die Aminosäuresequenz bei genau dem gemessenen $\mathrm{m} / \mathrm{z}$-Wert. Das Profil der Idealverteilung wird im nachfolgenden Schritt durch die Annäherung der Masse, Auflösung, Intensität und Ladungszahl angepasst. Im Fall einer qualitativ guten Anpassung wird der Wert zur Peakliste hinzugefügt und weitere Peaks angepasst (Berndt et al. 1999).

Anschließend werden die experimentell bestimmten Massen der Peptide mit den errechneten Massen der Datenbank Wert für Wert abgeglichen. Jedes Peptid, das zu einem Protein mit einer angegebenen Massentoleranz zugeordnet werden kann wird gezählt, wobei jedes theoretisch errechnete Peptid eine empirische Gewichtung erhält.

Diese Gewichtung hängt von dem relativen Vorkommen des Peptides ab und wird maßgeblich durch seine Zusammensetzung bestimmt. Selten vorkommende Aminosäuren (Prolin, Cystein bei Prokaryoten) oder spezielle für ein Protein hochspezifische Domänen beeinflussen somit den MOWSE-Score besonders signifikant (Pappin et al. 1993).

Neben der Gewichtung der Peptide geht auch die Massentoleranz in die Berechnung mit ein. Hohe Massentoleranzen wirken sich negativ auf den Score aus.

In Tabelle 11 sind die Standardsuchparameter des Datenbankabgleich mit der SWISS-ProtDatenbank dargestellt. 
Tabelle 11: Suchparameter des Datenbankabgleich der akquirierten MS-Spektren mit der SWISSProt Proteindatenbank.

\begin{tabular}{|ll|}
\hline Feld & Variable \\
Suchtyp & Peptide Mass Fingerprint (PMF) \\
Enzym & Trypsin \\
Fixe Modifikation & Carbamidomethyl (C) \\
Variable Modifikation & Oxidation (M) \\
Massetyp & Monoisotopisch \\
Toleranz & $\pm 0,6 \mathrm{Da}$ \\
Ladungszahl & $1+$ \\
Maximale Anzahl verpasster Trypsinspaltstellen & 1 \\
MOWSE Signifikanzgrenze & 55 \\
Irrtumswahrscheinlichkeit & 0,05 \\
\hline
\end{tabular}

Eine Proteinidentifizierung gilt als Signifikant, wenn der MOWSE-Score die Signifikanzgrenze von 55 mit einer Irrtumswahrscheinlichkeit von $p=0,05$ unterschreitet. Je nach Spezies und Datenbank (SWISS-Prot, NCBI, MSDB) und Datenbankgröße sind jedoch die Signifikanzgrenzen für den MOWSE-Score individuell verschieden. Die Ergebnisse sind wie folgt aufgelistet: Für Identifizierungen, die die Signifikanzgrenze überschritten haben, sind die genauen Peptidmassen und Abweichungen aufgelistet.

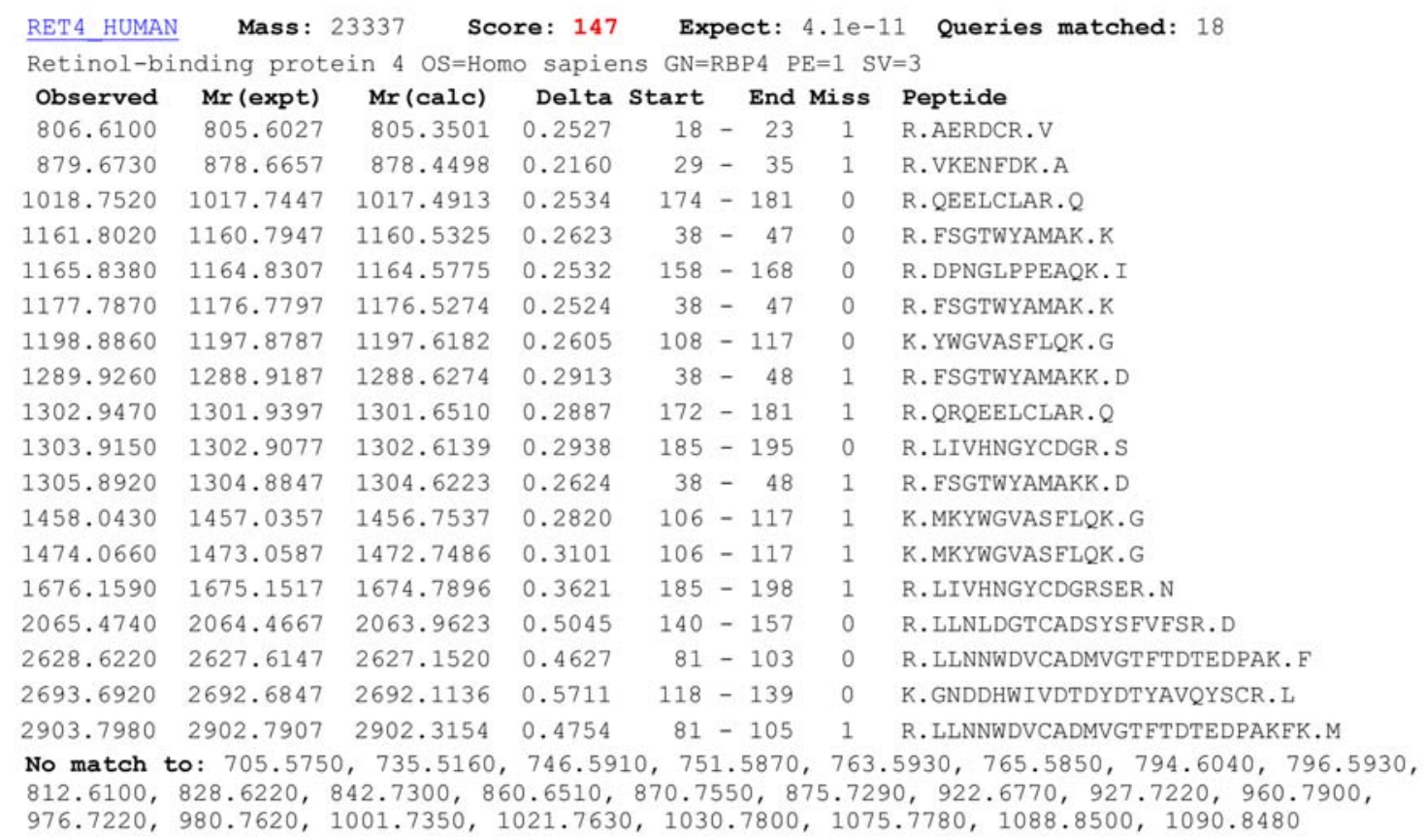

Abbildung 14: Auflistung der Massen, die im Rahmen einer PMF-Analyse mit der SWISS-Prot Proteindatenbank abgeglichen werden konnten. Die Tabelle enthält neben der gemessenen Masse Observed die berechnete Masse $\mathrm{Mr}(\mathrm{Calc})$, die Masseabweichung Delta, die nicht verdauten Trypsinschnittstellen Miss und die Peptidsequenz im Einbuchstabencode. Anhand der nicht aufgeführten Gewichtung der 18 Peptide errechnet sich der MOWSE-Score von 147 des gemessenen Retinol-Binding Protein 4. 


\subsection{Chromatographische Methoden}

\subsubsection{Funktionsprinzip der Immunodepletion}

Das Funktionsprinzip einer MARC ( multiple affinity removal column) ist schematisch in Abbildung 15 dargestellt und basiert auf den Grundlagen der Immunaffinitätschromatographie. Die high abundant Proteine, d.h. Proteine, die in sehr großen Quantitäten vorliegen, werden durch die Funktionalisierung des Chromatographiematerials mit polyklonalen Antikörpern zurückgehalten und verbleiben auf der Säule. Die low abundant Proteine befinden sich im Durchlauf, weil sie nicht an die Säule binden.

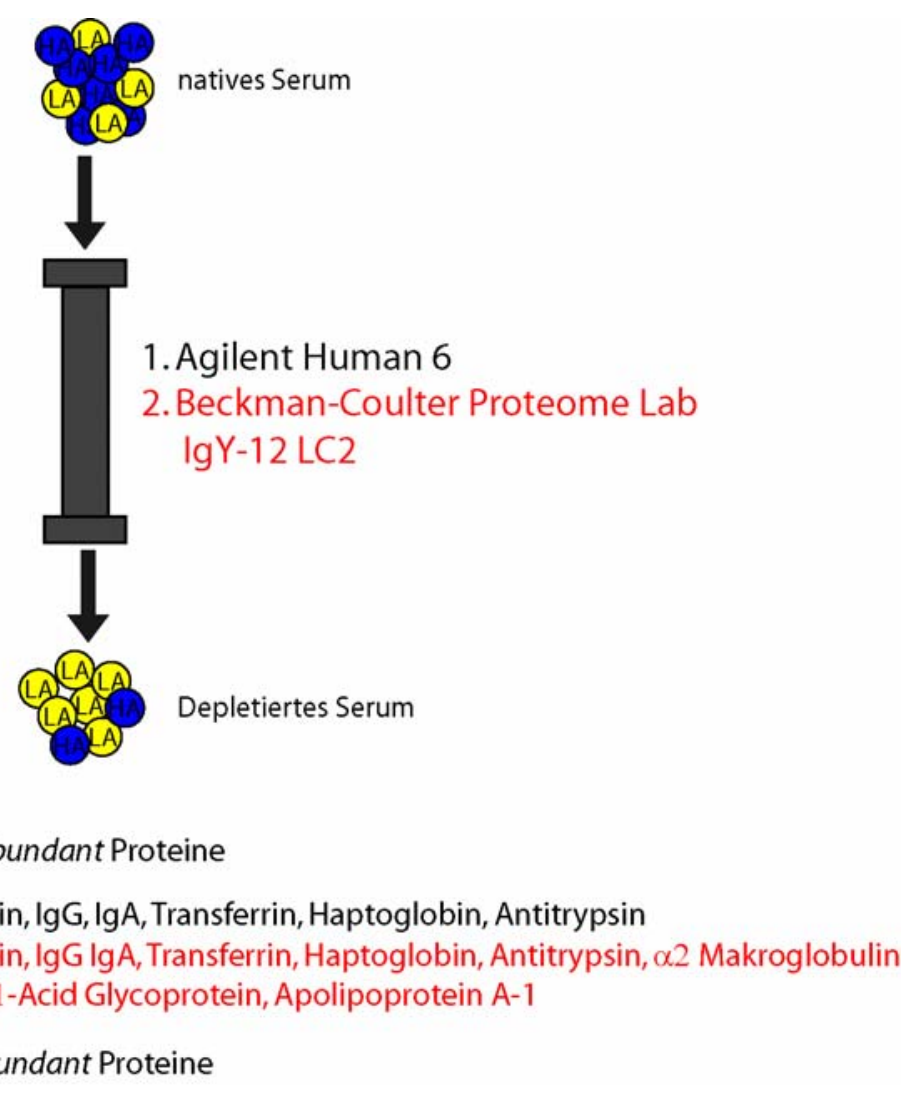

Abbildung 15: Funktionsprinzip einer MARC (multiple affinity removal column) und Auflistung der depletierten Proteine durch die (1) Agilent Human 6 Depletionssäule und die (2) Beckman-Coulter Proteome Lab lgY-12 LC2 Depletionssäule.

\subsubsection{Agilent Human 6 Depletionssäule}

Bei der Agilent Human 6 Depletionssäule handelt es sich um eine Immunaffinitätssäule in den Dimensionen 4,6 × $100 \mathrm{~mm}$. Das Chromatographiematerial ist hochgradig mit polyklonalen Antikörpern gegen die sechs häufigsten Serumproteine funktionalisiert und ermöglicht die Depletion von Albumin, Transferrin, IgG, IgA, Antitrypsin und Haptoglobin in einem einzelnen 
Schritt. Laut Hersteller ist die Depletion von bis zu $60 \mu \mathrm{l}$ Serum für mindestens 200 Durchläufe validiert.

Zur Entfernung möglicher Präzipitate wird das humane Serum zuvor im Verhältnis 1:5 mit dem Equilibrierpuffer verdünnt und durch einen 0,22 $\mu \mathrm{m}$ Filter gefiltert. Das Injektionsvolumen beträgt $200 \mu \mathrm{l}$ des verdünnten und gefilterten Serums.

$\mathrm{Da}$ es sich methodisch um eine Affinitätschromatographie handelt, beschränkt sich die Methode auf ein wässriges Puffersystem: ein Puffer zum Equilibrieren (Puffer A; 10 mM Tris$\mathrm{HCl} \mathrm{pH}$ 7,4), Eluieren (Puffer B; 100 mM Glycin-HCl pH 2,5) und ein Neutralisationspuffer (Puffer C; 100 mM Tris-HCl pH 8,0). Im Fall einer Nichtbenutzung von mindestens drei Tagen wird dem Equilibrierpuffer 0,3\% (w/v) $\mathrm{NaN}_{3}$ zugesetzt, die Säule mit 10 Säulenvolumen gespült und anschließend bei $4{ }^{\circ} \mathrm{C}$ gelagert.

Der Depletionslauf erfolgt mit einer Flussrate von $1 \mathrm{ml} / \mathrm{min}$ bei Raumtemperatur und einer Detektorwellenlänge von $280 \mathrm{~nm}$. Nach dem Auftragen mit Puffer A von Minute 0 bis 15 wird zunächst eine Durchlauffraktion von Minute 2,5 bis 7,5 aufgefangen. Diese Fraktion beinhaltet die so genannten „low abundant" Proteine. Ab Minute 15 erfolgt die Elution über einen Stufengradienten mit $100 \%$ B und es wird von Minute 17,5 bis 21 eine Elutionsfraktion aufgefangen, die aus den sechs depletierten Serumproteinen besteht und als „high abundant" Fraktion bezeichnet wird. Ab Minute 25 erfolgt die Neutralisation und Reequilibrierung der Säule. Ab Minute 30 wird die Säule mit Puffer A reequilibriert.

Die aus den Läufen erhaltenen Fraktionen werden durch die in Punkt 5.2.2 beschriebenen Probenaufarbeitungsmethoden bearbeitet.

\subsubsection{Beckman-Coulter Proteome Lab IgY-12 LC2 Depletionssäule}

Die Beckman-Coulter Depletionssäule entfernt 12 verschiedene Proteine des menschlichen Blutes. Neben Albumin, IgG, Transferrin, $\alpha_{2}$-Makroglobulin, IgM, $\alpha_{1}$-Acid Glykoprotein, Apolipoprotein A-I, und Apolipoprotein A-II entfernt sie auch Fibrinogen und ist somit auch für die Analyse von humanen Plasma einsetzbar. Sie hat die Dimensionen 4,6 x $50 \mathrm{~mm}$ und erlaubt die Depletion von bis zu $50 \mu \mathrm{l}$ humanen Serums oder Plasma.

Das experimentelle Layout orientiert sich an dem Protokoll der Agilent Human 6 Depletionssäule. Es werden dieselben Puffer und Lösungen verwendet. Das Serum wird 1:5 in Puffer A verdünnt und durch einen 0,2 $\mu \mathrm{m}$ Filters gefiltert. Das Injektionsvolumen beträgt $200 \mu \mathrm{l}$ des verdünnten und gefilterten Serums.

Der Depletionslauf erfolgt von Minute 0-25 mit einer Flussrate von 0,25 ml/min mit Puffer A bei Raumtemperatur und einer Detektorwellenlänge von $280 \mathrm{~nm}$. Es wird von Minute 6,8 bis Minute 21 eine Durchlauffraktion aufgefangen (low abundant). Ab Minute 25 wird die Flussrate auf $1 \mathrm{ml} / \mathrm{min}$ erhöht und in einem Stufengradienten auf $100 \%$ Puffer B die high abundant Proteine von der Säule eluiert. Es wird von Minute 28 bis 34 eine Eluatsfraktion aufgefangen. 
Anschließend erfolgt ab Minute 35 eine Neutralisation der Säule mit Puffer C mit fünf Säulenvolumina und eine Reequilibrierung.

\subsubsection{Entsalzungs- und Fraktionierungsmethoden}

Die Methoden dieses Abschnitts basieren auf den Mechanismen der reversed phase (RP) Chromatographie. Dabei erfolgt eine Trennung nach der Hydrophobizität einer Substanz. Es wurde ausschließlich die Agilent mRP hi recovery protein column verwendet.

Die makroporöse C-18 Umkehrphasensäule (mRP-C18-Column) ist eine silicabasierende Säule zur Auftrennung und Entsalzung komplexer Proteingemische mit hohen Wiederfindungsraten. Das makroporöse Material hat eine Porengröße von $5 \mu \mathrm{m}$ und kann daher auch für die Auftrennung großer Biomoleküle verwendet werden.

Das Material ist in eine Säule aus PEEK Kunststoff gepackt, was unspezifische Adsorption von Proteinen minimiert Die Beladungskapazität der Säule ist laut Hersteller mit $380 \mu \mathrm{g}$ Protein angegeben.

\subsubsection{Entsalzung}

Die Entsalzung einer proteinhaltigen Probe erfolgte bei einer Flussrate von 0,75 ml/min, einer Temperatur von $80^{\circ} \mathrm{C}$ und einer Detektorwellenlänge von $280 \mathrm{~nm}$. Es wurden ausschließlich depletierte Serumproben entsalzt. Vor Applikation wurde jeweils $1 \mathrm{ml}$ Depletat mit $480 \mathrm{mg}$ Harnstoff versetzt und mit $13 \mu \mathrm{l}$ Eisessig angesäuert. Die Probe wurde anschließend durch eines 0,2 $\mu \mathrm{m}$ Spritzenvorsatzfilters gefiltert und eine Proteinbestimmung durchgeführt. Das Injektionsvolumen richtet sich nach der Konzentration des depletierten Serums und darf einen Grenzwert von $380 \mu \mathrm{g}$ nicht überschreiten.

Nach Applikation der Proteinprobe wird für 10 Säulenvolumina mit Laufmittel A $\left(\mathrm{H}_{2} \mathrm{O}+0,05 \%\right.$ (v/v) TFA) gewaschen. Die Elution der gebundenen Proteine erfolgte durch einen Stufengradienten ab Minute 10 mit Laufmittel B $(A C N+0,05 \%(v / v)$ TFA). Diese Fraktion wird aufgefangen (Sammlung von Minute 11 bis Minute 15; entsprechend einer Fraktion von $3 \mathrm{ml}$ ) und bis zur Trockne eingeengt. Anschließend wird das lyophilisierte Protein in Lysepuffer resuspendiert und bis zur weiteren Verarbeitung bei $-20{ }^{\circ} \mathrm{C}$ eingefroren.

\subsubsection{Fraktionierung durch eine Gradiententrennung}

Die Gradientenauftrennung des depletierten Serums (Agilent Human 6 Depletionssäule) erfolgte an dem Äkta ${ }^{\circledR}$ System (GE Healthcare). Die Temperierung der Säule erfolgte über ein Doppelmantelmetallrohr (Eigenbau), das über ein Wasserbad beheizt wurde. 
Vor Applikation wurde $1 \mathrm{ml}$ depletiertes Serum mit $480 \mathrm{mg}$ Harnstoff versetzt und mit $13 \mu \mathrm{l}$ Eisessig angesäuert. Anschließend wurde die Probe durch eines 0,2 $\mu \mathrm{m}$ Spritzenvorsatzfilters gefiltert und Protein bestimmt. Das Injektionsvolumen richtet sich nach der Konzentration des depletierten Serums und darf eine Proteinmenge von $380 \mu \mathrm{g}$ nicht überschreiten.

Die Auftrennung erfolgte bei konstanten Flussrate von $0,75 \mathrm{ml} / \mathrm{min}$ und einer Detektorwellenlänge von $280 \mathrm{~nm}$. Bis zu 1,8 ml Probe wurden bei einer Konzentration von 3 \% B aufgetragen. Die erste Gradientenstufe erfolgte von Minute 5 bis 10 mit einer linearen Konzentrationserhöhung von $3 \%$ B bis 30 \% B. Ab Minute 10 bis Minute 45 erfolgte die zweite Gradientenstufe mit einer linearen Konzentrationserhöhung von $30 \%$ B bis $50 \%$ B. Ab Minute 45 bis 50 wurde die Konzentration von 50 \% B auf $100 \%$ B erhöht und für 10 Minuten nicht verändert. Ab Minute 60 erfolgte einer Reequilibrierung der Säule mit 3 \% B.

Für die Fraktionierung wurde ab Minute 10 in Abständen von zwei Minuten bis einschließlich Minute 50 insgesamt 20 Fraktionen aufgefangen, die ein Volumen von jeweils 1,5 ml hatten. Um genügend Protein für die Analysen zu erhalten, wurde der Lauf mehrfach durchgeführt und die gesammelten Fraktionen zusammengeführt. Die Fraktionen wurden anschließend in einem Vakuumkonzentrator zur Trockne eingeengt und das resultierende Proteinpellet in 20-50 $\mu$ Lysepuffer resuspendiert.

\subsubsection{Fraktionierung durch einen Stufengradienten}

Die chromatographische Auftrennung der Proteine des Depletierten Serums (Agilent Human 6 Depletionssäule) erfolgte neben einer Gradiententrennung auch als Stufengradient. Die Probenvorbereitung war identisch zu der Entsalzungsmethode und Gradiententrennung. Insgesamt wurden 8 Trennungsstufen mit einem Trennintervall von 10 Minuten gewählt, die unterschiedliche Acetonitrilkonzentrationen aufwiesen: 33, 36, 39, 42, 45, 48, 55, $100 \%$ Acetonitril. Die Auftrennung erfolgte an einem Shimadzu LC10-System bei einer Flussrate von $0,75 \mathrm{ml} / \mathrm{min}$, einer Detektorwellenlänge von $280 \mathrm{~nm}$ und einer Säulentemperatur von $80^{\circ} \mathrm{C}$.

Ab Minute 20 wurde für die Dauer von jedem Trennintervall (10 Minuten) eine Fraktion von $7,5 \mathrm{ml}$ aufgefangen. Um genügend Protein für die Analysen zu erhalten, wurden mehrere Läufe durchgeführt und die Fraktionen zusammengeführt. Die Fraktionen wurden anschließend in einem Vakuumkonzentrator zur Trockne eingeengt und das resultierende Proteinpellet in 20-50 $\mu$ l Lysepuffer resuspendiert. 


\section{Ergebnisse}

\subsection{Patientenproben}

\subsubsection{Synoviale Fibroblasten}

Es wurden in Kooperation mit den Orthopädischen Kliniken Kassel e.G. unter der Mitarbeit von Herrn Dr. Mai insgesamt 15 Gewebeproben durch Synovektomien gesammelt. Aufgrund der Proteinmenge, die für die 2D-Gel-Analytik benötigt wurde, wurden nur Gewebe aus Knie, Hüft- und Schultergelenken verwendet, da nur in diesen Gelenken ausreichende Mengen Synovia anfielen. Die Gewebe wurden zur Gewinnung der Synovialen Fibroblasten mit Kollagenase-Dispase verdaut und die gewonnenen Zellen bis zur vierten Passage kultiviert und anschließend in Lysepuffer aufgeschlossen. In den nachfolgenden Abschnitten werden die synovialen Fibroblasten der Patientengruppe RA als RASF (rheumatoid synovial fibroblast) und für die Gruppe OA als OASF (osteoarthritis synovial fibroblast) bezeichnet.

Für die Patientengruppe RA konnte Gewebe von 10 Patienten akquiriert werden. Es handelte sich um 8 weibliche und 2 männliche Spender im Alter von 34 - 78 Jahren. Das Gewebe stammte aus Synovektomien des Knies $(n=7)$, der Hüfte $(n=2)$ und der Schulter $(n=1)$.

Für die Patientengruppe OA konnte Gewebe von 5 Patienten akquiriert werden: Es wurden 2 männlichen und 3 weiblichen Spendern Gewebe hauptsächlich aus dem Knie $(n=4)$ und der Schulter $(n=1)$ entnommen. Die Patienten waren zwischen 60 und 81 Jahren alt.

\subsubsection{Serum}

Es wurden drei Serumpools erstellt: RA, OA und Gesund. Eine schematische Übersicht der Alters- und Geschlechtsverteilung ist in Abbildung 16 dargestellt.
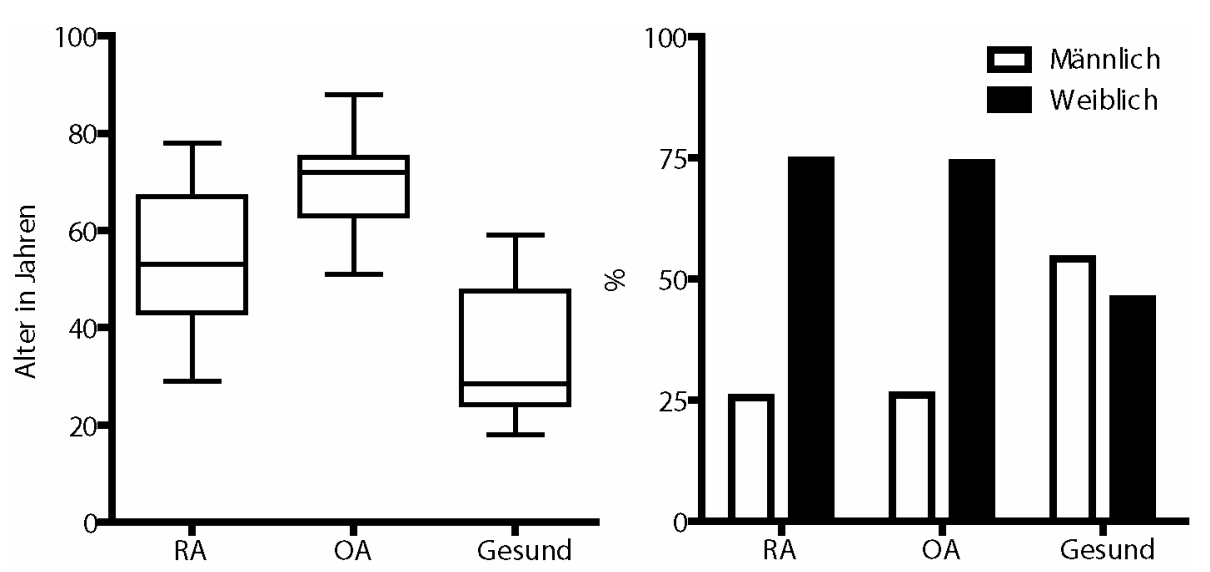

Abbildung 16: Alters- und Geschlechtsverteilung der drei untersuchten Serumpools. (RA) Rheumatiker; (OA) Arthrosepatienten; (Gesund) Kontrollpatienten. 
Für die Patientengruppe RA konnten 43 Seren gesammelt werden, die allesamt einen deutlich erhöhten CCP-Spiegel aufwiesen. Dies war im Rahmen des Projektes das einzige Ausschlusskriterium für das Akquirieren des Serums. Es handelte sich dabei um 32 weibliche und 11 männliche Patienten im Alter von 29 - 78 Jahren (Mittelwert 55,34 Jahre).

Für die Patientengruppe OA konnten 24 Seren gesammelt werden. Es handelte sich hier um 6 männliche und 17 weibliche Spender im Alter von 51 - 88 Jahren (Mittelwert 70,16 Jahre). Als weitere Kontrollgruppe wurden Seren von gesunden Personen gesammelt, die keine rheumatische oder entzündliche Gelenkskrankheit aufwiesen. Es wurden für die gesunde Kontrollgruppe 48 Serumproben gesammelt, wobei es sich um 26 männliche und 22 weibliche Spender im Alter von 18 - 59 Jahren handelte (Mittelwert 34,85 Jahre).

\subsection{Synoviale Fibroblasten}

\subsubsection{Kultivierung synovialer Fibroblasten}

Die Kultivierung der synovialen Fibroblasten erwies sich als problematisch, weil sich die einzelnen Zellchargen in ihrem Wachstumsverhalten stark unterschieden. Zur weiteren Betrachtung wurden daher nur Zellen nach der dritten Passage verwendet, die ein ähnliches Wachstumsverhalten aufwiesen.

Die Wachstumscharakteristika der einzelnen Zellchargen ist in Abbildung 17 dargestellt.

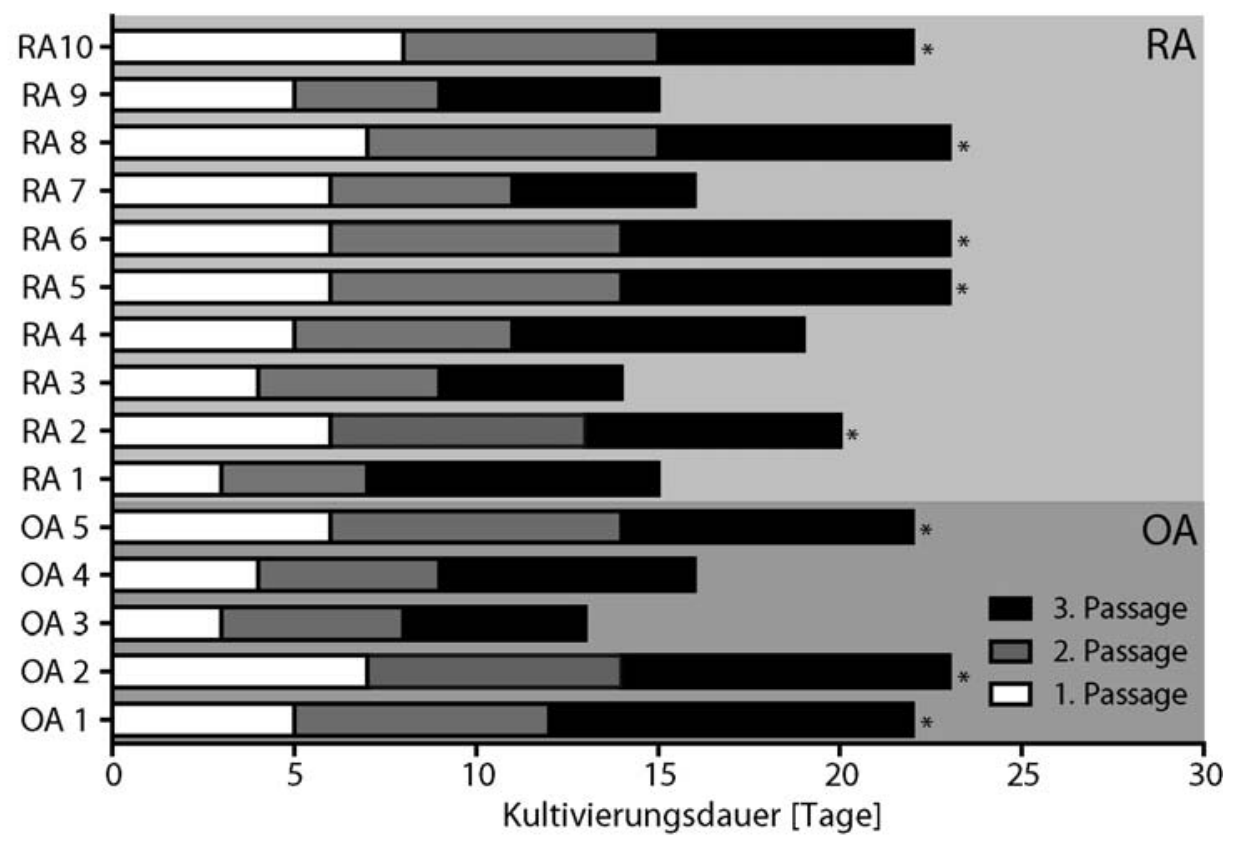

Abbildung 17: Kultivierungsdauer synovialer Fibroblasten, die mittels Kollagenase-Dispase-Verdau aus Synovia gewonnen wurden und bis zur dritten Passage kultiviert wurden. Nur Zellchargen, die sich in ihrer Wachstumscharakteristik ähnelten, wurden für die weiteren Experimente verwendet und sind mit einem $\left(^{*}\right)$ markiert. 
Es ergaben sich für die Patientengruppe RA insgesamt fünf Proben (Wachstumsdauer 20-23 Tage) und in der Patientengruppe OA drei Proben (Wachstumsdauer 22-23 Tage), die in Bezug auf Zellmorphologie, Wachstumsdauer, Probenmenge und Passagenzahl die geforderten Kriterien entsprachen.

\subsubsection{Gelelektrophoretische Analyse der synovialen Fibroblasten}

Nach Erreichen der dritten Passage der Kultivierung der synovialen Fibroblasten wurden die Zellen abtrypsiniert, mehrmals in PBS gewaschen und anschließend in Lysepuffer lysiert. Die verschiedenen Zelllysate wurden mittels 2D-SDS-PAGE analysiert, Proteinspots mittels peptide mass fingerprint (PMF) identifiziert und durch Delta2D (Decodon AG) quantifiziert. Insgesamt konnten 191 Proteine identifiziert werden. Die 2D-Gele wiesen große Gemeinsamkeiten auf, unterschieden sich jedoch in ihrer Gesamtspotanzahl (vgl. Anhang Abschnitt.10.1.1, Seite 106 und Abschnitt 10.1.2, Seite 107). An dieser Stelle soll daher nur ein exemplarisches 2D-Gel dargestellt werden soll. Die restlichen Gele, sowie die identifizierten Proteine sind im Anhang zu finden (siehe Anhang Abschnitt 10.1.3).

Es konnten Expressionsunterschiede für Vimentin, $\beta$-Actin, HSPB1 und Destrin gefunden werden.

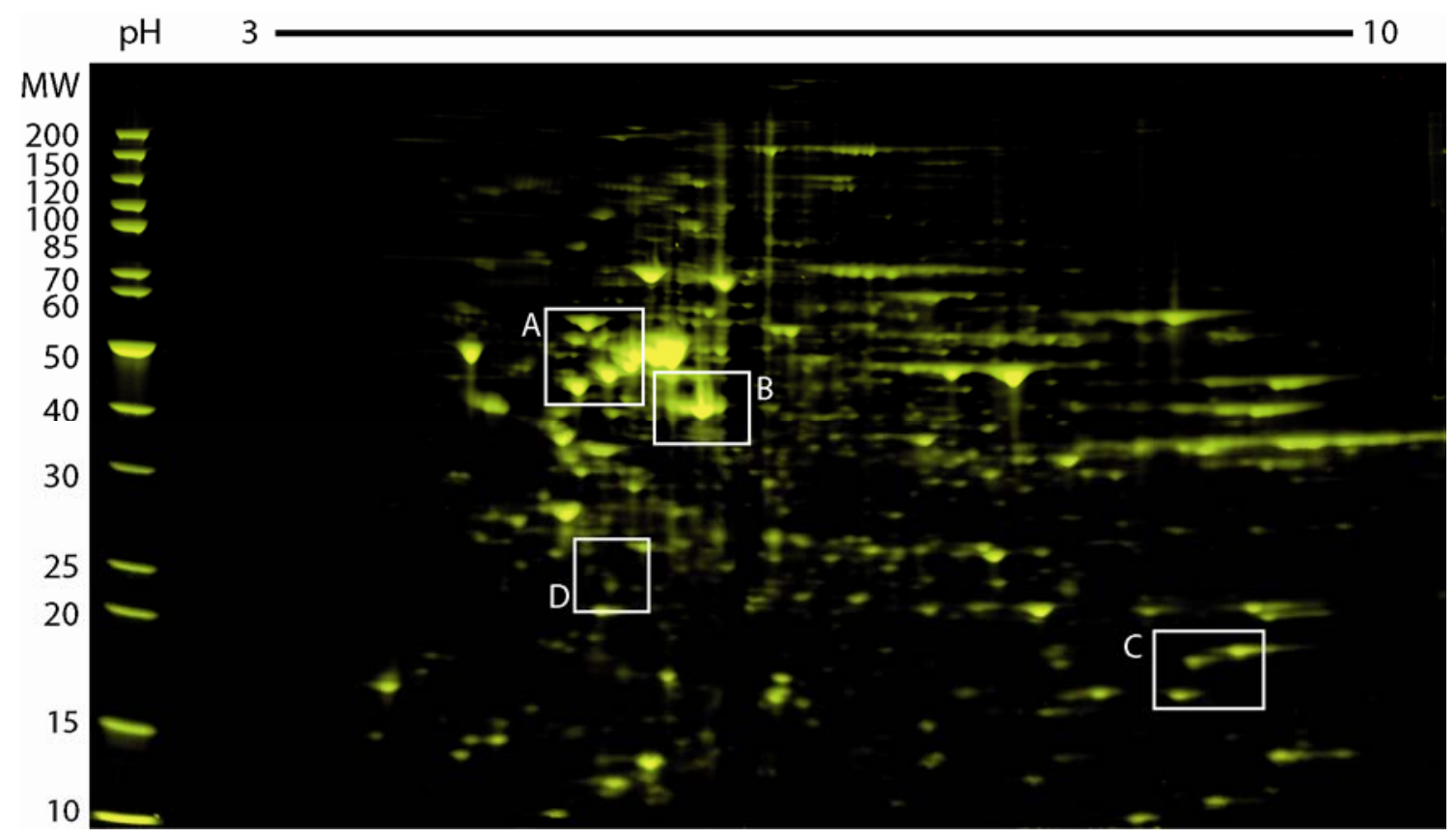

Abbildung 18: 2D-SDS-PAGE eines Zelllysats von synovialen Fibroblasten. Synoviale Fibroblasten wurden mittels Kollagenase-Dispase-Verdau aus Synovia gewonnen, bis zur dritten Passage kultiviert und in Lysepuffer lysiert. $150 \mu \mathrm{g}$ Protein wurden auf einem IPGStreifen $\mathrm{pH}^{3-10}$ (BIORAD) fokussiert und auf einem Criterion ${ }^{\circledR} 12 \%$ Bis-Tris-Gel (BIORAD) aufgetrennt. Zur Visualisierung wurde das Gel fixiert und mit Flamingo ${ }^{\circledR}$ (BIORAD) gefärbt. Unterschiedliche Spotintensitäten und deren vergrößerte Darstellung ist in den folgenden Abbildungen dargestellt: (A) Vimentin, (B) $\beta$-Actin, (C) Destrin, (D) HSPB1 und Vimentin (Fragmente). 
Die Auswertung der Gele erfolgte nach dem in Abschnitt 5.6 beschriebenen Schema zur Auswertung Flamingo ${ }^{\circledR}$-gefärbter Gele. Als Kriterium für eine signifikante Regulierung eines Proteins galt ein Quotient der normierten Spotintensitäten der Proben von 2 für eine Hochregulation und 0,6 für eine Herunterregulation bei einer Irrtumswahrscheinlichkeit von 0,05. Es wurden nur Spots betrachtet, die auf allen Gelen identifiziert werden konnten.

In Abbildung 23 sind die Expressionsunterschiede und deren vergrößerte Lokalisation im Gel aufgetragen.
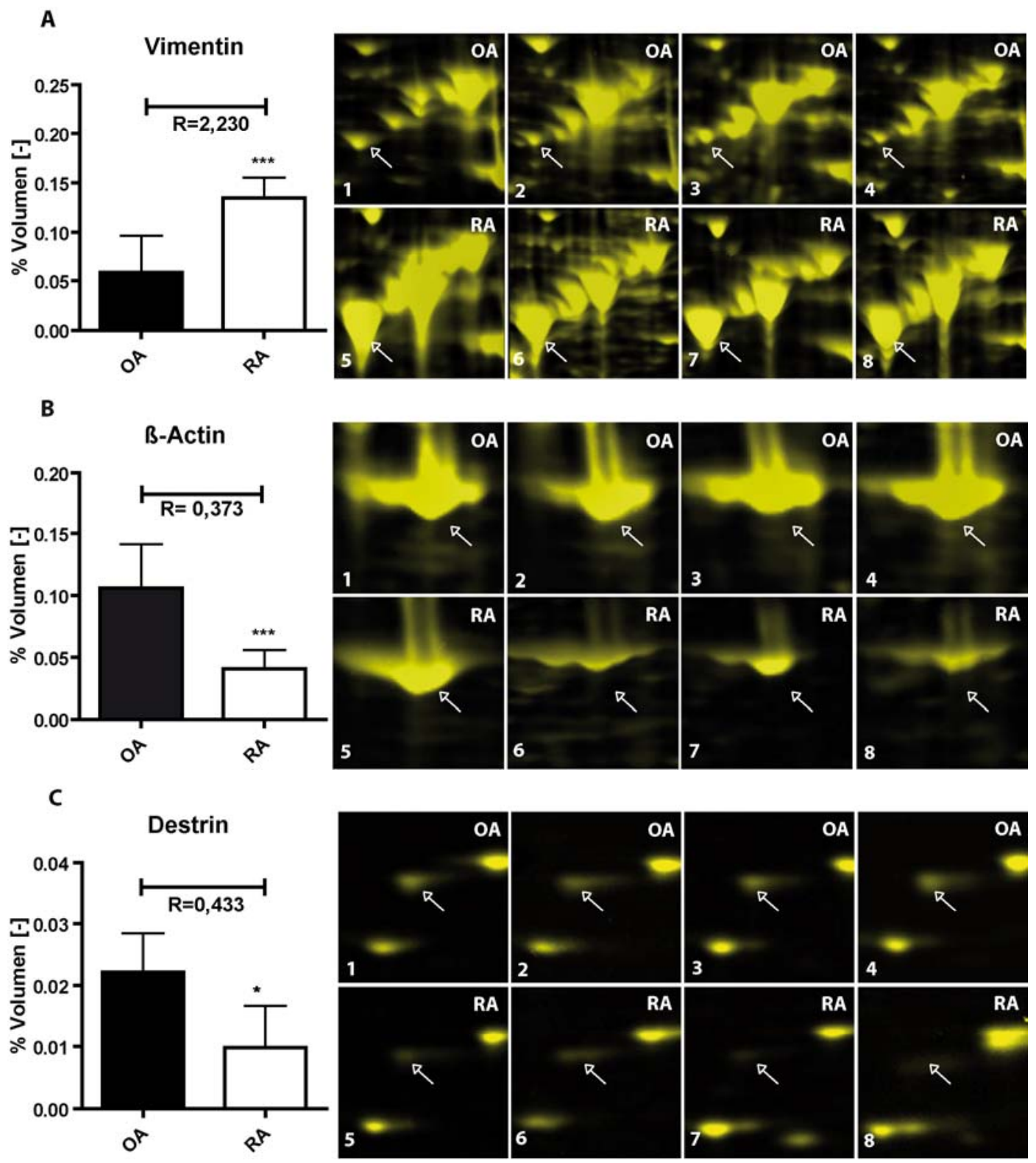

Abbildung 19: Darstellung der Expressionsunterschiede von (A) Vimentin, (B) $\beta$-Actin und (C) Destrin. Auftragung des normierten Spotvolumens der Gruppe RA und OA. R bezieht sich auf den Quotienten der beiden Mittelwerte und gibt die relativen Expressionsunterschiede an. Ungepaarter t-Test mit folgenden Irrtumswahrscheinlichkeiten: $\left.{ }^{*}\right) p=0,05,\left({ }^{* * *}\right) p=0,001$. Die Gelregionen mit den jeweils zugrunde liegenden Spotintensitäten sind in den Bilden 1-8 abgebildet. Bild 1-4 Gele OA, Bild 5-8 Gele RA. 

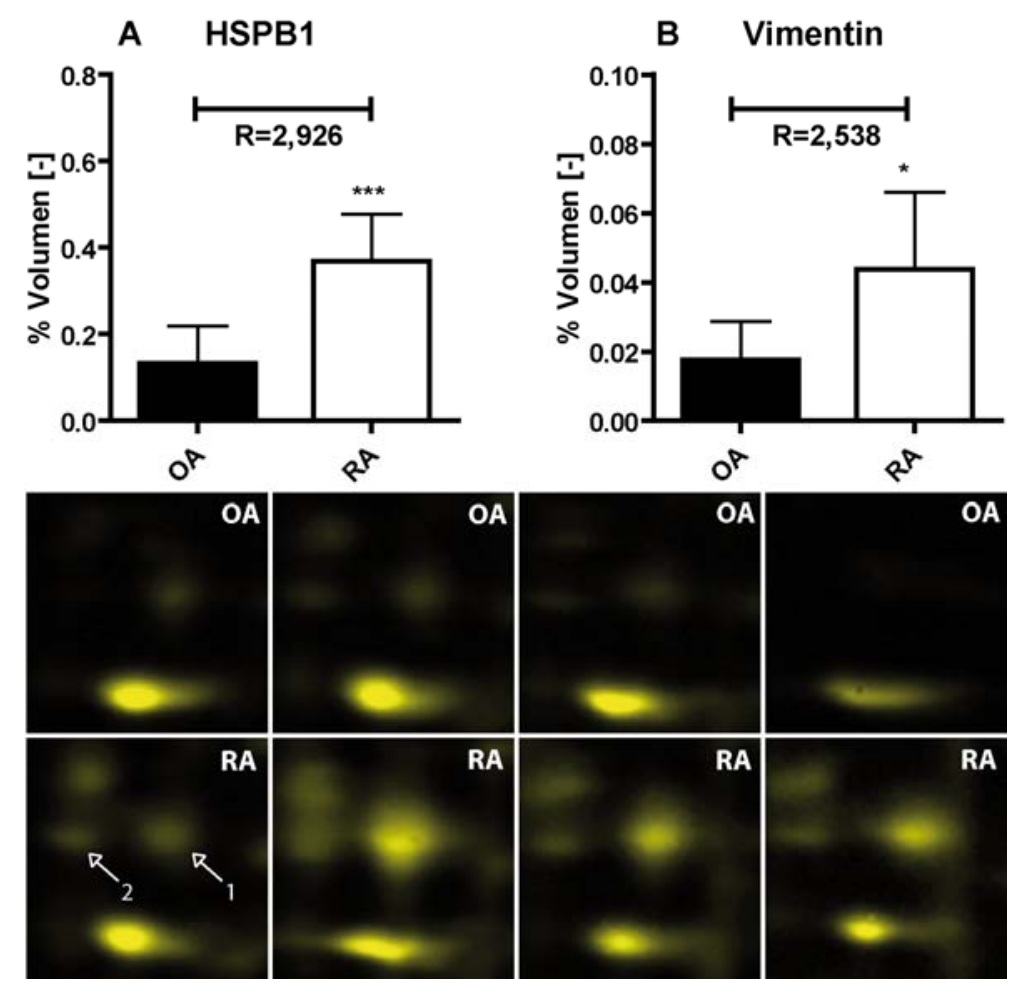

Abbildung 20: Darstellung der Expressionsunterschiede von (A) Hitzeschockprotein Beta 1 (Spot 1) und (B) Vimentin (Fragmente, Spot 2). R bezieht sich auf den Quotienten der beiden Mittelwerte und gibt die relativen Expressionsunterschiede an. Ungepaarter t-Test mit folgenden Irrtumswahrscheinlichkeiten: $\left(^{*}\right) p=0,01,\left({ }^{* *}\right) p=0,001$. Die Gelregionen mit den jeweils zugrunde liegenden Spotintensitäten sind in den Bilden 1-8 abgebildet. Bild 1-4 Gele OA, Bild 5-8 Gele RA.

Es wurde mittels 2D-SDS-PAGE Expressionsunterschiede von Vimentin identifiziert. Diese Unterschiede sind in Abbildung 19 und 20 dargestellt. Die Patientengruppe RA zeigte im bei Vimentin einen Regelungsunterschied von 2,23 $(p=0,001)$ bezüglich eines Degradationsprodukts mit einem Molekulargewicht von ca. $44 \mathrm{kDa}$ (siehe Abschnitt 10.1.3, Spot 20). In Abbildung 20 sind Fragmente von Vimentin (Spot 10) mit einem Molekulargewicht von 25 kDa identifiziert worden, die einen Regulationsunterschied in der Patientengruppe RA von $2,54(p=0,05)$ aufweisen. Die restlichen identifizierten Formen des Vimentins (siehe Abschnitt 10.1.3; Spot 21, 22, 23) zeigen keine signifikanten Regulationsunterschiede.

Abbildung 20 zeigt darüber hinaus, dass die RASF mit einer 3-fachen Regulation $(p=0,001)$ im Vergleich zu den OASF eine deutliche verstärkte Expression des Hitzeschockprotein Beta 1 (HSPB1, Spot 9) aufweisen.

Des Weiteren konnte bei die RASF eine Herunterregulation von $R=0,37(p=0,001)$ von $\beta$-Actin (Spot 24) im Vergleich zu den OASF festgestellt werden. Dieses Ergebnis ist in Abbildung 19 zu erkennen.

Die Herunterregulation des Actin-bindenden Proteins Destrin (Spot 41) bei RASF mit einer Regulationsrate von $\mathrm{R}=0,43(\mathrm{p}=0,05)$ im Vergleich zu den OASF ist im unteren Drittel der Abbildung 19 beschrieben. 


\subsubsection{Validierung der Expressionsunterschiede durch Western Blot}

Die Expressionsunterschiede der Proteine Vimentin, Hitzeschockprotein Beta 1 und Destrin wurden mittels Western Blot untersucht. Dazu wurden $40 \mu \mathrm{g}$ Protein elektrophoretisch in einem 12,5 \% Tris-HCl Gel (Biorad, Mini-Protean ${ }^{\circledR}$-Kammer) aufgetrennt und auf eine PVDFMembran geblottet. Die Proteine und deren Fragmente wurden anschließend durch spezifischer Antikörper nachgewiesen.

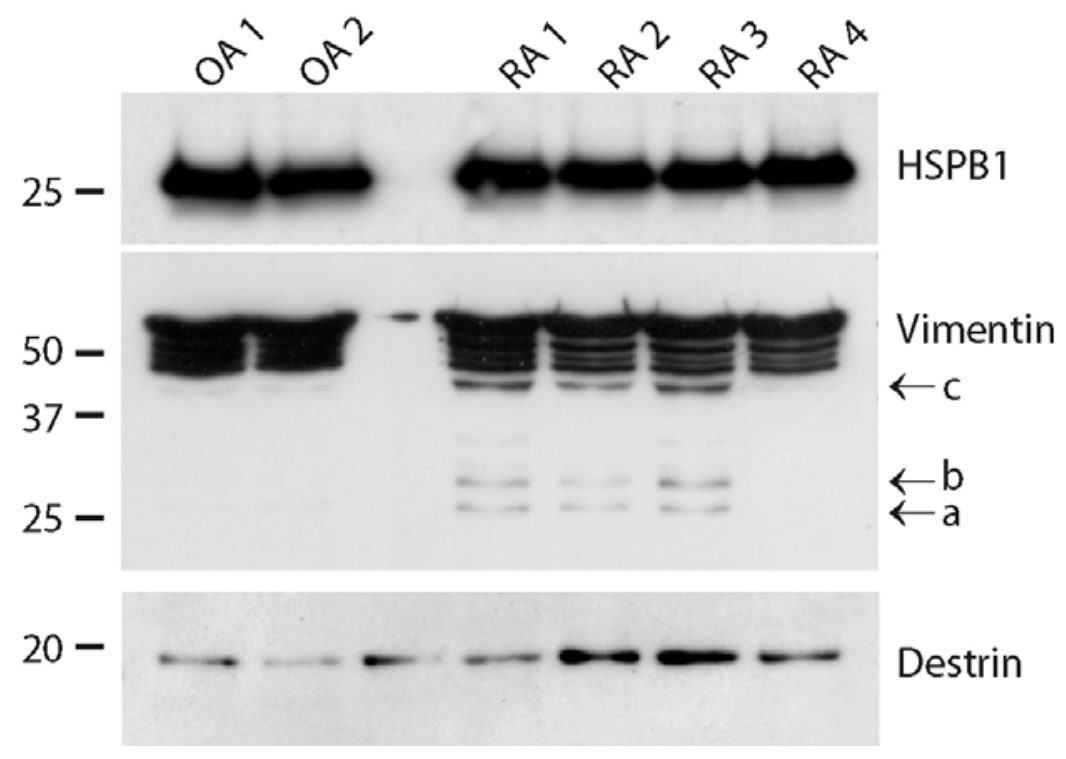

Abbildung 21: Western Blots der Zelllysate der RASF und OASF. Dazu wurden jeweils $40 \mu \mathrm{g}$ von zwei unterschiedlichen Patienten der Gruppe OA und drei verschiedene Patientenproben der Gruppe RA mittels SDS-PAGE $\left(12,5 \%\right.$ Tris- $\mathrm{HCl}$, Mini-Protean ${ }^{\circledR}$, BIORAD) aufgetrennt und auf eine PVDF-Membran geblottet. Die Detektion erfolgte mittels spezifischer Antikörper gegen HSPB1 (Anti-HSPB1, R\&D; 1:500), Vimentin (Anti Vimentin, Sigma AldRICH; 1:2000) und Destrin (Anti-Destrin, SIGMA AldRICH; 1:1000). (a), (b) und (c) sind Vimentinfragmente, die in drei von vier RA - Patienten nachgewiesen werden konnten.

Die durch 2D-SDS-PAGE gezeigten Ergebnisse konnten nur zum Teil durch Western Blot bestätigt werden. Wie aus Abbildung 21 ersichtlich wird, konnte kein signifikanter Regulationsunterschied beim HSPB1 gefunden werden. Die Bandenintensitäten sind bei RA und OA nahezu identisch.

Bei der Expression des Intermediärfilaments Vimentin hingegen zeigte sich bei drei von vier RA-Patienten ein spezifisches Bandenmuster an Vimentinfragmenten zwischen 25, $37 \mathrm{kDa}$ (a \& b), sowie bei $40 \mathrm{kDa}(\mathrm{c})$.

Bei Destrin konnte eine erhöhte Expression bei der Gruppe RA im Vergleich zur Gruppe OA detektiert werden. 


\subsubsection{Nachweis citrullierter Proteine in Zelllysaten synovialer Fibroblasten}

Der Nachweis von citrullierten Proteinen erfolgte in zwei unterschiedlichen Ansätzen: die immunologische Detektion von Citrullinresten in unmodifizierter und modifizierter Form.

Beim Nachweis von Citrullin ohne vorhergehende Modifizierung wurde der Anti-Citrullin Antikörper (Anti-Citrullin, BIOMOL) verwendet. Im zweiten Ansatz, d.h. nach Modifizierung (vgl. Abschnitt 5.4.2), wurde der monoklonale Antikörper des Anti-Citrullin Detection Kits (BIOMOL) verwendet, der Citrullin in seiner modifizierten Form erkennt.

Die korrekte Funktionsweise des Kits und die spezifität des Anti-Citrullin-Antikörpers konnte durch ein Lysat der Zellen der Hornhaut bestätigt werden. Die Präsenz von citrullierten Proteinen in der humanen Epidermis ist von Senshu et al. mittels des Anti-Citrullin-Detection Kit nachgewiesen worden und dient als Kontrolle (Senshu et al. 1992). Zur Gewinnung citrullierter Proteine wurde mittels eines Skalpells die Zellen der Hornhaut abgekratzt und lysiert (2\% SDS (w/v) $20 \mathrm{mM}$ TCEP 10 Minuten $98{ }^{\circ} \mathrm{C}$ ), ungelöste Bestandteile bei $16.000 \mathrm{~g}$ für eine Minute abzentrifugiert und anschließend 2-10 $\mu$ lals Kontrolle aufgetragen.

Abbildung 22 zeigt die Ergebnisse der zwei unterschiedlichen Detektionsstrategien.

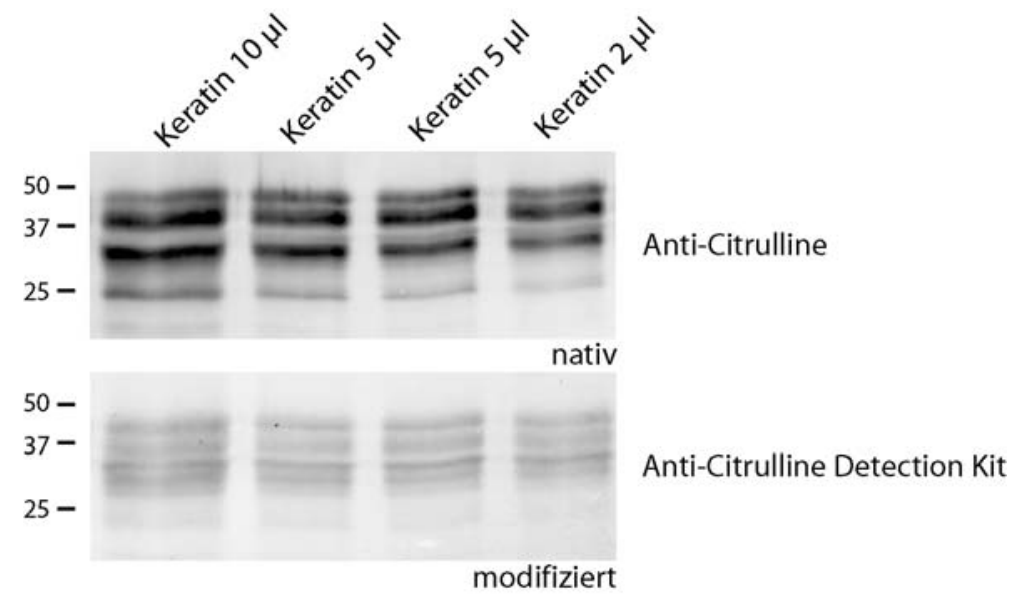

Abbildung 22: Western Blots von Zelllysaten der humanen Epidermis. Nach dem Aufschluss der Zellen in $20 \mathrm{mM}$ TCEP $2 \%$ SDS bei $98{ }^{\circ} \mathrm{C}$ für 10 Minuten wurden 2, 5 und $10 \mu \mathrm{l}$ des Lysats mittels SDS-PAGE (12\% Gel) aufgetrennt und anschließend auf eine PVDFMembran geblottet. Der Nachweis unmodifizierter citrullierter Proteine erfolgte durch den Anti-Citrullin Antikörper (BIOMOL; 1:1000). Beim Nachweis mit vorhergehender Modifizierung der Citrullinresiduen wurden die Proteine mittels 4 \% PFA auf der Membran fixiert, anschließend erfolgte eine Modifizierung der Citrullinreste durch Inkubation mit 2,3-butadione monoxim und Antipyrin in stark saurem Milieu und eine Detektion mittels Anti-Citrullin (modifiziert) Antikörper (BıOMOL; 1:500).

Anhand der Kontrolle wurden die Reaktionsbedingungen der Modifizierungsreaktion für die Auftragung der RASF und OASF optimiert. Zur besseren Retention wurden die Proteine 
zunächst durch eine 30-minütige Inkubation mit $4 \%$ (w/v) PFA in PBS auf der PVDFMembran fixiert. Anschließend erfolgte die Modifikation bei $37^{\circ} \mathrm{C}$ für $3 \mathrm{~h}$. Längere Inkubationszeiten resultierten in einem massiven Proteinverlust und sind daher nicht zu empfehlen.

Nitrozellulosemembranen sind aufgrund der geringen chemischen Beständigkeit gegenüber den extremen Modifizierungsbedingungen nicht zu verwenden. Die Retention der Proteine war deutlich schlechter als bei PVDF-Membranen.

Wie aus Abbildung 22 zu erkennen ist, unterscheiden sich die Signalintensitäten der Detektionsstrategien stark. Während sich die Banden bei der Detektion in unmodifizierter Form stark abzeichnen, sind die Intensitäten der Detektion durch Modifizierung deutlich abgeschwächt. Die Signalschwäche bei der Detektion nach Modifizierung konnte durch die Erhöhung der Proteinmenge, noch durch die Verlängerung der Modifikationsreaktion signifikant beeinflusst werden.

Nach der Optimierung wurden die Lysate der RASF und OASF untersucht. Trotz mehrerer Replikate und Variationen in Proteinmenge konnte kein signifikanter Nachweis für citrullierte Proteine in den Zelllysaten der RASF oder OASF erbracht werden.

\subsection{Serumanalytik}

\subsubsection{Elektrophoretische Auftrennung von Serumproteinen}

Abbildung 23 zeigt die elektrophoretische Auftrennung von Serum nach Fällung der Proteine durch die der in Abschnitt 5.2.2.2 beschriebene Chloroform-Methanol-Fällung. $20 \mu$ humanes Serum der gesunden Kontrollgruppe wurden 1:5 mit PBS verdünnt, gefält und durch 2DSDS-PAGE analysiert. Es wurden 26 Spots ausgeschnitten und durch PMF identifiziert (siehe Anhang Abschnitt 10.2.1 Seite 111 ). Insgesamt konnten nur acht verschiedene Proteine identifiziert werden: Albumin, Serotransferrin, $\alpha_{1}$-Antitrypsin, Clusterin, Haptoglobin, $\beta_{2^{-}}$Glykoprotein, Apolipoprotein A-I und IgG, aufgetrennt in ihre schwere $\gamma$ - und leichte $\kappa$-Domäne. Bei diesen Proteine handelt es sind vorrangig um funktionelle, high abundant Proteine, die wegen der natürlichen Varianzen in ihren Anteilen keinen Aufschluss über den pathologischen Zustand des Patienten geben.

Aufgrund der hohen Dynamik der Proteinverteilung des Serumproteoms ist hier die Grenze der Proteine festzusetzen, die durch 2D-SDS-PAGE zu visualisieren sind.

Insbesondere Albumin (Spots 1-3, 6-12, 16) ist in großen Bereichen des Gels vorhanden und erstreckt sich über den gesamten pl-Bereich. Aufgrund der hohen Konzentration ist eine korrekte Fokussierung nicht möglich. Die schwere $\gamma$ - (Spots 19, 20) und leichte $\kappa$-Domäne (Spots 22, 23) der IgG resultieren aufgrund des hohen Anteils an stark geladener Glykosilie- 
rungen in einem unaufgelösten Proteinpattern bei $25 \mathrm{kDa}$ und $50 \mathrm{kDa}$. Albumin und IgG mit einem Gesamtproteinanteil von über $50 \%$ beeinflussen die Beladungskapazität und die Gelqualität somit am nachhaltigsten.

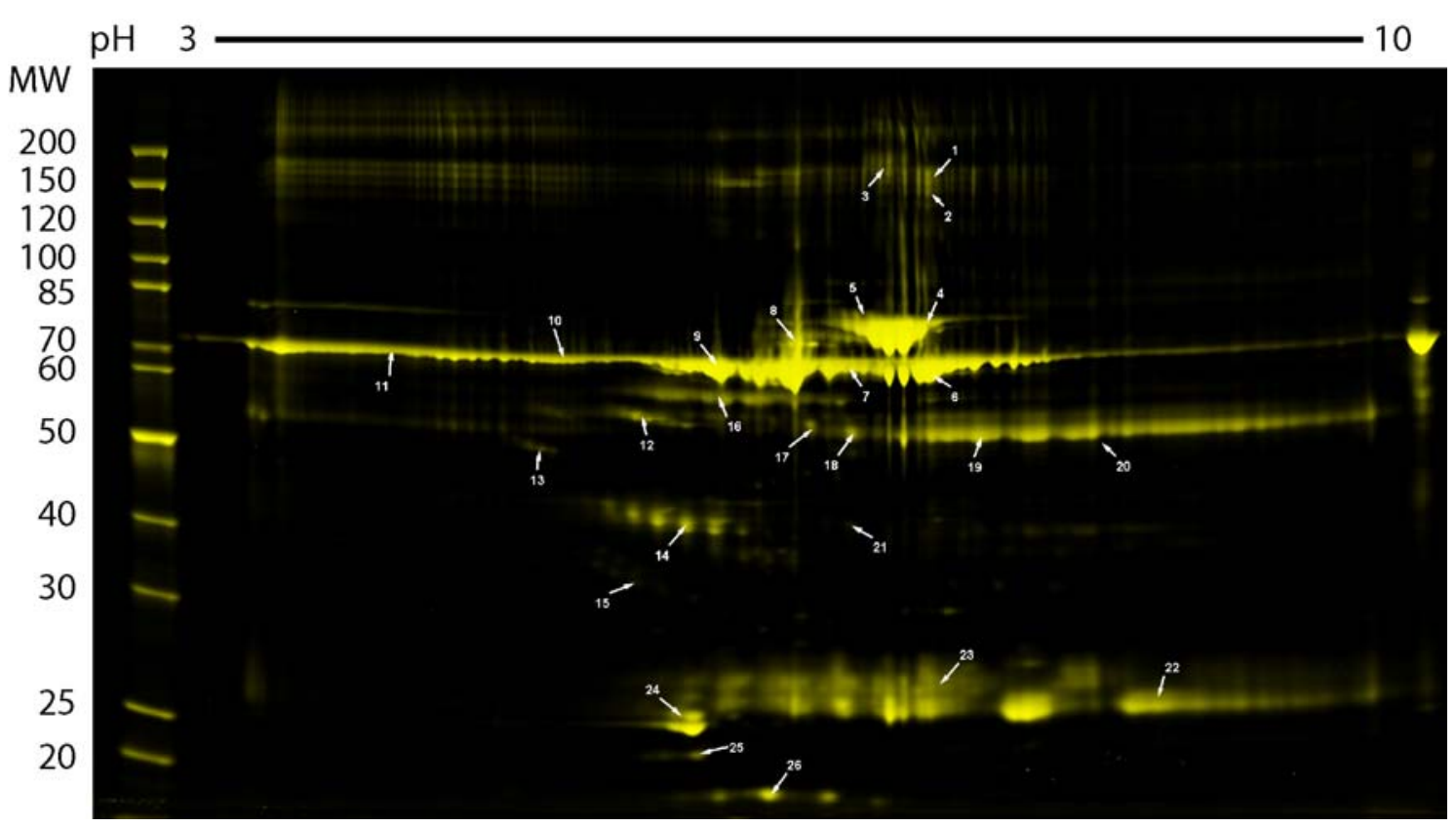

Abbildung 23: 2D-Gel von undepletiertem Serum der gesunden Kontrollgruppe. $20 \mu \mathrm{l}$ Serum wurden 1:5 mit PBS verdünnt und durch Chloroform-Methanol-Fällung (Abschnitt 5.2.2.2) entsalzt. $150 \mu \mathrm{g}$ Protein wurden auf einem IPG-Streifen pH 3-10 (BIORAD) fokussiert. Es wurden 26 Spots ausgeschnitten, tryptisch verdaut und durch PMF identifiziert. Die SDS-Page erfolgte über ein $10 \%$ Bis-Tris Criterion (BIORAD) Neutralgel. Marker Page Ruler $^{\text {TM }}$ (FERMENTAS). Die Färbung der Proteine erfolgte mittels Flamingo ${ }^{\circledR}$ (BIORAD).

Zur Abreicherung der high abundant Proteine kamen in dieser Arbeit zwei verschiedene Depletionssäulen zum Einsatz; die Agilent Human 6 Depletionssäule (vgl. Abschnitt 5.9.2) und die Beckman Coulter Proteome Lab IgY12 LC2 Depletionssäule (vgl. Abschnitt 5.9.3). Die Säulen unterscheiden sich nicht nur in ihren Dimensionen und Beladungskapazitäten, sondern auch in der Spezifität der polyklonalen Antikörper, die kovalent an das Chromatographiematerial gebunden sind. Während Agilent keine Angaben über die Beschaffenheit und die Spezies macht, verweist Beckman Coulter explizit auf die Tatsache, dass ausschließlich polyklonale Antikörper verwendet wurden, die im Huhn produziert wurden. Durch den größeren phylogenetischen Unterschied zwischen humanen Proteinen und denen des Huhns kommt es zu weniger Kreuzreaktionen zwischen den applizierten humanen Proteinen und den Antikörpern. Die Bindung der high abundant Proteine soll deutlich spezifischer erfolgen, als bei der Verwendung von polyklonalen Antikörpern, die in Säugetieren produziert wurden (Huang et al. 2008).

Die Chromatogramme der Depletionsläufe sind exemplarisch für jede Säule in der Abbildung 24 dargestellt. 

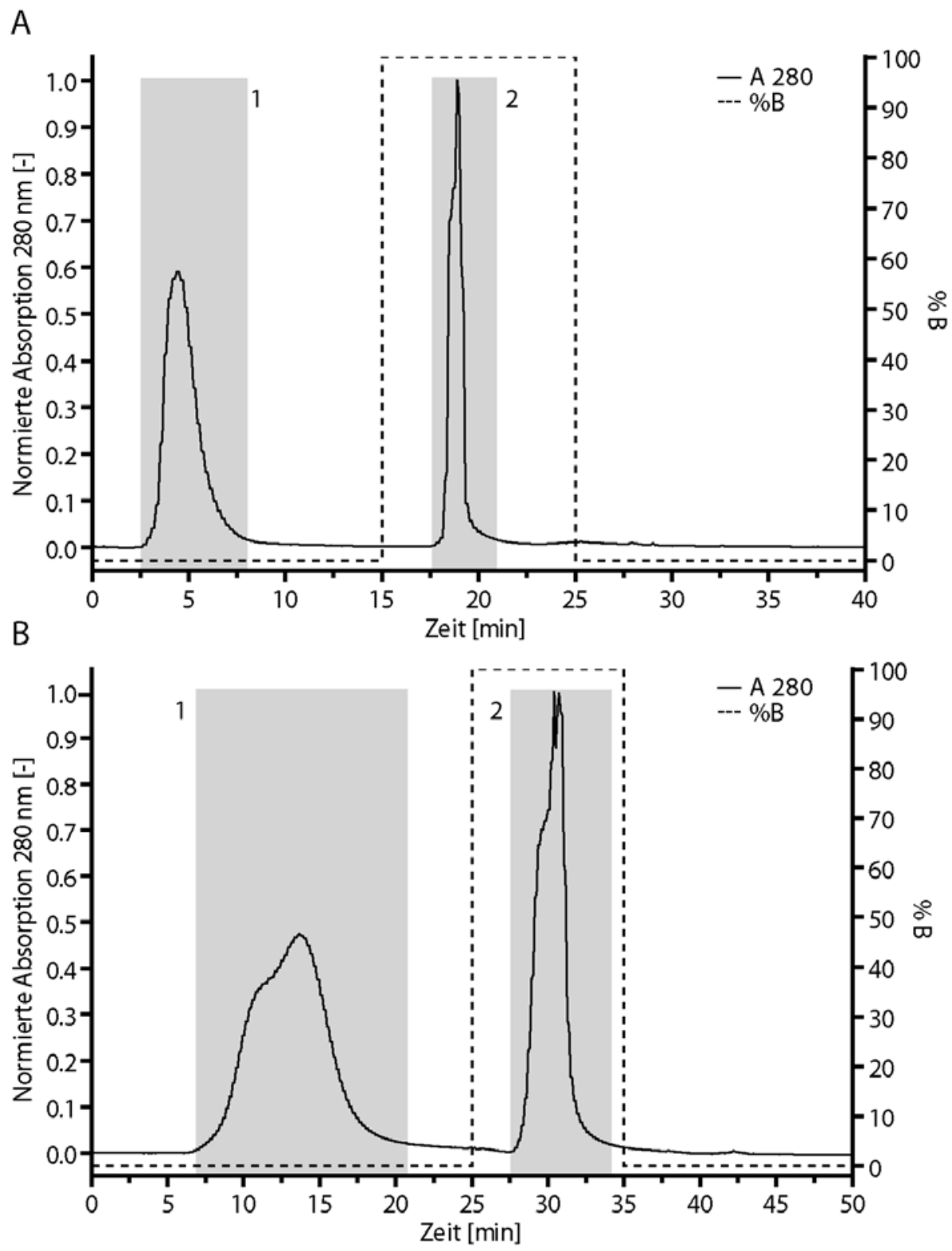

Abbildung 24: Chromatogramme der unterschiedlichen Depletionssäulen. Es wurden $40 \mu$ l humanes Serum der gesunden Kontrollgruppe 1:5 mit dem Equilibrierpuffer $A$ verdünnt und auf die Säulen appliziert. (A) Chromatogramm der Agilent Human 6 (AH6) Depletionssäule (B) Chromatogramm der Beckman Coulter Proteome Lab IgY12 LC“ (BCY12) Depletionssäule. Es wurden zwei Fraktionen für jeden Lauf gesammelt: (1) low abundant Fraktion (Durchlauf) und nach dem Wechsel auf das Elutionslaufmittel B die (2) high abundant Fraktion mit den 6 (AH6) bzw. 12 (BCY12) gebundenen Proteinen.

Das chromatographische Verhalten der Säulen ist wegen der unterschiedlichen Dimensionen $(4,6 \times 10 \mathrm{~mm}$ vs. $6,4 \times 63 \mathrm{~mm})$ anders. Die Agilent Human 6 Depletionssäule produzierte deutlich schärfere Peaks ohne so genanntes fronting (vgl. Peak 1). Diese Peaks ähnelten mehr einer Gaußverteilung und wiesen keine Inhomogenitäten wie der Durchlaufspeak der Beckman-Coulter Depletionssäule auf. Des Weiteren wurde deutlich schneller nach dem Durchlaufen der Probe das Signal wieder auf Niveau der Basislinie gebracht. Dies lässt auf 
eine verminderte Proteinretention durch unspezifische Bindung am Chromatographiematerial oder Säulenmaterial (Agilent PEEK, Beckman Coulter PS) schließen. Nicht nur wegen der kürzeren Laufzeit, sondern auch wegen der besseren chromatographischen Eigenschaften und Säulenmaterials ist die Agilent Human 6 gegenüber der Beckman Coulter vorzuziehen. Des Weiteren biete die Agilent eine höhere Kapazität.

\subsubsection{Optimierung der depletierten Serumproben für die 2D-SDS- PAGE}

Bei der isoelektrischen Fokussierung wurden die Proben durch passiven Rehydratation appliziert. Es konnte ein maximales Probenvolumen von $200 \mu \mathrm{l}$ pro $11 \mathrm{~cm}$ IPG-Streifen aufgetragen werden. Außerdem wurden bei DIGE aufgrund der Volumenvorgaben sehr hohe Proteinkonzentrationen in den Proben (> $5 \mu \mathrm{g} / \mu \mathrm{l}$ ) benötigt. Durch die chromatographischen Methoden kam es jedoch zu einer starken Verdünnung der Proben mit den Equilibrier- und Elutionspuffer.

Nicht nur der Verdünnungsfaktor, sondern auch der Salzeintrag machte eine Aufarbeitung der Proteine der Fraktionen unabdingbar. Dabei kamen bei der Ankonzentrierung der Proben die Acetonfällung, die Chloroform-Methanol-Fällung und die Entsalzung der depletierten Serumproben durch die Agilent high recovery protein column zum Einsatz.

Die genannten Ankonzentrierungsmethoden waren universell zur Ankonzentrierung von Proteinen geeignet. Sie unterschieden sich jedoch in ihren Ausbeuten und Spezifitäten. Je nach Methode wurden daher einzelne Proteine besser ankonzentriert als andere.

Aus diesem Grund besaß jede Methode ihr charakteristisches Proteinpattern. Beim Vergleich von 2D-Gelen, deren Proteine auf unterschiedliche Weise ankonzentriert wurden, konnten deutliche Unterschiede in der Spotanzahl zu detektieren werden. Diese Unterschiede waren jedoch methodisch begründet.. Daher waren Proben, die auf unterschiedliche Weise aufgearbeitet wurden, nicht vergleichbar. Es sollte sich zu Beginn einer Studie auf eine Methode festgelegt werden. Dabei war die Methode am besten zu bewerten, die in der größten Spotanzahl und der besten Proteinabdeckung resultierte.

Zur Optimierung der Ankonzentrierungs- und Entsalzungsstrategie kam ausschließlich Serum zum Einsatz, das mit der Agilent Human 6 Depletionssäule depletiert wurde.

Die Ergebnisse der unterschiedlichen Strategien sind in der folgenden Abbildung 25 aufgeführt. Unterschiede der Proteinspatterns sind durch die Buchstaben A-F gekennzeichnet und geben nicht einzelne, distinktive Spots wieder, sondern Bereiche, wo Unterschiede erkennbar sind. 
$\mathrm{pH} \mathrm{NL} 3$ 10
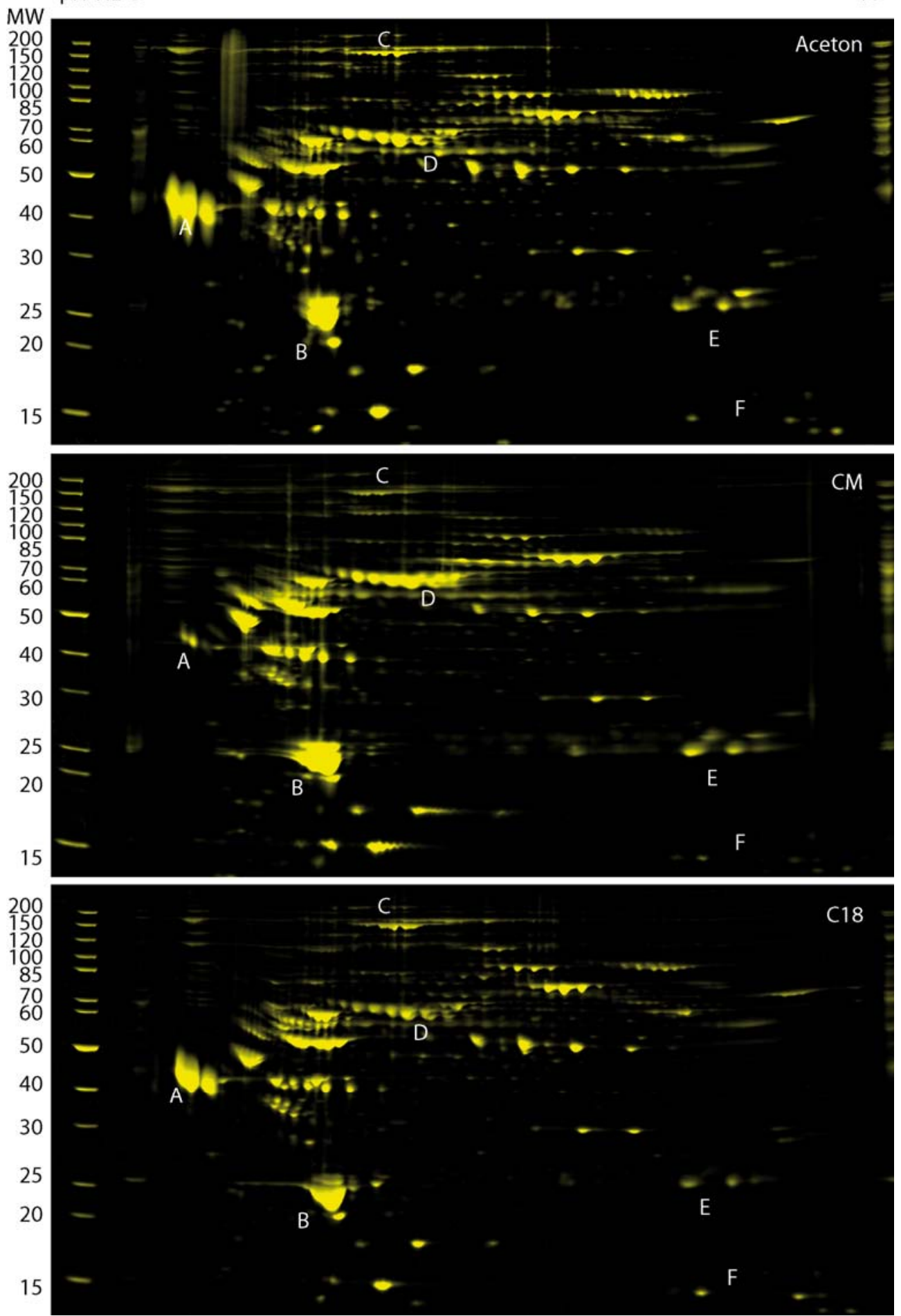

Abbildung 25: 2D-SDS-PAGE (pH 3-10 NL, $12 \%$ Bis-Tris Criterion ${ }^{\circledR}$ Gel) von unterschiedlich ankonzentrierten und entsalzten depletierten Seren der gesunden Kontrollgruppe. (Aceton) Depletiertes Serum wurde durch Aceton gefällt. (CM) Depletiertes Serum wurde zunächst durch eine Vivaspin ${ }^{\circledR} 5000$ Da MWCO-Membran auf $100 \mu$ l eingeengt und anschließend durch Chloroform-Methanol-Fällung entsalzt. (C18) Chromatographische Entsalzung mit der Agilent mpCP high recovery protein column. Die Visualisierung erfolgte über Flamingo ${ }^{\circledR}$-Färbung. Unterschiede sind durch A-F gekennzeichnet und werden im Text behandelt. 
Bei der Fällung der Proteine mit Aceton wurde direkt nach der Depletion der Durchlauf mit den low abundant Proteinen mit dem Dreifachen an Aceton vermischt und der Ansatz bei -20 C über Nacht inkubiert. Es erfolgte im Anschluss eine Zentrifugation bei $6.000 \mathrm{~g}$ für 30 Minuten. Das resultierende Proteinpellet wurde in $40 \mu \mathrm{l}$ Lysepuffer resuspendiert. Bei der

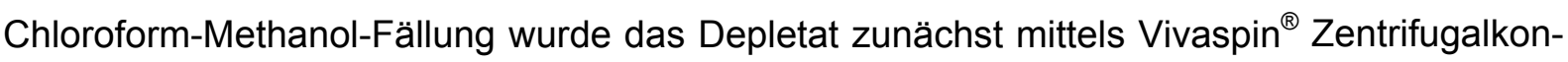
zentratoren mit einem Cut-Off von 5000 Da auf ein Volumen von $100 \mu$ l eingeengt. Diese $100 \mu \mathrm{l}$ wurden nach dem in Abschnitt 5.2.2.2 beschriebenen Protokoll gefällt und das Proteinpellet in $40 \mu \mathrm{l}$ Lysepuffer aufgenommen.

Als drittes wurde das depletierte Serum chromatographisch entsalzt und ankonzentriert. Dabei wurde das Depletat mit Harnstoff versetzt und mit Eisessig angesäuert. $350 \mu \mathrm{g}$ Protein wurden auf die Säule (Agilent mpCP hi-recovery protein column) appliziert. Das Eluat wurde aufgefangen, zur Trockne eingeengt und das resultierende, lyophilisierte Proteinpellet in 40 $\mu$ Lysepuffer aufgenommen. Diese Methode wird in der Abbildung 25 als C18 abgekürzt. Alle Aufarbeitungsmethoden zeigten ein gutes Ergebnis und könnten zur Entsalzung und Ankonzentrierung depletierter Serumproben verwendet werden. Bei der Spotanzahl und -verteilung waren jedoch Unterschiede der drei Methoden auszumachen.

Die Chloroform-Methanol-Fällung weist im Bereich der sauren Proteine, d.h. in einem pH von 3-6 eine deutlich verringerte Spotintensität des $\alpha_{1}$-Acid-Glykoproteins auf (Bereich A), während die Intensität des Apolipoproteins A-1 im Vergleich zu den anderen Aufarbeitungsmethoden erhöht ist (Bereich B). Des Weiteren sind die Konzentrationen an $\alpha_{2}$-Makroglobulin und Complement Faktor $\mathrm{H}$ im Vergleich zu den anderen Aufarbeitungsmethoden deutlich verringert (Bereich C) . Insgesamt ist eine Abnahme der Spotschärfe auszumachen. Das Hemopexin (Bereich D) ist im Vergleich zu Aceton und C18 deutlich schlechter fokussiert.

Die Aufarbeitungsmethoden Aceton und C18 weisen sehr vergleichbare Spotpatterns auf, unterscheiden sich jedoch in Bereich $E$ bei der Fokussierung der leichten $\kappa$-Domäne des IgG. Des Weiteren sind Intensitätsunterschiede im unteren Molekulargewichtsbereich auszumachen (Bereich F).

Bei der Betrachtung erwies sich die Fällung mit Aceton als die einfachste, methodisch robusteste und mit der größten Spotabdeckung. Im Gegensatz zur Chloroform-MethanolFällung konnte diese Methode auch bei größeren Probenvolumina eingesetzt werden. Im Vergleich zur Entsalzung durch die Agilent $\mathrm{mpCR}$ high recovery protein column wurde kein Chromatographiegerät benötigt. Die Zugabe von kaltem Aceton direkt nach der Depletion schützte die Proteine durch augenblickliche Absenkung der Temperatur und Denaturierung vor proteolytischem Abbau. Wegen dieser Vorteile wurde die Acetonfällung bei der Analytik depletierten Serums vorgezogen und fand in dieser Arbeit vorrangig Anwendung. 


\subsubsection{Vergleich der Depletionssäulen}

Nachdem in Abschnitt 6.3.2 festgelegt wurde, welche Probenaufarbeitungsmethode für die Ankonzentrierung depletierten Serums zu wählen war, erfolgte der Vergleich der beiden Depletionssäulen auf Basis von 2D-Gelen. Als ausschlaggebende Kriterien für die Beurteilung der Depletionsleistung wurden die Gesamtspotzahl, Unterschiede im Spotpattern und die Gelqualität gewählt. Im Vergleich zur Agilent Human 6 Depletionssäule sollte die Proteome Lab IgY-12 LC2 eine deutliche Verringerung der high abundant Proteine erzielen, da sie mit sechs weiteren polyklonalen Antikörpern funktionalisiert war. Die theoretische Berechnung des Restproteinanteils nach der Depletion ist in Abbildung 26 dargestellt.

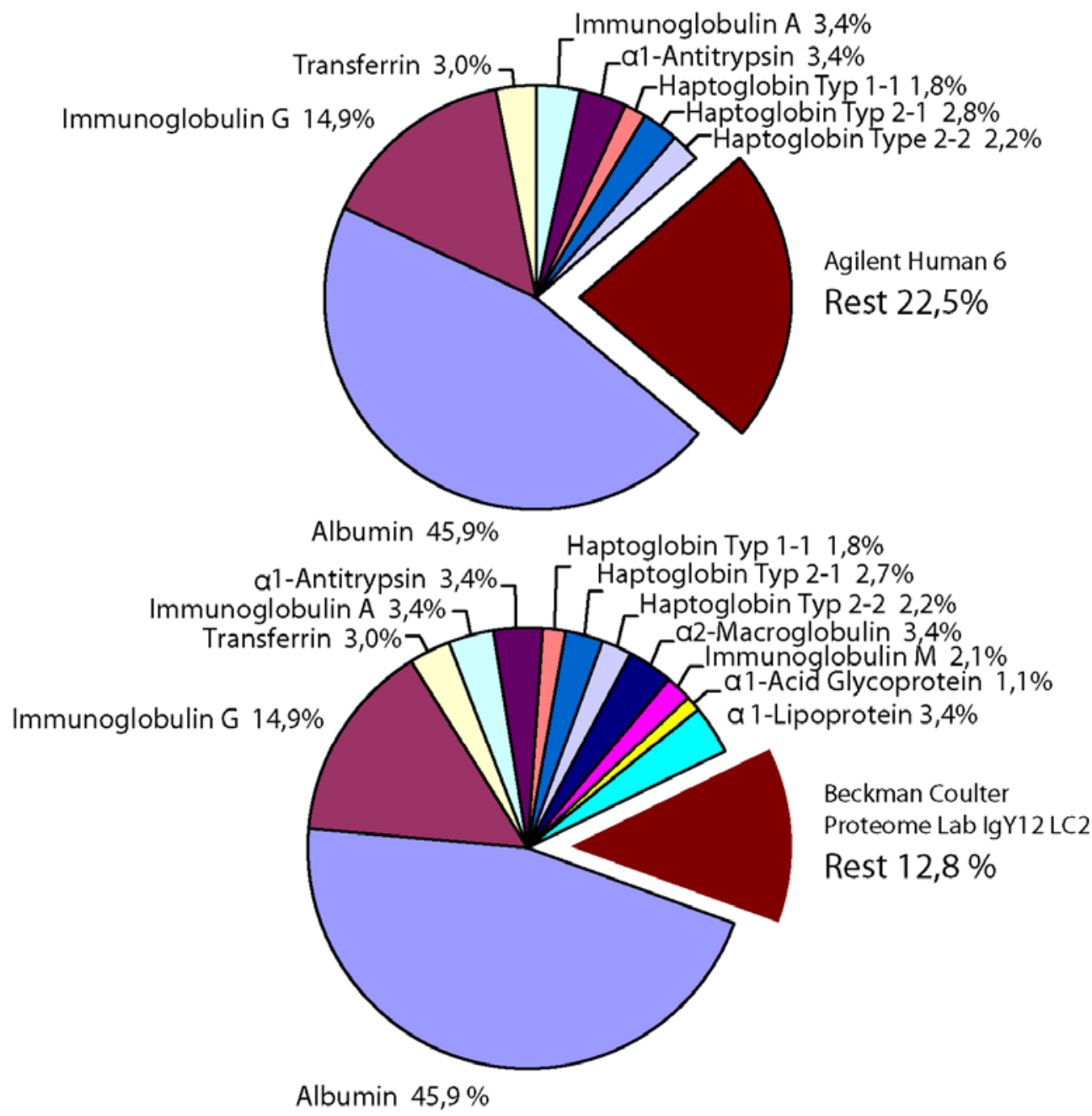

Abbildung 26: Prozentuale Verteilung der high abundant Proteine im humanen Serum. Bei den auf $100 \%$ fehlenden Werten handelt es sich um low abundant Proteine. Die Graphik wurde durch Addition und Normierung der Serumkonzentrationen der gelisteten Proteine erstellt. Werte aus „The Plasma Proteins“, Volume IV, 2. Ausgabe 1984 von Frank W. Putnam. 
Nach der tabellarischen Auflistung der Konzentration der Serumproteine und deren Verrechnung war bei der Agilent Human 6 Depletionssäule mit einem Restproteinanteil von 22,5 \% zu rechnen. Bei der Beckman Coulter Proteome Lab IgY12 LC2 waren es aufgrund der zusätzlichen Depletion von $\alpha_{2}$-Makroglobulin, IgM, $\alpha_{1}$-Acid Glykoprotein und Apolipoprotein A-1 theoretisch nur 12,8\%. Diese Anteile galten jedoch nur bei der Annahme, dass die Depletion eines Proteins zu 100 \% war und kein Restprotein im Depletat verblieb.

In Abbildung 27 ist ein Vergleich der realen Depletionsleistungen durch 2D-SDS-PAGE dargestellt.

$\mathrm{pH} \mathrm{NL} 3 \longrightarrow 10$

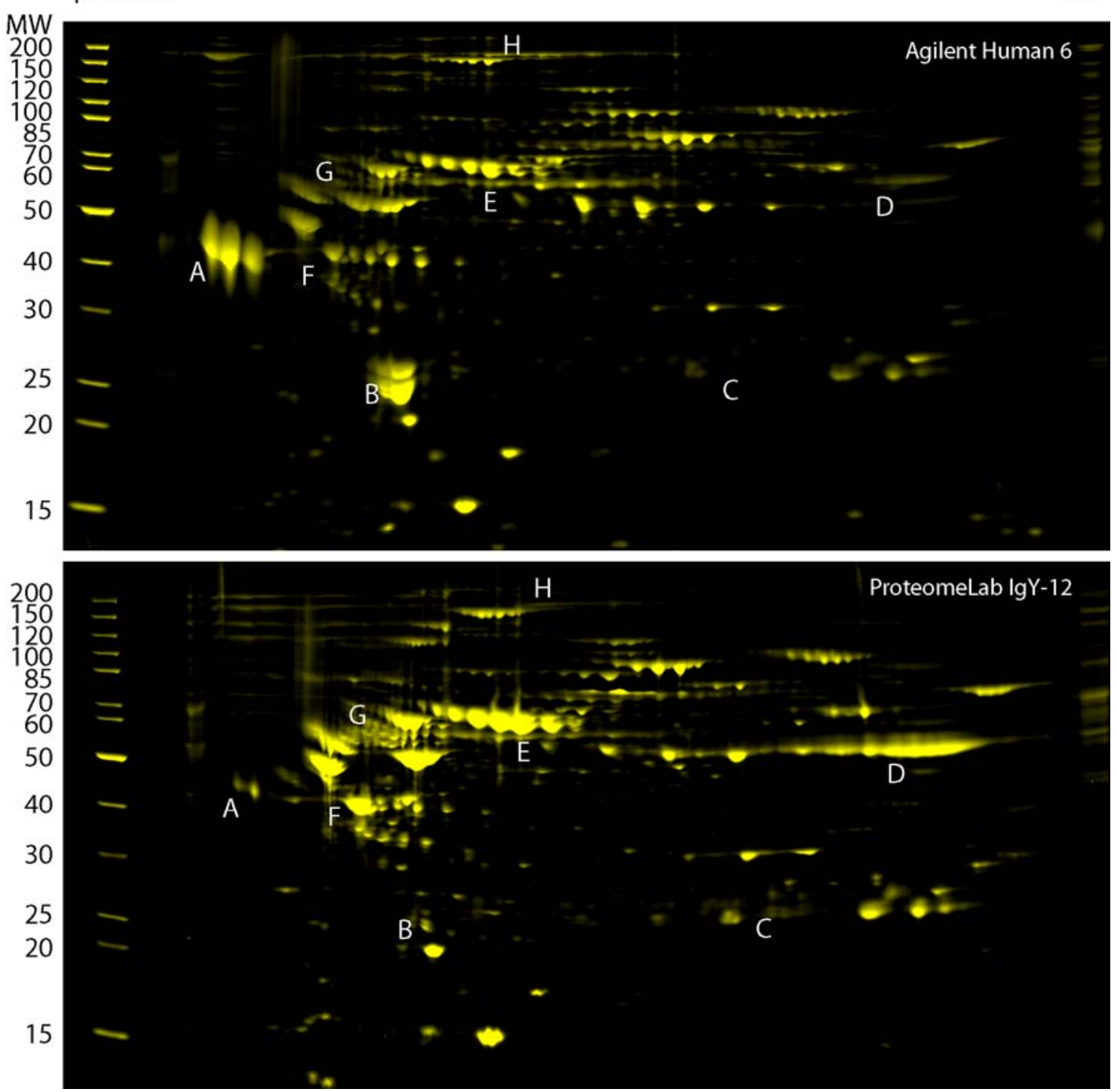

Abbildung 27 2D-SDS-PAGE von depletiertem Serum der gesunden Kontrollgruppe. Es wurden jeweils $150 \mu \mathrm{g}$ Protein aufgetragen und im Bereich pH 3-10 NL fokussiert. Anschließend erfolgte die SDS-Page auf einem Criterion ${ }^{\circledR} 12 \%$ Bis-Tris Gel. Die Färbung der Proteine erfolgte mit Flamingo ${ }^{\circledR}$. Die jeweiligen Unterschiede A-H sind im nachfolgenden Abschnitt erläutert. 
Abbildung 27 zeigt an den Bereichen $\mathrm{A}-\mathrm{H}$, dass Unterschiede in den Spotpattern der Depletate vorhanden waren. Im Bereich A war bei der Proteome Lab Depletionssäule die Intensität des Spots stark vermindert. Da es sich hierbei um das $\alpha_{1}$-Acid-Glykoprotein handelte, wurde es erwartungsgemäß von der Beckman-Coulter Proteome Lab IgY12 LC2 entfernt. Gleiches traf auch für die Spots im Bereich B (Apolipoprotein A-1) und $\mathrm{H}\left(\alpha_{2}\right.$ Makroglobulin) zu. Alle drei Proteine wurden im Vergleich zur Agilent Human 6 deutlich abgereichert, sind jedoch noch in kleinen Quantitäten vorhanden.

Im Gegensatz dazu waren bei den Spots im Bereich $C(\kappa-K e t t e ~ d e r ~ I g G)$, Bereich D ( $\gamma$-Kette der lgG) und Bereich $F$ (Haptoglobin) eine deutlich geringere Abreicherung der Proteine im Vergleich zur Agilent Human 6 Depletionssäule zu verzeichnen.

In den Bereichen $E$ und $G$ war eine erhöhte Konzentration der Proteine im Depletat der Beckman Coulter Proteome Lab IgY12 LC2 festzustellen. Es handelte sich im Bereich E um Spots von Hemopexin während im Bereich G Spots von Kininogen, $\alpha_{1}$-Glykoprotein und Vitamin-D-bindendes Protein zu identifizieren waren. Diese Proteine wurden nicht durch die Depletionssäulen entfernt und liegen aufgrund der Abreicherung der high abundant Proteine in ihren Quantitäten erhöht vor.

Trotz der erfolgreichen Abreicherung des $\alpha_{1}$-Acid-Glykoprotein, Apolipoprotein A-1 und $\alpha_{2}$-Makroglobulin ähnelten sich die Spotpatterns der beiden Depletionssäulen. Das Ziel, dass sich durch die Depletion von weiteren Proteinen andere low abundant Proteine darstellen lassen, konnte nicht erreicht werden. Die Depletion des Immunglobulin G (Spotregion C und D) war bei der Beckman Coulter Proteome Lab lgY12 deutlich schlechter als bei der Agilent Human 6.

Die Analyse der 2D-Gele zeigte, dass bei beiden Depletionssäulen alle depletierten Proteine in der Durchlaufsfraktion noch in großen Quantitäten nachweisbar waren. Die Depletion stellte somit nur eine Abreicherung der Proteine dar, durch die jedoch eine deutlich bessere Visualisierung von low abundant Proteinen erreicht werden konnte.

\subsubsection{Identifizierungen im humanen depletierten Serum}

Nach Ermittlung der optimalen Aufarbeitungsmethoden des depletierten Serums (vgl. Abschnitt 6.3.2 und Erörterung der Säulenwahl (vgl. Abschnitt 6.3.3) wurde im nachfolgenden Schritt die Gesamtheit der darstellbaren Proteine identifiziert. Dazu wurden aus einem 2D-SDS-PAGE Gel mit dem pH 3-10 NL insgesamt 103 Proteine durch PMF identifiziert. Abbildung 28 zeigt das Gel und die identifizierten Proteine. Die Tabelle aller identifizierten Proteine ist im Anhang (Abschnitt 10.2.2, Seite 112) zu finden. Anhand der Identifizierungen dieses Gels wurden die Spots in anderer Gelen zugeordnet. 


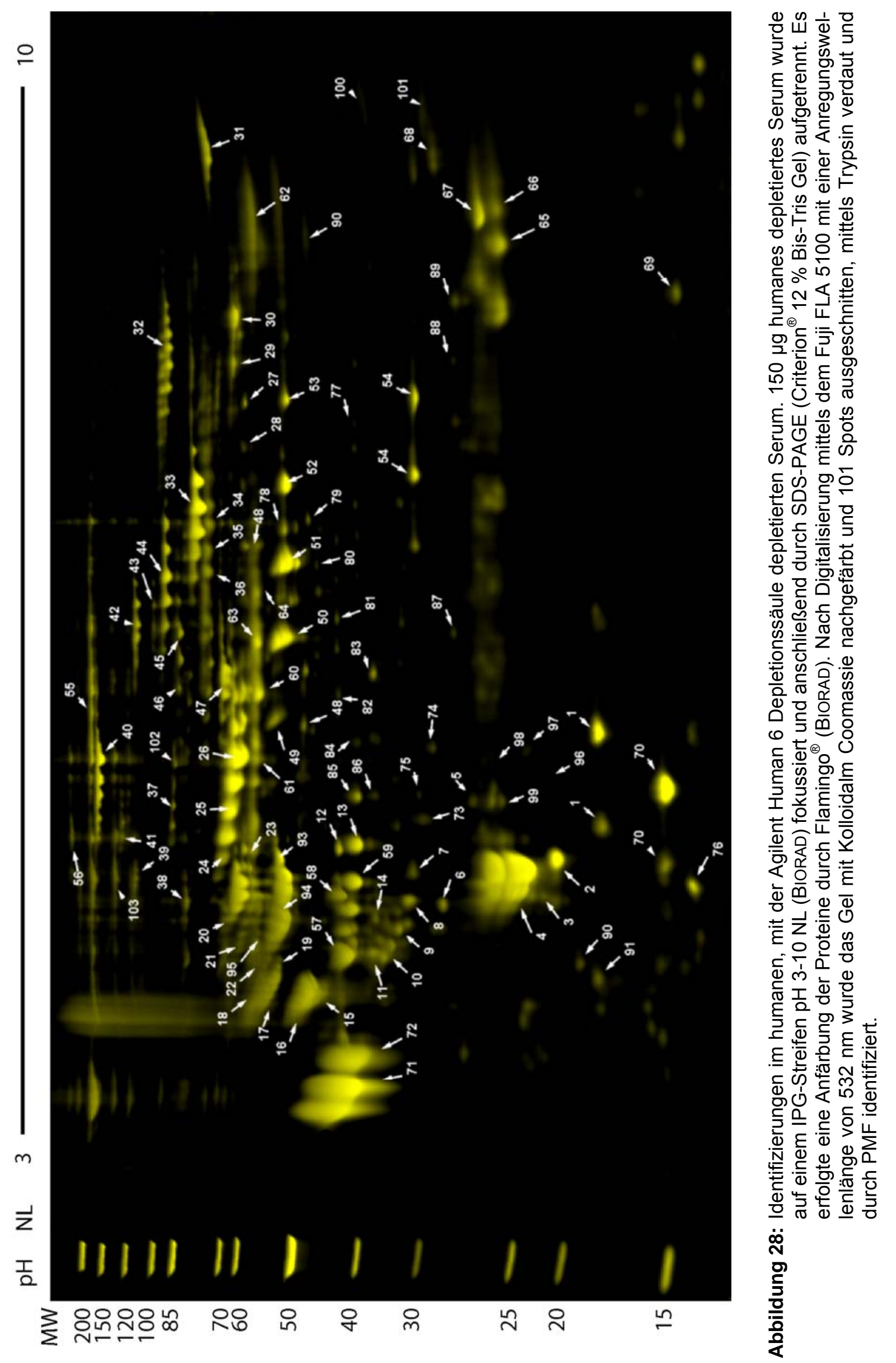


Durch den hohen Anteil an Glykosilierungen der Serumproteine ist das Aussehen eines 2D-Gels grundlegend anders als das von Zelllysaten (vgl. Abbildung 18, Seite 51). Durch die verschiedenen posttranslationalen Modifikationen erstrecken sich viele Proteine als horizontal verlaufende Spotkaskaden. Bei der Identifizierung durch PMF ergaben sich daher für diese unterschiedlichen Spots identische Identifizierungsergebnisse. Als Beispiele für Proteine, die sich über eine Kaskade von Proteinspots erstrecken, sind das Hemopexin (Spots 24-26), das $\beta_{2}$-Glykoprotein (Spots 49-53) und das $\alpha_{1}$-Acid-Glykoprotein (Spots 71-72) zu nennen. Aus diesem Grund konnten 52 verschiedene Proteine identifiziert werden, obwohl im Verlauf der Arbeit weit mehr als 103 Proteine analysiert wurden.

\subsubsection{Fraktionierung von depletiertem Serum}

\subsubsection{Fraktionierung durch eine Gradiententrennung}

Aufgrund der geringen Varianz der Proteindistribution und der unvollständigen Abreicherung der high abundant Proteine wurde eine Methode gesucht, um die Anzahl der detektierbaren Proteinen zu erhöhen. Dies sollte durch eine Fraktionierung erfolgen, bei der die Serumproteine spezifisch in Fraktionen angereichert würden.

Zum Einsatz kam die Agilent mpCP high recovery protein column, die im Abschnitt 6.3.2 zur Entsalzung und Ankonzentrierung beschrieben wurde. Bei dieser Art der chromatographischen Separation werden die Proteine gemäß ihrer Hydrophobizität aufgetrennt.

Zunächst wurde eine Methode mit einer Gradientenelution (vgl. 5.9.4.2, Seite 47) entwickelt, um die Proteine des Serums zu fraktionieren. Die Proteine wurden auf die Säule appliziert und anschließend durch einen ansteigenden Acetonitrilgradienten von der Säule eluiert. Von Minute 10 bis Minute 40 wurden im Abstand von jeweils zwei Minuten 20 Fraktionen gesammelt. Das Elutionsprofil dieser Methode ist in Abbildung 29 dargestellt.

Da die Proteinausbeute der einzelnen Fraktionen aufgrund der geringen Beladungskapazität der Säule sehr gering war, mussten die Fraktionen aus mehreren Läufen vereint werden. Die vereinten Fraktionen wurden zur Trockne eingeengt, das lyophilisierte Protein in Lysepuffer resuspendiert und durch 1D-SDS-PAGE analysiert.

Die in Abbildung 29 dargestellte Fraktionierung zeigte eine gute Auftrennung der Serumproteine. Dabei verteilte sich der größte Anteil der Proteine auf die Fraktionen 2-16. Aufgrund der geringen Proteinkonzentration in Fraktion 17, die aus einem Pool der Fraktionen 17-20 besteht, ist eindeutig belegt, dass das Absorptionssignal im Chromatogramm nicht durch Proteine verursacht ist, sondern durch Lipide, die erst bei hohen Acetonitrilkonzentrationen eluiert werden. 

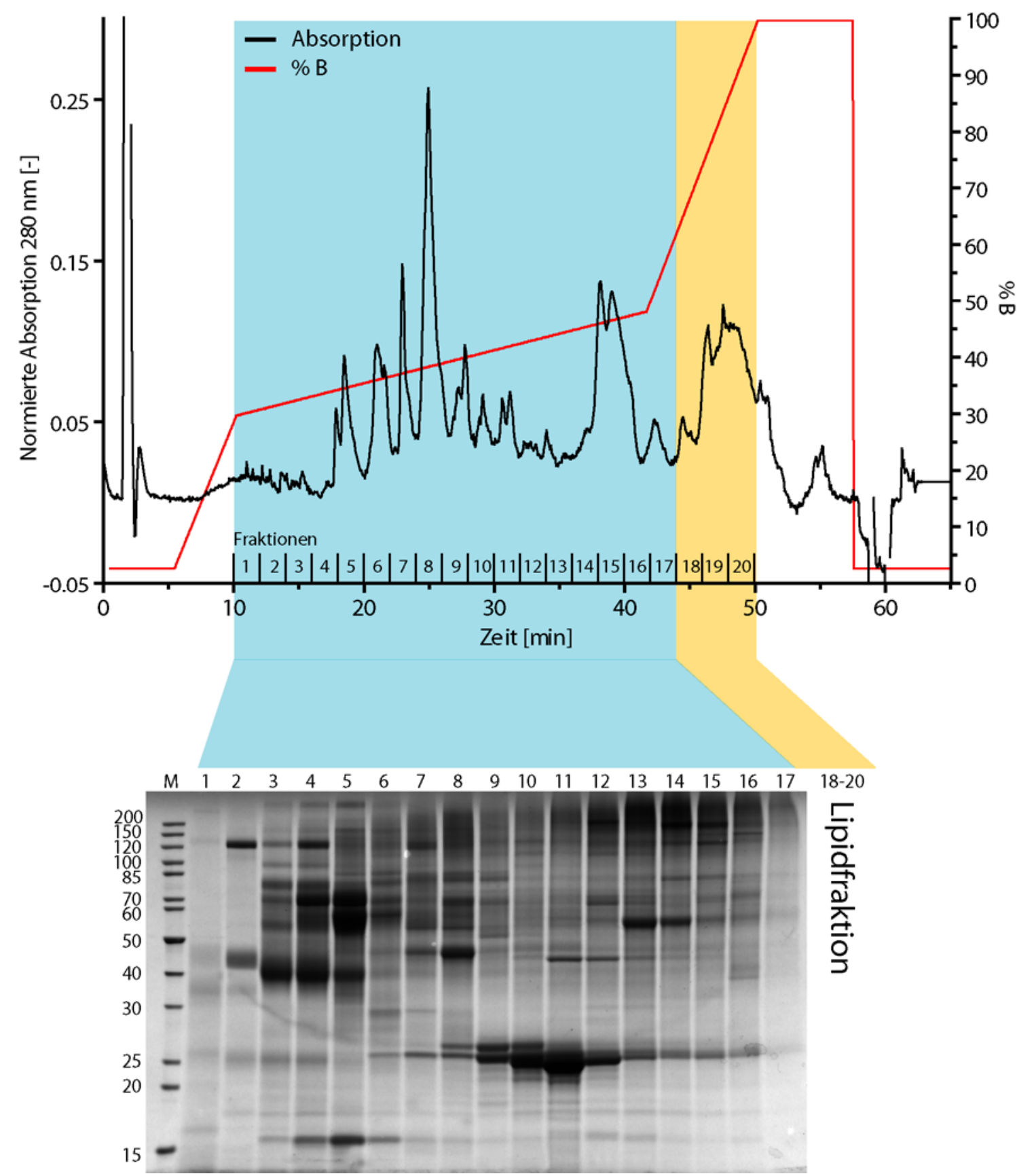

Abbildung 29: Chromatogramm der Gradientenelutionsmethode von depletiertem Serum der gesunden Kontrollgruppe. $1 \mathrm{ml}$ Depletat wurde mit $480 \mathrm{mg}$ Urea und $13 \mu \mathrm{l}$ Eisessig versetzt und nach Filtration auf die Agilent $\mathrm{mpCR}$ high recovery protein column appliziert. Die Elution erfolgte durch einen ansteigenden Acetonitrilgradienten. Die Detektion erfolgte bei einer Wellenlänge von $280 \mathrm{~nm}$. Von Minute 10 bis Minute 50 wurden im Abstand von 2 Minuten Fraktionen von $1,5 \mathrm{ml}$ aufgefangen, zur Trockne eingeengt und das resultierende Proteinpellet in Lysepuffer resuspendiert und durch 1D-SDSPAGE analysiert. Die Färbung der Proteine erfolgte durch kolloidales Coomassie.

Zur Identifizierung von Proteinen und zum Vergleich einzelner Proteine ist die Auftrennung durch 1D-SDS-PAGE nicht ausreichend. Aus diesem Grund sollten die Fraktionen durch 2DSDS-PAGE untersucht werden. Für diese Analyse waren jedoch pro Fraktion 100-150 $\mu \mathrm{g}$ Protein erforderlich, um ein 2D-Gel anschließend mit kolloidalem Coomassie färben und Proteine durch PMF identifizieren zu können. Dies hätte bedeutet dass man die Fraktionen 
aus 10-15 Chromatographieläufen vereinen hätte müssen, um genügend Protein für das Gel einer Fraktion zu erhalten. Aus diesem Grund musste absolute Reproduzierbarkeit der Retentionszeiten der Proteine garantiert werden. Schwankungen in der Retentionszeit der Proteine würden sich in einer Änderung des Proteinpatterns niedergeschlagen.

Abbildung 30 zeigt, dass trotz modernster apparativer Ausstattung signifikante Änderungen der Retentionszeit zu detektieren waren.

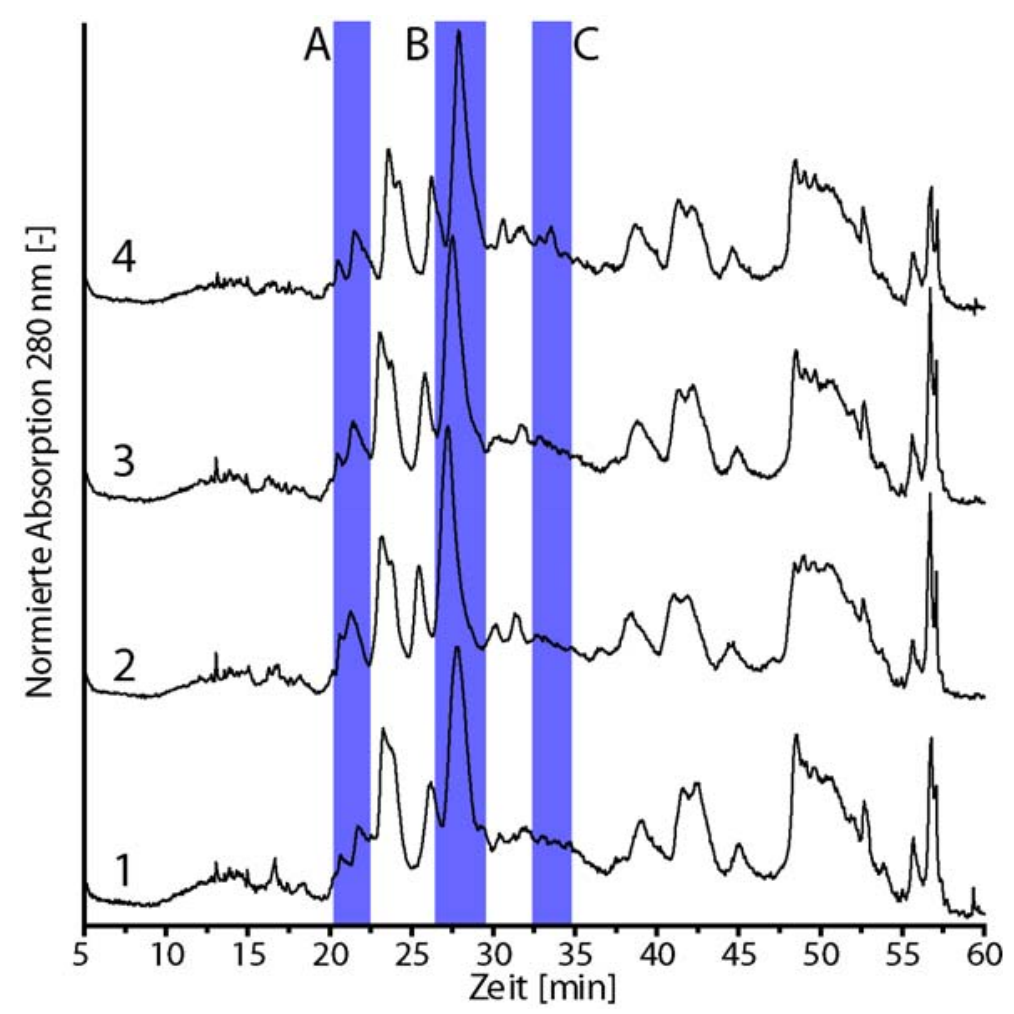

Abbildung 30: Vergleich der Chromatogramme der Gradientenelution von depletiertem Serum der gesunden Kontrollgruppe (Agilent Human 6) mit der Agilent mpCR high recovery protein column. Pro Lauf (1-4) wurden $380 \mu \mathrm{g}$ Protein appliziert. Veränderungen der Retentionszeit sind in den Bereichen A-C dargestellt.

Im Bereich $A$ ist eine signifikante Veränderung der Retentionszeiten und der Auflösung zu erkennen. Im ersten und zweiten Lauf ist nur eine unvollständige Trennung der beiden Peaks zu erkennen. In Bereich B ist die Retentionszeit der einzelnen Läufe mit einer Differenz von $\mathrm{t}=1,5$ Minuten deutlich unterschiedlich. Im Bereich $\mathrm{C}$ ist im vierten Lauf ein Peak auszumachen, der in den anderen Läufen nicht vorhanden ist.

Aufgrund der Änderungen der Retentionszeiten einzelner Proteine ist eine Fraktionierung durch eine Gradiententrennung nicht empfehlenswert. Die Abweichungen des Proteinpatterns der 2D-Gele dieser Fraktionen wären zu groß.

Abhilfe könnte eine größer dimensionierte Säule schaffen, die genügend Protein in einem einzelnen Lauf binden könnte. Mit Hilfe von Standardproteinen könnten die Laufunterschiede abgeglichen und die Fraktionierung angepasst werden. Allerdings könnten sich durch dieses 
upscaling die chromatographischen Eigenschaften der Säule verändern. Die Separationsleistung müsste daher erneut bestätigt werden und kann nicht direkt aus diesen Experiment übernommen werden.

\subsubsection{Fraktionierung durch eine Stufenelution}

Um die fehlende Präzision der Gradiententrennung zu verbessern wurde eine Stufenelutionsmethode (siehe Abschnitt 5.9.4.3, Seite 48) entwickelt. Es wurden insgesamt 8 Stufen mit den Acetonitrilkonzentrationen von 33, 36, 39, 42, 45, 48, 55, 100 \%. Jede Konzentrationsstufe wurde für 10 Minuten gehalten und eine Fraktion von $7,5 \mathrm{ml}$ gesammelt. Eine schematische Übersicht über das Retentionsverhalten ist in Abbildung 31 dargestellt.

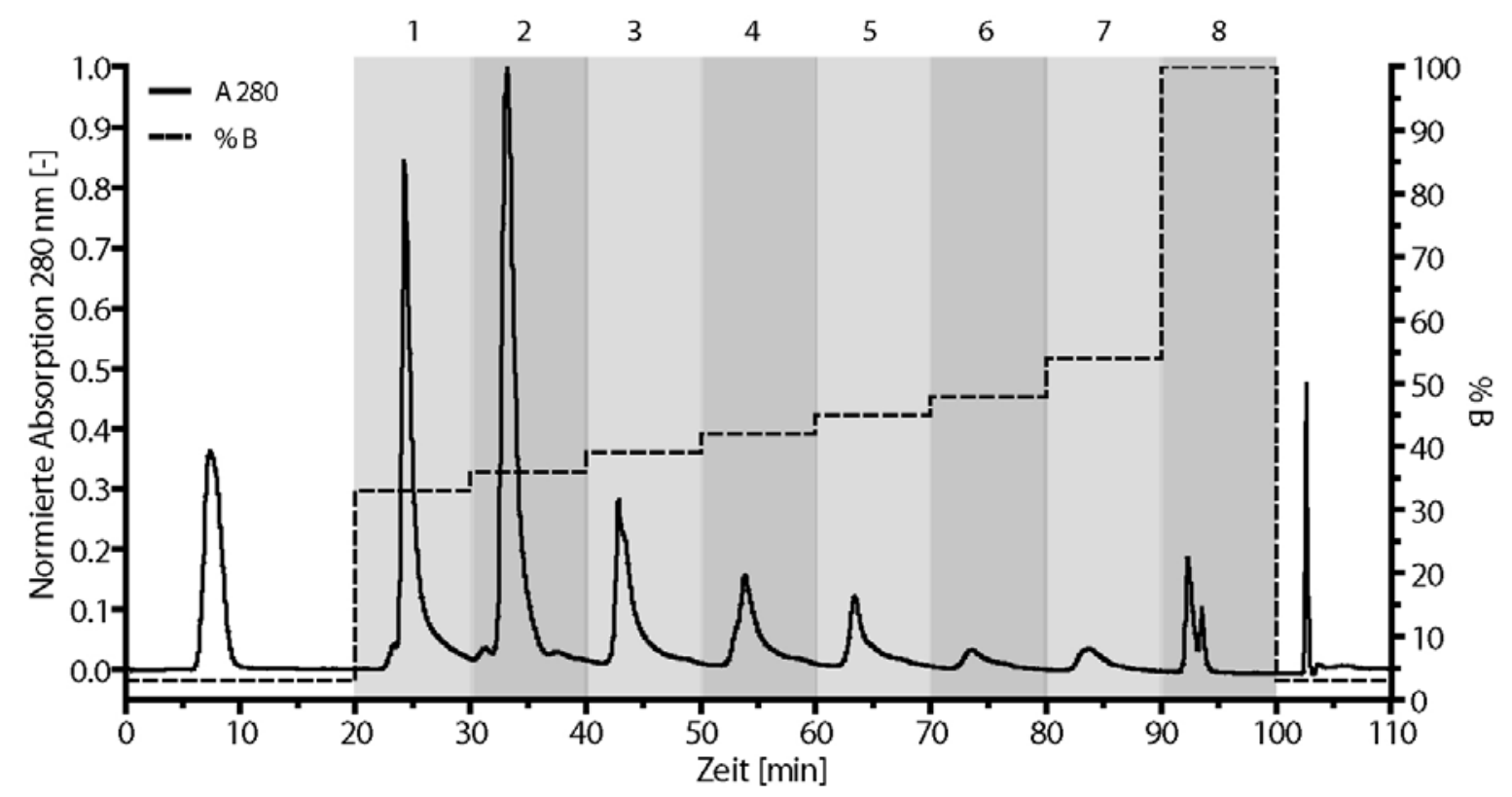

Abbildung 31: Chromatogramm der Stufenelution von depletiertem Serum (Agilent Human 6) mit der Agilent mpCR high recovery protein column. Es wurden $380 \mu \mathrm{g}$ Protein auf die Säule appliziert und in 8 Stufen $(33,36,39,42,45,48,55,100 \%$ ACN) von der Säule eluiert. Für jede Stufe wurde eine Fraktion von $7,5 \mathrm{ml}$ aufgefangen, die zur Trockne eingeengt wurde. Das resultierende lyophilisierte Protein wurde in Lysepuffer resuspendiert und mittels 2D-SDS-PAGE analysiert.

Das Chromatogramm der Stufenelutionsmethode gab keinen Aufschluss über die Retentionszeit einzelner Proteine. Bei jeder Änderung der Acetonitrilkonzentration wurde parallel eine deutliche Änderung der Absorption gemessen.

In den Fraktionen 6-8 nahm diese pro Gradientenschritt deutlich ab. Aufgrund der geringen Proteinkonzentration der letzten Fraktion und des hohen Anteils an Lipiden, die die folgenden Analysen stören konnten, wurde diese Fraktion nicht analysiert und die Fraktionen 6 und 7 vereint. Man erhält daher sechs Fraktionen zur Analyse, deren elektrophoretische Auftragungen in den Abbildungen 32 und 33 dargestellt sind. 


\section{$\mathrm{pH} 3$}
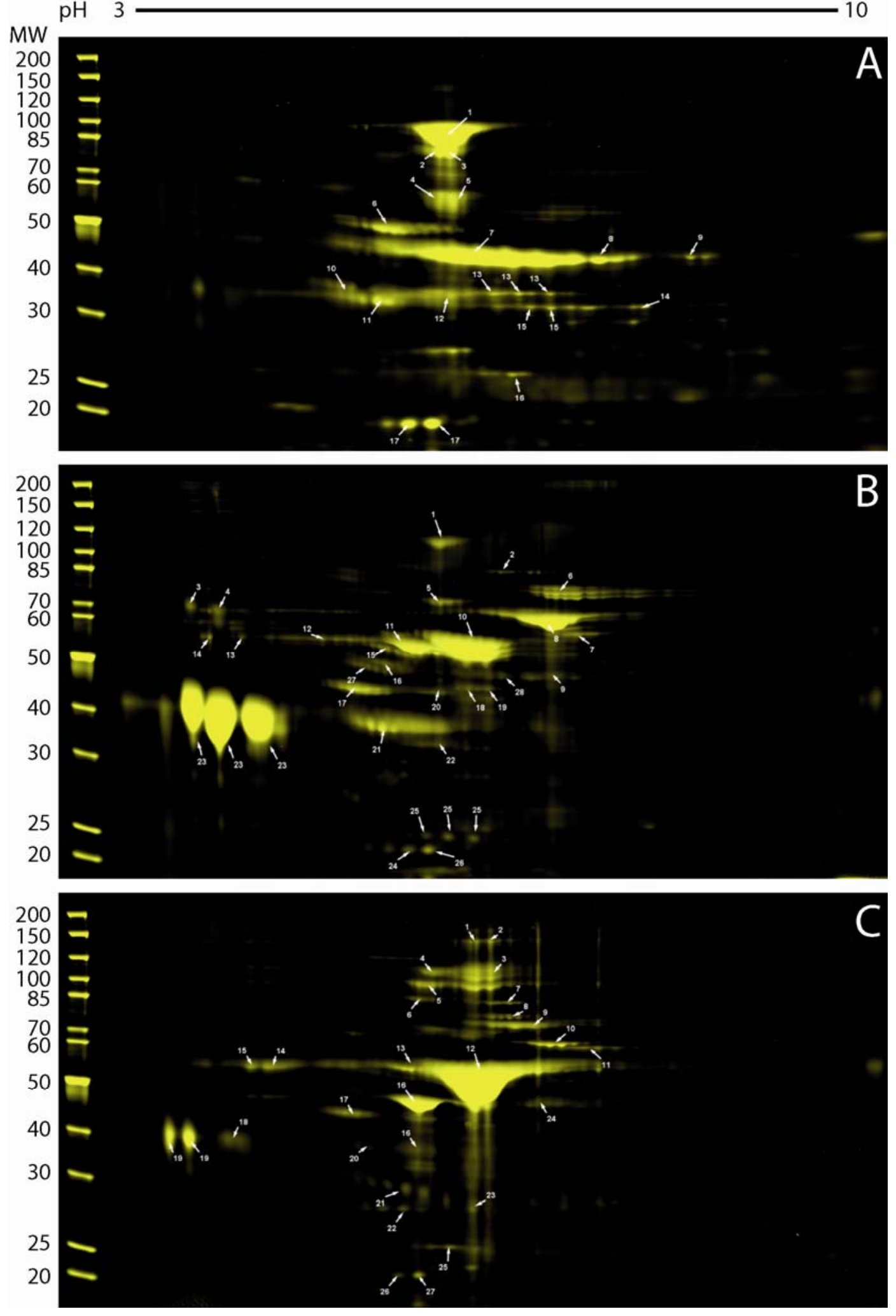

Abbildung 32: 2D-SDS-PAGE von depletiertem humanem Serum der Patientengruppe RA. Es wurden $100 \mu \mathrm{g}$ Protein pro Gel aufgetragen und im Bereich von pH 3-10 fokussiert. Die Auftrennung erfolgte über ein Criterion ${ }^{\circledR} 10 \%$ Bis-Tris Gel. (A) Fraktion $33 \%$ ACN, (B) Fraktion $36 \%$ ACN, (C) Fraktion $39 \%$ ACN. Die Identifizierungen der Spots sind im Anhang im Abschnitt 10.2.3 zu finden. 


\section{$\mathrm{pH} 3$}
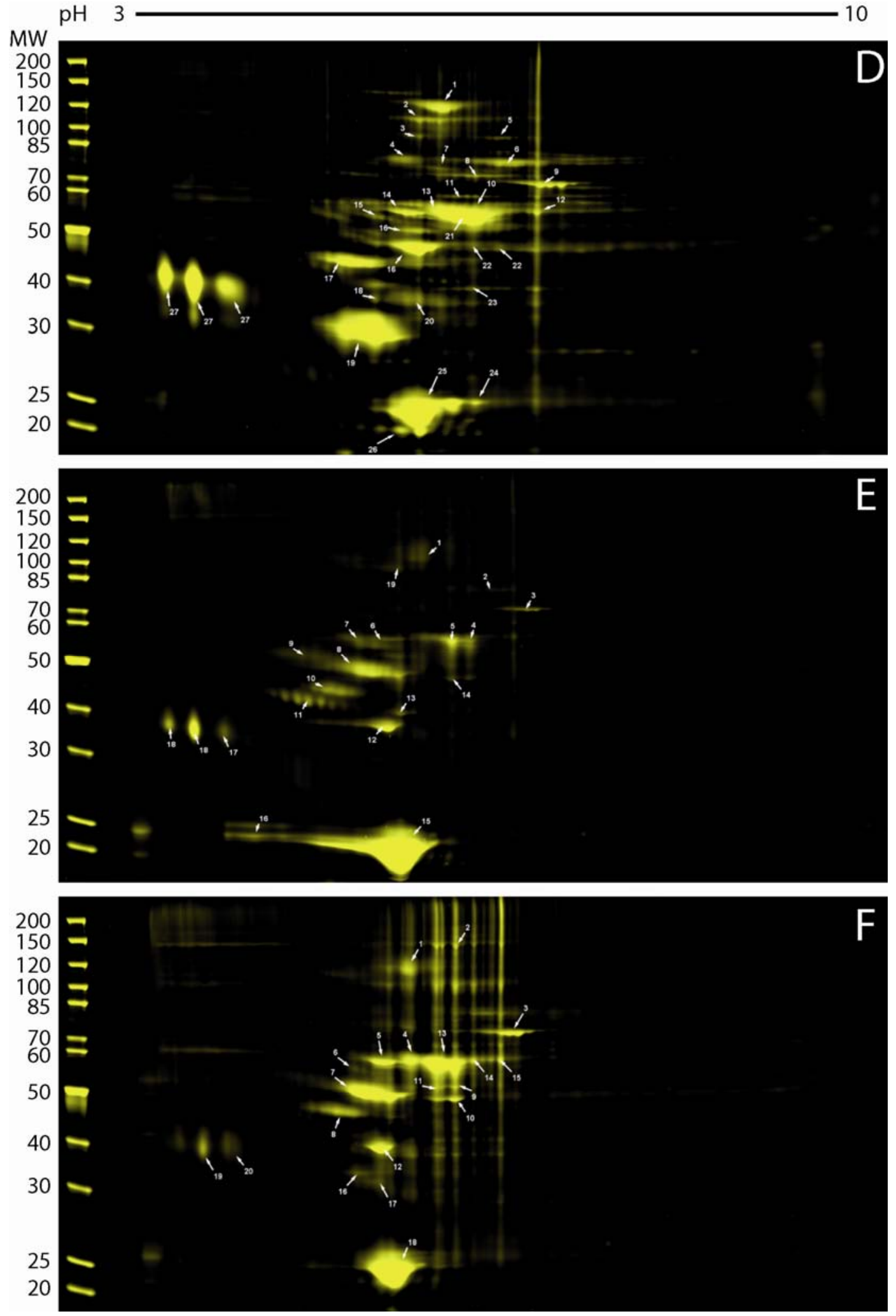

Abbildung 33: 2D-SDS-PAGE von depletiertem humanem Serum der Patientengruppe RA. Es wurden $100 \mu \mathrm{g}$ Protein pro Gel aufgetragen und im Bereich von pH 3-10 fokussiert. Die Auftrennung erfolgte über ein Criterion ${ }^{\circledR} 10 \%$ Bis-Tris Gel .(D) Fraktion $42 \%$ ACN, (E) Fraktion $45 \%$ ACN, (F) Fraktion $48 \%$ ACN und $55 \%$ ACN (Pool). Die Identifizierungen der Spots sind im Anhang im Abschnitt 10.2.3 zu finden. 
Tabelle 12: Auflistung und Vorkommen der in den Fraktionen identifizierten Proteine. Insgesamt wurden 132 Spots identifiziert, die in 40 unterschiedliche Proteine resultierten. Die Identifizierungen der Spots sind im Anhang im Abschnitt 10.2.3 Seite 114 zu finden.

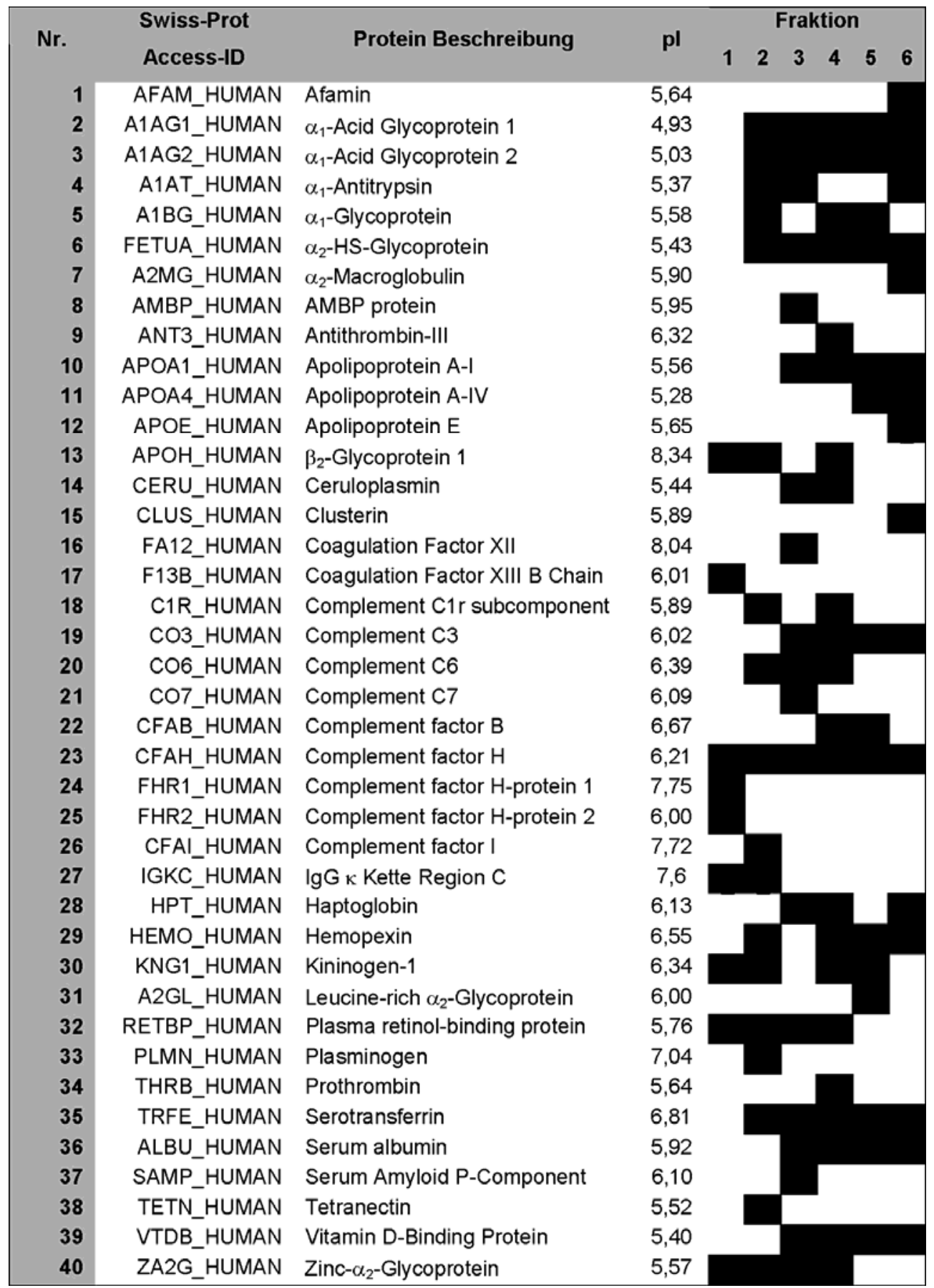

Die Fraktionierung von depletiertem Serum resultierte in einem nicht zufrieden stellenden Ergebnis. Die Anzahl an identifizierten Proteinen, die durch die aufwendige Fraktionierung erreicht wurde, war nicht höher, als die, die man durch eine Depletion alleine erreicht hatte (vgl. Abbildung 28, Seite 65). Zudem ist die Gelqualität der Fraktionen nicht optimal. Die Fraktion F war durch starke vertikale Streifenbildung gekennzeichnet. Insgesamt waren die meisten Proteine deutlich schlechter aufgetrennt als bei Fokussierungen von unfraktioniertem Depletat. 
Aufgrund der geringen Säulenkapazität mussten die Fraktionen aus 5 Läufen vereint werden. Für jede Fraktion wurden daher $37,5 \mathrm{ml}$ zur Trockne eingeengt. Dies benötigte je nach Acetonitrilgehalt 10-12 h. Ein gravierendes Problem bei der Einengung ist die Ankonzentrierung der Trifluoressigsäure (TFA), die in Anteilen von 0,05 vol.- $\%$ in beiden Laufmitteln enthalten war. Sie veränderte den $\mathrm{pH}$-Wert der Proben nach dem Resuspendieren der lyophilisierten Proteinpellets sehr stark. Durch die Zugabe kleiner Mengen $100 \%$ Ethanol nach dem Trocknen wurde versucht, die TFA zu verestern. Durch diese Umwandlung war sie im Lyophilisator leichter abdampfbar und konnte besser entfernt werden. Trotzdem musste vor den Analysen die Proben durch eine 0,1 M Tris-HCl-Lösung $(\mathrm{pH} \mathrm{9,0)}$ wieder ausgeglichen werden. Der hieraus entstandene, hohe Salzeintrag resultierte in einer deutlichen Verschlechterung der isoelektrischen Fokussierung.

Insbesondere bei DIGE-Gelen konnten nur unzureichende Fokussierer- und Intensitätsergebnisse erzielt werden. Da zur Kopplung der Fluoreszenzfarbstoffe ein pH-Wert von mindestens 8,0 benötigt wurde, musste bei dieser Art der Probenvorbereitung stark gegentitriert werden.

Obwohl Proteine, wie z.B. Afamin, $\alpha_{2}$-Macroglobulin und Clusterin ausschließlich in einzelnen Fraktion (Fraktion 6) nachgewiesen werden konnten, so gibt es andere, die in sämtliche Fraktionen in mittleren bis großen Quantitäten nachweisbar waren. Zu diesen Proteinen zählten das $\alpha_{1}$-Acid Glykoprotein 1, $\alpha_{1}$-Acid Glykoprotein 2, $\alpha_{2}$-HS-Glykoprotein, Komplement Faktor $\mathrm{H}$ und Serotransferrin. Auffällig ist, dass Proteine, die durch die Depletion entfernt werden sollten, nach der Fraktionierung wieder deutlich intensiver auf den Gelen auszumachen waren. Dies ist gut an Abbildung 32 Gel C zu erkennen. Die Spot 12-14 wurde alle als Serumalbumin identifiziert. Die starke Anreicherung des Albumins zeigt in diesem Gel eine ähnliche Fokussierproblematik wie in Abbildung 23 bei undepletiertem Serum. Das Protein ist schlecht aufgetrennt über den gesamten $\mathrm{pH}$-Bereich verteilt. Beim Apolipoprotein A-1 (Spot 24, 25 Gel D; Spot 15, 16 Gel E; Spot 18 Gel F, Abbildung 33) ist eine weitere, überdurchschnittliche Anreicherung zu beobachten. Dieses lipidbindende Protein ist in den Fraktionen ab einem Acetonitrilanteil von 42 \% (ab Fraktion 4) sehr stark angereichert. Aufgrund der lipophilen Trenneigenschaften einer reversed-phase (RP) Chromatographie wurde dieses Protein selektive angereichert.

Es befinden sich zudem deutlich weniger Spots auf den Gelen.

Die Fraktionierung hat sich daher zur Visualisierung weiterer low abundant Proteine als nicht geeignet herausgestellt. Die Prozedur ist langwierig und aufgrund der großen Verdünnung der Proben und den langwierigen Einengungsschritten äußerst umfangreich.

Es wurde sich stattdessen auf die Etablierung der DIGE-Technologie konzentriert und deren Anwendung bei der Analyse depletierter Seren. 


\subsubsection{DIGE-Vergleich der depletierten Seren}

Durch den hohen Glykosilierungsanteil der Serumproteine ergeben sich bei der 2D-SDSPAGE oft keine klar abgegrenzten Spots, sondern häufig Spotkaskaden und unförmige Spotmuster. Der konventionelle Vergleich dieser Spotmuster ist nur sehr schwer möglich und resultiert stets in fragwürdigen Quantifizierungen mit schlechten Signifikanzen und Standardabweichungen. Der Vorteil, dass im Falle eines DIGE-Experimentes die Proben in nur einem Gel laufen und anschließend die Intensitäten durch den Abgleich mit einem internen Standard normiert werden, ermöglicht quantitativ hochsignifikante Quantifizierungsergebnisse.

Die Durchführung eines DIGE-Experimentes und deren statistische Auswertung ist in Abschnitt 5.5 ausführlich beschrieben.

Da in dieser Arbeit von den 103 identifizierten Proteinen im Serum (siehe Abbildung 28, Identifizierungen Abschnitt 10.2.2, Seite 112) $80,7 \% \mathrm{im} \mathrm{pH} \mathrm{4-7} \mathrm{liegen} \mathrm{und} \mathrm{nur} 19,3 \% \mathrm{im}$ Bereich 7-10 wurde für die Analyse mittels DIGE-Gele der pH 4-7 gewählt. Nach Kopplung der Proben (50 $\mu \mathrm{g}$ Protein) mit ihren jeweiligen Farbstoffen (400 pmol / Farbstoff und Probe) wurden die depletierten Serumproben auf einem IPG-Streifen $\mathrm{pH} \mathrm{4-7} \mathrm{fokussiert} \mathrm{und} \mathrm{mittels}$ SDS-PAGE aufgetrennt. Zwei exemplarische Gele für den Vergleich der Gruppe RA mit OA und RA mit Gesund sind in den Abbildungen 35 und 36 dargestellt.

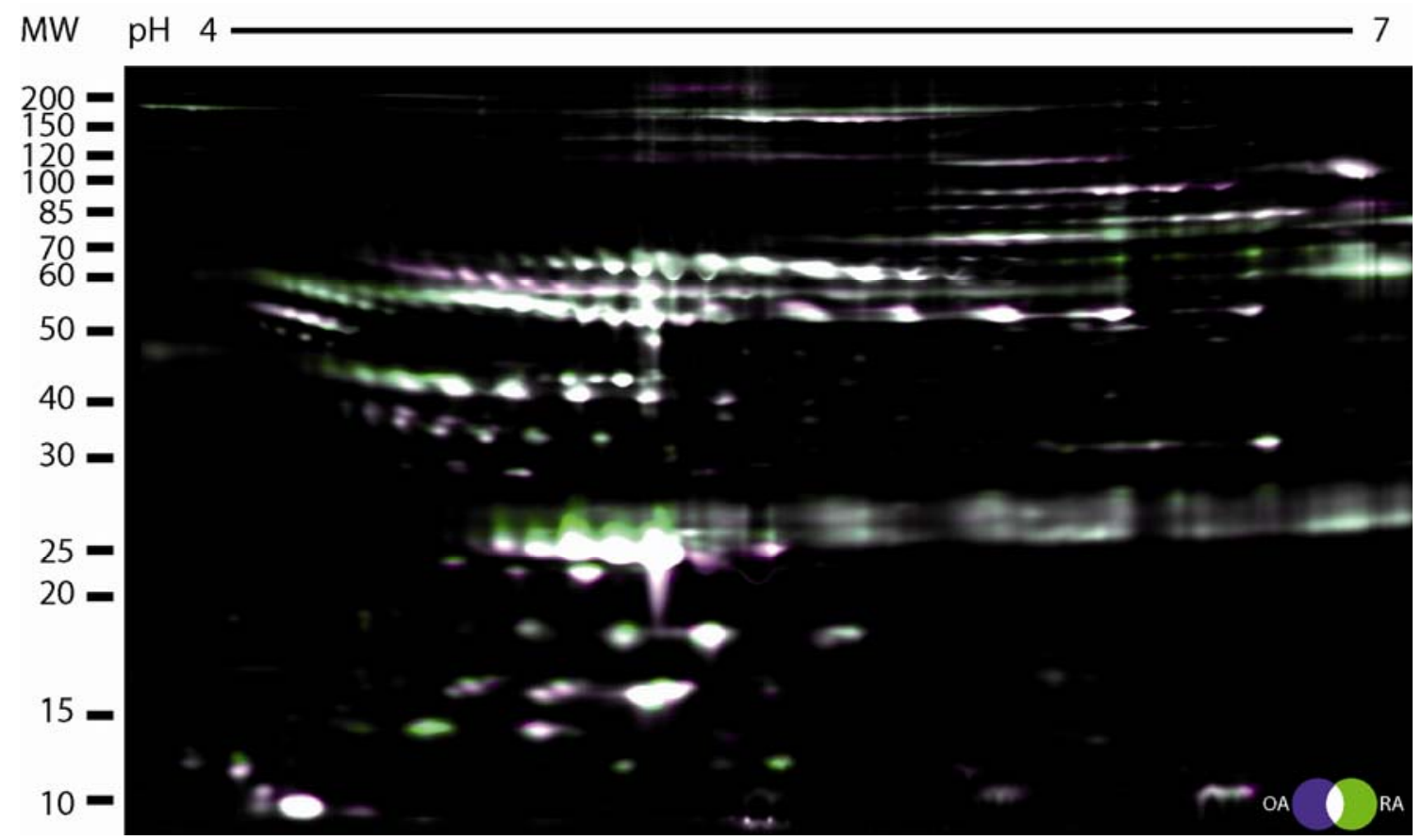

Abbildung 34: Darstellung eines DIGE-Gels, in dem depletiertes Serum (Agilent Human 6 Depletionssäule) der RA-Patientengruppe mit dem der OA-Patientengruppe verglichen wurde. $\mathrm{pH} 4-7,12 \%$ Criterion ${ }^{\circledR}$ Bis-Tris Neutralgel (BIORAD). 


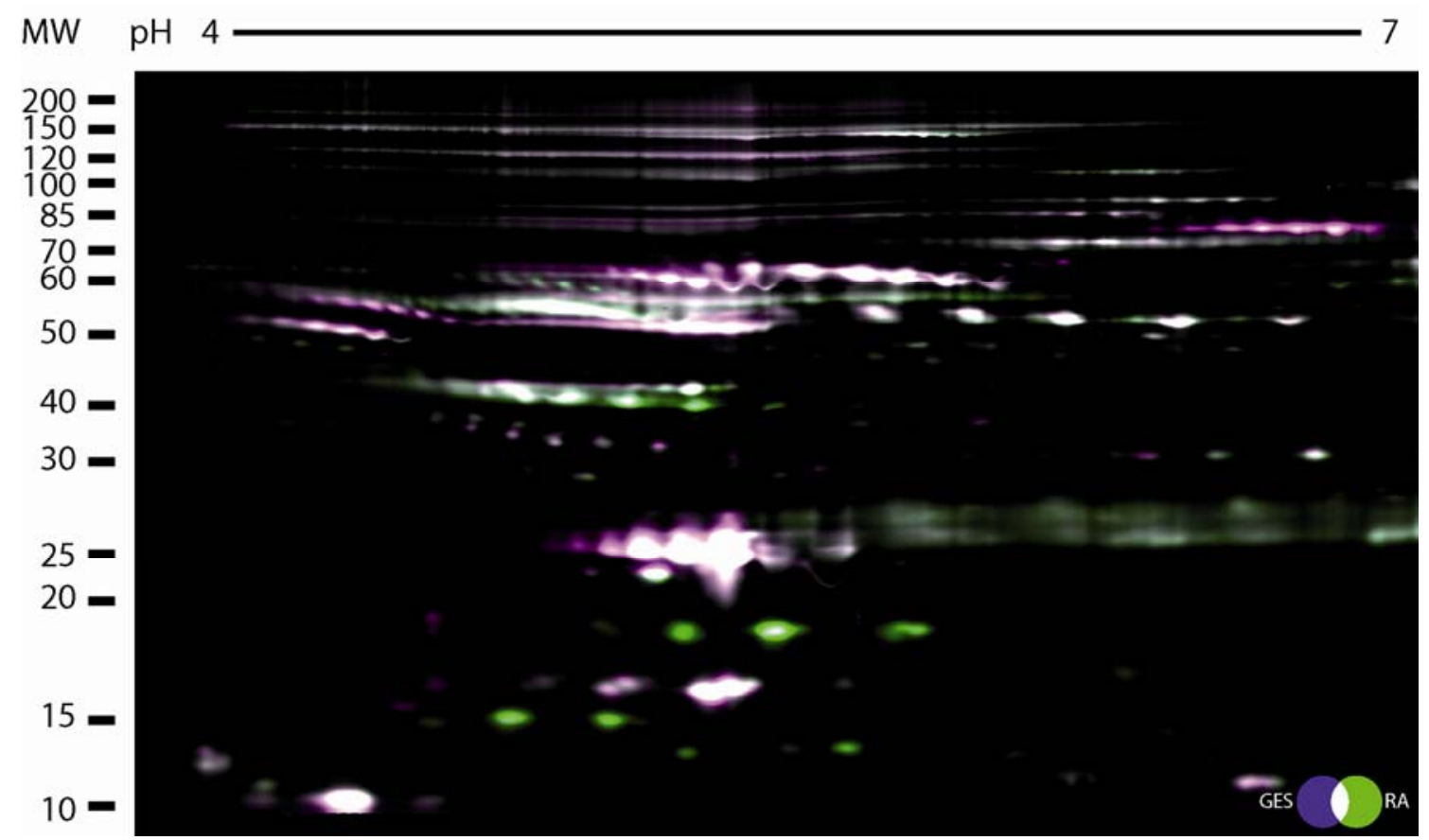

Abbildung 35: Darstellung eines DIGE-Gels, in dem depletiertes Serum (Agilent Human 6 Depletionssäule) der RA-Patientengruppe mit dem der gesunden Kontrollgruppe verglichen wurde. pH 4-7, $12 \%$ Criterion $^{\circledR}$ Bis-Tris Neutralgel (BIORAD).

Bei der Patientengruppe RA konnte im Vergleich zu den OA-Patienten und den gesunden Kontrollpersonen keine neuen Spots identifiziert werden. Es wurden jedoch Expressionsunterschiede verschiedener Proteine gemessen, die in den DIGE-Gelen je nach Regulation farblich markiert sind.

Aus diesem Grund wurden die Quantitäten der identifizierten Proteine verglichen. Um sicherstellen zu können, dass die Expressionsunterschiede nicht durch die Depletion resultieren, wurden die DIGE-Experimente neben den Depletaten der Agilent Human 6 zusätzlich mit depletierten Seren der Beckman-Coulter Proteome Lab IgY-12 LC2 durchgeführt. Durch diese Ausweitung konnten quantitative Daten aus den folgenden vier Ansätzen gewonnen werden:

Tabelle 13: Übersicht der unterschiedlichen DIGE-Experimente

\begin{tabular}{|cll|}
\hline Experiment & Vergleich & Depletionssäule \\
A & RA vs. OA & Agilent Human 6 \\
B & RA vs. OA & BC Proteome Lab IgY12 \\
C & RA vs. Gesund & Agilent Human 6 \\
D & RA vs. Gesund & BC Proteome Lab IgY12 \\
\hline
\end{tabular}

Die identifizierten Proteine und deren Spotzuordnung sind im Anhang unter Abschnitt 10.2.4 (Seite 117) zu finden. Die 78 durchgeführten Proteinidentifizierungen resultierten in 26 unterschiedlichen Proteinen, deren relative Expressionsunterschiede und Abkürzungen in Abbildung 36 dargestellt sind. 


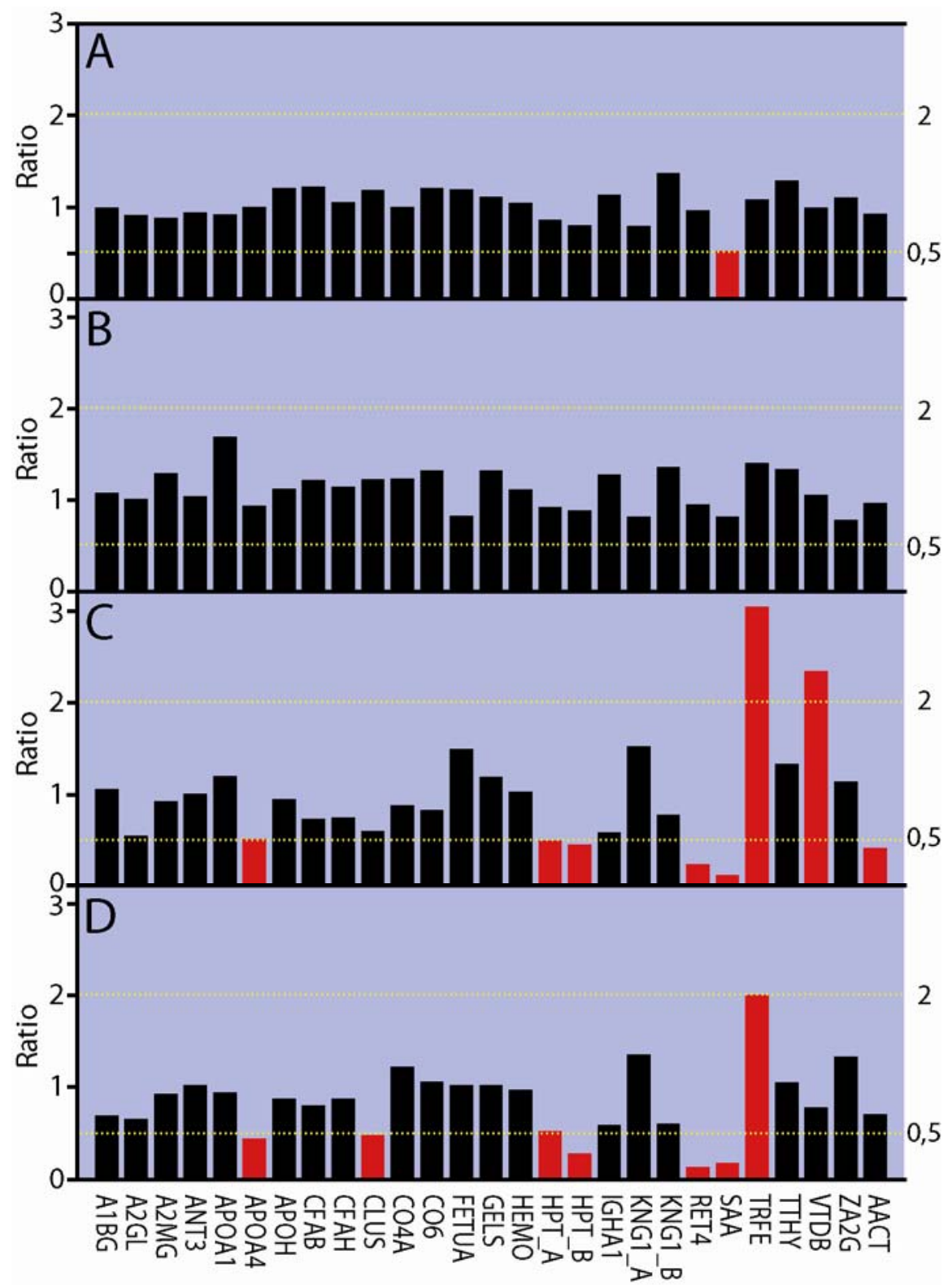

\begin{tabular}{|rl|}
\hline Protein ID & \multicolumn{1}{c|}{ Proteinname } \\
A1BG & $\alpha_{1}$-Glykoprotein \\
A2GL & Leucine-rich $\alpha_{2}$-Glykoprotein \\
A2MG & $\alpha_{2}$-Makroglobulin \\
ANT3 & Antithrombin-III \\
APOA1 & Apolipoprotein A-I \\
APOA4 & Apolipoprotein A-IV \\
APOH & $\beta_{2}$-Glykoprotein 1 \\
CFAB & Complement factor B \\
CFAH & Complement factor H \\
CLUS & Clusterin \\
CO4A & Komplement C4-A \\
CO6 & Komplement C6 \\
FETUA & $\alpha_{2}$-HS-Glykoprotein \\
GELS & Gelsolin \\
\hline
\end{tabular}

\begin{tabular}{|rl|}
\hline Protein ID & \multicolumn{1}{c|}{ Proteinname } \\
HEMO & Hemopexin \\
HPT_A & Haptoglobin HMW \\
HPT_B & Haptoglobin LMW \\
IGHA1 & Ig alpha-1 chain C region \\
KNG1_A & Kininogen-1 LMW \\
KNG1_B & Kininogen-1 HMW \\
RET4 & Retinol-Binding Protein 4 \\
SAA & Serum Amyloid A Protein \\
TRFE & Serotransferrin \\
TTHY & Transthyretin \\
VTDB & Vitamin D-Binding protein \\
ZA2G & Zinc- $\alpha_{2}$-Glykoprotein \\
AACT & $\alpha_{1}$-Antichymotrypsin \\
\hline
\end{tabular}

Abbildung 36 Relative Expressionsunterschiede (Ratio) der 26 untersuchten Proteine der DIGEAnsätze A-D (vgl. Tabelle 13). Expressionsunterschiede $>2$ und $<0,6$ gelten als signifikant geregelt und sind farbig markiert (Werte: Anhang Abschnitt 10.2.4). 
In den Experimenten $A$ und $B$, die den Vergleich der Pools RA mit OA darstellen, ist nur eine signifikante Regulierung zu erkennen (siehe Abbildung 37). Das Serum Amyloid A Protein ist im Experiment $A$ mit einem relativen Expressionsunterschied von 0,55 beim Pool OA heruntergeregelt. Dieser Expressionsunterschied ist in Experiment $B$ nicht signifikant und beträgt 0,79. In den Experimenten $C$ und $D$ ist es hochsignifikant herunterreguliert mit Quotienten von 0,075 und 0,128 .
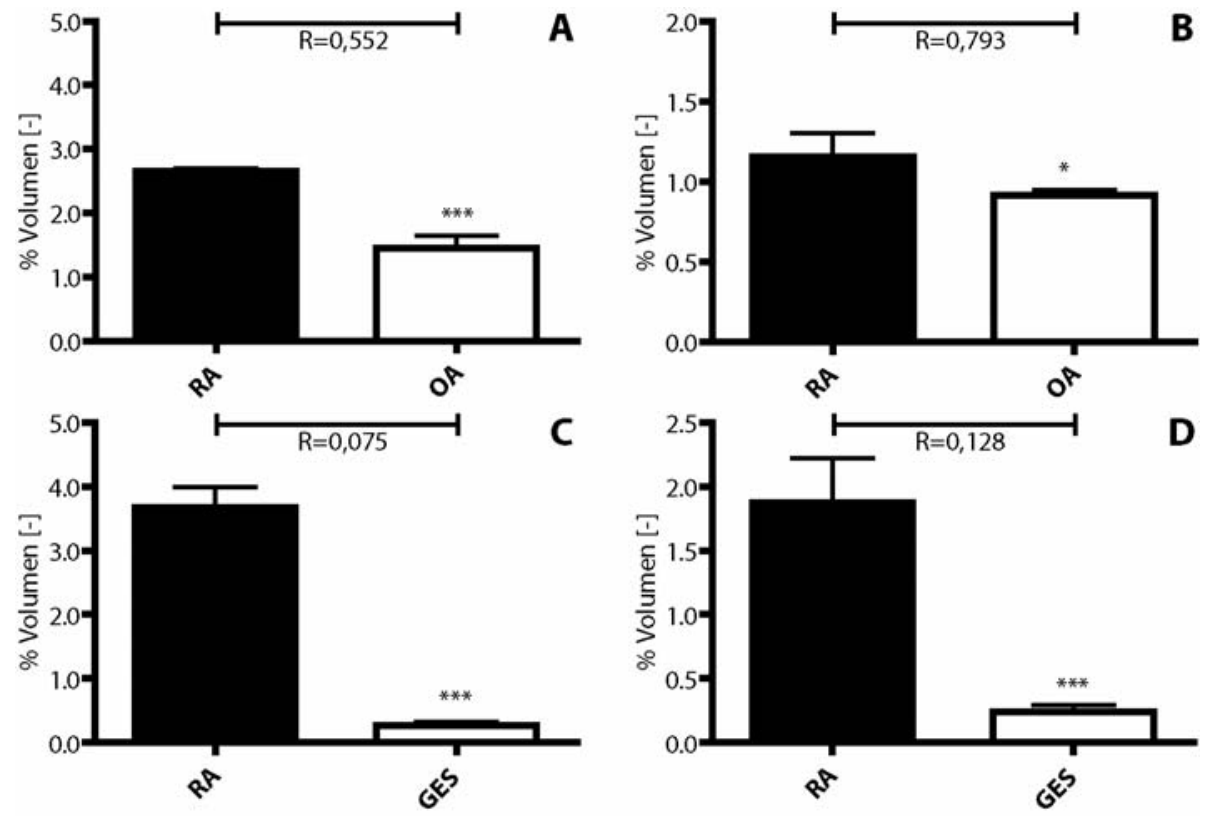

Abbildung 37: Regulationsunterschiede des Serum Amyloid A Proteins (SAA). in den unterschiedlichen DIGE-Experimenten A-D R bezieht sich auf den Quotienten der beiden Mittelwerte und gibt die relativen Expressionsunterschiede an. Ungepaarter t-Test mit folgenden Irrtumswahrscheinlichkeiten: $\left(^{*}\right) p=0,05\left(^{* *}\right) p=0,01\left(^{* * *}\right) p=0,001$.

Beim Experiment $C$ konnten folgende Regulationsunterschiede detektiert werden: Haptoglobin (LMW) $(R=0,549)$, Haptoglobin (HMW) $(R=0,321)$, Apolipoprotein A-IV $(R=0,572)$, Retinol Binding Protein $4 \quad(R=0,191)$, Serum Amyloid A Protein $(R=0,075), \quad \alpha_{1}$ Antichymotrypsin $(R=0,403)$, Serotransferrin $(R=4,367)$ und Vitamin D Binding Protein $(R=2,326)$.

Das Experiment $D$ zeigte insgesamt sechs Regulationsunterschiede in den folgenden Proteinen: Haptoglobin (LMW) $(R=0,506)$, Haptoglobin (HMW) $(R=0,235)$, Retinol Binding Protein $4(R=0,085)$, Apolipoprotein A-IV $(R=0,425)$, Serum Amyloid A Protein $(R=0,128)$, Clusterin $(R=0,466)$ und Serotransferrin $(R=1,951)$. 


\subsubsection{Nachweis von citrullierten Proteinen im humanen Serum}

Der Nachweis von citrullierten Proteinen basiert auf den gleichen Bedingungen und Methoden, für die im Abschnitt 6.2.4 die Kontrollen dargestellt sind.

In Abbildung 38 sind die verschiedene Nachweise aufgeführt, durch die jedoch kein signifikanter Nachweis von citrullierten Proteinen im Serum erbracht werden konnte.

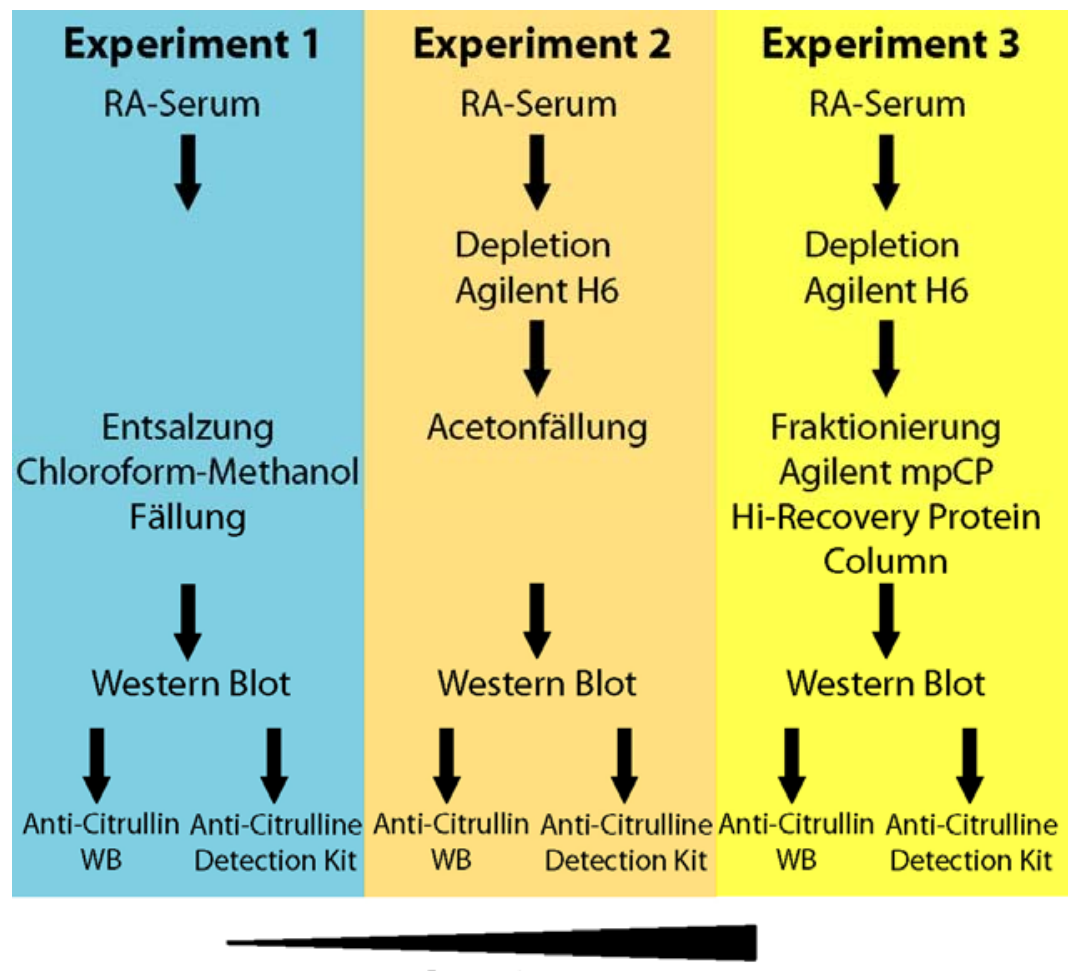

Proteinmenge

Abbildung 38: Experimentelle Ansätze zur Detektion citrullierter Proteine im humanen Serum.

Im ersten Experiment wurde natives, undepletiertes Serum von unterschiedlichen Patienten der Gruppe RA aufgetragen, die vorher mittels der in Abschnitt 5.2.2.2 beschriebenen Chloroform-Methanol-Fällung entsalzt wurden. Da keine citrullierung Proteine nachgewiesen werden konnten, wurde im zweiten Experiment $40 \mu \mathrm{g}$ depletiertes Serum (Agilent Human 6 Depletionssäule) aufgetragen und somit die dynamische Verteilung der aufgetragenen Proteine deutlich erhöht. Es konnten auch in diesem zweiten Experiment keine citrullierten Proteine nachgewiesen werden.

Um die dynamische Verteilung der Proteine nochmals zu erhöhen, wurde depletiertes, fraktioniertes Serum aufgetragen. Zum Einsatz kamen hierbei die Fraktionen der Gradientenelutionsmethode (Abschnitt 5.9.4.2). Es wurde jeweils $40 \mu \mathrm{g}$ Protein pro Fraktion aufgetragen und geblottet. Trotz der drastisch erhöhten relativen Proteinmenge im Vergleich zum ersten Experiment konnten keine citrullierten Proteine nachgewiesen werden. 


\section{Diskussion}

\subsection{Ergebnisteil Synoviale Fibroblasten}

\subsubsection{Methodische Einflüsse auf die Analysen}

Synoviale Fibroblasten gehören neben den synovialen Makrophagen zu den zwei Hauptzelltypen des Pannusgewebes. Im gesunden Stadium eines Gelenkes sind die synovialen Fibroblasten an der Kollagen- und Hyaluronsäureproduktion beteiligt und bilden als Zellverband die Verbindungsmembran (membrana synovialis) zwischen Bindegewebe und Knochen. Es konnte gezeigt werden, dass neben den einwandernden Zellen des Immunsystems auch die synovialen Fibroblasten selbst eine aktive Rolle in der Gelenkzerstörung einnehmen (Migita et al. 2004). Da bisher nicht alle pathologischen Veränderungen dieser Zellen aufgrund der Untersuchungen bekannter Signalkaskaden zu erklären sind, erfolgte in dieser Arbeit eine explorative Analyse des Proteoms dieser Zellen durch 2D-SDS-PAGE.

Die Analysen wurden im Vorfeld durch die Patientenauswahl, die Gewebeentnahme und die anschließenden Bearbeitungsschritte beeinflusst. Es wurde nur Gewebe aus großen Gelenken (Knie, Schulter und Hüfte) gesammelt, da aufgrund der Methodik viel Probe benötigt wurde.

Dies schränkte die Anzahl von möglichen Spendern stark ein. Des Weiteren war die Ausbeute synovialer Fibroblasten je nach Probe sehr unterschiedlich. In den Gelenken von Rheumatikern, die ein sehr fortgeschrittenes Stadium der Krankheit hatten, war nahezu keine Synovia mehr vorhanden. Die Chronifizierung der Krankheit und die damit verbundene langjährige Sekretion von Matrix-Metalloproteasen (MMPs) haben zu einer starken Verschmälerung bzw. zum vollständigen Verlust der membrana synovialis geführt. Viele der Proben führten daher zu einer sehr geringen Zellausbeute und konnten mit dem zur Verfügung stehenden, methodischen Spektrum nicht oder nur unvollständig analysiert werden. Aus diesem Grund konnten die Ergebnisse der 2D-SDS-PAGE bei vier von acht Zelllysaten der RASF durch Western Blots bestätigt werden (Abbildung 21). Bei den fünf Proben der OASF konnte die Validierung durch zwei Lysate erfolgen

Unterschiede der beiden Patientengruppen konnten bereits durch den Verdau der Gewebe festgestellt werden. Nach Verdau der extrazellulären Matrix durch Kollagenase und Dispase zur Freisetzung der Pannuzyten, waren neben den spindelförmigen synovialen Fibroblasten eine Vielzahl runder Monozyten zu erkennen. Die Anteile dieser Zellpopulationen unterschieden sich stark vom Schweregrad der Entzündungsreaktion. Im Fall einer akuten Entzündung war das Gewebe stark durchblutet und wies sehr viele Monozyten auf, die jedoch nicht adhärent wuchsen. 
Da nur das Proteom der synovialen Fibroblasten untersucht werden sollte, musste ausgeschlossen werden, dass die Zellpopulationen nicht durch Anteile weiterer Zellen des Immunsystems verunreinigt waren. Zimmermann et al. bestimmten 2001 die Anteile der Zellpopulationen nach einem solchen Verdau und Kultivierung bis zur dritten Passage mittels FACS. Sie konnten zeigen, dass die Anteile an $\mathrm{CD}^{+}$T-Lymphozyten, CD19 ${ }^{+}$B-Lymphozyten, CD $38^{+}$Plasmazellen, $\mathrm{CD}^{+} 6^{+}$zytotoxischen T-Lymphozyten und $\mathrm{CD} 3^{+}$Dendritischen Zellen nach der dritten Passage insgesamt nur $3 \%$ der Gesamtzellzahl ausmachen (Zimmermann et al. 2001). Die Gefahr der Kontamination der Zelllysate durch die Proteinanteile anderer Zellen ist somit als minimal einzustufen und ermöglichte daher eine gezielte proteomische Betrachtung der Fibroblasten.

Neben den synovialen Fibroblasten sind synoviale Makrophagen und deren Einfluss auf die Pathogenese der RA weit reichend diskutiert worden (Simon et al. 2001). Synoviale Makrophagen sind durch die Ausschüttung proinflammatorischer Zytokine und Chemokine, oder durch Proliferation von Monozyten an den Entzündungsort gelangt. Makrophagen modulieren den Entzündungsprozess, jedoch scheint ihre Rolle in der Chronifizierung der RA eher untergeordnet zu sein (Simon et al. 2001; Bondeson et al. 2006; Szekanecz et al. 2007).

RASF unterscheiden sich stark von Fibroblasten aus gesunden Gelenken. Dieser aktivierte Phänotyp setzt sich aus Änderungen in Wachstumsverhalten (Nakano et al. 2004; Pohlers et al. 2006), Apoptoseverhalten (Pap et al. 2000; Yamanishi et al. 2002) und der Zellmorphologie zusammen. Insbesondere die Sekretion von MMPs (Bradley et al. 2004), Zytokinen und Wachstumsfaktoren (Hoberg et al. 2007; Sakuma et al. 2007; Aicher et al. 2008) unterscheidet die aktivierten RASF von ihren gesunden Vorläufern.

Der aktivierte Phänotyp der RASF ist nicht über eine unbegrenzte Passagenzahl aufrecht zu erhalten. Die Zellen verlieren mit der Zeit ihre rheumatypischen Eigenschaften. Des Weiteren ist mit großen Varianzen des Phänotyps zu rechnen, da es sich bei den Zellpopulationen um Primärzellen handelt, die stark exogen beeinflusst werden können. Aus diesem Grund wurden ausschließlich Zellen nach der dritten Passage untersucht, um möglichst nah an den in vivo Verhältnissen zu bleiben.

\subsubsection{Diskussion der Expressionsunterschiede von HSPB1 und Destrin in RASF}

Die Analyse der synovialen Fibroblasten durch 2D-SDS-PAGE resultierte in Expressionsunterschieden der Proteine Vimentin, $\beta$-Actin, Hitzeschockprotein Beta-1 (HSPB1) und Destrin. Der Expressionsunterschied von HSPB1 konnte durch Western Blot nicht bestätigt werden. Dies könnte durch einen Phosphorylierungsunterschied zu erklären sein. Durch die 
Phosphorylierung wird der pl des HSPB1 verändert. Dies zeigte sich jedoch nur im 2D-Gel und nicht im Western Blot. Das HSPB1 gehört zur Gruppe der Hitzeschockproteine, die in einer Vielzahl von zellulären Prozessen involviert sind. Unter Stresseinwirkung kann das HSPB1 an mehreren Stellen phosphoryliert werden (Faucher et al. 1993; Daub et al. 2008). Sur et al. konnten 2008 in Keratozyten eine Aktivierung des NF-кB-Signalwegs in Abhängigkeit der Expression von HSPB1 nachweisen, die die Produktion von IL-8 und PGE(2) reguliert (Sur et al. 2008). Auf diese Weise könnte das HSPB1 in inflammatorische Prozesse involviert sein. Dies konnte bisher jedoch noch nicht bei den RASF gezeigt werden.

Eine deutlich verstärkte Expression in der Gruppe der RA-Patienten zeigte Destrin. Hierbei handelt es sich um einen Regulator des Zytoskeletts, der für die Depolymerisation der Actinfilamente zuständig ist (Hawkins et al. 1993). Die Bedeutung des Destrins in der RA ist nicht geklärt. Hatanaka et al. konnten 1996 eine sehr starke strukturelle Ähnlichkeit von Destrin mit dem ebenfalls Actin-regulierenden Protein Gelsolin feststellen (Hatanaka et al. 1996). Osborn et al. beschrieben 2008 eine verringerte Konzentration von Gelsolin im Plasma von RA-Patienten (Osborn et al. 2008). Somit könnte Destrin neben Gelsolin eine Rolle in der Bindung extrazellulären Actins spielen, das bei Gewebeverletzungen freigesetzt wird und dem eine proinflammatorische Wirkung zugeschrieben wird. (Erukhimov et al. 2000; Murphy et al. 2003). Ein direkter Zusammenhang mit der RA muss allerdings noch erbracht werden.

\subsubsection{Vimentinfragmente als spezifische Gewebemarker der RA}

Von den Proteinen, die durch Western Blots untersucht wurden, konnten die Expressionsunterschiede von Vimentin eindeutig mittels Western Blot bestätigt werden. Vergleichbar zur Analyse durch 2D-SDS-PAGE zeigten sich hier RA-spezifische Vimentinfragmente bei 45, 30 und $25 \mathrm{kDa}$.

Citrulliertes Vimentin wurde 2004 als Epitop des Anti-SA-Autoantikörpers beschrieben (Vossenaar et al. 2004), der hochspezifisch für die RA ist (Despres et al. 1994; Hayem et al. 1999; Hueber et al. 1999). Dabei ist die Modifizierung des Vimentins essentiell für die Spezifität (De Rycke et al. 2005). Im Folgenden soll erörtert werden, ob es sich bei den Fragmenten um das spezifische SA-Antigen handeln könnte, dessen zelluläre Herkunft bisher nicht geklärt ist.

Abbildung 39 zeigt eine Gegenüberstellung der Western Blot Ergebnisse von Hueber et al. und denen dieser Arbeit. Das SA-Antigen wurde von Hueber et al. partiell aus Lysaten humaner Plazenta aufgereinigt. Anschließend wurde mit Seren von 25 RA-Patienten ein Immunoblot durchgeführt. In Teil A der Abbildung ist das spezifische Bandenmuster des SAAntigens dargestellt, während in Teil B der Western Blot der Lysate von RASF und OASF mit Anti-Vimentin abgebildet ist. 

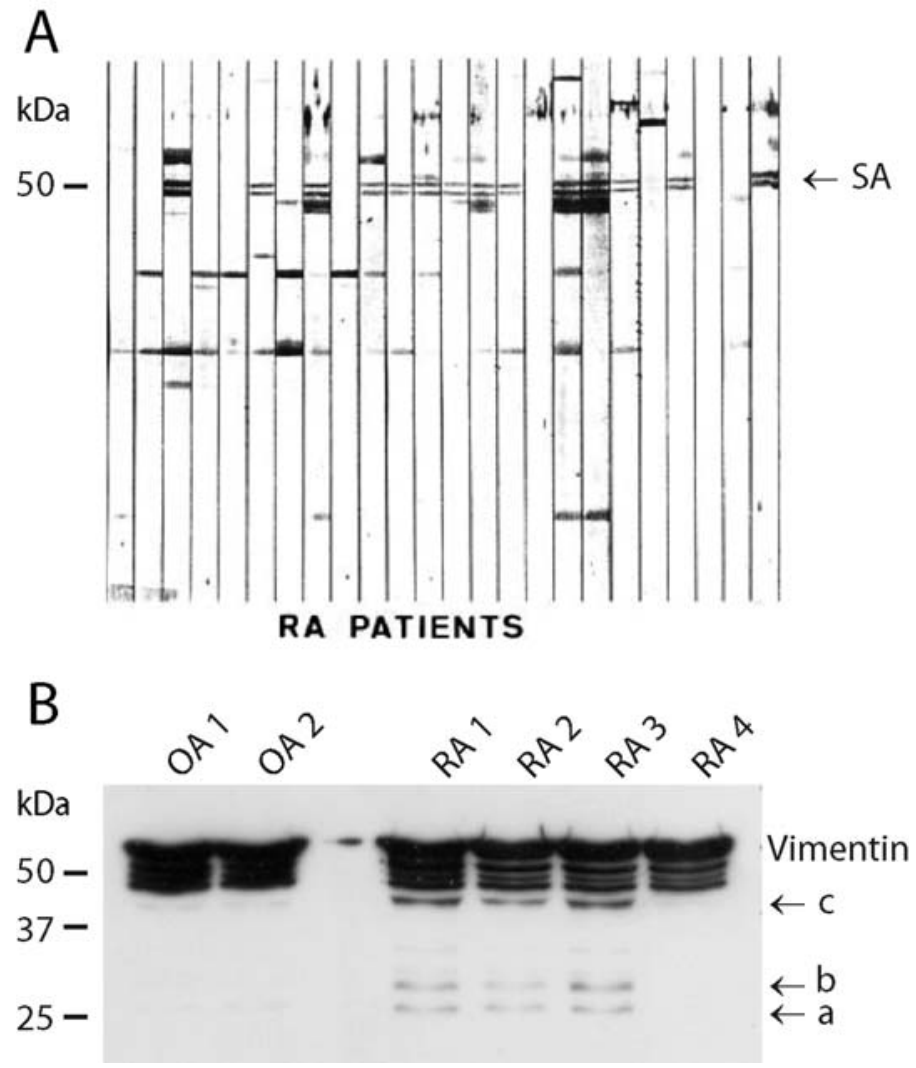

Abbildung 39: Gegenüberstellung des spezifischen Bandenmusters des Anti-SA-Autoantikörpers aus Seren von RA-Patienten (A) und der spezifischen Vimentinfragmente der RASF (B). Abbildung A zeigt einen Western Blot des aufgereinigten SA-Antigens (Größe ca. $50 \mathrm{kDa}$ ) gegen Seren von RA-Patienten. Ausschnitt der Abbildung 1 nach Hueber et al. 1999. Abbildung B zeigt Vimentin Spaltprodukte (a-c) der RASF in vivo (vgl. Ergebnisteil synoviale Fibroblasten, Abbildung 21).

Es sind Parallelen zwischen beiden Blots zu erkennen. Das SA-Antigen, das später als citrulliertes Vimentin identifiziert wurde, weist spezifische Banden auf, deren approximierte Größe im Bereich der Vimentinfragmente liegen, die auch bei den Lysaten der RASF gefunden wurden.

Trotz der Ähnlichkeiten der Fragmentgrößen gibt es Gründe, die gegen die Ähnlichkeit mit dem SA-Antigen sprechen. Zum einen wurde das in Abbildung A dargestellte Bandenmuster in einem teilweise aufgereinigten Lysat von humaner Milz und Plazenta detektiert. Somit ist die spezifische Fragmentierung von Vimentin nicht nur auf synoviale Zellen begrenzt, sondern scheint auch in anderen Geweben vorzukommen. Zum anderen konnte durch den Anti-Citrullin-Detektionskit kein modifiziertes Vimentin in den Lysaten der RASF nachgewiesen werden.

Die Citrullierung von Vimentin ist demnach nicht nur auf die Synovia begrenzt, sondern erfolgt auch in anderen Geweben. Dies wirft die Frage auf, warum citrulliertes Vimentin keine Autoantigenität in diesen Geweben hervorruft und keine Produktion von ACPA mit sich bringt. Da das SA-Antigen in der Plazenta gefunden wurde, müssten bei Autoantigenität von citrulliertem Vimentin auch schwangere Frauen einen erhöhten ACPA-Spiegel aufweisen. Es 
konnten jedoch keine Daten in der Literatur gefunden werden, die diesen Verdacht bestätigen oder widerlegen.

Diese Ergebnisse können allerdings durch die in Abschnitt 7.2 beschriebene Problematik der Detektion citrullierter Proteine beeinflusst worden sein. Der Nachweis von Citrullin in der Aminosäuresequenz von Proteinen ist im Augenblick fast ausschließlich nach vorhergehender Modifizierung über einen Immunoblot möglich. Trotz vielfältiger Bemühungen der Optimierung dieser komplexen Analysemethode konnte kein Nachweis für eine Citrullierung erbracht werden. Wenn es sich jedoch um ein methodisches Artefakt handelt, könnten die Vimentinfragmente sehr gut als Gewebemarker für die RA Verwendung finden. Zur Abklärung dieser Frage bedarf es jedoch einer besseren Methode zur Detektion von Citrullin.

\subsubsection{Die Bedeutung von Vimentin bei Apoptose der RASF}

\subsubsection{Vimentin als anti-apoptotisches Protein}

RASF zeichnen sich im Gegensatz zu den OASF durch eine erhöhte Apoptoseresistenz aus (Mountz et al. 2001). Neben citrulliertem Vimentin als spezifisches Antigen der RA konnte der Einfluss von unmodifiziertem Vimentin bei der Regulation apoptotischer Prozesse und des Zellzyklus bei RASF nachgewiesen werden. Im Folgenden soll der Einfluss des Vimentins auf die so genannte TRAIL-vermittelte Apoptose (uumor necrosis factor-related apoptosis-inducing ligand) diskutiert werden.

Der Einfluss der TRAIL-vermittelten Apoptose konnte bisher in Tumorzellinien gezeigt werden (Wiley et al. 1995). Bei RASF konnte bisher nur eine Abhängigkeit des Rezeptors TRAIL-R2 (auch DR5, death receptor 5 genannt) nachgewiesen werden, jedoch nicht für den TRAIL-R1 (auch unter DR4 bekannt) (Jungel et al. 2006).

Die genaue Regulation der TRAIL-vermittelten Apoptose ist nicht vollständig geklärt. Ein möglicher Regulationsmechanismus besteht in der Expression von p53 (El-Deiry 2001; Wang et al. 2003). So beschrieben Guan et al. 2001 eine Abhängigkeit der Expression des TRAIL-R1 durch p53 (Guan et al. 2001).

Die Expression von intrazellulärem p53-Protein ist durch das Onkoprotein Mdm2 reguliert. Im Fall einer Bindung des Mdm2 wird das p53-Protein ubiquitiniert, wodurch es zu einem schnellen Abbau des p53-Proteins durch das 26S-Proteasom kommt (Daujat et al. 2001; Inoue et al. 2001). Im Fall einer Akkumulation werden von freiem p53-Protein einerseits DNA-Reparatur-Mechanismen in Gang gesetzt und der Zellzyklus gestoppt, andererseits kann auch Apoptose eingeleitet werden (Efeyan et al. 2007). Der genaue Vorgang dieser Regulation ist allerdings bisher ungeklärt.

Neben der Bindung des Mdm2-Proteins kann p53 auch über Bindung mit Vimentin in seiner Verfügbarkeit beeinflusst werden und somit den Zellzyklus und die Apoptose aktiv beeinflus- 
sen. Bei Tumorzellen konnte gezeigt werden, dass p53 und Vimentin miteinander interagieren und dadurch die Resistenz gegenüber Apoptose verstärkt wird (Klotzsche et al. 1998). Yang et al. konnten durch Immunpräzipitation einen Komplex aus Vimentin und p53 bei RASF nachweisen. Des Weiteren konnte gezeigt werden, dass bei Spaltung des spezifischen p53-Vimentin-Komplexes durch Caspase-4 die Apoptoserate in RASF erhöht werden konnte. Bei Blockierung der spezifischen Caspase-Spaltstelle durch den Einsatz eines mutierten Vimentinkonstruktes hatten die RASF eine deutlich erhöhte Apoptoseresistenz bei Stimulation mit TNF- $\alpha$ (Yang et al. 2005).

Pundt et al. konnten überdies eine starke Abhängigkeit der TRAIL-vermittelten Apoptose bei RASF zum Zellzyklus feststellen. RASF, die sich in der S- oder G2/M-Phase befanden, wiesen eine deutlich verringerte Apoptoserate bei Stimulation mit TNF- $\alpha$ auf. RASF, die sich in der G0/G1-Phase befanden, zeigten deutlich höhere Apoptoseraten (Pundt et al. 2009).

Somit könnte Vimentin ein zentrales Element in der Regulation der Apoptose und des Zellzyklus der RASF darstellen. Es kann durch die Bindung den Abbau von p53 Protein modulieren und somit die TRAIL-vermittelte Apoptose durch das Anhalten des Zellzyklus verlangsamen. Die Zelle befindet sich demnach in einem Zwischenstadium der Apoptose und kann diese nicht beenden (siehe Abbildung 40).
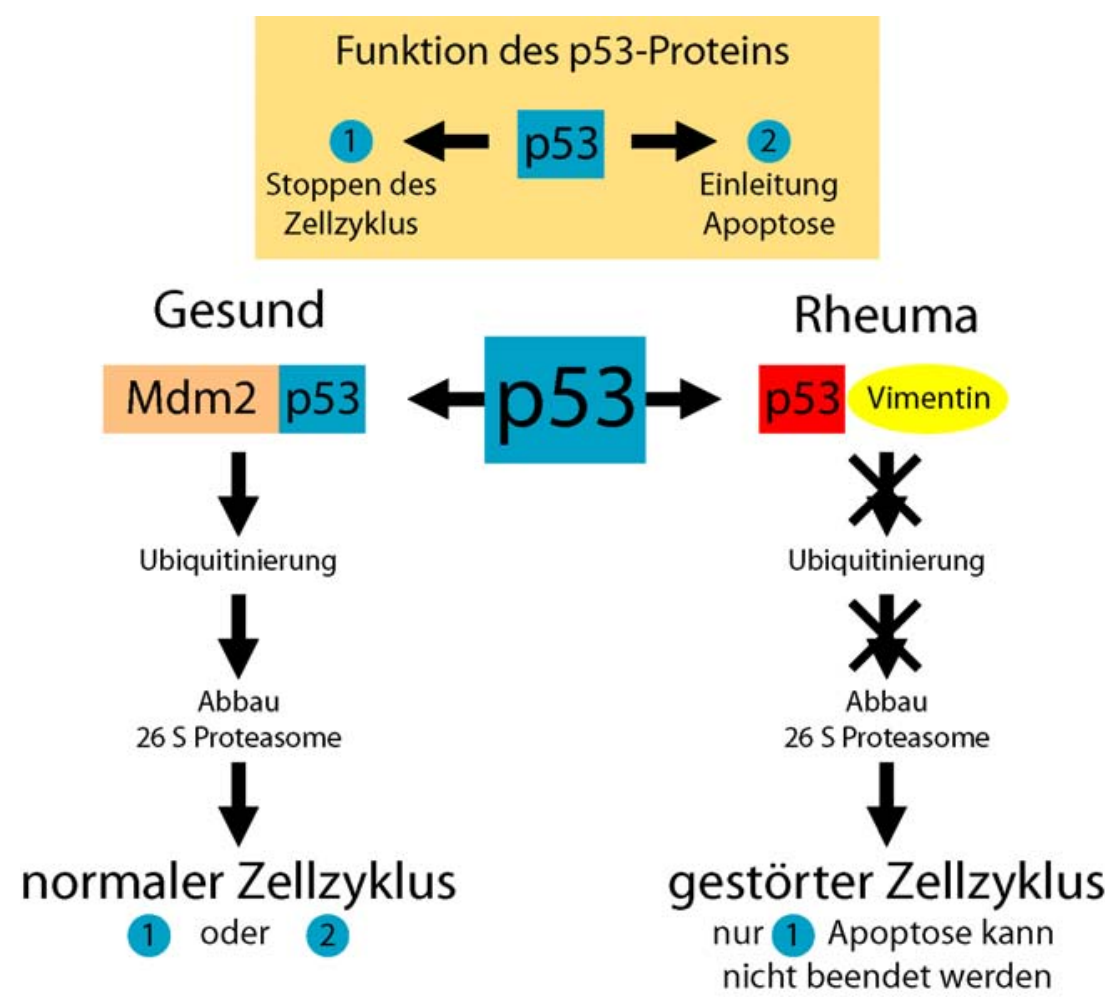

Abbildung 40: Einfluss des p53-Proteins auf die TRAIL-vermittelte Apoptose. Durch die Bildung eines Vimentin-p53-Komplexes kann die Verfügbarkeit von p53 beeinflusst werden. Dies könnte eine Störung des Zellzyklus mit sich bringen und das Apoptoseverhalten modulieren. 
Bei den Vimentinfragmenten, die in den Lysaten der RASF identifiziert wurden, könnte es sich um Intermediärprodukte der Caspase-Kaskade handeln, die nicht vollständig prozessiert wurden und in der zellulären Granula aggregieren. Diese Fragmente könnten Mutationen in ihrer Aminosäuresequenz aufweisen, die die Affinität zum p53 positiv beeinflussen und somit zu einer verstärkten Bildung des Vimentin-p53-Komplex führen. Somit wären die Fragmente unter anderem als Indiz anzusehen, dass die Apoptose in diesen Zellen gestört verläuft.

Es konnte auch auf Seiten des p53-Proteins eine Vielzahl von Mutationen der Aminosäuresequenz bei RA Patienten nachgewiesen werden (Firestein et al. 1997; Yamanishi et al. 2002). Diese Mutationen waren insbesondere bei Fibroblasten zu detektieren, die sich in Regionen mit hoher erosiver Aktivität befanden. Die Änderung der Aminsäuresequenz könnte auch zu veränderten Bindungsaffinitäten des p53 zu Vimentin führen.

In den nachfolgenden Studien sollten daher zur Validierung dieser These Studien über die durch Mutationen veränderten Bindungsverhältnisse von p53 mit Vimentin durchgeführt werden.

In wie weit jedoch die TRAIL-vermittelte Apoptose bei RASF die Pathogenese der RA an sich beeinflusst, bleibt fragwürdig. Es konnten weitere molekulare Mechanismen identifiziert werden, die an der Apoptoseresistenz synovialer Fibroblasten beteiligt sind. Vorrangig zu nennen sind hier die anti-apoptotischen Mediatoren FLIP (FLICE inhibitory protein) und Sentrin (SUMO-1). Dabei bewirkt FLIP die Inhibition des intrazellulären Apoptose induzierenden Enzyms Caspase-8 (Kataoka 2005). In RASF konnte durch Inhibierung von FLIP mit antisense Oligonukleotiden eine Verstärkung der Fas-vermittelten Apoptose bewirkt werden (Palao et al. 2004). Sentrin modifiziert das Leukämieprotein PML und verhindert somit die Freisetzung von DAXX (death-associated protein), was sowohl die Fas- als auch die TNFinduzierte Apoptose inhibiert. Sentrin wurde stark überexprimiert in RASF gefunden (Franz et al. 2000).

Die Analyse der Apoptose bei RASF scheint daher ein aussichtsreiches Forschungsgebiet zu sein, das einen bedeutenden Teil zur Aufklärung der Mechanismen der RA beitragen könnte.

\subsubsection{Vimentin als pro-apoptotisches Protein}

Es gibt jedoch auch Hinweise darauf, dass die detektierten Fragmente des Vimentins die Apoptose fördern. Vimentin wird bei apoptotischen Prozessen durch Caspasen in spezifische Fragmente gespalten. Die Spaltprodukte von Vimentin durch Caspasen in vitro und der Vergleich mit den in vivo Verhältnissen ist in Abbildung 41 dargestellt.

Durch den Vergleich der ermittelten Fragmente von Byun et al. und der Auftragung der Proteinlysate der RASF ergibt sich ein vergleichbares Bandenmuster von Vimentin. Diese 
Fragmente sollten daher bei allen Zellen detektierbar sein, bei denen die Caspase-Kaskade im Rahmen apoptotischer Prozesse aktiviert ist. Byun et al. konnten zunächst durch in vitro Experimente an aufgereinigtem, ${ }^{35}$ S-gelabeltem Vimentin zeigen, dass unter Einfluss der Caspasen 3, 6 und 8 Vimentin am effektivsten proteolytisch gespalten wurde. Bei den Caspasen 3 und 8 wurde Vimentin vorrangig in die Fragmente II und III gespalten, während die Caspase 6 Vimentin hauptsächlich in die Fragmente IV und V spaltete (Blot A). Diese Fragmente konnten bei der Stimulation von HeLa-Zellen mit TNF $\alpha$ und Staurosporin (Apoptose induzierendes Alkaloid des Bakteriums Streptomyces staurosporeus) in vergleichbarer Form nachgewiesen werden (Blot B). Der Vergleich mit den Spaltprodukten des Vimentins bei den RASF (Blot $C$ ) zeigt bei drei von vier Patienten ein ähnliches Muster mit spezifischen Banden bei 25-30 kDa. Es handelt sich bei den Banden höchstwahrscheinlich um Vimentinfragmente, die durch die proteolytische Spaltung durch die Caspasen 3, 6 und 8 entstanden sind.

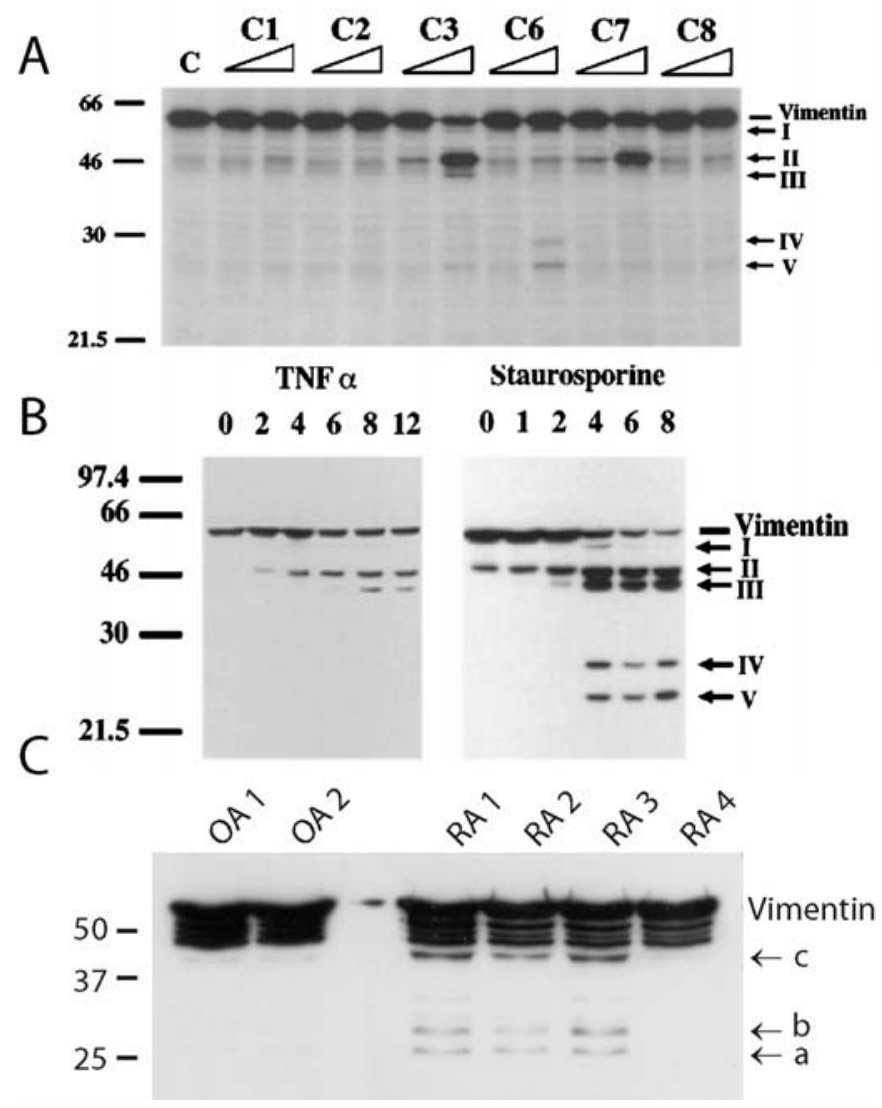

Abbildung 41: Vergleich der spezifischen Vimentin-Spaltprodukte durch Caspasen. (A) Spaltprodukte von Vimentin in vitro durch die Caspasen 1, 2, 3, 6, 7, 8. Es wurden 2,5 bzw. $25 \mathrm{ng}$ pro Ansatz aufgetragen (radiographische Darstellung durch ${ }^{35} \mathrm{~S}$-gelabeltes humanes Vimentin). Spaltprodukte sind durch die Ziffern I-V bezeichnet. (B) Vimentin Spaltprodukte (I-V) in vivo. HeLa-Zellen wurden mit $10 \mathrm{ng} / \mathrm{ml} \mathrm{TNF} \alpha$ bzw. $1 \mu \mathrm{m}$ Staurosporin stimuliert und die Spaltprodukte von Vimentin in verschiedenen Zeitabständen (0, 2, 4, 5, 8, $12 \mathrm{~h}$ ) mittels Western Blot (anti-Vimentin, SIGMA ALDIRCH, 1:1000) analysiert. (C) Vimentin Spaltprodukte der RASF (a-c) in vivo (vgl. Ergebnisteil synoviale Fibroblasten, Abbildung 21). Abbildungen (A) und (B) nach Byun et al. "Caspase cleavage of vimentin disrupts intermediate filaments and promotes apoptosis" Cell Death and Differentiation (2001) 8, 443 - 450. 
Bei den Fragmenten könnte es sich nach Byun et al. um ein amino-terminales Spaltprodukt handeln. Dieses wird als truncated vimentin bezeichnet und kann keine Intermediärfilamente mehr ausbilden (Hofmann et al. 1992). Des Weiteren bildet es granuläre Aggregate in apoptotischen Zellen. Obwohl bisher nicht eindeutig bewiesen, postulieren Byun et al. einen pro-apoptotischen Effekt dieses Fragmentes. Da truncated vimentin in RASF vorkommt und deren Apoptoserate erhöhen soll, ist diese Aussage konträr zu den Beobachtungen, dass RASF apoptoseresistenter sind als normale, nichtaktivierte synoviale Fibroblasten.

\subsection{Detektion citrullierter Proteine}

Die Einführung von Citrullin in Proteine wird posttranslational durch so genannte Peptidylarginindeiminasen (PAD) bewerkstelligt. Diese calciumabhängigen Enzyme katalysieren die Umwandlung des positiv geladenen Arginins zum neutralen Citrullin, was zu einer Änderung der Tertiärstruktur, der Nettoladung und der Bindungsverhältnisse der Wasserstoffbrückenbindungen führen kann (Tarcsa et al. 1996). Bisher sind fünf Isoformen dieser Enzyme bekannt (PAD1-4, PAD6) und in eine Vielzahl regulatorischer Prozesse der Differenzierung und Entwicklung involviert. PAD1 spielt beispielsweise bei der Keratinisierung der Haut eine Rolle (Ishida-Yamamoto et al. 2002), PAD2 bei der Myelinentwicklung (Pritzker et al. 1999), PAD3 bei der Entwicklung und Aushärtung der Haarfollikel (Rogers et al. 1997) und PAD4 bei der Histondeiminierung (Cuthbert et al. 2004). Bisher ist sehr wenig über die Verteilung der Isoformen in unterschiedlichen Geweben und deren potentielle Zielproteine bekannt. Bei der RA konnten aus Synovia Monozyten und Makrophagen gewonnen werden, die vorrangig die Isoformen PAD2 und PAD4 exprimierten (Chang et al. 2005). Diese Enzyme stehen bei der RA im Verdacht durch posttranslationale Modifikation von Proteinen für die Produktion von hochspezifischem Autoantikörper (ACPA, Abschnitt 2.3.2, Seite 7) gegen citrullierte Proteine verantwortlich zu sein.

Bei der RA sind viele Proteine in der Synovia und der Synovialflüssigkeit als citrulliert beschrieben und als Autoantigen klassifiziert worden. Masson-Bessiere et al. konnten mittels Immunohistochemie die Präsenz von deiminierten $\alpha$ - und $\beta$-Ketten von Fibrin in Synovialgewebe nachweisen (Masson-Bessiere et al. 2001). Diese Ergebnisse wurden in einer darauf folgenden Studie bestätigt. Jedoch zeigte sich, dass citrulliertes Fibrin keine alleinige Spezifität für RA hat, da man diese Modifizierung auch in Proteinen der Synovia von Osteoarthritisund Spondylarthropathiepatienten nachweisen konnte (Chapuy-Regaud et al. 2005). Ferner wurden Fibronectin (Chang et al. 2005; Tabushi et al. 2008), Filaggrin (Masson-Bessiere et al. 2000), $\alpha$-Enolase (Kinloch et al. 2005), Epstein-Barr nuclear antigen 1 (EBNA-1) (Pratesi et al. 2006), F-actin capping protein $\alpha-1$ subunit (CapZa-1), Asporin (Matsuo et al. 2006), 
Histonproteine (Wang et al. 2004) und Vimentin (Tabushi et al. 2008) bei der RA als citrulliert beschrieben. Bei all diesen Proteinen handelt es sich um ubiquitär zelluläre Bestandteile.

Citrullierte Proteine nehmen daher bei der RA eine Schlüsselstellung ein, konnten jedoch im Rahmen dieser Arbeit weder im Serum, noch in den Lysaten der synovialen Fibroblasten detektiert werden. Nur anhand eines Kontrollblots mit einer hohen Konzentration von citrulliertem Keratin der Hornhaut konnte überhaupt eine Citrullierung nachgewiesen werden.

Die Detektion von Citrullin erfolgte in zwei verschiedenen Ansätzen. Zunächst wurde versucht, Citrullin in seiner unmodifizierten, nativen Form nachzuweisen. Dabei kam der AntiCitrullin-Antikörper (Biomol) zum Einsatz. Da sich Citrullin nur marginal von Arginin unterscheidet, ist eine spezifische Erkennung des äußerst kleinen Epitops mit Hilfe von immunologischen Methoden sehr unwahrscheinlich. Vielmehr spielen die angrenzenden Aminosäuren eine weitaus bedeutendere Rolle. Daher könnte sich die Spezifität des zuerst verwendeten Antikörpers auf die Erkennung von Hautkeratinen beschränken und nicht auf eine spezifische Citrullierungsstelle im Protein. Da sich im Serum kein Keratin befindet, waren keine positiven Signale auf den Blots erkennbar.

Die Konzentration von Antikörpern gegen citrullierte Proteine war bei den RA-Patienten sehr hoch. Es wurde daher postuliert, dass sich ein unbekanntes, citrulliertes Antigen im Serum befindet. Aus diesem Grund wurde die Spezifität des ersten Antikörpers angezweifelt und die Ergebnisse durch den Anti-Citrullin-Detektionskit (Biomol) überprüft.

Dieser Kit basiert auf einem veränderten Detektionsmechanismus. Die Ureidogruppe der Citrullinseitenkette kann spezifisch modifiziert werden, was in einem deutlich vergrößerten Epitop resultierte. Senshu et al. konnten einen Antikörper gegen das modifizierte Citrullin entwickeln, dessen Spezifität durch enzymatisch deiminierte Histone im Western Blot bewiesen werden konnte (Senshu et al. 1992). Es zeigte sich, dass durch diese Modifikation die Detektion von Citrullin in Proteinen deutlich weniger abhängig von den umgebenden Aminosäuren war.

Die Bedingungen, die die Modifizierungsreaktion mit sich bringt, sind jedoch sehr extrem. Es kamen bei der Modifikation sehr starke Säuren in hohen Konzentrationen zum Einsatz. Neben dem starken Proteinverlust von der Membran besteht daher die Gefahr, dass die Proteine modifiziert oder hydrolysiert wurden. Des Weiteren mangelt es der Methode an einer Kontrolle, die zeigt, ob die Modifizierungsreaktion korrekt und vollständig abgelaufen ist. Ferner gibt die Methode keine Auskunft über den Grad der Modifizierung und die spezifischen Modifizierungsstellen.

Jedoch konnten auch nach Modifikation keine citrullierten Proteine in Serum und Lysaten der synovialen Fibroblasten nachgewiesen werden. Dieses Ergebnis konnte durch die Veränderungen in der Proteinbeladung, Verdünnung des Primärantikörpers und der Dauer der Modifizierungsreaktion nicht beeinflusst werden. 
Da die beiden verwendeten Detektionsmethoden Schwächen aufweisen, kann nicht vollständig ausgeschlossen werden, dass tatsächlich keine citrullierten Proteine vorlagen. Für den Fall, dass die Analysen den tatsächlichen in-vivo Verhältnissen entsprechen, scheinen sich citrullierte Proteine bei der RA nur lokal auf das Gelenk zu begrenzen. Eine Freisetzung der Proteine in das Blut kann somit nicht bestätigt werden.

Eine erhöhte Aktivität der PAD konnte bisher nur bei den einwandernden Makrophagen und Monozyten nachgewiesen werden, jedoch nicht bei synovialen Fibroblasten (Vossenaar et al. 2004; Szekanecz et al. 2007). Dies würde erklären, warum in den Lysaten keine citrullierten Proteine nachgewiesen werden konnten.

Die Aktivität der Makrophagen im Rahmen einer Entzündungsreaktion ist jedoch nicht nur bei der RA zu beobachten. Makrygiannakis et al. konnten 2006 zeigen, dass citrullierte Proteine auch in anderen, chronisch entzündeten Geweben zu detektieren sind (Makrygiannakis et al. 2006).

Zur Klärung, ob es sich bei den vorliegenden Analysen um ein methodisches Artefakt handelt, ist eine genauere Detektionsmethode nötig. Die Massenspektrometrie bietet zur Zeit diverse Möglichkeiten zur Detektion posttranlationaler Modifikationen (Ouvry-Patat et al. 2009). Auf Basis der Massenspektrometrie ist die Detektion von Citrullin in Peptiden nur über eine sehr hohe Auflösung möglich, da sich die molekularen Massen von Arginin $\left(\mathrm{MW}=174,20 \mathrm{~g} \mathrm{~mol}^{-1}\right)$ und Citrullin $\left(\mathrm{MW}=175,19 \mathrm{~g} \mathrm{~mol}^{-1}\right)$ kaum unterscheiden. Ein Masseschift von 1 Da kann zudem durch mehrere Modifikationen zu messen sein (Citrullierung, Amidierung, Deaminierung) und ist folglich nicht spezifisch für ein Peptid im PMF. Holm et al zeigten 2006 eine Methode, in der sie die Detektion citrullierter Proteine im Rahmen der Proteinidentifizierung mittels 1D LC ESI-MS/MS erbrachten (Holm et al. 2006). Durch die Modifikation entsteht ein optisch aktives Peptid, das im Fall einer in sich tragenden modifizierten Citrullinseitenkette spezifisch bei $464 \mathrm{~nm}$ absorbiert. Im Fall eines positiven Signals wäre belegt, dass das Peptid Citrullin enthält. Bisher konnte diese Methode jedoch nicht auf Peptidpools aus tryptischen Verdaus angewendet werden, sondern nur an synthetisch erzeugten Peptiden. Diese Methode stellt dennoch einen Erfolg versprechenden Ansatz zur Detektion citrullierter Proteine dar.

\subsection{Ergebnisteil Serumanalytik}

\subsubsection{Akquirierung der Seren}

Die HUPO (Human Proteome Organisation) verfasste 2005 (Rai et al. 2005) eine Liste von präanalytischen Variablen, um eine Standardisierung in die proteomische Betrachtung von Serum oder Plasma zu bekommen. Generell sollten die Serum- und Plasmaproben aliquotiert werden und die Anzahl der Auf- und Abtauzyklen möglichst gering gehalten werden. Die 
Gabe von Proteaseinhibitoren sollte je nach experimentellem Layout abgewogen werden, da beispielsweise Aprotinin mit der Massenspektrometrie interferiert und PMSF und AEBSF an Proteine binden können (Rai et al. 2005; Tammen et al. 2005; Tammen et al. 2005; WestNielsen et al. 2005). Im Vergleich zu Serum enthält Plasma antikoagulatorische Substanzen wie Heparin, EDTA oder Natriumcitrat. Die Zugabe von EDTA resultiert in einem geringeren proteolytischen Abbau ex vivo und wird daher für die proteomische Betrachtung präferiert. Allerdings wird dieser Aspekt noch kontrovers diskutiert (Baumann et al. 2005). In der klinischen Routineanalytik wird jedoch fast ausschließlich mit Serum gearbeitet, wie auch in der vorliegenden Arbeit.

Durch den proteolytischen Abbau, der durch die fehlende Zugabe von Proteasehemmern, durch die Verwendung von Serum anstelle von Plasma (EDTA) oder durch die unterschiedlichen Standzeiten des Serums bei der Abnahme entstanden ist, können eine Vielzahl von Ergebnissen beeinflusst worden sein. Die in Abschnitt 6.3.5 beschriebene Fraktionierung von depletiertem Serum weist durchweg eine geringe Spotdichte auf. Durch die vielen Bearbeitungsschritte und die langen Standzeiten der einzelnen Fraktionen während und nach der Fraktionierung kann es schon im Vorfeld der Experimente zu einem Verlust von low abundant Proteinen durch proteolytischen Abbau gekommen sein. Gleiches gilt auch für die geringe Anzahl unterschiedlich regulierter Proteine bei dem Vergleich der Patientengruppen RA und OA in Abschnitt 6.3.6.

\subsubsection{Methodenoptimierung}

Wie aus der Auftragung von undepletiertem Serum (Abbildung 23) ersichtlich, ist für die Analyse des Serumproteoms eine Aufarbeitung in Form von Fraktionierung oder Depletion zwingend erforderlich, da wenige Proteine dargestellt werden konnten. Diese Proteine (Albumin, Transferrin, Haptoglobin, Antitrypsin, Apolipoprotein A-1, Antitrypsin) kommen in großen Quantitäten im Serum vor und können aufgrund ihrer Konzentrationsschwankungen im Patientenkollektiv nicht als Biomarker verwendet werden. Wie bereits im Einleitungsteil erwähnt wurde, stellt die Abreicherung der high abundant Proteine die zur Zeit aussichtsreichste Technologie für die Biomarkerfindung dar. Es kamen hier zwei MARCs zum Einsatz, die in den Experimenten deutliche Unterschiede in ihren Depletionsleistungen erzielten. Die Agilent Human 6 erwies sich schon bei der Flüssigkeitschromatographie der Beckman Coulter IgY12 LC2 als überlegen, da sie eine deutlich schärfere Trennung aufwies. Dies ist unter anderem auf die hochwertigeren Säulenmaterialien (PEEK bei Agilent, PS bei Beckman Coulter) und das Chromatographiematerial zurückzuführen, das deutlich weniger Proteine bindet. Den Vorteil der Verwendung des IgY-Systems der Beckman Coulter, das in deutlich weniger Kreuzreaktionen resultieren sollte, konnte nicht beobachtet werden. Insbesondere die Abreicherung der IgG ist mit der Proteome Lab IgY12-Säule deutlich schlechter. 
Des Weiteren konnte durch die Abreicherung der weiteren Proteine (vgl. Abbildung 26) keine signifikante Verbesserung der Visualisierung der low abundant Proteine erreicht werden.

Bei der Probenaufarbeitung durch Fällung des depletierten Serums stellte sich die Acetonfällung als die einfachste und reproduzierbarste Methode mit der größten Spotabdeckung dar. Die Entsalzung und Aufkonzentrierung mit Hilfe der Chloroform-Methanol-Extraktion nach Wessel et al. ist durch ihr geringes Probenvolumen von maximal $100 \mu$ l beschränkt. Des Weiteren erweist sich die daher notwendige Ankonzentrierung des Depletats durch Ultrafiltration (Vivaspin-Konzentratoren) als sehr aufwendig. Die Spotabdeckung ist insbesondere im sauren pH-Bereich deutlich schlechter als bei anderen Methoden (z. B. Acetonfällung).

Die Entsalzung durch die Agilent high recovery protein column erwies sich als eine apparativ aufwendige Methode, die jedoch in einer guten Spotabdeckung resultierte. Die Beschränkung der Säulenkapazität von $380 \mu$ g Protein pro Lauf und die lang andauernde Einengung der Probe im Lyophilisator macht diese Methode für die Analyse durch 2D-SDS-PAGE jedoch nicht sehr attraktiv.

Bei der Probenvorbereitung sind generell Methoden vorzuziehen, die nur wenige Bearbeitungsschritte benötigen und eine gute Proteinausbeute aufweisen. Die Acetonfällung erweist sich daher als die Methode, die vorrangig in dieser Arbeit zum Einsatz kam.

\subsubsection{Identifizierungen der Proteine im depletierten Serum und deren Rolle in der Pathogenese der RA}

Nach der Depletion mit Hilfe der Agilent Human 6 und anschließender Fällung konnten im Serum durch 2D-SDS-PAGE 103 Proteine nachgewiesen werden (vgl. Abschnitt 10.2.2). Durch die Abreicherung der sechs häufigsten Proteine konnte die Anzahl der visualisierten Proteine drastisch erhöht werden.

Serum hat eine extreme Verteilungscharakteristik der Proteinkonzentrationen. Albumin macht fast $50 \%$ des gesamten Proteingehaltes aus, während einige Zytokine oder andere Botenstoffe nur in Spuren vorkommen. Es soll daher zunächst geklärt werden, ob in dem dargestellten Konzentrationsbereich ein möglicher Biomarker detektierbar ist.

Die Depletion durch eine MARC erwies sich bei der Abreicherung der high abundand Proteine als sehr zuverlässig. In den Depletaten war nahezu kein Albumin mehr zu detektieren. Auch die Abreicherung der Immunglobuline war sehr gut. Die Spotanzahl konnte im Vergleich zum undepletierten Serum deutlich gesteigert werden.

Einige der visualisierten Proteine sind bisher schon als Biomarker für die RA diskutiert. Darunter ist das Gelsolin. Dieses Actin-bindende Protein ist in der Aufrechterhaltung der Zellmorphologie, Beweglichkeit und in apoptotischen Prozessen involviert. Eine extrazelluläre Gelsolin-Isoform kann im Plasma in Konzentrationen von 200-250 mg/l nachgewiesen 
werden. Osborn et al. konnten 2008 durch ELISA zeigen, dass Plasmakonzentrationen von Gelsolin bei RA-Patienten deutlich herabgesetzt waren (Osborn et al. 2008). Devauchelle et al. konnten 2004 durch RT-PCR und DNA Micoarrays eine deutliche Verminderung der Expression von Clusterin in Synovialgewebe von RA-Patienten nachweisen (Devauchelle et al. 2004). Rossol et al. konnten 2005 eine deutlich verringerte Expression von Apolipoprotein A-I bei RA-Patienten nachweisen (Bierther et al. 1974; Devauchelle et al. 2004; Rossol et al. 2005). Das S100A8 Protein wurde von Uchida et al. 2002 durch SELDI-TOF sowohl in der Synovialflüssigkeit als auch im Serum als hochreguliert beschrieben.

Diese Proteine konnten auch in dieser Arbeit detektiert werden und bestätigen, dass die Methodik und der dargestellte Konzentrationsbereich zur Auffindung eines Biomarkers herangezogen werden kann. Es konnte aber keine signifikante Regulierung dieser Proteine im Rahmen dieser Arbeit erbracht werden.

Allerdings zeigte dieser proteomische Ansatz auch Schwächen auf. Es konnte nicht auf die Spezifität der Immunglobuline geschlossen werden. Gerade bei Autoimmunkrankheiten wie der RA ist die Präsenz eines Autoantikörpers (Rheumafaktor, Anti-SA, Anti-CCP, Anti-MCV) hochspezifisch für die Krankheit. Aufgrund der Denaturierung der Antikörper durch die Fällung ist keine Klassifizierung und genaue Determination des Paratops mehr möglich.

Eine immunologische Ausrichtung eines proteomischen Ansatzes wäre dennoch in anderer Weise möglich. Durch die Bindung eines spezifischen Antikörpers oder Antigens an eine Säule wird eine spezifische Immunaffinitätssäule erstellt. Ähnlich zu MARCs, jedoch spezifischer auf die Fragestellung ausgerichtet, kann die Säule selektiv zur Anreicherung der Bindungspartner aus dem Serum oder Plasma benutzt werden. Als Beispiel kann die spezifische Analyse von Glykoproteinen genannt werden, die mit Hilfe von Lektinen spezifisch angereichert werden können (Liu et al. 2005; Ramachandran et al. 2006). Durch Kombination unterschiedlicher Immunaffinitätssäulen würde die Komplexität des aufzutrennenden Proteingemisches herabgesetzt werden.

\subsubsection{Untersuchung des depletierten und fraktionierten Serums}

Durch den Einsatz der MARCs konnte eine deutlich bessere Visualisierung der Serumproteine erreicht werden. Die Fraktionierung sollte anschließend eine noch bessere Trennung und Darstellung weiterer low abundand Proteine erzielen. Es wurden zur Trennung zwei verschiedene Methoden entwickelt.

Die Auftrennung der Serumproteine konnte durch die Fraktionierung mit der Agilent high recovery protein column nicht verbessert werden. Insbesondere die Standardisierung des HPLC-Laufs stellte ein schwerwiegendes Problem dar. Wie aus Abbildung 30 ersichtlich wird, kam es im Rahmen der Gradiententrennung zu massiven Veränderungen der Retentionszeiten. Die Auftrennung mittels Stufengradienten brachte mehr Standardisierung, jedoch 
überzeugte die Auftragung der Fraktionen auf 2D-Gele hinsichtlich der Gelqualität und der gebotenen Spotanzahl nicht (vgl. Abbildung 32 und 33). Wie aus Tabelle 12 ersichtlich wird, konnten durch die Fraktionierung keine weiteren Proteine im Vergleich zum depletierten Serum nachgewiesen werden. Des Weiteren waren die meisten Proteine deutlich schlechter fokussiert.

Die Verarbeitung des Serums benötigte eine Vielzahl von weiteren Bearbeitungsschritten. Aufgrund von Adsorption an den Gefäßwandungen und saurer Hydrolyse von Proteinen $(\mathrm{pH}$ $2.5,80^{\circ} \mathrm{C}$ ) ist es eventuell zu einem hohen Proteinverlust gekommen. Diese methodischen Unzulänglichkeiten belegen, dass die Säule Schwächen im Bereich der semipräparativen Serumfraktionierung hat. Diese liegen vor allem bei der geringen Kapazität von $380 \mu \mathrm{g}$ Protein pro Lauf und den umständlichen Einengungsschritten. Ihre Eigenschaften als Entsalzungssäule hingegen sind deutlich besser. Spotausbeute und -abdeckung sind nahezu vergleichbar zur Acetonfällung.

Die Fraktionierung wurde daher nicht weiter verfolgt. Es wurde sich auf die Analyse der Seren mittels DIGE konzentriert.

\subsubsection{Untersuchungen der DIGE-Gele}

Den aussichtsreichsten Ansatz dieser Arbeit zur Analyse des Serumproteoms mittels 2DSDS-PAGE stellte die DIGE-Technologie dar (differential in gel eletrophoresis), da durch sie die Laufunterschiede im Vergleich zur konventionellen 2D-SDS-PAGE minimiert werden konnten.

Plasma, Serum und andere Körperflüssigkeiten haben einen hohen Anteil an modifizierten Proteinen, die in einem sehr komplexen Spotpattern resultieren. Aufgrund der starken Laufunterschiede sind diese Gele nur schwer vergleichbar. Die Quantifizierung ist kaum möglich und resultiert meist in einer geringen Signifikanz und hohen Standardabweichungen. Doch gerade die posttranslationalen Modifizierungen machen diese Methode sehr attraktiv. Änderungen der Proteine durch Glykosylierung, Phosphorylierung, Degradation oder Isoformen durch alternatives Spleißen lassen sich sehr gut darstellen. DIGE schafft daher den Brückenschlag zwischen der Visualisierung posttranslationaler Modifikationen, guter Reproduzierbarkeit und Quantifizierbarkeit. (Minden 2007; Timms et al. 2008)

In diesem Projekt konnte durch DIGE beim Vergleich der depletierten Seren der Gruppen RA und $\mathrm{OA}$ ein Protein identifiziert werden, bei dem eine signifikante Herunterregulation bei der Gruppe OA zu verzeichnen war (vgl. Abbildung 37). Das Serum Amyloid A Protein (SAA) gehört zur Gruppe der Apolipoproteine und wird zu den Akute-Phase-Proteinen gezählt (O'Brien et al. 2006). Im Rahmen einer Entzündungsreaktion wird es von der Leber produziert und sezerniert. Bei kontinuierlicher Ausschüttung dieser Proteine durch Chronifizierung einer entzündlichen Krankheit wie der RA kommt es zu Ablagerungen und Aggregatbildung 
in einer Vielzahl von Geweben und Organen (Nakamura 2008). Diese Merkmale werden unter dem Krankheitsbegriff Amyloidose zusammengefasst. Amyloidose kommt bei RAPatienten sehr häufig vor und kann durch die Gabe eines TNF- $\alpha$-Antagonisten (Etanercept, Embrel $^{\circledR}$ ) behandelt werden, da die Ausschüttung von SAA maßgeblich durch TNF- $\alpha$ und IL1 reguliert wird (Nakamura et al. 2007; Nakamura 2008; Pettersson et al. 2008).

SAA scheint darüber hinaus selbst in die Pathogenese der RA einzugreifen. Koga et al. konnten zeigen, dass SAA die IL-6-Produktion bei RASF induziert (Koga et al. 2008). Okamato et al. bestätigten diese Beobachtung und konnten eine Stimulierung des NFKBSignalwegs durch Bindung des SAA an den Rezeptor für advanced glycation end products (RAGE) feststellen (Okamoto et al. 2008). Durch Stimulation mit rekombinantem SAA konnte in RASF die Produktion von MMPs induziert werden (Migita et al. 1998; O'Hara et al. 2004). Des Weiteren konnte gezeigt werden, dass SAA aktiv von RASF produziert wird (Kumon et al. 1999; O'Hara et al. 2000; Vallon et al. 2001) und dass die Expression in starker Abhängigkeit vom IL-18 steht (Tanaka et al. 2004). Durch die Expression und Ausschüttung von SAA konnten Mullan et al. belegen, dass SAA die Produktion von VCAM-1 (vascular cell adhesion molecule 1) und ICAM-1 (intercellular adhesion factor molecule 1) induziert. Dies führt zur Gefäßbildung im Pannusgewebe und trägt zur Infiltration von Immunzellen bei (Mullan et al. 2006).

All diese Arbeiten belegen, dass dem SAA in der RA eine bedeutende Rolle zugeschrieben wird. Es ist jedoch fraglich, in wie weit diese Interaktionen ausschließlich auf die RA bezogen werden können und ob daher SAA als spezifischer Biomarker der RA anzusehen ist. SAA als Akute-Phase-Protein unterliegt generell einer massiven Regulation während Entzündungsreaktionen. Somit ist SAA auch während der akuten Entzündungsphase bei anderen, degenerativen Formen des Gelenkrheumas messbar. De Seny et al. konnten auf Basis der SELDITechnologie keine messbaren Unterschiede des Serum-SAA-Spiegels bei Patienten mit RA, Psoriasis-Arthritis und Spondylitis ankylosans nachweisen (de Seny et al. 2008). Kokubun et al. verwiesen auf große Schwankungen der SAA-Konzentration bei RA-Patienten und schlugen die Normierung des SAA-Wertes mit CRP vor (Kokubun et al. 2005).

Neben der RA ist SAA bei diversen Krebsarten durch Proteomanalysen als serotologischer Marker beschrieben worden. Beim Lungenkarzinom konnte auf Basis von AntikörperMikroassays (Gao et al. 2005) und MALDI-TOF (Howard et al. 2003) SAA als Marker identifiziert werden, beim Prostatakarzinom auf Basis von SELDI-TOF (Le et al. 2005), beim Ovarkarzinom auf Basis von SELDI-TOF (Moshkovskii et al. 2005), beim Pankreaskarzinom auf Basis von SELDI- und MALDI-TOF (Koomen et al. 2005; Yokoi et al. 2005). und beim Nierenzellkarzinom durch SELDI-TOF (Rossi et al. 2006). Des Weiteren konnte mittels SELDI-TOF eine Korrelation vom SAA-Spiegel und der Metastasierung bei Hirntumoren hergestellt werden (Combaret et al. 2005). Beim Magenkarzinom konnte im Serum von 
Mäusen, die mit Krebszellen infiziert wurden, mittels 2D-SDS-PAGE im Serum erhöhte SAAWerte nachgewiesen werden (Juan et al. 2004).

SAA wird zur Zeit in den unterschiedlichsten medizinischen Fachgebieten als serotologischer Marker diskutiert. Der Einfluss des SAA auf die Pathologie der unterschiedlichen Krankheiten ist in jedem Fachgebiet hinreichend belegt und diskutiert. Somit stellt SAA ein Protein dar, das man bei erhöhtem Spiegel als Indiz für eine krankhafte Veränderung ansehen kann. Jedoch scheint SAA zu unspezifisch, um es als Frühdiagnosemarker für die RA einzusetzen. Dennoch können deutlich erhöhte SAA-Spiegel in Kombination mit den restlichen rheumaspezifischen Parametern zur Sicherung einer Diagnose helfen.

Zur Validierung der Methodik und Ergebnisse wurden in den DIGE-Ansätzen C und D (siehe Tabelle 13) das Serum der RA-Patienten mit Serum gesunder Kontrollpatienten verglichen. Dabei erwiesen sich die Spiegel von Tranferrin bei gesunden Patienten als deutlich erhöht, während die Spiegel des Serum Amyloid A Proteins, Haptoglobins und Apolipoproteins A4 deutlich erniedrigt waren. Diese Ergebnisse entsprechen den erwarteten Regulationsunterschieden im Rahmen einer chronischen Entzündungsreaktion (Ritchie et al. 1999; Ritchie et al. 2000) und können somit als Bestätigung der Methodik angesehen werden. 


\section{Zusammenfassung}

Auf Basis der Proteomanalyse wurden in dieser Arbeit zwei Ansätze verfolgt, um einen Biomarker für die Früherkennung der rheumatoiden Arthritis zu finden.

Im ersten Ansatz wurden die pathologisch veränderten, aktivierten synovialen Fibroblasten (RASF) mit den nichtaktivierten Fibroblasten von Arthrosepatienten (OASF) verglichen und unterschiedlich exprimierte Proteine identifiziert. Da die Citrullierung von Proteinen sehr spezifisch für die RA ist, wurden die Lysate der RASF und OASF auf diese Modifikation untersucht, um nähere Informationen über dessen zellulären Ursprung zu erhalten.

Durch 2D-SDS-PAGE konnten unterschiedliche Expressionsmuster des IntermediärfilamentProteins Vimentin detektiert und mittels Western Blot bestätigt werden. Diese spezifischen Proteinfragmente wurden ausschließlich in den Zelllysaten der RASF detektiert.

Es wird zur Zeit ein Autoantikörper gegen mutiertes, citrulliertes Vimentin als diagnostischer Früherkennungsmarker diskutiert. Daher wurde zunächst erörtert, ob es sich bei den Fragmenten des Vimentins um das spezifische Antigen handelt, das von diesem Autoantikörper erkannt wird. Es konnten jedoch keine citrullierten Proteine in den Lysaten der RASF nachgewiesen werden. Daher konnte kein Beleg dafür gefunden werden, dass der zelluläre Ursprung des Antigens in den RASF zu finden ist.

Neben der Aufrechterhaltung der Zellmorphologie hat Vimentin Einfluss auf eine Vielzahl anderer zellulärer Prozesse. Dabei wurde auf die Interaktion mit dem p53-Protein fokussiert und erörtert, welchen Einfluss dies auf die erhöhte Apoptoseresistenz der RASF gegenüber den OASF hatte.

Im zweiten Ansatz erfolgte eine Proteomanalyse humanen Serums. In depletierten Seren von RA-Patienten konnte durch DIGE eine erhöhte Konzentration des Serum Amyloid A Proteins (SAA) nachgewiesen werden. Dabei war der Expressionsunterschied nur nach Depletion mit der Agilent Human 6 Depletionssäule statistisch signifikant.

Das SAA-Protein zeigt bei der Pathogenese der RA zahlreiche Interaktionen. Es reguliert unter anderem die Expression von proinflammatorischen Zytokinen, Matrix-Metalloproteasen (MMPs), fördert die Angiogenese und stimuliert die Expression von Adhäsionsmolekülen, die zur Infiltration des Gewebes durch die Zellen des Immunsystems beitragen.

Dennoch wird eine Erhöhung der SAA-Konzentration im Serum bei einer Vielzahl anderer entzündlicher Krankheiten und bei mehreren Karzinomen beobachtet. Die Erhöhung der SAA-Konzentration im Serum bei RA-Patienten ist wahrscheinlich auf die deutlich längere Persistenz der Krankheit im Vergleich zur Osteoarthritis zurück zu führen.

Im Serum konnten des Weiteren keine citrullierten Proteine nachgewiesen werden. Das spezifische Antigen, das die Produktion der ACPA zur Folge hat, ist demnach nicht im Serum zu finden. 


\section{Literaturverzeichnis}

Aebersold, R. and M. Mann (2003). "Mass spectrometry-based proteomics." Nature 422(6928): 198-207.

Agrawal, S., R. Misra, et al. (2007). "Autoantibodies in rheumatoid arthritis: association with severity of disease in established RA." Clin Rheumatol 26(2): 201-4.

Ahmed, N., G. Barker, et al. (2003). "An approach to remove albumin for the proteomic analysis of low abundance biomarkers in human serum." Proteomics 3(10): 1980-7.

Aicher, W. K., T. Pap, et al. (2008). "[Laminin-dependent inflammatory response in synovial fibroblasts of rheumatoid arthritis patients]." Z Rheumatol 67(1): 59-61.

America, A. H. and J. H. Cordewener (2008). "Comparative LC-MS: a landscape of peaks and valleys." Proteomics 8(4): 731-49.

Anderson, L. (2005). "Candidate-based proteomics in the search for biomarkers of cardiovascular disease." J Physiol 563(Pt 1): 23-60.

Anderson, N. L. and N. G. Anderson (2002). "The human plasma proteome: history, character, and diagnostic prospects." Mol Cell Proteomics 1(11): 845-67.

Arnett, F. C., S. M. Edworthy, et al. (1988). "The American Rheumatism Association 1987 revised criteria for the classification of rheumatoid arthritis." Arthritis Rheum 31(3): 315-24.

Baggerman, G., E. Vierstraete, et al. (2005). "Gel-based versus gel-free proteomics: a review." Comb Chem High Throughput Screen 8(8): 669-77.

Baumann, S., U. Ceglarek, et al. (2005). "Standardized approach to proteome profiling of human serum based on magnetic bead separation and matrix-assisted laser desorption/ionization time-of-flight mass spectrometry." Clin Chem 51(6): 973-80.

Becker, S., L. H. Cazares, et al. (2004). "Surfaced-enhanced laser desorption/ionization timeof-flight (SELDI-TOF) differentiation of serum protein profiles of BRCA-1 and sporadic breast cancer." Ann Surg Oncol 11(10): 907-14.

Bennett, J. C. (1973). "The role and character of immunoglobulins in rheumatoid inflammation." Fed Proc 32(2): 138-42.

Berndt, P., U. Hobohm, et al. (1999). "Reliable automatic protein identification from matrixassisted laser desorption/ionization mass spectrometric peptide fingerprints." Electrophoresis 20(18): 3521-6.

Bernhard, J. u. V., P. M. (2001). "Rheumatoide Arthritis: Pathogenese und

Pathologie." Schweiz Med Forum 8: 179-183.

Berth, M., F. M. Moser, et al. (2007). "The state of the art in the analysis of two-dimensional gel electrophoresis images." Appl Microbiol Biotechnol 76(6): 1223-43.

Bierther, M. and R. Wagner (1974). "[Electron microscope studies of the pannus in rheumatoid arthritis]." Z Rheumatol 33(1): 32-42.

Bjorhall, K., T. Miliotis, et al. (2005). "Comparison of different depletion strategies for improved resolution in proteomic analysis of human serum samples." Proteomics 5(1): 307-17.

Bondeson, J., S. D. Wainwright, et al. (2006). "The role of synovial macrophages and macrophage-produced cytokines in driving aggrecanases, matrix metalloproteinases, and other destructive and inflammatory responses in osteoarthritis." Arthritis Res Ther 8(6): R187.

Bonneville, M., E. Scotet, et al. (1998). "Epstein-Barr virus and rheumatoid arthritis." Rev Rhum Engl Ed 65(6): 365-8.

Boschetti, E. and P. Giorgio Righetti (2008). "Hexapeptide combinatorial ligand libraries: the march for the detection of the low-abundance proteome continues." Biotechniques 44(5): 663-5.

Boschetti, E., L. Lomas, et al. (2007). "Romancing the "hidden proteome", Anno Domini two zero zero seven." J Chromatogr A 1153(1-2): 277-90.

Boschetti, E. and P. G. Righetti (2008). "The ProteoMiner in the proteomic arena: a nondepleting tool for discovering low-abundance species." J Proteomics 71(3): 255-64. 
Bradford, M. M. (1976). "A rapid and sensitive method for the quantitation of microgram quantities of protein utilizing the principle of protein-dye binding." Anal Biochem 72: 248-54.

Bradley, K., J. C. Scatizzi, et al. (2004). "Retinoblastoma suppression of matrix metalloproteinase 1, but not interleukin-6, through a p38-dependent pathway in rheumatoid arthritis synovial fibroblasts." Arthritis Rheum 50(1): 78-87.

Burrage, P. S., K. S. Mix, et al. (2006). "Matrix metalloproteinases: role in arthritis." Front Biosci 11: 529-43.

Cantaert, T., L. De Rycke, et al. (2006). "Citrullinated proteins in rheumatoid arthritis: crucial...but not sufficient!" Arthritis Rheum 54(11): 3381-9.

Castagna, A., D. Cecconi, et al. (2005). "Exploring the hidden human urinary proteome via ligand library beads." J Proteome Res 4(6): 1917-30.

Chang, X., R. Yamada, et al. (2005). "Citrullination of fibronectin in rheumatoid arthritis synovial tissue." Rheumatology (Oxford) 44(11): 1374-82.

Chang, X., R. Yamada, et al. (2005). "Localization of peptidylarginine deiminase 4 (PADI4) and citrullinated protein in synovial tissue of rheumatoid arthritis." Rheumatology (Oxford) 44(1): 40-50.

Chapuy-Regaud, S., M. Sebbag, et al. (2005). "Fibrin deimination in synovial tissue is not specific for rheumatoid arthritis but commonly occurs during synovitides." $\underline{\mathrm{J} \text { Immunol }}$ 174(8): 5057-64.

Chen, G., T. G. Gharib, et al. (2003). "Protein profiles associated with survival in lung adenocarcinoma." Proc Natl Acad Sci U S A 100(23): 13537-42.

Cho, S. Y., E. Y. Lee, et al. (2005). "Efficient prefractionation of low-abundance proteins in human plasma and construction of a two-dimensional map." Proteomics 5(13): 338696.

Combaret, V., C. Bergeron, et al. (2005). "Protein chip array profiling analysis of sera from neuroblastoma patients." Cancer Lett 228(1-2): 91-6.

Cuthbert, G. L., S. Daujat, et al. (2004). "Histone deimination antagonizes arginine methylation." Cell 118(5): 545-53.

Daub, H., J. V. Olsen, et al. (2008). "Kinase-selective enrichment enables quantitative phosphoproteomics of the kinome across the cell cycle." Mol Cell 31(3): 438-48.

Daujat, S., H. Neel, et al. (2001). "MDM2: life without p53." Trends Genet 17(8): 459-64.

De Rycke, L., A. P. Nicholas, et al. (2005). "Synovial intracellular citrullinated proteins colocalizing with peptidyl arginine deiminase as pathophysiologically relevant antigenic determinants of rheumatoid arthritis-specific humoral autoimmunity." Arthritis Rheum 52(8): 2323-30.

de Seny, D., M. Fillet, et al. (2008). "Monomeric calgranulins measured by SELDI-TOF mass spectrometry and calprotectin measured by ELISA as biomarkers in arthritis." Clin Chem 54(6): 1066-75.

Depper, J. M. and N. J. Zvaifler (1981). "Epstein-Barr virus. Its relationship to the pathogenesis of rheumatoid arthritis." Arthritis Rheum 24(6): 755-61.

Despres, N., G. Boire, et al. (1994). "The Sa system: a novel antigen-antibody system specific for rheumatoid arthritis." J Rheumatol 21(6): 1027-33.

Devauchelle, V., S. Marion, et al. (2004). "DNA microarray allows molecular profiling of rheumatoid arthritis and identification of pathophysiological targets." Genes Immun 5(8): 597-608.

Dihazi, H., G. A. Muller, et al. (2007). "Characterization of diabetic nephropathy by urinary proteomic analysis: identification of a processed ubiquitin form as a differentially excreted protein in diabetic nephropathy patients." Clin Chem 53(9): 1636-45.

Doyle, A., J. B. Griffiths, et al. (1996). "Cell and Tissue Culture: Laboratory Procedures."

Echan, L. A., H. Y. Tang, et al. (2005). "Depletion of multiple high-abundance proteins improves protein profiling capacities of human serum and plasma." Proteomics 5(13): 3292-303.

Efeyan, A. and M. Serrano (2007). "p53: guardian of the genome and policeman of the oncogenes." Cell Cycle 6(9): 1006-10. 
El-Deiry, W. S. (2001). "Insights into cancer therapeutic design based on p53 and TRAIL receptor signaling." Cell Death Differ 8(11): 1066-75.

Eravci, M., S. Fuxius, et al. (2007). "Improved comparative proteome analysis based on twodimensional gel electrophoresis." Proteomics 7(4): 513-23.

Erukhimov, J. A., Z. L. Tang, et al. (2000). "Actin-containing sera from patients with adult respiratory distress syndrome are toxic to sheep pulmonary endothelial cells." $\underline{\mathrm{Am} \mathrm{J}}$ Respir Crit Care Med 162(1): 288-94.

Faucher, C., J. Capdevielle, et al. (1993). "The 28-kDa protein whose phosphorylation is induced by protein kinase $\mathrm{C}$ activators in MCF-7 cells belongs to the family of low molecular mass heat shock proteins and is the estrogen-regulated $24-\mathrm{kDa}$ protein." $\mathrm{J} \mathrm{Bi}-$ ol Chem 268(20): 15168-73.

Fernandes, J. C., J. Martel-Pelletier, et al. (2002). "The role of cytokines in osteoarthritis pathophysiology." Biorheology 39(1-2): 237-46.

Fernandez-Suarez, A., S. Reneses, et al. (2005). "Efficacy of three ELISA measurements of anti-cyclic citrullinated peptide antibodies in the early diagnosis of rheumatoid arthritis." Clin Chem Lab Med 43(11): 1234-9.

Firestein, G. S., F. Echeverri, et al. (1997). "Somatic mutations in the p53 tumor suppressor gene in rheumatoid arthritis synovium." Proc Natl Acad Sci U S A 94(20): 10895-900.

Fox, R. I., M. Lotz, et al. (1985). "Epstein-Barr virus in rheumatoid arthritis." Clin Rheum Dis 11(3): 665-88.

Franz, J. K., T. Pap, et al. (2000). "Expression of sentrin, a novel antiapoptotic molecule, at sites of synovial invasion in rheumatoid arthritis." Arthritis Rheum 43(3): 599-607.

Fu, Q., C. P. Garnham, et al. (2005). "A robust, streamlined, and reproducible method for proteomic analysis of serum by delipidation, albumin and $\operatorname{lgG}$ depletion, and twodimensional gel electrophoresis." Proteomics 5(10): 2656-64.

Gao, W. M., R. Kuick, et al. (2005). "Distinctive serum protein profiles involving abundant proteins in lung cancer patients based upon antibody microarray analysis." BMC Cancer 5: 110.

Georgiou, H. M., G. E. Rice, et al. (2001). "Proteomic analysis of human plasma: failure of centrifugal ultrafiltration to remove albumin and other high molecular weight proteins." Proteomics 1(12): 1503-6.

Girbal-Neuhauser, E., J. J. Durieux, et al. (1999). "The epitopes targeted by the rheumatoid arthritis-associated antifilaggrin autoantibodies are posttranslationally generated on various sites of (pro)filaggrin by deimination of arginine residues." $\mathrm{J}$ Immunol 162(1): 585-94.

Gonzalez-Gay, M. A., C. Garcia-Porrua, et al. (2002). "Influence of human leukocyte antigenDRB1 on the susceptibility and severity of rheumatoid arthritis." Semin Arthritis Rheum 31(6): 355-60.

Graham, D. R., C. P. Garnham, et al. (2005). "Improvements in two-dimensional gel electrophoresis by utilizing a low cost "in-house" neutral $\mathrm{pH}$ sodium dodecyl sulfatepolyacrylamide gel electrophoresis system." Proteomics 5(9): 2309-14.

Greenough, C., R. E. Jenkins, et al. (2004). "A method for the rapid depletion of albumin and immunoglobulin from human plasma." Proteomics 4(10): 3107-11.

Guan, B., P. Yue, et al. (2001). "Evidence that the death receptor DR4 is a DNA damageinducible, p53-regulated gene." J Cell Physiol 188(1): 98-105.

Gultekin, H. and K. H. Heermann (1988). "The use of polyvinylidenedifluoride membranes as a general blotting matrix." Anal Biochem 172(2): 320-9.

Gundry, R. L., Q. Fu, et al. (2007). "Investigation of an albumin-enriched fraction of human serum and its albuminome." J Proteomics - Clinical Applications 1: 73-88.

Hajiroussou, V. J., J. Skingle, et al. (1985). "Significance of antikeratin antibodies in rheumatoid arthritis." J Rheumatol 12(1): 57-9.

Hatanaka, H., K. Ogura, et al. (1996). "Tertiary structure of destrin and structural similarity between two actin-regulating protein families." Cell 85(7): 1047-55.

Hawkins, M., B. Pope, et al. (1993). "Human actin depolymerizing factor mediates a pHsensitive destruction of actin filaments." Biochemistry 32(38): 9985-93. 
Hayem, G., P. Chazerain, et al. (1999). "Anti-Sa antibody is an accurate diagnostic and prognostic marker in adult rheumatoid arthritis." J Rheumatol 26(1): 7-13.

Hellman, U., C. Wernstedt, et al. (1995). "Improvement of an "In-Gel" digestion procedure for the micropreparation of internal protein fragments for amino acid sequencing." Anal Biochem 224(1): 451-5.

Hijmans, W., H. R. Schuit, et al. (1964). "Comparative Study for the Detection of Antinuclear Factors with the Fluorescent Antibody Technique." Ann Rheum Dis 23: 73-7.

Hillenkamp, F. and M. Karas (1990). "Mass spectrometry of peptides and proteins by matrixassisted ultraviolet laser desorption/ionization." Methods Enzymol 193: 280-95.

Hinerfeld, D., D. Innamorati, et al. (2004). "Serum/Plasma depletion with chicken immunoglobulin $\mathrm{Y}$ antibodies for proteomic analysis from multiple Mammalian species." $\underline{\mathrm{J}}$ Biomol Tech 15(3): 184-90.

Hoberg, M., M. Rudert, et al. (2007). "Attachment to laminin-111 facilitates transforming growth factor beta-induced expression of matrix metalloproteinase-3 in synovial fibroblasts." Ann Rheum Dis 66(4): 446-51.

Hofmann, I. and H. Herrmann (1992). "Interference in vimentin assembly in vitro by synthetic peptides derived from the vimentin head domain." J Cell Sci 101 ( Pt 3): 687-700.

Holm, A., F. Rise, et al. (2006). "Specific modification of peptide-bound citrulline residues." Anal Biochem 352(1): 68-76.

Horn, A., S. Kreusch, et al. (2006). "Multidimensional proteomics of human serum using parallel chromatography of native constituents and microplate technology." Proteomics 6(2): 559-70.

Howard, B. A., M. Z. Wang, et al. (2003). "Identification and validation of a potential lung cancer serum biomarker detected by matrix-assisted laser desorption/ionization-time of flight spectra analysis." Proteomics 3(9): 1720-4.

Huang, L. and X. Fang (2008). "Immunoaffinity fractionation of plasma proteins by chicken IgY antibodies." Methods Mol Biol 425: 41-51.

Hueber, W., W. Hassfeld, et al. (1999). "Sensitivity and specificity of anti-Sa autoantibodies for rheumatoid arthritis." Rheumatology (Oxford) 38(2): 155-9.

Inoue, T., R. K. Geyer, et al. (2001). "MDM2 can promote the ubiquitination, nuclear export, and degradation of p53 in the absence of direct binding." $\mathrm{J}$ Biol Chem 276(48): 45255-60.

Ishida-Yamamoto, A., T. Senshu, et al. (2002). "Sequential reorganization of cornified cell keratin filaments involving filaggrin-mediated compaction and keratin 1 deimination." $\underline{J}$ Invest Dermatol 118(2): 282-7.

Juan, H. F., J. H. Chen, et al. (2004). "Identification of tumor-associated plasma biomarkers using proteomic techniques: from mouse to human." Proteomics 4(9): 2766-75.

Jungel, A., V. Baresova, et al. (2006). "Trichostatin A sensitises rheumatoid arthritis synovial fibroblasts for TRAIL-induced apoptosis." Ann Rheum Dis 65(7): 910-2.

Kataoka, T. (2005). "The caspase-8 modulator c-FLIP." Crit Rev Immunol 25(1): 31-58.

Keskin, G., A. Inal, et al. (2008). "Diagnostic utility of anti-cyclic citrullinated peptide and antimodified citrullinated vimentin antibodies in rheumatoid arthritis." Protein Pept Lett 15(3): 314-7.

Khani-Hanjani, A., D. Lacaille, et al. (2002). "Expression of QK/QR/RRRAA or DERAA motifs at the third hypervariable region of HLA-DRB1 and disease severity in rheumatoid arthritis." J Rheumatol 29(7): 1358-65.

Kinloch, A., V. Tatzer, et al. (2005). "Identification of citrullinated alpha-enolase as a candidate autoantigen in rheumatoid arthritis." Arthritis Res Ther 7(6): R1421-9.

Kleveland, G., T. Egeland, et al. (1988). "Quantitation of rheumatoid factors (RF) of IgM, IgA and IgG isotypes by a simple and sensitive ELISA. Discrimination between false and true IgG-RF." Scand J Rheumatol Suppl 75: 15-24.

Klotzsche, O., D. Etzrodt, et al. (1998). "Cytoplasmic retention of mutant tsp53 is dependent on an intermediate filament protein (vimentin) scaffold." Oncogene 16(26): 3423-34.

Koga, T., T. Torigoshi, et al. (2008). "Serum amyloid A-induced IL-6 production by rheumatoid synoviocytes." FEBS Lett 582(5): 579-85. 
Kokubun, M., Y. Imafuku, et al. (2005). "Serum amyloid A (SAA) concentration varies among rheumatoid arthritis patients estimated by SAA/CRP ratio." Clin Chim Acta 360(1-2): 97-102.

Koomen, J. M., L. N. Shih, et al. (2005). "Plasma protein profiling for diagnosis of pancreatic cancer reveals the presence of host response proteins." Clin Cancer Res 11(3): 1110-8.

Kumon, Y., T. Suehiro, et al. (1999). "Local expression of acute phase serum amyloid A mRNA in rheumatoid arthritis synovial tissue and cells." J Rheumatol 26(4): 785-90.

Laemmli, U. K. (1970). "Cleavage of structural proteins during the assembly of the head of bacteriophage T4." Nature 227(5259): 680-5.

Le, L., K. Chi, et al. (2005). "Identification of serum amyloid A as a biomarker to distinguish prostate cancer patients with bone lesions." Clin Chem 51(4): 695-707.

Liu, T., W. J. Qian, et al. (2005). "Human plasma N-glycoproteome analysis by immunoaffinity subtraction, hydrazide chemistry, and mass spectrometry." J Proteome Res 4(6): 2070-80.

Luhn, S., M. Berth, et al. (2003). "Using standard positions and image fusion to create proteome maps from collections of two-dimensional gel electrophoresis images." Proteomics 3(7): 1117-27.

Makrygiannakis, D., E. af Klint, et al. (2006). "Citrullination is an inflammation-dependent process." Ann Rheum Dis 65(9): 1219-22.

Martosella, J., N. Zolotarjova, et al. (2005). "Reversed-phase high-performance liquid chromatographic prefractionation of immunodepleted human serum proteins to enhance mass spectrometry identification of lower-abundant proteins." J Proteome Res 4(5): 1522-37.

Masson-Bessiere, C., M. Sebbag, et al. (2000). "In the rheumatoid pannus, anti-filaggrin autoantibodies are produced by local plasma cells and constitute a higher proportion of IgG than in synovial fluid and serum." Clin Exp Immunol 119(3): 544-52.

Masson-Bessiere, C., M. Sebbag, et al. (2001). "The major synovial targets of the rheumatoid arthritis-specific antifilaggrin autoantibodies are deiminated forms of the alphaand beta-chains of fibrin." J Immunol 166(6): 4177-84.

Mathsson, L., M. Mullazehi, et al. (2008). "Antibodies against citrullinated vimentin in rheumatoid arthritis: higher sensitivity and extended prognostic value concerning future radiographic progression as compared with antibodies against cyclic citrullinated peptides." Arthritis Rheum 58(1): 36-45.

Matsuo, K., Y. Xiang, et al. (2006). "Identification of novel citrullinated autoantigens of synovium in rheumatoid arthritis using a proteomic approach." Arthritis Res Ther 8(6): R175.

Mertens, M. and J. A. Singh (2009). "Anakinra for rheumatoid arthritis." Cochrane Database Syst Rev(1): CD005121.

Migita, K., Y. Kawabe, et al. (1998). "Serum amyloid A protein induces production of matrix metalloproteinases by human synovial fibroblasts." Lab Invest 78(5): 535-9.

Migita, K., T. Miyashita, et al. (2004). "Suppressive effect of leflunomide metabolite (A77 1726 ) on metalloproteinase production in IL-1beta stimulated rheumatoid synovial fibroblasts." Clin Exp Immunol 137(3): 612-6.

Minden, J. (2007). "Comparative proteomics and difference gel electrophoresis." Biotechniques 43(6): 739, 741, 743 passim.

Moshkovskii, S. A., M. V. Serebryakova, et al. (2005). "Ovarian cancer marker of $11.7 \mathrm{kDa}$ detected by proteomics is a serum amyloid A1." Proteomics 5(14): 3790-7.

Mountz, J. D. and H. G. Zhang (2001). "Regulation of apoptosis of synovial fibroblasts." Curr Dir Autoimmun 3: 216-39.

Mullan, R. H., B. Bresnihan, et al. (2006). "Acute-phase serum amyloid A stimulation of angiogenesis, leukocyte recruitment, and matrix degradation in rheumatoid arthritis through an NF-kappaB-dependent signal transduction pathway." Arthritis Rheum 54(1): 105-14.

Muller-Ladner, U., R. E. Gay, et al. (2000). "Activation of synoviocytes." Curr Opin Rheumatol 12(3): 186-94. 
Murphy, J. T. and S. Duffy (2003). "ZO-1 redistribution and F-actin stress fiber formation in pulmonary endothelial cells after thermal injury." J Trauma 54(1): 81-9; discussion 8990.

Nakamura, T. (2008). "Clinical strategies for amyloid A amyloidosis secondary to rheumatoid arthritis." Mod Rheumatol 18(2): 109-18.

Nakamura, T., S. Higashi, et al. (2007). "Efficacy of etanercept in patients with AA amyloidosis secondary to rheumatoid arthritis." Clin Exp Rheumatol 25(4): 518-22.

Nakano, K., Y. Okada, et al. (2004). "Induction of RANKL expression and osteoclast maturation by the binding of fibroblast growth factor 2 to heparan sulfate proteoglycan on rheumatoid synovial fibroblasts." Arthritis Rheum 50(8): 2450-8.

Negishi, A., M. Ono, et al. (2008). "Large-scale quantitative clinical proteomics by label-free liquid chromatography and mass spectrometry." Cancer Sci.

Newsome, G. (2002). "Guidelines for the management of rheumatoid arthritis: 2002 update." J Am Acad Nurse Pract 14(10): 432-7.

Nienhuis, R. L. and E. Mandema (1964). "A New Serum Factor in Patients with Rheumatoid Arthritis; the Antiperinuclear Factor." Ann Rheum Dis 23: 302-5.

Nogueira, L., M. Sebbag, et al. (2001). "Performance of two ELISAs for antifilaggrin autoantibodies, using either affinity purified or deiminated recombinant human filaggrin, in the diagnosis of rheumatoid arthritis." Ann Rheum Dis 60(9): 882-7.

O'Brien, K. D. and A. Chait (2006). "Serum amyloid A: the "other" inflammatory protein." Curr Atheroscler Rep 8(1): 62-8.

O'Hara, R., E. P. Murphy, et al. (2000). "Acute-phase serum amyloid A production by rheumatoid arthritis synovial tissue." Arthritis Res 2(2): 142-4.

O'Hara, R., E. P. Murphy, et al. (2004). "Local expression of the serum amyloid A and formyl peptide receptor-like 1 genes in synovial tissue is associated with matrix metalloproteinase production in patients with inflammatory arthritis." Arthritis Rheum 50(6): 1788-99.

Ohyama, N., T. Honda, et al. (1983). "Advanced coded-aperture imaging system for nuclear medicine." Appl Opt 22(22): 3555.

Okamoto, H., Y. Katagiri, et al. (2008). "Serum amyloid A activates nuclear factor-kappaB in rheumatoid synovial fibroblasts through binding to receptor of advanced glycation end-products." J Rheumatol 35(5): 752-6.

Ordeig, J. and J. Guardia (1984). "Diagnostic value of antikeratin antibodies in rheumatoid arthritis." J Rheumatol 11(5): 602-4.

Osborn, T. M., M. Verdrengh, et al. (2008). "Decreased levels of the gelsolin plasma isoform in patients with rheumatoid arthritis." Arthritis Res Ther 10(5): R117.

Ospelt, C. and S. Gay (2008). "The role of resident synovial cells in destructive arthritis." Best Pract Res Clin Rheumatol 22(2): 239-52.

Ouvry-Patat, S. A., M. P. Torres, et al. (2009). "Top-down proteomics on a high-field Fourier transform ion cyclotron resonance mass spectrometer." Methods Mol Biol 492: 21531.

Palao, G., B. Santiago, et al. (2004). "Down-regulation of FLIP sensitizes rheumatoid synovial fibroblasts to Fas-mediated apoptosis." Arthritis Rheum 50(9): 2803-10.

Pap, T., J. K. Franz, et al. (2000). "Activation of synovial fibroblasts in rheumatoid arthritis: lack of Expression of the tumour suppressor PTEN at sites of invasive growth and destruction." Arthritis Res 2(1): 59-64.

Pappin, D. J., P. Hojrup, et al. (1993). "Rapid identification of proteins by peptide-mass fingerprinting." Curr Biol 3(6): 327-32.

Pettersson, T., Y. T. Konttinen, et al. (2008). "Treatment strategies for amyloid A amyloidosis." Expert Opin Pharmacother 9(12): 2117-28.

Pieper, R., C. L. Gatlin, et al. (2003). "The human serum proteome: display of nearly 3700 chromatographically separated protein spots on two-dimensional electrophoresis gels and identification of 325 distinct proteins." Proteomics 3(7): 1345-64.

Pieper, R., Q. Su, et al. (2003). "Multi-component immunoaffinity subtraction chromatography: an innovative step towards a comprehensive survey of the human plasma proteome." Proteomics 3(4): 422-32. 
Pohlers, D., R. Huber, et al. (2006). "Expression of platelet-derived growth factors C and D in the synovial membrane of patients with rheumatoid arthritis and osteoarthritis." Arthritis Rheum 54(3): 788-94.

Pratesi, F., C. Tommasi, et al. (2006). "Deiminated Epstein-Barr virus nuclear antigen 1 is a target of anti-citrullinated protein antibodies in rheumatoid arthritis." Arthritis Rheum 54(3): 733-41.

Pritzker, L. B., T. A. Nguyen, et al. (1999). "The developmental expression and activity of peptidylarginine deiminase in the mouse." Neurosci Lett 266(3): 161-4.

Pundt, N., M. A. Peters, et al. (2009). "Susceptibility of RASF to FasL- and TRAIL- induced apoptosis is cell cycle dependent." Arthritis Res Ther 11(1): R16.

Rai, A. J., C. A. Gelfand, et al. (2005). "HUPO Plasma Proteome Project specimen collection and handling: towards the standardization of parameters for plasma proteome samples." Proteomics 5(13): 3262-77.

Ramachandran, P., P. Boontheung, et al. (2006). "Identification of N-linked glycoproteins in human saliva by glycoprotein capture and mass spectrometry." J Proteome Res 5(6): 1493-503.

Rantapaa-Dahlqvist, S., B. A. de Jong, et al. (2003). "Antibodies against cyclic citrullinated peptide and IgA rheumatoid factor predict the development of rheumatoid arthritis." Arthritis Rheum 48(10): 2741-9.

Righetti, P. G. and E. Boschetti (2008). "The ProteoMiner and the FortyNiners: searching for gold nuggets in the proteomic arena." Mass Spectrom Rev 27(6): 596-608.

Ritchie, R. F., G. E. Palomaki, et al. (1999). "Reference distributions for the negative acutephase serum proteins, albumin, transferrin and transthyretin: a practical, simple and clinically relevant approach in a large cohort." J Clin Lab Anal 13(6): 273-9.

Ritchie, R. F., G. E. Palomaki, et al. (2000). "Reference distributions for the positive acute phase serum proteins, alpha1-acid glycoprotein (orosomucoid), alpha1-antitrypsin, and haptoglobin: a practical, simple, and clinically relevant approach in a large cohort." J Clin Lab Anal 14(6): 284-92.

Rogers, G., B. Winter, et al. (1997). "Peptidylarginine deiminase of the hair follicle: characterization, localization, and function in keratinizing tissues." J Invest Dermatol 108(5): 700-7.

Rose, H. M., C. Ragan, et al. (1948). "Differential agglutination of normal and sensitized sheep erythrocytes by sera of patients with rheumatoid arthritis." Proc Soc Exp Biol Med 68(1): 1-6.

Rosenfeld, J., J. Capdevielle, et al. (1992). "In-gel digestion of proteins for internal sequence analysis after one- or two-dimensional gel electrophoresis." Anal Biochem 203(1): 173-9.

Rossi, L., B. M. Martin, et al. (2006). "Inflammatory protein profile during systemic high dose interleukin-2 administration." Proteomics 6(2): 709-20.

Rossol, M., H. Hantzschel, et al. (2005). "[T cell-dependent monocyte activation, TNFalpha and apolipoprotein A-I in autoimmunity and inflammation]." Z Rheumatol 64(4): 24954.

Roudier, J. (2006). "HLA-DRB1 genes and extraarticular rheumatoid arthritis." $\underline{\text { Arthritis Res }}$ Ther 8(1): 103.

Rui, Z., J. Jian-Guo, et al. (2003). "Use of serological proteomic methods to find biomarkers associated with breast cancer." Proteomics 3(4): 433-9.

Sakuma, M., K. Hatsushika, et al. (2007). "TGF-beta type I receptor kinase inhibitor downregulates rheumatoid synoviocytes and prevents the arthritis induced by type II collagen antibody." Int Immunol 19(2): 117-26.

Schellekens, G. A., B. A. de Jong, et al. (1998). "Citrulline is an essential constituent of antigenic determinants recognized by rheumatoid arthritis-specific autoantibodies." $\underline{\mathrm{J}}$ Clin Invest 101(1): 273-81.

Schellekens, G. A., H. Visser, et al. (2000). "The diagnostic properties of rheumatoid arthritis antibodies recognizing a cyclic citrullinated peptide." Arthritis Rheum 43(1): 155-63.

Scott, D. L., J. P. Delamere, et al. (1981). "Significance of laminar antikeratin antibodies to rat oesophagus in rheumatoid arthritis." Ann Rheum Dis 40(3): 267-71. 
Sebbag, M., M. Simon, et al. (1995). "The antiperinuclear factor and the so-called antikeratin antibodies are the same rheumatoid arthritis-specific autoantibodies." $\underline{\mathrm{J} \text { Clin Invest }}$ 95(6): 2672-9.

Senshu, T., T. Sato, et al. (1992). "Detection of citrulline residues in deiminated proteins on polyvinylidene difluoride membrane." Anal Biochem 203(1): 94-100.

Serdaroglu, M., H. Cakirbay, et al. (2008). "The association of anti-CCP antibodies with disease activity in rheumatoid arthritis." Rheumatol Int 28(10): 965-70.

Sghiri, R., E. Bouajina, et al. (2008). "Value of anti-mutated citrullinated vimentin antibodies in diagnosing rheumatoid arthritis." Rheumatol Int 29(1): 59-62.

Shmerling, R. H. and T. L. Delbanco (1991). "The rheumatoid factor: an analysis of clinical utility." Am J Med 91(5): 528-34.

Shores, K. S., D. G. Udugamasooriya, et al. (2008). "Use of peptide analogue diversity library beads for increased depth of proteomic analysis: application to cerebrospinal fluid." $\underline{\mathrm{J}}$ Proteome Res 7(5): 1922-31.

Silvestris, F., J. S. Goodwin, et al. (1985). "lgM, IgA and IgG rheumatoid factors in patients with rheumatoid arthritis and normal donors." Clin Rheumatol 4(4): 392-8.

Simon, J., R. Surber, et al. (2001). "Systemic macrophage activation in locally-induced experimental arthritis." J Autoimmun 17(2): 127-36.

Sondag-Tschroots, I. R., C. Aaij, et al. (1979). "The antiperinuclear factor. 1. The diagnostic significance of the antiperinuclear factor for rheumatoid arthritis." Ann Rheum Dis 38(3): 248-51.

States, D. J., G. S. Omenn, et al. (2006). "Challenges in deriving high-confidence protein identifications from data gathered by a HUPO plasma proteome collaborative study." Nat Biotechnol 24(3): 333-8.

Steel, L. F., D. Shumpert, et al. (2003). "A strategy for the comparative analysis of serum proteomes for the discovery of biomarkers for hepatocellular carcinoma." Proteomics 3(5): 601-9.

Sur, R., P. A. Lyte, et al. (2008). "Hsp27 regulates pro-inflammatory mediator release in keratinocytes by modulating NF-kappaB signaling." J Invest Dermatol 128(5): 111622.

Szekanecz, Z. and A. E. Koch (2007). "Macrophages and their products in rheumatoid arthritis." Curr Opin Rheumatol 19(3): 289-95.

Tabushi, Y., T. Nakanishi, et al. (2008). "Detection of citrullinated proteins in synovial fluids derived from patients with rheumatoid arthritis by proteomics-based analysis." Ann Clin Biochem 45(Pt 4): 413-7.

Tammen, H., I. Schulte, et al. (2005). "Peptidomic analysis of human blood specimens: comparison between plasma specimens and serum by differential peptide display." Proteomics 5(13): 3414-22.

Tammen, H., I. Schulte, et al. (2005). "Prerequisites for peptidomic analysis of blood samples: I. Evaluation of blood specimen qualities and determination of technical performance characteristics." Comb Chem High Throughput Screen 8(8): 725-33.

Tanaka, F., K. Migita, et al. (2004). "Interleukin-18 induces serum amyloid A (SAA) protein production from rheumatoid synovial fibroblasts." Life Sci 74(13): 1671-9.

Tarcsa, E., L. N. Marekov, et al. (1996). "Protein unfolding by peptidylarginine deiminase. Substrate specificity and structural relationships of the natural substrates trichohyalin and filaggrin." J Biol Chem 271(48): 30709-16.

Teitsson, I. (1988). "IgA rheumatoid factor as predictor of disease activity." Scand J Rheumatol Suppl 75: 233-7.

Thulasiraman, V., S. Lin, et al. (2005). "Reduction of the concentration difference of proteins in biological liquids using a library of combinatorial ligands." Electrophoresis 26(18): 3561-71.

Timms, J. F. and R. Cramer (2008). "Difference gel electrophoresis." Proteomics 8(23-24): 4886-97.

Torrigiani, G. and I. M. Roitt (1967). "Antiglobulin factors in sera from patients with rheumatoid arthritis and normal subjects. Quantitative estimation in different immunoglobulin classes." Ann Rheum Dis 26(4): 334-40. 
Towbin, H., T. Staehelin, et al. (1979). "Electrophoretic transfer of proteins from polyacrylamide gels to nitrocellulose sheets: procedure and some applications." Proc Natl Acad Sci U S A 76(9): 4350-4.

Vallon, R., F. Freuler, et al. (2001). "Serum amyloid A (apoSAA) expression is up-regulated in rheumatoid arthritis and induces transcription of matrix metalloproteinases." $\mathrm{J} \mathrm{Im}$ munol 166(4): 2801-7.

van Gaalen, F. A., H. Visser, et al. (2005). "A comparison of the diagnostic accuracy and prognostic value of the first and second anti-cyclic citrullinated peptides (CCP1 and CCP2) autoantibody tests for rheumatoid arthritis." Ann Rheum Dis 64(10): 1510-2.

Veenstra, T. D., T. P. Conrads, et al. (2005). "Biomarkers: mining the biofluid proteome." Mol Cell Proteomics 4(4): 409-18.

Vencovsky, J., S. Machacek, et al. (2003). "Autoantibodies can be prognostic markers of an erosive disease in early rheumatoid arthritis." Ann Rheum Dis 62(5): 427-30.

Vincent, C., L. Nogueira, et al. (2002). "Detection of antibodies to deiminated recombinant rat filaggrin by enzyme-linked immunosorbent assay: a highly effective test for the diagnosis of rheumatoid arthritis." Arthritis Rheum 46(8): 2051-8.

Vossenaar, E. R., N. Despres, et al. (2004). "Rheumatoid arthritis specific anti-Sa antibodies target citrullinated vimentin." Arthritis Res Ther 6(2): R142-50.

Vossenaar, E. R., T. R. Radstake, et al. (2004). "Expression and activity of citrullinating peptidylarginine deiminase enzymes in monocytes and macrophages." Ann Rheum Dis 63(4): 373-81.

Waaler, E. (2007). "On the occurrence of a factor in human serum activating the specific agglutintion of sheep blood corpuscles. 1939." Apmis 115(5): 422-38; discussion 439.

Wang, S. and W. S. El-Deiry (2003). "Requirement of p53 targets in chemosensitization of colonic carcinoma to death ligand therapy." Proc Natl Acad Sci U S A 100(25): 15095-100.

Wang, Y., J. Wysocka, et al. (2004). "Human PAD4 regulates histone arginine methylation levels via demethylimination." Science 306(5694): 279-83.

Wessel, D. and U. I. Flugge (1984). "A method for the quantitative recovery of protein in dilute solution in the presence of detergents and lipids." Anal Biochem 138(1): 141-3.

West-Nielsen, M., E. V. Hogdall, et al. (2005). "Sample handling for mass spectrometric proteomic investigations of human sera." Anal Chem 77(16): 5114-23.

Westermeier, R. (2004). "Isoelectric focusing." Methods Mol Biol 244: 225-32.

Westermeier, R., W. Postel, et al. (1983). "High-resolution two-dimensional electrophoresis with isoelectric focusing in immobilized pH gradients." $\mathrm{J}$ Biochem Biophys Methods 8(4): 321-30.

Westermeier, R. and B. Scheibe (2008). "Difference gel electrophoresis based on lys/cys tagging." Methods Mol Biol 424: 73-85.

Wiley, S. R., K. Schooley, et al. (1995). "Identification and characterization of a new member of the TNF family that induces apoptosis." Immunity 3(6): 673-82.

Yamanishi, Y., D. L. Boyle, et al. (2002). "Regional analysis of p53 mutations in rheumatoid arthritis synovium." Proc Natl Acad Sci U S A 99(15): 10025-30.

Yang, X., J. Wang, et al. (2005). "Cleavage of p53-vimentin complex enhances tumor necrosis factor-related apoptosis-inducing ligand-mediated apoptosis of rheumatoid arthritis synovial fibroblasts." Am J Pathol 167(3): 705-19.

Yates, J. R., 3rd (2004). "Mass spectral analysis in proteomics." Annu Rev Biophys Biomol Struct 33: 297-316.

Yokoi, K., L. C. Shih, et al. (2005). "Serum amyloid A as a tumor marker in sera of nude mice with orthotopic human pancreatic cancer and in plasma of patients with pancreatic cancer." Int J Oncol 27(5): 1361-9.

Youinou, P. and G. Serre (1995). "The antiperinuclear factor and antikeratin antibody systems." Int Arch Allergy Immunol 107(4): 508-18.

Zimmermann, T., E. Kunisch, et al. (2001). "Isolation and characterization of rheumatoid arthritis synovial fibroblasts from primary culture--primary culture cells markedly differ from fourth-passage cells." Arthritis Res 3(1): 72-6. 


\section{Anhang}

\subsection{Synoviale Fibroblasten}

\subsubsection{D-SDS-PAGE Patientengruppe OA}

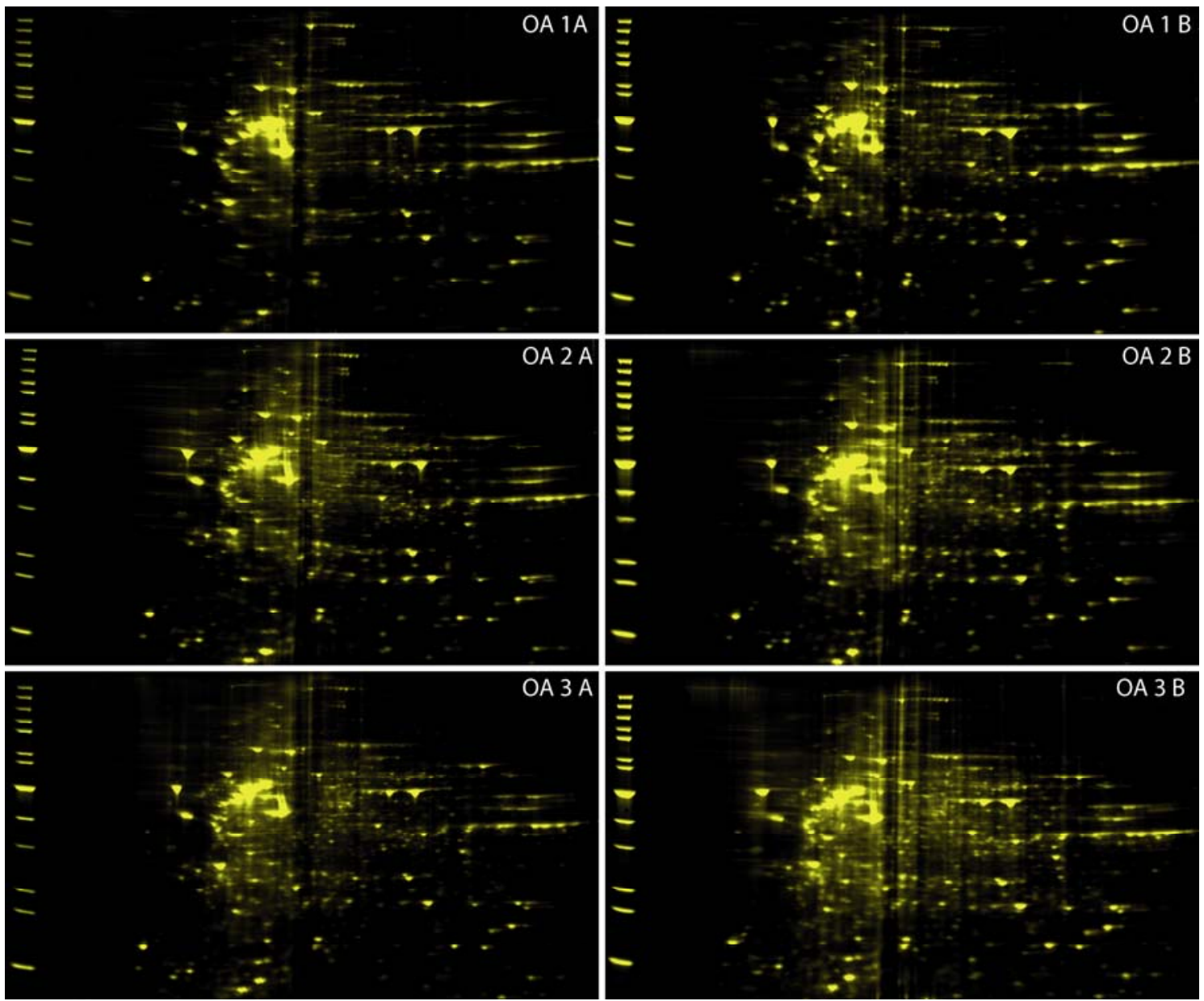

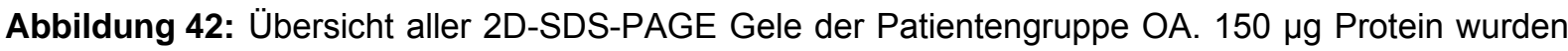
auf einen IPG-Streifen (BIORAD) aufgetragen und fokussiert. Die Auftrennung nach Größe erfolgte auf einem Criterion ${ }^{\circledR} 12 \%$ Bis-Tris Neutralgel (BIORAD). Als Marker wurde der Page Ruler ${ }^{T M}$ (FERMENTAS) verwendet. Die Färbung der Proteine erfolgte über Flamingo ${ }^{\circledR}$ (Biorad). 


\subsubsection{D-SDS-PAGE Patientengruppe RA}

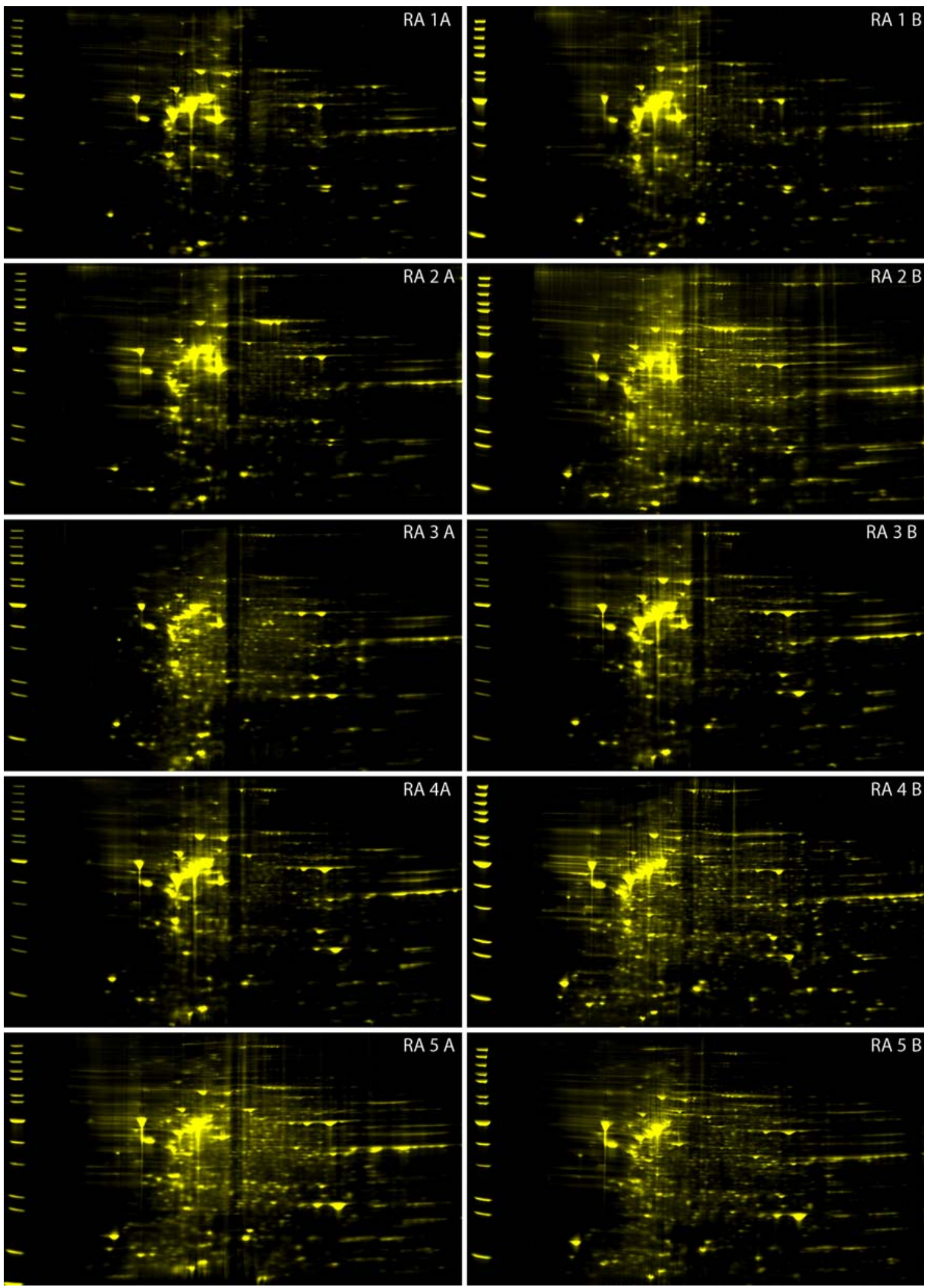

Abbildung 43: Übersicht aller 2D-SDS-PAGE Gele der Patientengruppe OA. $150 \mu g$ Protein wurden auf einen IPG-Streifen (BIORAD) aufgetragen und fokussiert. Die Auftrennung nach Größe erfolgte auf einem Criterion ${ }^{\circledR} 12 \%$ Bis-Tris Neutralgel (BIORAD). Als Marker wurde der Page Ruler' ${ }^{\mathrm{TM}}$ (FERMENTAS) verwendet. Die Färbung der Proteine erfolgte über Flamingo ${ }^{\circledR}$ (Biorad). 


\subsubsection{Identifizierungen von Proteinen der Lysate von synovialen} Fibroblasten
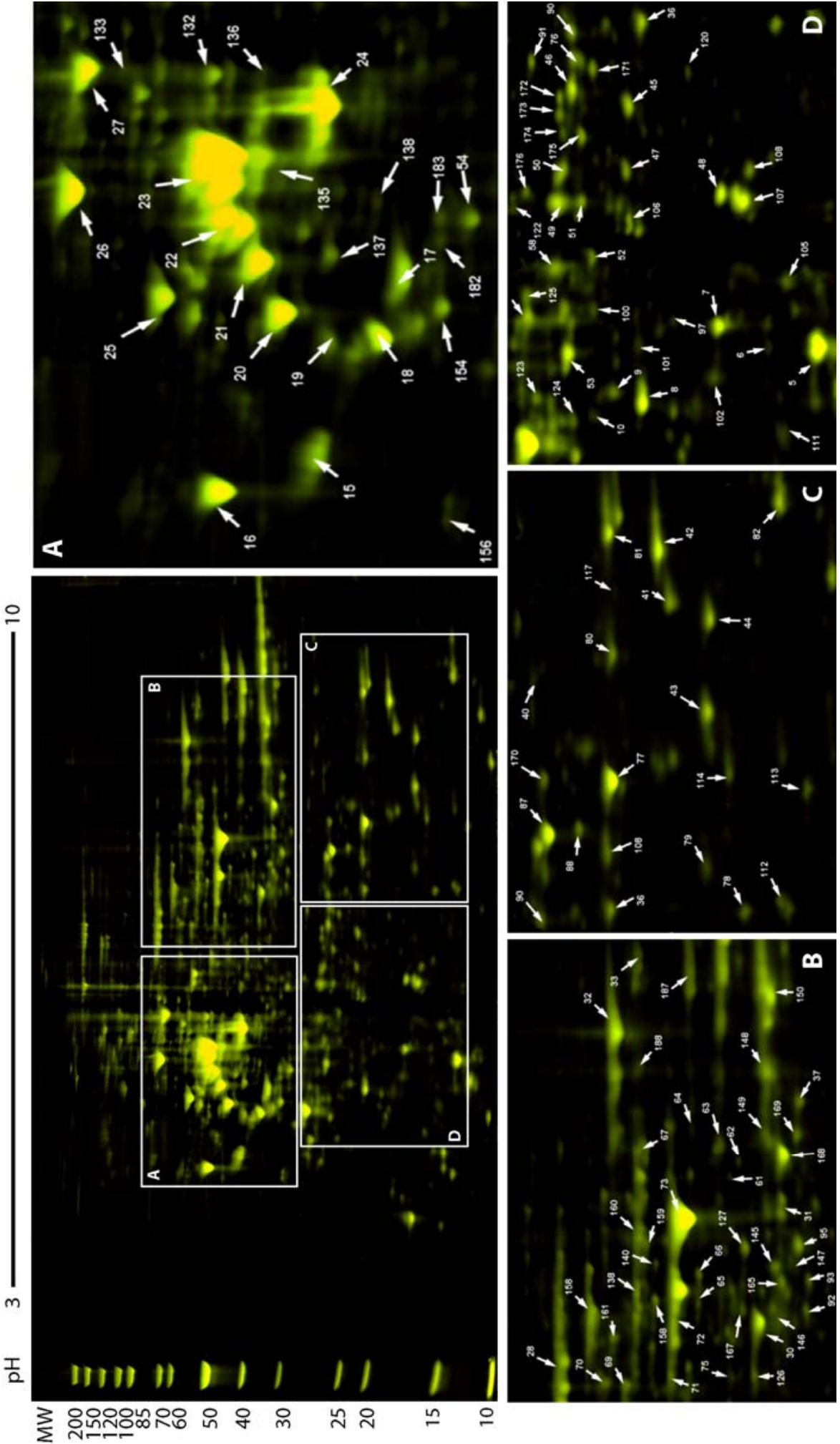

Abbildung 44. Identifizierungen der Proteine in den Lysaten synovialer Fibroblasten. $150 \mu \mathrm{g}$ Protein wurden auf einen IPG-Streifen (BIORAD) aufgetragen und fokussiert. Die Auftrennung nach Größe erfolgte auf einem Criterion ${ }^{\circledR} 12 \%$ Bis-Tris Neutralgel (BIORAD). Als Marker wurde der Page Ruler ${ }^{\text {TM }}$ (FERMENTAS) verwendet. Die Färbung der Proteine erfolgte über Flamingo ${ }^{\circledR}$ (Biorad). 


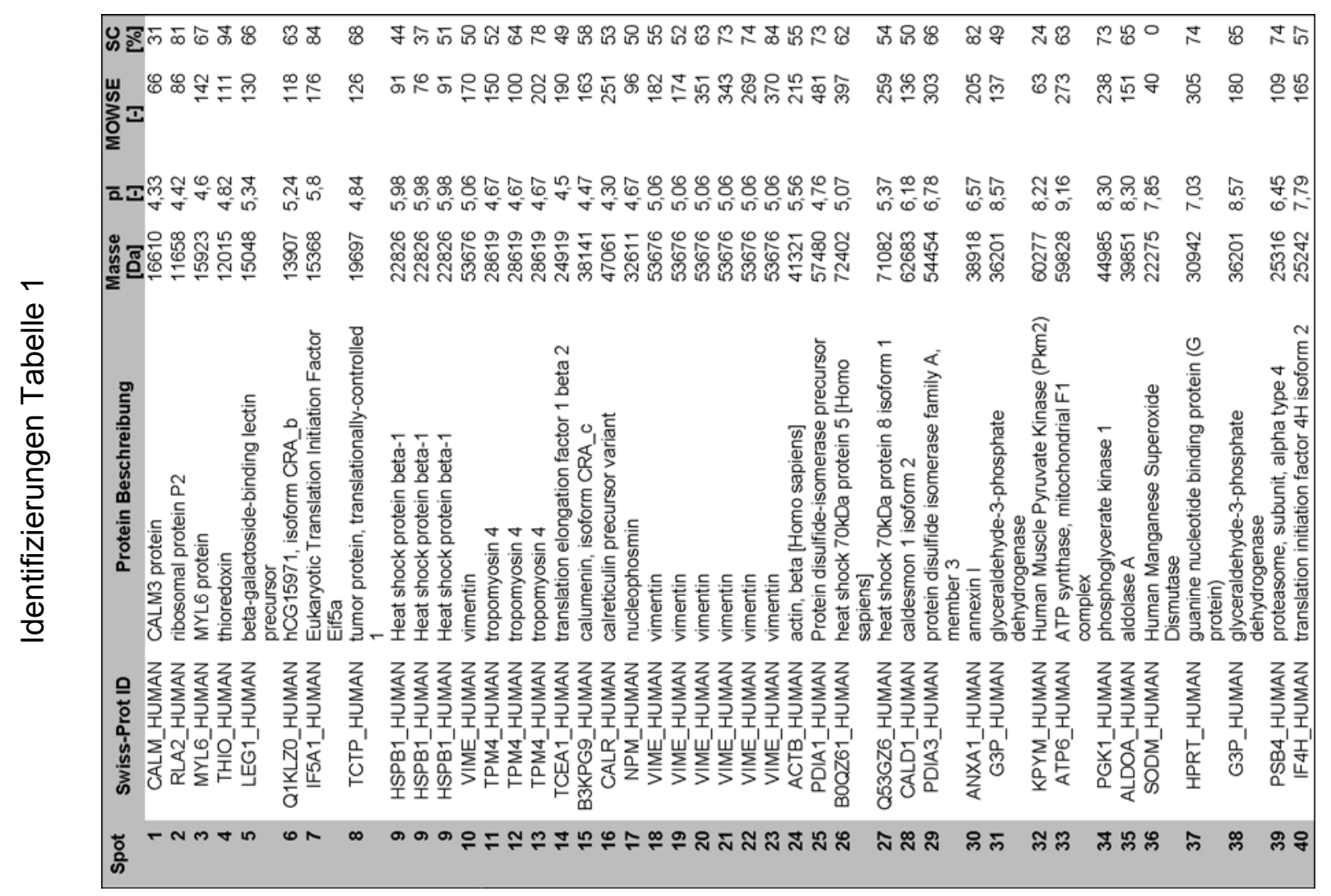

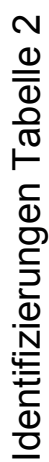

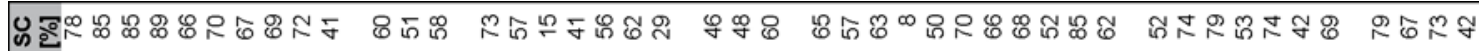
嵌 운

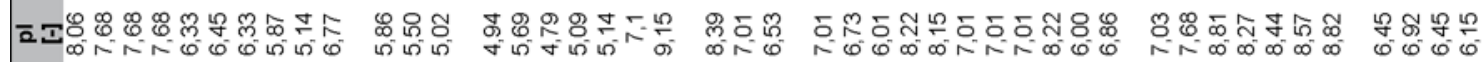

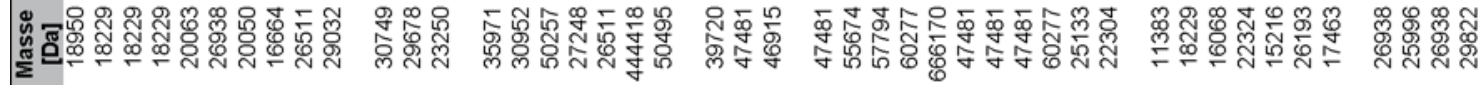

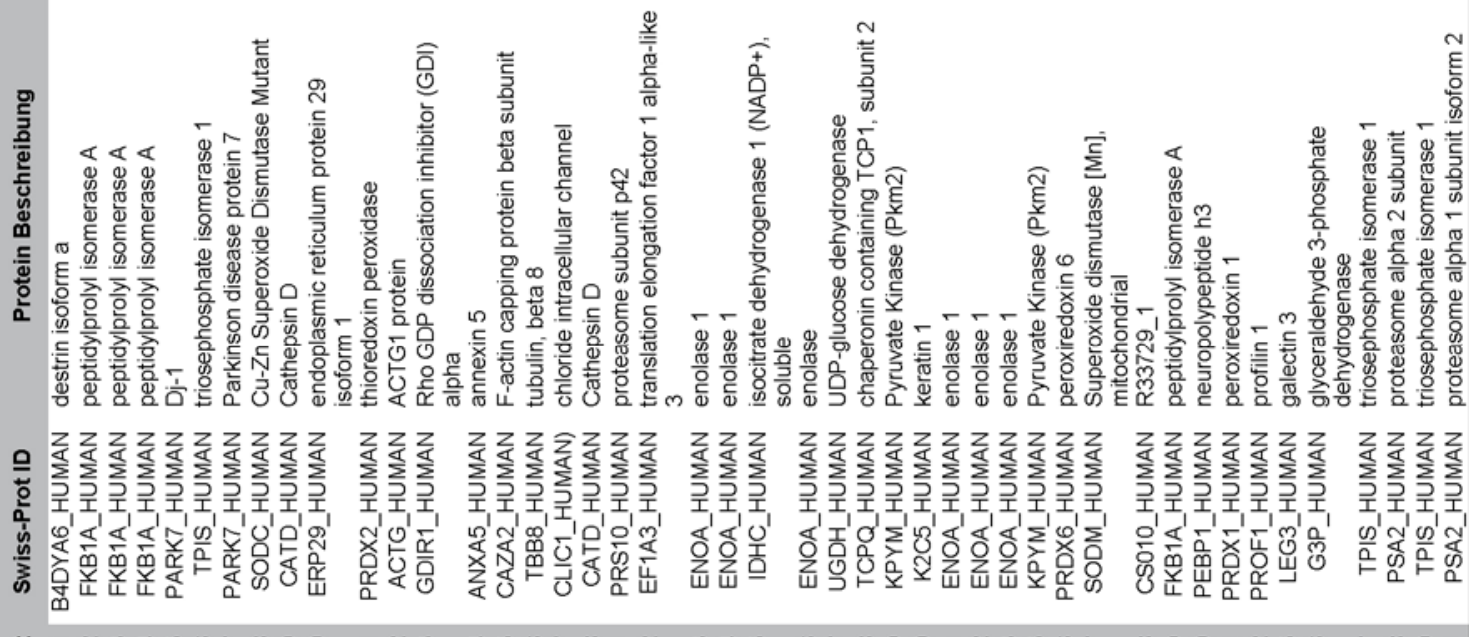

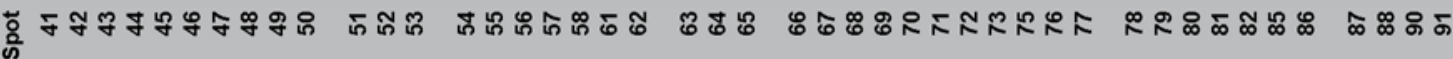



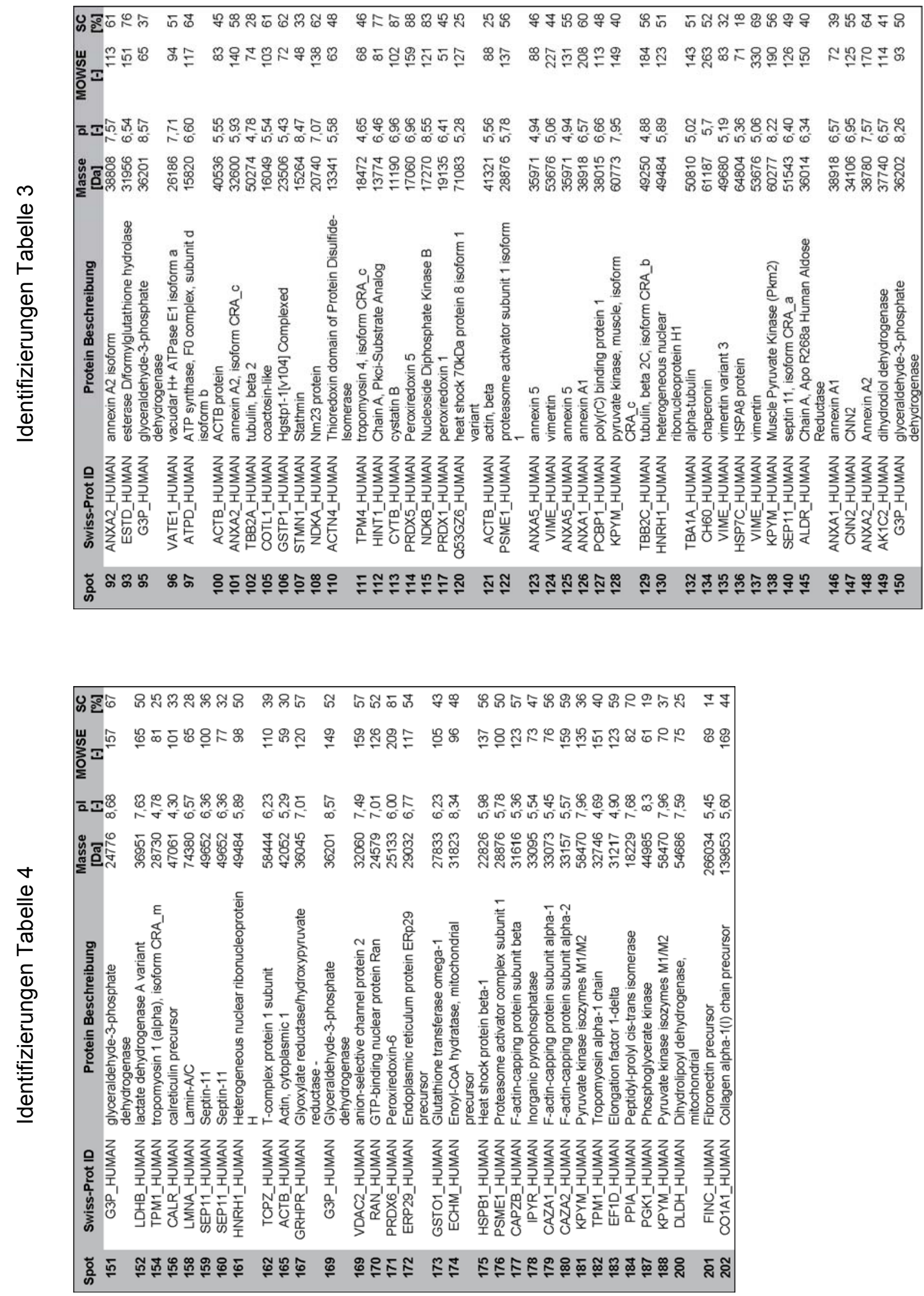


\subsection{Serumanalytik}

\subsubsection{Identifizierungen der Proteine im nativen Serum}

2D-SDS-PAGE natives, entsalztes Serum

$\mathrm{pH} 3$

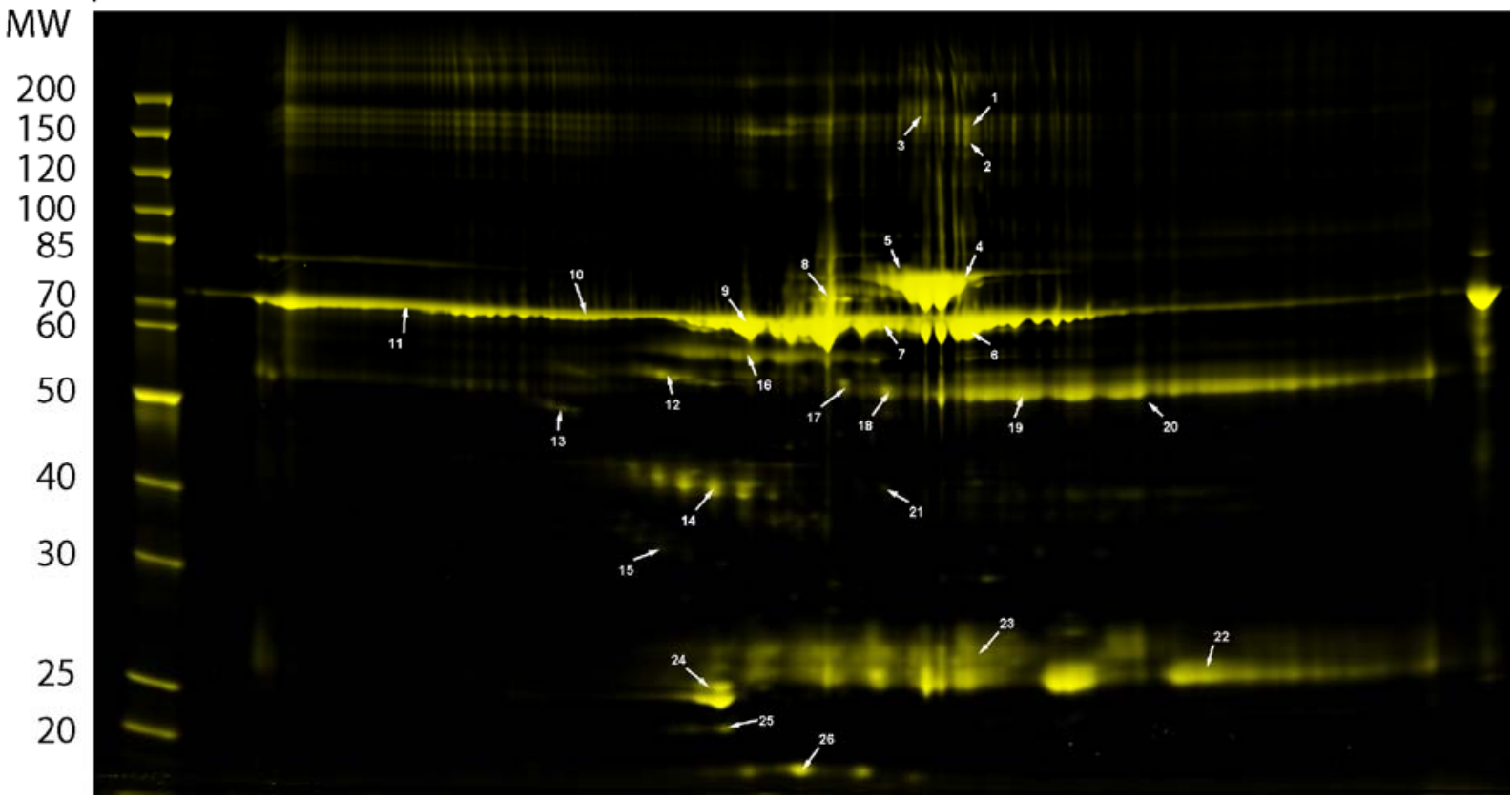

Identifizierungen

\begin{tabular}{rllccrc|}
\hline Spot & Swiss-Prot ID & Protein Beschreibung & $\begin{array}{c}\text { Masse } \\
\text { [Da] }\end{array}$ & $\begin{array}{c}\text { pl } \\
{[-]}\end{array}$ & $\begin{array}{c}\text { Mowse } \\
{[-]}\end{array}$ & $\begin{array}{c}\text { SC } \\
{[\%]}\end{array}$ \\
$\mathbf{1}$ & ALBU_HUMA Serum albumin & 71317 & 5,92 & 311 & 70 \\
$\mathbf{2}$ & ALBU_HUMAN Serum albumin & 71317 & 5,92 & 156 & 42 \\
$\mathbf{3}$ & ALBU_HUMAN Serum albumin & 71317 & 5,92 & 262 & 64 \\
$\mathbf{4}$ & TRFE_HUMAN Serotransferrin precursor & 79280 & 6,81 & 241 & 51 \\
$\mathbf{5}$ & TRFE_HUMAN Serotransferrin precursor & 79280 & 6,81 & 311 & 56 \\
$\mathbf{6}$ & ALBU_HUMAN Serum albumin & 71317 & 5,92 & 335 & 70 \\
$\mathbf{7}$ & ALBU_HUMAN Serum albumin & 71317 & 5,92 & 163 & 55 \\
$\mathbf{8}$ & ALBU_HUMAN Serum albumin & 71317 & 5,92 & 139 & 51 \\
$\mathbf{9}$ & ALBU_HUMAN Serum albumin & 71317 & 5,92 & 115 & 43 \\
$\mathbf{1 0}$ & ALBU_HUMAN Serum albumin & 71317 & 5,92 & 145 & 39 \\
$\mathbf{1 1}$ & ALBU_HUMAN Serum albumin & 71317 & 5,92 & 109 & 41 \\
$\mathbf{1 2}$ & ALBU_HUMAN Serum albumin & 71317 & 5,92 & 90 & 44 \\
$\mathbf{1 3}$ & A1AT_HUMAN Alpha-1-antitrypsin & 46878 & 5,37 & 272 & 56 \\
$\mathbf{1 4}$ & HPT_HUMAN Haptoglobin & 45861 & 6,13 & 122 & 34 \\
$\mathbf{1 5}$ & CLUS_HUMAN Clusterin & 53031 & 5,89 & 79 & 34 \\
$\mathbf{1 6}$ & ALBU_HUMAN Serum albumin & 71317 & 5,92 & 124 & 0 \\
$\mathbf{1 7}$ & APOH_HUMAN Beta-2-glycoprotein 1 & 39584 & 8,34 & 159 & 51 \\
$\mathbf{1 8}$ & APOH_HUMAN & Beta-2-glycoprotein 1 & 39584 & 8,34 & 174 & 58 \\
$\mathbf{1 9}$ & IGHG1_HUMAN & Ig gamma-1 chain C region & 36596 & 8,46 & 93 & 52 \\
$\mathbf{2 0}$ & IGHG1_HUMAN Ig gamma-1 chain C region & 36596 & 8,46 & 110 & 56 \\
$\mathbf{2 1}$ & TRFE_HUMAN Serotransferrin & 79280 & 6,81 & 134 & 46 \\
$\mathbf{2 2}$ & IGKC_HUMAN Ig kappa chain C region & 11773 & 5,58 & 73 & 87 \\
$\mathbf{2 3}$ & IGKC_HUMAN Ig kappa chain C region & 11773 & 5,58 & 59 & 66 \\
$\mathbf{2 4}$ & APOA1_HUMAN Apolipoprotein A-I & 30759 & 5,56 & 323 & 80 \\
$\mathbf{2 5}$ & APOA1_HUMAN Apolipoprotein A-I & 30759 & 5,56 & 202 & 83 \\
$\mathbf{2 6}$ & HPT_HUMAN Haptoglobin & 45861 & 6,13 & 59 & 20 \\
\hline
\end{tabular}




\subsubsection{Identifizierungen der Proteine im depletierten Serum}

2D-SDS-PAGE depletiertes Serum (Agilent Human 6 Depletionssäule)

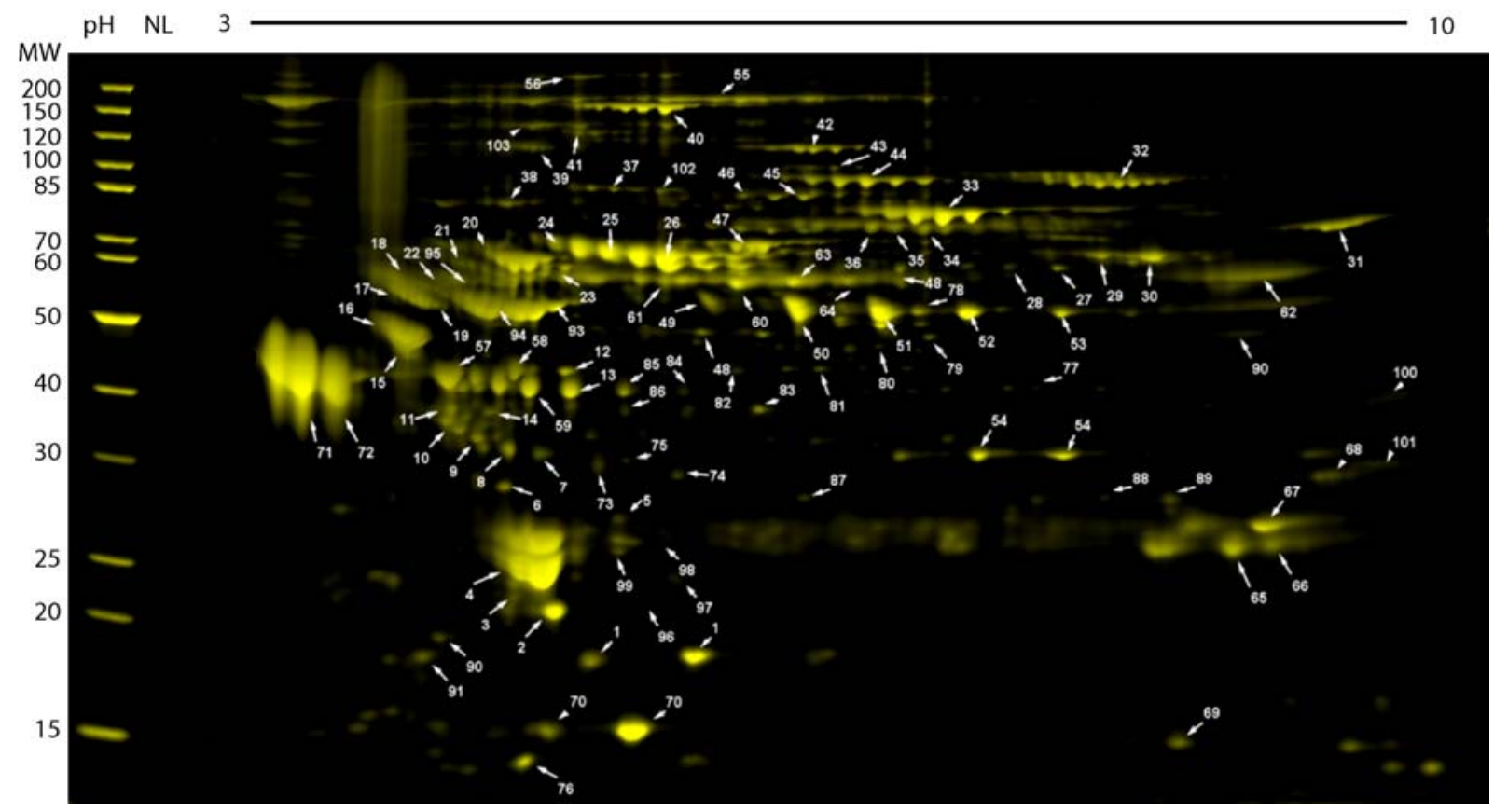

Identifizierungen

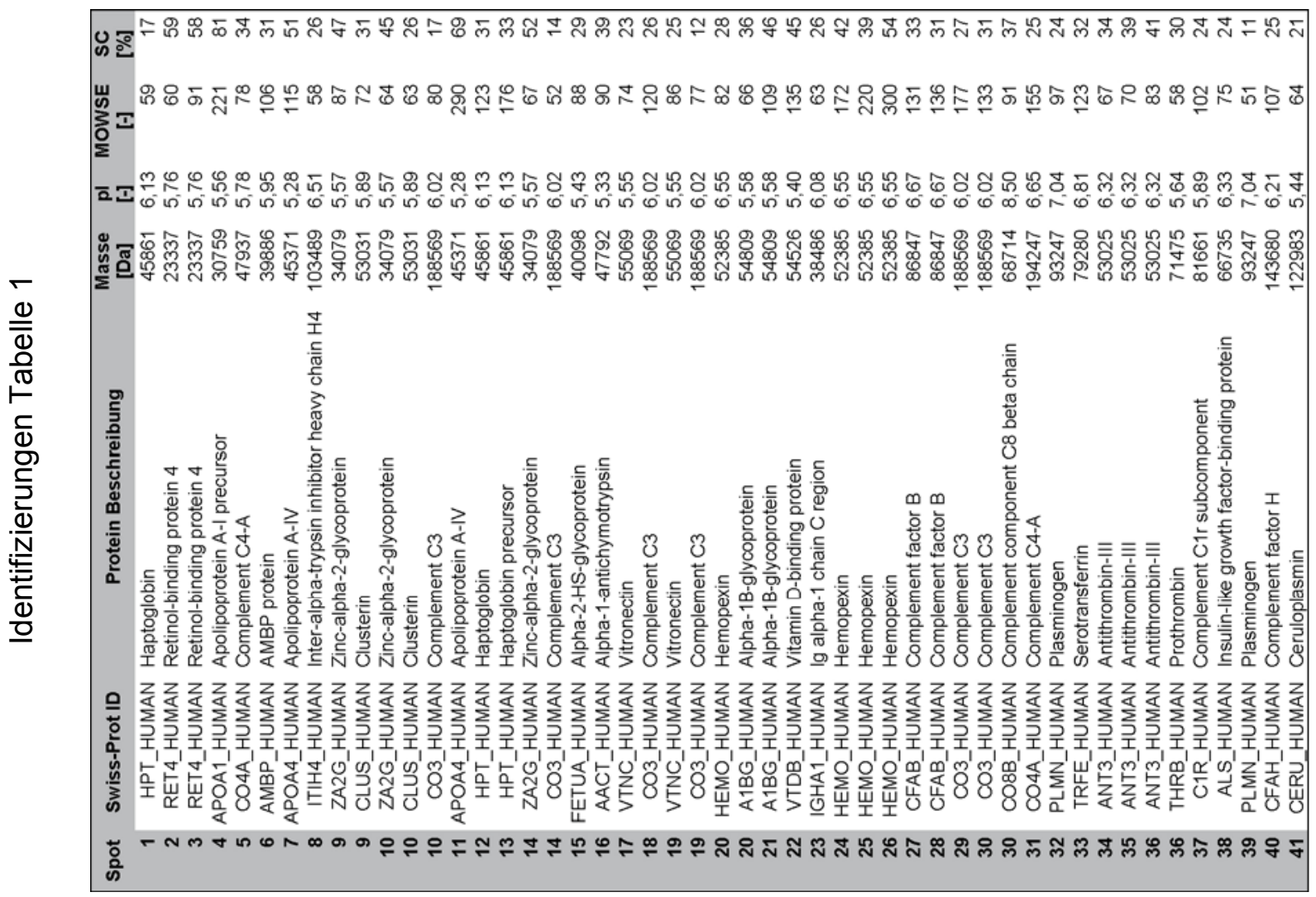



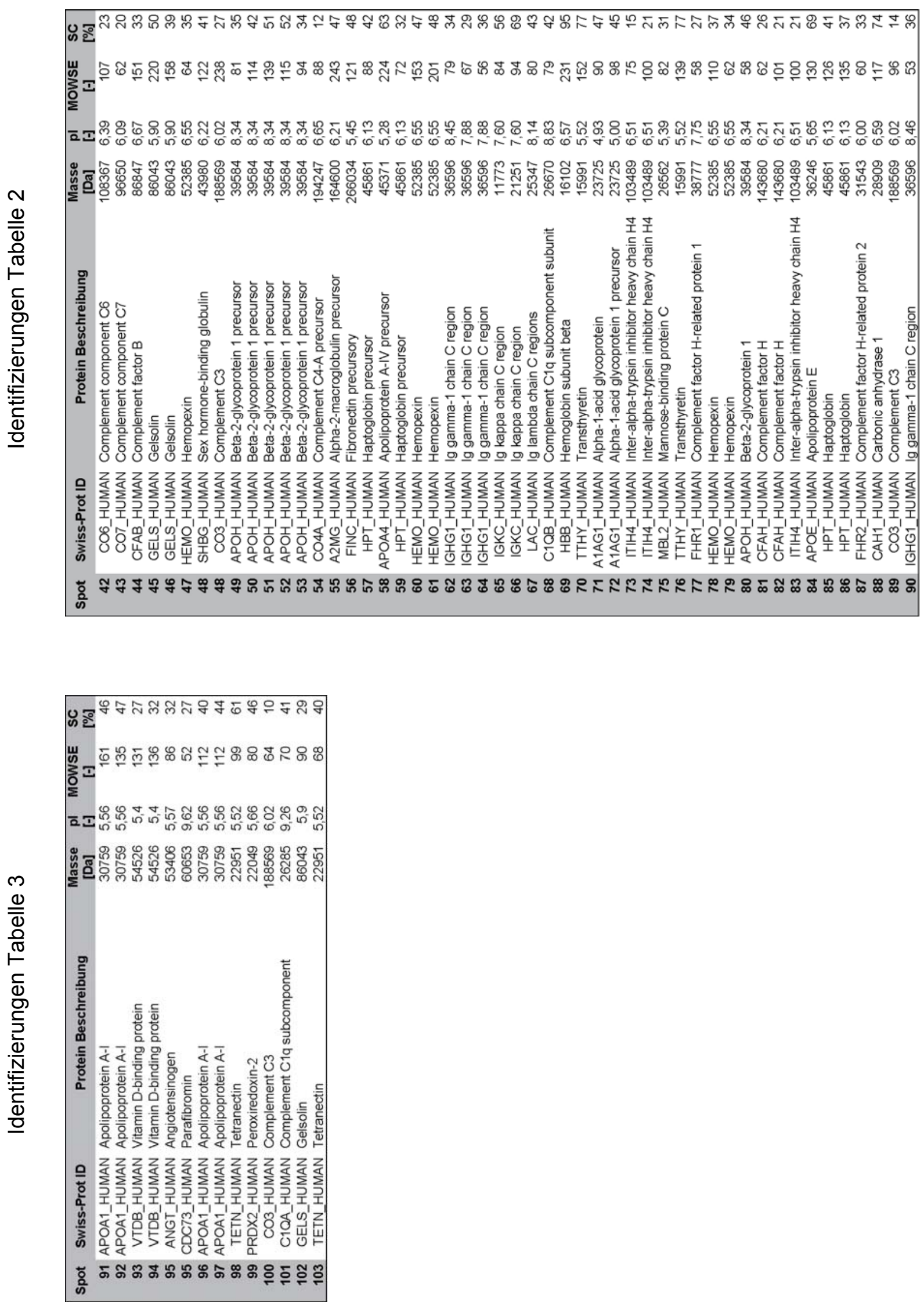


\subsubsection{Identifizierungen der Proteine der Stufenfraktionierung}

Identifizierungen Fraktion 1

\begin{tabular}{|c|c|c|c|c|c|c|}
\hline Spot & Swiss-Prot ID & Protein Beschreibung & $\begin{array}{c}\text { Masse } \\
\text { [Da] }\end{array}$ & $\begin{array}{l}\text { pl } \\
{[-]}\end{array}$ & $\begin{array}{c}\text { MOWSE } \\
{[-]}\end{array}$ & SC [\%] \\
\hline 1 & CFAH_HUMAN & Complement factor $\mathrm{H}$ & 143680 & 6,21 & 225 & 46 \\
\hline 2 & CFAH_HUMAN & Complement factor $\mathrm{H}$ & 143680 & 6,21 & 261 & 51 \\
\hline 3 & CFAH_HUMAN & Complement factor $\mathrm{H}$ & 143680 & 6,21 & 308 & 51 \\
\hline 4 & F13B_HUMAN & Coagulation factor XIII B chain & 77742 & 6,01 & 101 & 37 \\
\hline 5 & F13B_HUMAN & Coagulation factor XIII B chain & 77742 & 6,01 & 197 & 49 \\
\hline 6 & KNG1_HUMAN & Kininogen-1 & 72996 & 6,34 & 117 & 32 \\
\hline 7 & APOH_HUMAN & Beta-2-glycoprotein 1 & 39584 & 8,34 & 90 & 54 \\
\hline 8 & APOH_HUMAN & Beta-2-glycoprotein 1 & 39584 & 8,34 & 104 & 54 \\
\hline 9 & APOH_HUMAN & Beta-2-glycoprotein 1 & 39584 & 8,34 & 100 & 42 \\
\hline 10 & ZA2G_HUMAN & Zinc-alpha-2-glycoprotein & 34079 & 5,57 & 150 & 55 \\
\hline 11 & ZA2G_HUMAN & Zinc-alpha-2-glycoprotein & 34079 & 5,57 & 144 & 58 \\
\hline 12 & HPT_HUMAN & Haptoglobin & 45861 & 6,13 & 68 & 32 \\
\hline 14 & FHR1_HUMAN & Complement factor $\mathrm{H}$ - protein 1 & 38777 & 7,75 & 100 & 31 \\
\hline 15 & FHR1_HUMAN & Complement factor $\mathrm{H}$ - protein 1 & 38777 & 7,75 & 117 & 31 \\
\hline 16 & FHR2_HUMAN & Complement factor $\mathrm{H}$ - protein 2 & 31543 & 6 & 98 & 34 \\
\hline 17 & RETBP_HUMAN & Plasma retinol-binding protein & 23337 & 5,76 & 111 & 62 \\
\hline 13 & HPT_HUMAN & Haptoglobin & 45861 & 6,13 & 97 & 37 \\
\hline
\end{tabular}

Identifizierungen Fraktion 2

\begin{tabular}{|c|c|c|c|c|c|c|}
\hline Spot & Swiss-Prot ID & Protein Beschreibung & $\begin{array}{c}\text { Masse } \\
\text { [Da] }\end{array}$ & $\begin{array}{l}\text { pl } \\
{[-]}\end{array}$ & $\begin{array}{c}\text { MOWSE } \\
{[-]}\end{array}$ & SC [\%] \\
\hline 1 & CFAH_HUMAN & Complement factor $\mathrm{H}$ & 143680 & 6,21 & 250 & 48 \\
\hline 2 & CO6_HUMAN & Complement component C6 & 108367 & 6,39 & 86 & 22 \\
\hline 3 & A1AG1_HUMAN & Alpha-1-acid glycoprotein 1 & 23725 & 4,93 & 86 & 40 \\
\hline 4 & A1AG1_HUMAN & Alpha-1-acid glycoprotein 1 & 23725 & 4,93 & 94 & 40 \\
\hline 5 & C1R_HUMAN & Complement $\mathrm{C} 1 \mathrm{r}$ subcomponent & 81661 & 5,89 & 123 & 28 \\
\hline 6 & PLMN_HUMAN & Plasminogen & 93247 & 7,04 & 200 & 44 \\
\hline 7 & TRFE_HUMAN & Serotransferrin & 79280 & 6,81 & 180 & 53 \\
\hline 8 & TRFE_HUMAN & Serotransferrin & 79280 & 6,81 & 300 & 56 \\
\hline 9 & TRFE_HUMAN & Serotransferrin & 79280 & 6,81 & 237 & 51 \\
\hline 10 & HEMO_HUMAN & Hemopexin & 52385 & 6,55 & 105 & 32 \\
\hline 11 & A1BG_HUMAN & Alpha-1B-glycoprotein & 54809 & 5,58 & 124 & 42 \\
\hline 12 & A1BG_HUMAN & Alpha-1B-glycoprotein & 54809 & 5,58 & 59 & 33 \\
\hline 12 & HEMO_HUMAN & Hemopexin & 52385 & 6,55 & 105 & 40 \\
\hline 13 & HEMO_HUMAN & Hemopexin & 52385 & 6,55 & 107 & 41 \\
\hline 14 & HEMO_HUMAN & Hemopexin & 52385 & 6,55 & 125 & 42 \\
\hline 15 & KNG1_HUMAN & Kininogen-1 & 72996 & 6,34 & 77 & 20 \\
\hline 15 & FETUA_HUMAN & Alpha-2-HS-glycoprotein & 40098 & 5,43 & 73 & 27 \\
\hline 16 & A1AT_HUMAN & Alpha-1-antitrypsin & 46787 & 5,37 & 275 & 66 \\
\hline 17 & ZA2G_HUMAN & Zinc-alpha-2-glycoprotein & 34079 & 5,57 & 103 & 39 \\
\hline 18 & HEMO_HUMAN & Hemopexin & 52385 & 6,55 & 131 & 39 \\
\hline 19 & HEMO_HUMAN & Hemopexin & 52385 & 6,55 & 129 & 40 \\
\hline 20 & HEMO_HUMAN & Hemopexin & 52385 & 6,55 & 149 & 41 \\
\hline 20 & CFAI_HUMAN & Complement factor I & 68072 & 7,72 & 82 & 29 \\
\hline 21 & HPT_HUMAN & Haptoglobin & 45861 & 6,13 & 97 & 37 \\
\hline 22 & HPT_HUMAN & Haptoglobin & 45861 & 6,13 & 84 & 35 \\
\hline 23 & A1AG1_HUMAN & Alpha-1-acid glycoprotein 1 & 23725 & 4,93 & 107 & 42 \\
\hline 24 & RETBP_HUMAN & Plasma retinol-binding protein & 23337 & 5,76 & 80 & 59 \\
\hline 25 & TETN_HUMAN & Tetranectin & 22951 & 5,52 & 100 & 58 \\
\hline 26 & RETBP_HUMAN & Plasma retinol-binding protein & 23337 & 5,76 & 80 & 51 \\
\hline 27 & FETUA_HUMAN & Alpha-2-HS-glycoprotein & 40098 & 5,43 & 67 & 22 \\
\hline 28 & APOH_HUMAN & Beta-2-glycoprotein 1 & 39584 & 8,34 & 85 & 26 \\
\hline
\end{tabular}


Identifizierungen Fraktion 3

\begin{tabular}{|c|c|c|c|c|c|c|}
\hline Spot & Swiss-Prot ID & Protein Beschreibung & $\begin{array}{c}\text { Masse } \\
\text { [Da] }\end{array}$ & $\begin{array}{l}\text { pl } \\
{[-]}\end{array}$ & $\begin{array}{c}\text { MOWSE } \\
{[-]}\end{array}$ & SC [\%] \\
\hline 1 & ALBU_HUMAN & Serum albumin & 71317 & 5,92 & 283 & 62 \\
\hline 2 & ALBU_HUMAN & Serum albumin & 71317 & 5,92 & 313 & 71 \\
\hline 3 & ALBU_HUMAN & Serum albumin & 71317 & 5,92 & 338 & 72 \\
\hline 4 & CFAH_HUMAN & Complement factor $\mathrm{H}$ & 143680 & 6,21 & 313 & 45 \\
\hline 5 & CERU_HUMAN & Ceruloplasmin & 122983 & 5,44 & 146 & 33 \\
\hline 5 & ALBU_HUMAN & Serum albumin & 71317 & 5,92 & 84 & 35 \\
\hline 6 & CERU_HUMAN & Ceruloplasmin & 122983 & 5,44 & 147 & 28 \\
\hline 7 & ALBU_HUMAN & Serum albumin & 71317 & 5,92 & 95 & 35 \\
\hline 7 & CO6_HUMAN & Complement component $\mathrm{C} 6$ & 108367 & 6,39 & 90 & 27 \\
\hline 8 & ALBU_HUMAN & Serum album & 71317 & 5,92 & 99 & 47 \\
\hline 8 & CO7_HUMAN & Complement component C7 & 96650 & 6,09 & 135 & 45 \\
\hline 9 & TRFE_HUMAN & Serotransferrin & 79280 & 6,81 & 225 & 54 \\
\hline 10 & TRFE_HUMAN & Serotransferrin & 79280 & 6,81 & 224 & 53 \\
\hline 11 & FA12_HUMAN & Coagulation factor XII & 70055 & 8,04 & 105 & 37 \\
\hline 12 & ALBU_HUMAN & Serum albumin & 71317 & 5,92 & 314 & 72 \\
\hline 13 & ALBU_HUMAN & Serum albumin & 71317 & 5,92 & 360 & 75 \\
\hline 14 & ALBU_HUMAN & Serum albumin & 71317 & 5,92 & 287 & 69 \\
\hline 15 & ALBU_HUMAN & Serum albumin & 71317 & 5,92 & 327 & 71 \\
\hline 16 & VTDB_HUMAN & Vitamin D-binding protein & 54526 & 5,4 & 112 & 56 \\
\hline 16 & ALBU_HUMAN & Serum album & 71317 & 5,92 & 80 & 36 \\
\hline 17 & FETUA_HUMAN & Alpha-2-HS-glycoprotein & 40098 & 5,43 & 76 & 25 \\
\hline 18 & A1AG2_HUMAN & Alpha- 1 -acid glycoprotein 2 & 23725 & 5,03 & 70 & 40 \\
\hline 19 & A1AG1_HUMAN & Alpha- 1 -acid glycoprotein 1 & 23725 & 4,93 & 84 & 44 \\
\hline 20 & APOA1_HUMAN & Apolipoprotein A-I & 30759 & 5,56 & 650 & 44 \\
\hline 20 & ZA2G_HUMAN & Zinc-alpha-2-glycoprotein & 34079 & 5,57 & 112 & 58 \\
\hline 21 & A1AT_HUMAN & Alpha-1-antitrypsin & 46787 & 5,37 & 275 & 66 \\
\hline 22 & AMBP_HUMAN & AMBP protein & 39886 & 5,95 & 52 & 28 \\
\hline 23 & ALBU_HUMAN & Serum albumin & 71317 & 5,92 & 156 & 53 \\
\hline 24 & ALBU_HUMAN & Serum albumin & 71317 & 5,92 & 164 & 45 \\
\hline 24 & GPX3_HUMAN & Glutathione peroxidase 3 & 25765 & 8,26 & 85 & 50 \\
\hline 25 & SAMP_HUMAN & Serum amyloid P-component & 25485 & 6,1 & 78 & 31 \\
\hline 26 & RETBP_HUMAN & Plasma retinol-binding protein & 23337 & 5,76 & 86 & 40 \\
\hline 27 & RETBP HUMAN & Plasma retinol-binding protein & 23337 & 5,76 & 110 & 51 \\
\hline
\end{tabular}

\section{Identifizierungen Fraktion 4}

\begin{tabular}{|c|c|c|c|c|c|c|}
\hline Spot & Swiss-Prot ID & Protein Beschreibung & $\begin{array}{l}\text { Masse } \\
\text { [Da] }\end{array}$ & $\begin{array}{l}\text { pl } \\
{[-]}\end{array}$ & $\begin{array}{c}\text { MOWSE } \\
{[-]}\end{array}$ & SC [\%] \\
\hline 1 & CFAH_HUMAN & Complement factor $\mathrm{H}$ & 143680 & 6,21 & 307 & 44 \\
\hline 2 & CERU_HUMAN & Ceruloplasmin & 122983 & 5,44 & 93 & 31 \\
\hline 2 & CFAH_HUMAN & Complement factor $\mathrm{H}$ & 143680 & 6,21 & 158 & 32 \\
\hline 3 & CERU_HUMAN & Ceruloplasmin & 122983 & 5,44 & 93 & 16 \\
\hline 4 & ANT3_HUMAN & Antithrombin-III & 53025 & 6,32 & 113 & 41 \\
\hline 5 & CO6_HUMAN & Complement component C6 & 108367 & 6,39 & 147 & 25 \\
\hline 6 & CFAB_HUMAN & Complement factor B & 86847 & 6,67 & 153 & 39 \\
\hline 7 & C1R_HUMAN & Complement $\mathrm{C} 1 \mathrm{r}$ subcomponent & 81661 & 5,89 & 97 & 31 \\
\hline 7 & THRB_HUMAN & Prothrombin & 71475 & 5,64 & 94 & 29 \\
\hline 8 & ANT3_HUMAN & Antithrombin-III & 53025 & 6,32 & 74 & 35 \\
\hline 8 & ANT3_HUMAN & Antithrombin-III & 53025 & 6,32 & 78 & 44 \\
\hline 9 & TRFE_HUMAN & Serotransferrin & 79280 & 6,81 & 304 & 56 \\
\hline 10 & ALBU_HUMAN & Serum albumin & 71317 & 5,92 & 187 & 47 \\
\hline 11 & ANT3_HUMAN & Antithrombin-III & 53025 & 6,32 & 68 & 30 \\
\hline 12 & CO3_HUMAN & Complement C3 & 188569 & 6,02 & 129 & 26 \\
\hline 13 & ALBU_HUMAN & Serum albumin & 71317 & 5,92 & 77 & 43 \\
\hline 13 & HEMO_HUMAN & Hemopexin & 52385 & 6,55 & 103 & 38 \\
\hline 14 & A1BG_HUMAN & Alpha-1B-glycoprotein & 54809 & 5,58 & 93 & 33 \\
\hline 15 & KNG1_HUMAN & Kininogen-1 & 72996 & 6,34 & 120 & 34 \\
\hline 16 & VTDB_HUMAN & Vitamin D-binding protein & 54526 & 5,4 & 179 & 66 \\
\hline 17 & FETUA_HUMAN & Alpha-2-HS-glycoprotein & 40098 & 5,43 & 66 & 25 \\
\hline 18 & ZA2G_HUMAN & Zinc-alpha-2-glycoprotein & 34079 & 5,57 & 112 & 44 \\
\hline 19 & CLUS_HUMAN & Clusterin & 53031 & 5,89 & 72 & 30 \\
\hline 20 & HPT_HUMAN & Haptoglobin & 45861 & 6,13 & 86 & 32 \\
\hline 21 & HEMO_HUMAN & Hemopexin & 52385 & 6,55 & 105 & 30 \\
\hline 21 & ANT3_HUMAN & Antithrombin-III & 53025 & 6,32 & 84 & 44 \\
\hline 22 & APOH_HUMAN & Beta-2-glycoprotein 1 & 39584 & 8,34 & 88 & 41 \\
\hline 22 & ALBU_HUMAN & Serum albumin & 71317 & 5,92 & 61 & 28 \\
\hline 23 & ALBU_HUMAN & Serum albumin & 71317 & 5,92 & 64 & 30 \\
\hline 23 & HEMO_HUMAN & Hemopexin & 52385 & 6,55 & 62 & 28 \\
\hline 24 & APOA1_HUMAN & Apolipoprotein A-I & 30759 & 5,56 & 167 & 62 \\
\hline 25 & RET4_HUMAN & Plasma retinol-binding protein & 23337 & 5,76 & 90 & 63 \\
\hline 25 & APOA1_HUMAN & Apolipoprotein A-I & 30759 & 5,56 & 110 & 50 \\
\hline 26 & RETBP_HUMAN & Plasma retinol-binding protein & 23337 & 5,76 & 74 & 43 \\
\hline 26 & APOA1_HUMAN & Apolipoprotein A-I & 30759 & 5,56 & 148 & 61 \\
\hline 27 & A1AG1_HUMAN & Alpha-1-acid glycoprotein 1 & 23725 & 4,93 & 94 & 40 \\
\hline
\end{tabular}




\section{Identifizierungen Fraktion 5}

\begin{tabular}{|c|c|c|c|c|c|c|}
\hline Spot & Swiss-Prot ID & Protein Beschreibung & $\begin{array}{c}\text { Masse } \\
\text { [Da] }\end{array}$ & $\begin{array}{l}\text { pl } \\
{[-]}\end{array}$ & $\begin{array}{c}\text { MOWSE } \\
{[-]}\end{array}$ & SC [\%] \\
\hline 1 & CFAH_HUMAN & Complement factor $\mathrm{H}$ & 143680 & 6,21 & 140 & 35 \\
\hline 2 & APOA1_HUMAN & Apolipoprotein A-I & 30759 & 5,56 & 95 & 57 \\
\hline 3 & CO3_HUMAN & Complement $\mathrm{C}_{3}$ & 188569 & 6,02 & 190 & 35 \\
\hline 4 & CFAB_HUMAN & Complement factor B & 86847 & 7 & 161 & 30 \\
\hline 5 & TRFE_HUMAN & Serotransferrin & 79280 & 7 & 311 & 56 \\
\hline 6 & ALBU HUMAN & Serum albumin & 713170 & 5,92 & 131 & 27 \\
\hline 6 & CO3_HUMAN & Complement $\mathrm{C} 3$ & 188569 & 6,02 & 141 & 35 \\
\hline 7 & HEMO_HUMAN & Hemopexin & 52385 & 6,55 & 74 & 26 \\
\hline 7 & ALBU_HUMAN & Serum albumin & 713170 & 5,92 & 100 & 24 \\
\hline 8 & A1AT_HUMAN & Alpha-1-antitrypsin & 46878 & 5,37 & 215 & 58 \\
\hline 9 & A1BG_HUMAN & Alpha-1B-glycoprotein & 54809 & 5,58 & 64 & 26 \\
\hline 9 & A2GL_HUMAN & Leucine-rich alpha-2-glycoprotein & 38382 & 6 & 114 & 47 \\
\hline 9 & KNG1_HUMAN & Kininogen-1 & 72996 & 6,34 & 109 & 29 \\
\hline 10 & FETUA HUMAN & Alpha-2-HS-glycoprotein & 40098 & 5,43 & 73 & 25 \\
\hline 12 & APOA4_HUMAN & Apolipoprotein A-IV & 45371 & 5,28 & 218 & 59 \\
\hline 13 & VTDB_HUMAN & Vitamin D-binding protein & 54526 & 5 & 70 & 25 \\
\hline 15 & APOA1_HUMAN & Apolipoprotein A-I & 30759 & 5,56 & 157 & 63 \\
\hline 16 & APOA1_HUMAN & Apolipoprotein A-I & 30759 & 5,56 & 219 & 61 \\
\hline 17 & A1AG1 HUMAN & Alpha-1-acid glycoprotein 1 & 23725 & 5 & 70 & 42 \\
\hline
\end{tabular}

\section{Identifizierungen Fraktion 6}

\begin{tabular}{|c|c|c|c|c|c|c|}
\hline Spot & Swiss-Prot ID & Protein Beschreibung & $\begin{array}{c}\text { Masse } \\
\text { [Da] }\end{array}$ & pl & $\begin{array}{c}\text { MOWSE } \\
{[-]}\end{array}$ & Sc [\%] \\
\hline 1 & CFAH_HUMAN & Complement factor $\mathrm{H}$ & 143680 & 6,21 & 123 & 22 \\
\hline 2 & A2MG_HUMAN & Alpha-2-macroglobulin & 164600 & 6 & 88 & 23 \\
\hline 2 & CO3_HUMAN & Complement $\mathrm{C} 3$ & 188569 & 6,02 & 102 & 27 \\
\hline 3 & TRFE_HUMAN & Serotransferrin & 79280 & 6,81 & 241 & 51 \\
\hline 4 & HEMO_HUMAN & Hemopexin & 52385 & 6,55 & 84 & 33 \\
\hline 5 & HEMO_HUMAN & Hemopexin & 52385 & 6,55 & 92 & 35 \\
\hline 6 & AFAM_HUMAN & Afamin & 70963 & 5,64 & 80 & 25 \\
\hline 7 & VTDB_HUMAN & Vitamin D-binding protein & 54526 & 5,4 & 138 & 57 \\
\hline 7 & A1AT_HUMAN & Alpha-1-antitrypsin & 46878 & 5,37 & 106 & 39 \\
\hline 8 & A1AT_HUMAN & Alpha-1-antitrypsin & 46878 & 5,37 & 148 & 56 \\
\hline 9 & ALBU_HUMAN & Serum albumin & 71317 & 5,92 & 145 & 39 \\
\hline 10 & FETUA_HUMAN & Alpha-2-HS-glycoprotein & 40098 & 5,43 & 58 & 23 \\
\hline 11 & ALBU_HUMAN & Serum albumin & 71317 & 5,92 & 83 & 29 \\
\hline 12 & APOA4_HUMAN & Apolipoprotein A-IV & 45371 & 5,28 & 211 & 61 \\
\hline 13 & HEMO_HUMAN & Hemopexin & 52385 & 6,55 & 55 & 20 \\
\hline 13 & ALBU_HUMAN & Serum albumin & 71317 & 5,92 & 124 & 30 \\
\hline 14 & CO3_HUMAN & Complement C3 & 188569 & 6,02 & 180 & 31 \\
\hline 15 & CO3_HUMAN & Complement C3 & 188569 & 6,02 & 207 & 30 \\
\hline 16 & APOA1_HUMAN & Apolipoprotein A-I & 30759 & 5,56 & 70 & 49 \\
\hline 17 & APOE_HUMAN & Apolipoprotein E & 36246 & 5,65 & 103 & 53 \\
\hline 17 & APOA4_HUMAN & Apolipoprotein A-IV & 45371 & 5,28 & 80 & 40 \\
\hline 17 & APOA1_HUMAN & Apolipoprotein A-I & 30759 & 5,56 & 74 & 50 \\
\hline 18 & APOA1_HUMAN & Apolipoprotein A-I & 30759 & 5,56 & 167 & 62 \\
\hline 19 & A1AG1_HUMAN & Alpha-1-acid glycoprotein 1 & 23725 & 5 & 70 & 42 \\
\hline 20 & A1AG1_HUMAN & Alpha-1-acid glycoprotein 1 & 23725 & 5 & 84 & 40 \\
\hline
\end{tabular}




\subsubsection{Identifizierungen und Quantifizierungen der Proteine der DIGE-Gele}

DIGE 2D-SDS-PAGE depletiertes Serum (Agilent Human 6 Depletionssäule)

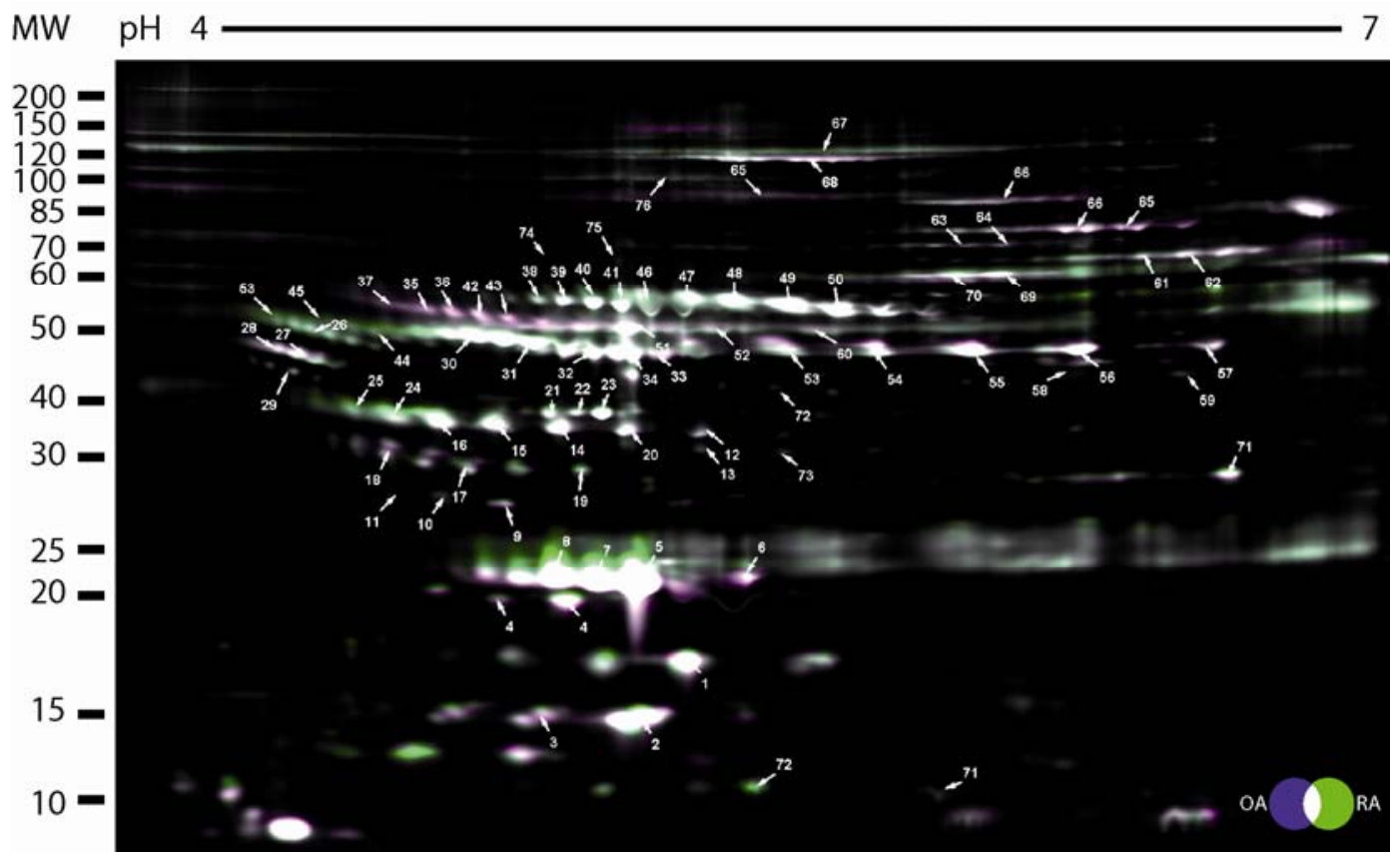

Identifizierungen

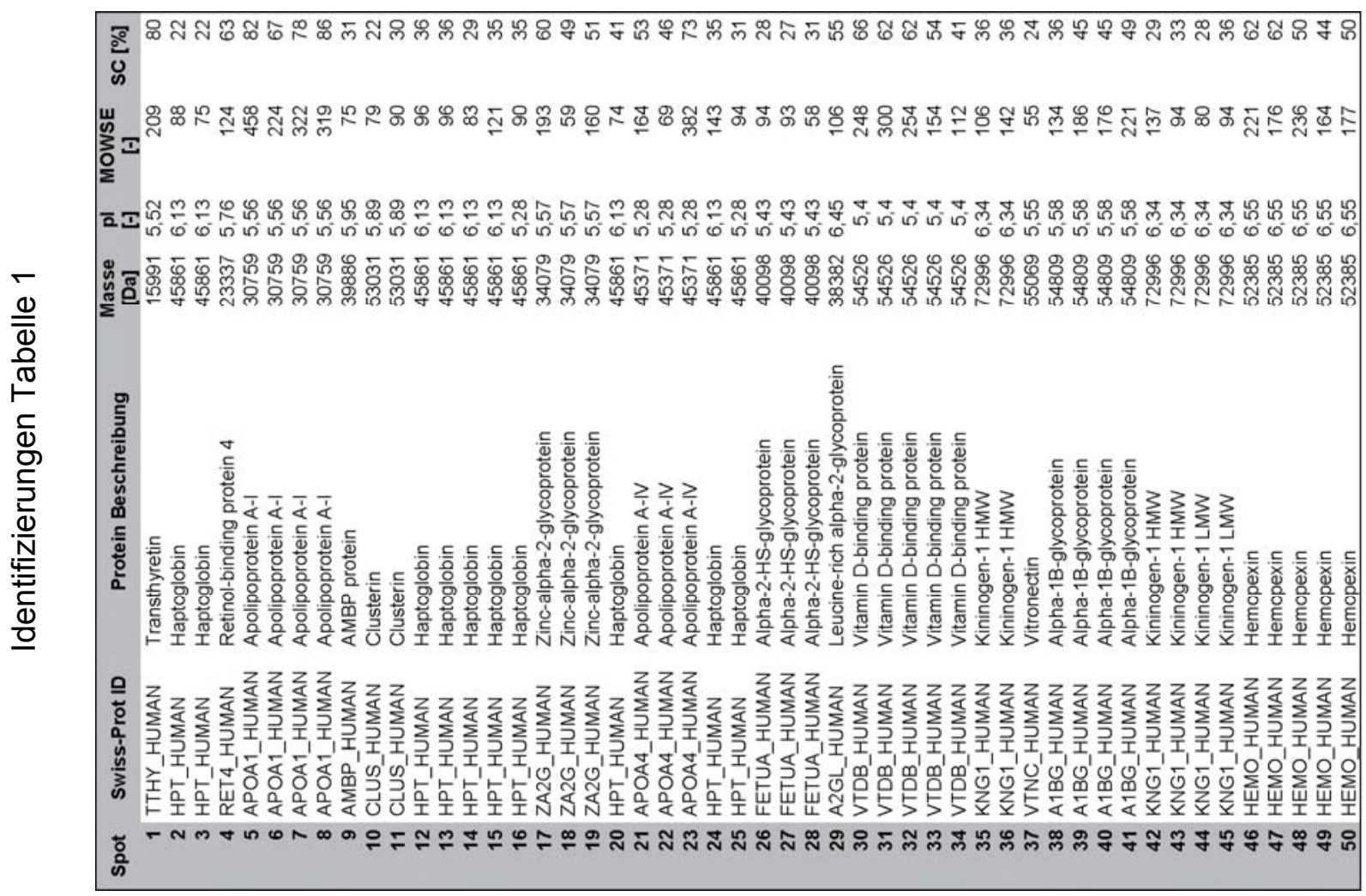




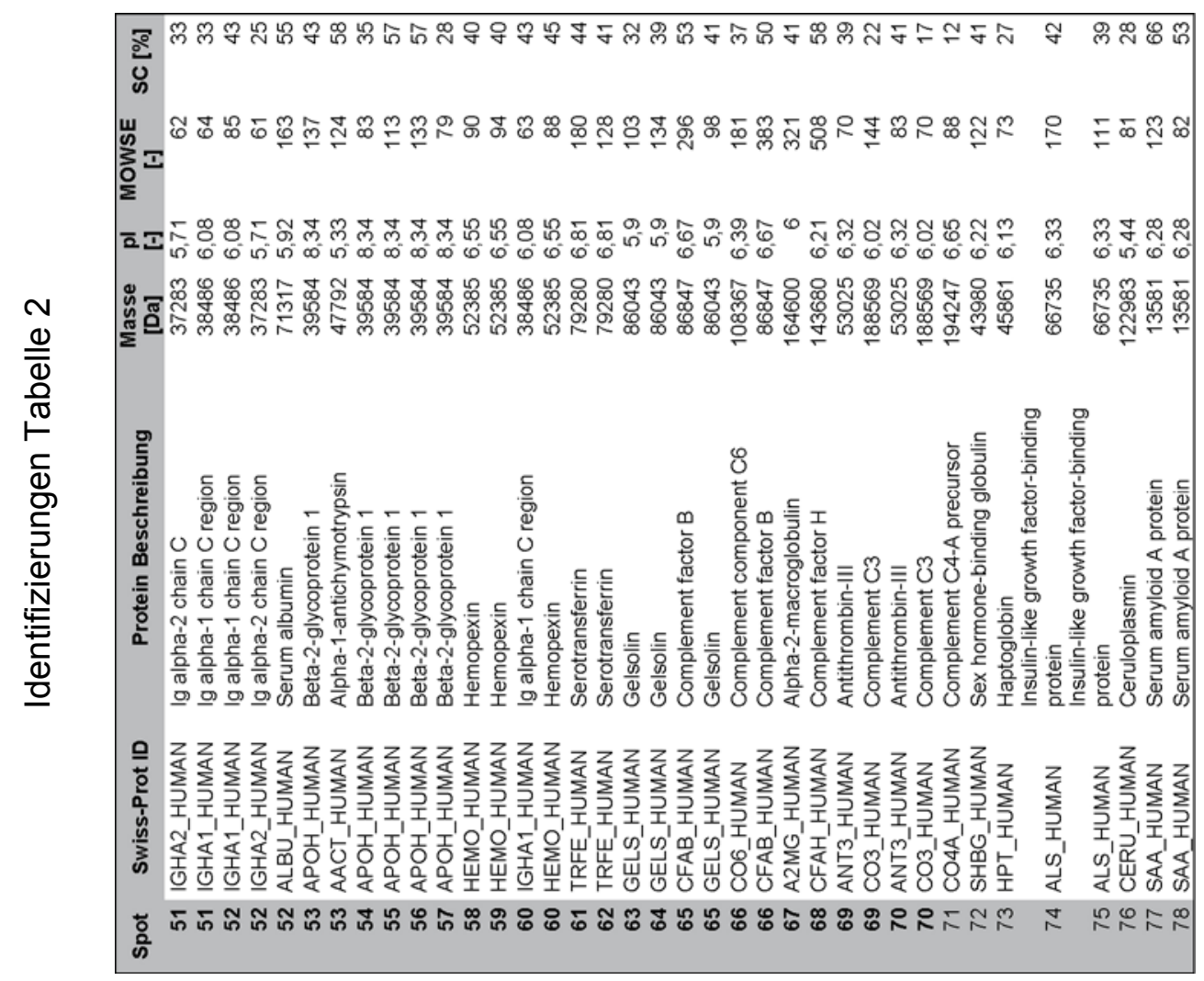




\section{Auswertung DIGE-Experiment A}

\begin{tabular}{|c|c|c|c|c|c|c|c|c|c|c|c|c|}
\hline \multirow{2}{*}{ ID } & \multirow{2}{*}{ Protein } & \multicolumn{3}{|c|}{ DIGE-Gele } & \multirow{2}{*}{ MW } & \multirow{2}{*}{$\begin{array}{l}\text { SD } \\
{[\%]}\end{array}$} & \multicolumn{3}{|c|}{ DIGE-Gele } & \multirow{2}{*}{ MW } & \multirow{2}{*}{$\begin{array}{l}\text { SD } \\
\text { [\%] }\end{array}$} & \multirow{2}{*}{$\begin{array}{c}\text { Ratio } \\
{[-]}\end{array}$} \\
\hline & & RA 1 & RA 2 & RA 3 & & & OA 1 & OA 2 & OA 3 & & & \\
\hline A1BG_HUMAN & Alpha-1B-gycoprotein & 1,039 & 0,999 & 0,966 & 1,001 & 2,974 & 0,934 & 0,991 & 1,017 & 0,981 & 3,466 & 0,979 \\
\hline A2GL_HUMAN & Leucine alpha-2-glycoprotein & 1,115 & 0,999 & 1,028 & 1,047 & 4,944 & 0,842 & 0,991 & 0,993 & 0,942 & 7,054 & 0,899 \\
\hline A2MG_HUMAN & Alpha-2-macroglobulin & 1,102 & 1,012 & 1,065 & 1,060 & 3,676 & 0,842 & 0,980 & 0,944 & 0,922 & 5,834 & 0,870 \\
\hline ANT3_HUMAN & Antithrombin-III & 1,082 & 1,009 & 0,998 & 1,030 & 3,736 & 0,881 & 0,986 & 0,994 & 0,954 & 5,138 & 0,926 \\
\hline APOA1_HUMAN & Apolipqprotein A-I & 0,908 & 1,175 & 1,158 & 1,081 & 12,212 & 1,143 & 0,884 & 0,895 & 0,974 & 11,942 & 0,901 \\
\hline APOA4_HUMAN & Apolipoprotein A-IV & 1,037 & 0,975 & 0,996 & 1,003 & 2,545 & 0,941 & 1,014 & 0,997 & 0,984 & 3,087 & 0,981 \\
\hline APOH_HUMAN & Beta-2-glycoprotein 1 & 4,967 & 4,167 & 4,336 & 4,490 & 34,427 & 4,989 & 5,598 & 5,466 & 5,351 & 26,165 & 1,192 \\
\hline CFAB_HUMAN & Complement factor B & 1,025 & 0,811 & 0,819 & 0,885 & 9,895 & 0,954 & 1,132 & 1,126 & 1,071 & 8,222 & 1,209 \\
\hline CFAH_HUMAN & Complement factor $\mathrm{H}$ & 1,013 & 0,952 & 0,948 & 0,971 & 2,994 & 0,968 & 1,028 & 1,030 & 1,009 & 2,903 & 1,039 \\
\hline CLUS_HUMAN & Clusterin & 0,954 & 0,885 & 0,904 & 0,914 & 2,921 & 1,064 & 1,088 & 1,064 & 1,072 & 1,118 & 1,173 \\
\hline CO4A_HUMAN & Complement C4-A precursor & 1,043 & 0,975 & 0,989 & 1,002 & 2,914 & 0,938 & 1,010 & 1,004 & 0,984 & 3,252 & 0,982 \\
\hline CO6_HUMAN & Complement component C6 & 1,007 & 0,831 & 0,843 & 0,893 & 8,047 & 0,976 & 1,112 & 1,104 & 1,064 & 6,226 & 1,191 \\
\hline FETUA_HUMAN & Alpha-2-HSglycoprotein & 1,019 & 0,834 & 0,861 & 0,905 & 8,157 & 0,968 & 1,123 & 1,105 & 1,066 & 6,913 & 1,178 \\
\hline GELS_HUMAN & Gelsolin & 1,035 & 0,877 & 0,896 & 0,936 & 7,046 & 0,938 & 1,082 & 1,057 & 1,026 & 6,291 & 1,096 \\
\hline HEMO_HUMAN & Hemopexin & 1,023 & 0,945 & 0,962 & 0,977 & 3,343 & 0,956 & 1,032 & 1,020 & 1,003 & 3,345 & 1,027 \\
\hline HPT_HUMAN & Haptoglobin - LMW & 1,134 & 1,057 & 1,041 & 1,077 & 4,051 & 0,819 & 0,952 & 0,966 & 0,912 & 6,625 & 0,847 \\
\hline HPT_HUMAN & Haptoglobin - HMW & 2,343 & 2,241 & 2,226 & 2,270 & 5,206 & 1,616 & 1,853 & 1,866 & 1,778 & 11,474 & 0,783 \\
\hline IGHA1_HUMAN & Ig alpha- 1 chain $\mathrm{C}$ region & 0,986 & 0,908 & 0,900 & 0,931 & 3,872 & 1,005 & 1,057 & 1,067 & 1,043 & 2,722 & 1,120 \\
\hline KNG1_HUMAN & Kininogen-1 LMW & 1,156 & 1,095 & 1,117 & 1,123 & 2,499 & 0,789 & 0,923 & 0,911 & 0,874 & 6,052 & 0,779 \\
\hline KNG1_HUMAN & Kininogen-1 HMW & 0,903 & 0,810 & 0,805 & 0,839 & 4,524 & 1,126 & 1,144 & 1,150 & 1,140 & 0,999 & 1,358 \\
\hline RET4_HUMAN & Retind-binding protein 4 & 3,256 & 2,982 & 2,918 & 3,052 & 14,640 & 2,651 & 3,009 & 3,046 & 2,902 & 17,837 & 0,951 \\
\hline SAA_HUMAN & Serum amyloid A protein & 2,668 & 2,687 & 2,610 & 2,655 & 3,259 & 1,245 & 1,541 & 1,586 & 1,457 & 15,120 & 0,549 \\
\hline TRFE_HUMAN & Serotransferrin & 0,996 & 0,937 & 0,941 & 0,958 & 2,710 & 0,992 & 1,030 & 1,032 & 1,018 & 1,833 & 1,063 \\
\hline TTHY_HUMAN & Transthyretin & 0,942 & 0,845 & 0,829 & 0,872 & 4,987 & 1,078 & 1,125 & 1,139 & 1,114 & 2,582 & 1,277 \\
\hline VTDB_HUMAN & Vitamin D-binding protein & 2,180 & 1,905 & 1,912 & 1,999 & 12,808 & 1,749 & 2,056 & 2,050 & 1,951 & 14,331 & 0,976 \\
\hline ZA2G_HUMAN & Zinc-alpha-2-glycoprotein & 3,020 & 2,712 & 2,771 & 2,834 & 13,343 & 2,951 & 3,177 & 3,144 & 3,091 & 9,983 & 1,090 \\
\hline AACT_HUMAN & Alpha-1 antichymotrypsin & 1,129 & 0,984 & 0,994 & 1,036 & 6,613 & 0,826 & 1,004 & 0,995 & 0,942 & 8,190 & 0,909 \\
\hline
\end{tabular}

Tabelle 14 Spotquantitäten der 26 untersuchten Proteine des DIGE-Experimentes A. Vergleich von depletiertem Serum der Gruppe Rheuma (RA) mit dem der Gruppe Osteoarthrose (OA). (MW) Mittelwert; (SD) Standardabweichung, (Ratio) Quotient der Mittelwerte der Vergleichgruppen. Spotquantitäten sind in Volumen-Prozent angegeben.

\section{Auswertung DIGE-Experiment B}

\begin{tabular}{|c|c|c|c|c|c|c|c|c|c|c|c|c|c|c|}
\hline \multirow{2}{*}{ ID } & \multirow{2}{*}{ Protein } & \multicolumn{4}{|c|}{ DIGE-Gele } & \multirow{2}{*}{ MW } & \multirow{2}{*}{$\begin{array}{l}\text { SD } \\
\text { [\%] }\end{array}$} & \multicolumn{4}{|c|}{ DIGEGele } & \multirow{2}{*}{ MW } & \multirow{2}{*}{$\begin{array}{l}\text { SD } \\
\text { [\%] }\end{array}$} & \multirow{2}{*}{$\begin{array}{c}\text { Ratio } \\
{[-]}\end{array}$} \\
\hline & & RA 1 & RA 2 & RA 3 & RA4 & & & OA1 & OA2 & OA3 & OA4 & & & \\
\hline A1BG_HUMAN & Alpha-1B-gkcoprotein & 0,948 & 0,936 & 0,985 & 0,998 & 0,967 & 2,564 & 1,037 & 1,044 & 1,015 & 0,988 & 1,021 & 2,165 & 1,056 \\
\hline A2GL HUMAN & Leucine alpha-2-glycoprotein & 1,037 & 1,003 & 0,994 & 0,981 & 1,004 & 2,082 & 0,952 & 0,971 & 1,005 & 1,040 & 0,992 & 3,357 & 0,988 \\
\hline A2MG_HUMAN & Alpha-2macrogldulin & 0,886 & 0,868 & 0,919 & 0,913 & 0,897 & 2,052 & 1,089 & 1,097 & 1,177 & 1,179 & 1,135 & 4,240 & 1,266 \\
\hline ANT3_HUNAN & Antithrombin-III & 0,949 & 0,970 & 1,028 & 1,007 & 0,988 & 3,086 & 1,035 & 1,007 & 0,957 & 1,040 & 1,010 & 3,281 & 1,021 \\
\hline APOA1_HUMA & Apolipqrotein A-I & 0,721 & 0,723 & 0,853 & 0,849 & 0,786 & 6,438 & 1,254 & 1,243 & 1,381 & 1,381 & 1,315 & 6,659 & 1,672 \\
\hline APOA4_HUMA & Apolipqrotein A-IV & 0,952 & 0,959 & 1,102 & 1,059 & 1,018 & 6,421 & 1,035 & 1,029 & 0,784 & 0,867 & 0,929 & 10,73 & 0,912 \\
\hline APOH_HUMAN & Beta-2-glyoprotein1 & 0,964 & 0,938 & 0,961 & 0,968 & 0,958 & 1,174 & 1,025 & 1,042 & 1,078 & 1,058 & 1,051 & 1,987 & 1,097 \\
\hline CFAB_HUMAN & Complement factorB & 1,001 & 0,939 & 0,909 & 0,892 & & 4,146 & 0,988 & 1,037 & 1,196 & & 1,116 & 10,624 & 1,193 \\
\hline CFAH_HUMAN & Com & & 0,916 & 0,977 & 0,961 & & & & & 1,044 & & & & 1,124 \\
\hline CLUS_HUMAN & Clust & 0,905 & 0,910 & 0,932 & 0,9 & & 1,6 & 1,0 & & 1,151 & & 1,108 & & 1,201 \\
\hline CO4ĀHUMAN & Com & 0,960 & 0,963 & 0,914 & 0,889 & & 3,1 & 1,0 & & 89 & & 1,127 & & 1,210 \\
\hline CO6_HUMAN & Com & 0,8 & 0,868 & 0,896 & 0,9 & & 1,8 & 1,0 & & 1,234 & & & & 1,296 \\
\hline FETUĀHUMAN & Alph & & 1,111 & 1,053 & 1,0 & & & 0,865 & $0, \varepsilon$ & 0,876 & & & 11 & 0,805 \\
\hline GELS_HUMAN & & & 0,868 & 0,896 & 0,9 & & & 1,090 & 1,0 & 1,234 & & & 87 & 1,296 \\
\hline HEMO_HUMAN & & & 0,927 & 0,976 & & & & 1,0 & & & & & & 1,093 \\
\hline HPT_HUMAN & Hap & & 1,049 & 1,025 & 1,037 & & & 0,952 & & 0,937 & & & & 0,903 \\
\hline HPT_HUMAN & & & 1,119 & 1,022 & 1,028 & & 5,458 & 0,901 & & 0,973 & & & & 0,866 \\
\hline IGHA1_HUMAN & & & & 0,957 & & & & 1,144 & & 1,021 & & & 627 & 1,252 \\
\hline & & & & & & & & & & 908 & & & & 0,795 \\
\hline JMAN & & & & & & & & & & 192 & & & & 1,334 \\
\hline & & & & & & & & & & 14 & & & & 0,929 \\
\hline & & & & 1,185 & & & & & & 0,910 & & & & 0,793 \\
\hline TRFE_HUMAN & Sero & 0,890 & 0,798 & 0,884 & 0,882 & & 3,796 & 1,084 & 1,152 & 1,261 & 1,260 & 1,189 &, 548 & 1,378 \\
\hline TTHY HUMAN & Tran & 0,843 & 0,825 & 0,923 & 0,929 & & 4,637 & 1,139 & 1,143 & 1,177 & & & 458 & 1,311 \\
\hline VTDB_HUMAN & Vitan & 0,971 & 0,985 & 1,007 & 0,970 & & 1,506 & 1,019 & & 0,970 & & & & 1,029 \\
\hline ZA2G HUMAN & Zinc- & 1,178 & 1,159 & 1,076 & 1,072 & & 4,776 & 0,848 & 0,875 & 0,837 & & & 1,361 & 0,760 \\
\hline AACT HUMAN & Alpha-1 antichymotrypsin & 1,040 & 0,996 & 1,022 & 1,017 & 1,019 & 1,564 & 0,962 & 0,994 & 0,934 & 0,953 & 0,961 & 2,165 & 0,943 \\
\hline
\end{tabular}

Tabelle 15: Spotquantitäten der 26 untersuchten Proteine des DIGE-Experimentes B. Vergleich von depletiertem Serum der Gruppe Rheuma (RA) mit dem der Gruppe Osteoarthrose (OA). (MW) Mittelwert; (SD) Standardabweichung, (Ratio) Quotient der Mittelwerte der Vergleichgruppen. Spotquantitäten sind in Volumen-Prozent angegeben. 
Auswertung DIGE-Experiment C

\begin{tabular}{|c|c|c|c|c|c|c|c|c|c|c|c|c|c|c|}
\hline \multirow{2}{*}{ ID } & \multirow{2}{*}{ Protein } & \multicolumn{4}{|c|}{ DIGEGele } & \multirow{2}{*}{ MW } & \multirow{2}{*}{$\begin{array}{l}\text { SD } \\
{[\%]}\end{array}$} & \multicolumn{4}{|c|}{ DIGE.Gele } & \multirow{2}{*}{ MW } & \multirow{2}{*}{$\begin{array}{l}\text { SD } \\
{[\%]}\end{array}$} & \multirow{2}{*}{$\begin{array}{c}\text { Ratio } \\
{[-]}\end{array}$} \\
\hline & & RA 1 & RA 2 & RA 3 & RA4 & & & G 1 & G 2 & G 3 & G 4 & & & \\
\hline A1BG_HUMAN & Alpha-1B-glcoprotein & 1,005 & 0,939 & 0,977 & 0,957 & 0,969 & 2,431 & 0,965 & 1,054 & 1,005 & 1,025 & 1,012 & 3,224 & 1,044 \\
\hline A2GL_HUMAN & Leucine alpha-2-glycoprotein & 1,241 & 1,223 & 1,277 & 1,268 & 1,252 & 2,126 & 0,611 & 0,686 & 0,696 & 0,686 & & 3,418 & 0,535 \\
\hline A2MG_HUMAN & Alpha-2macrogldulin & 1,022 & 1,045 & 1,018 & 1,020 & 1,026 & 1,101 & 0,925 & 0,913 & 0,950 & 0,947 & & & 0,910 \\
\hline ANT3_HUMAN & ntithrombin-III & 1,009 & 1,037 & 0,961 & 0,954 & 0,990 & 3,416 & 0,948 & 0,940 & 1,021 & 1,026 & & $4,0 œ 3$ & 0,994 \\
\hline APOA-1_HUMA & polipprotein A-I & 0,877 & 0,914 & 0,947 & 0,949 & 0,922 & 2,939 & 1,195 & 1,085 & 1,036 & 1,038 & 1,088 & 6,437 & 1,181 \\
\hline APOA4_HUMA & polipqrotein A-IV & 1,294 & 1,190 & 1,312 & 1,262 & 1,265 & 4,658 & 0,589 & 0,818 & 0,730 & 0,758 & 0,724 & 8,416 & 0,572 \\
\hline APOH_HUMAN & Beta-2-glyoprotein1 & 5,142 & 5,298 & 4,985 & 4,998 & 5,106 & 12,714 & 4,614 & 4,607 & 4,901 & & 4,756 & 14,572 & 0,932 \\
\hline CFAB_HUMAN & Complement factorB & 1,115 & 1,135 & 1,156 & 1,118 & 1,131 & 1,608 & 0,780 & 0,815 & 0,820 & 0,846 & & 2,333 & 0,721 \\
\hline CFAH_HUMAN & omplement factorH & 1,125 & 1,139 & 1,124 & 1,149 & 1,134 & 1,022 & 0,787 & 0,846 & 0,860 & & & & 0,735 \\
\hline CLUS_HUMAN & Clusterin & 1,231 & 1,159 & 1,255 & 1,292 & 1,234 & 4,873 & 0,598 & 0,810 & 0,761 & & & 7,851 & 0,584 \\
\hline CO4A_HUMAN & ment C4-A precursor & 1,046 & 1,075 & 1,031 & 1,034 & 1,0 & 1,727 & 0,878 & 0,891 & 0,936 & 0,928 & & & 0,868 \\
\hline CO6_HUMAN & ment component C6 & 1,089 & 1,066 & 1,094 & 1,071 & 1,0 & & 0,827 & 0,897 & 0,887 & & & & 0,814 \\
\hline FETUA_HUMAN & Alph & 0,856 & 0,815 & 0,782 & 0,804 & & 2,6 & 1,223 & 1,196 & 1,209 & & & 321 & 1,478 \\
\hline GELS_HUMAN & Gels & 0,933 & 0,934 & 0,903 & 0,893 & 0,9 & 1,835 & 1,069 & 1,057 & 1,082 & 1,089 & & 1,244 & 1,173 \\
\hline HEMO_HUMAN & Hem & 1,008 & 0,996 & 0,950 & 0,980 & 0,9 & 2,1 & 0,962 & 0,993 & 1,027 & 1,0 & & & 1,012 \\
\hline HPT_HUMAN & Hap & 1,287 & 1,196 & 1,351 & 1,285 & 1,279 & 5,568 & 0,575 & 0,796 & 0,699 & 0,742 & 0,703 & 8,105 & 0,549 \\
\hline HPT_HUMAN & HMW & 2,816 & 3,033 & 3,097 & 2,995 & 2,985 & 10,41 & 0,786 & 0,947 & 1,042 & 1,061 & 0,9 & 10,893 & 0,321 \\
\hline IGHĀ1_HUMAN & C region & 1,222 & 1,250 & 1,255 & 1,250 & 1,244 & 1,325 & 0,635 & 0,721 & 0,745 & 0,747 & 0,712 & 4,570 & 0,572 \\
\hline KNG1_HUMAN & & 0,828 & 0,820 & 0,772 & 0,808 & & 2,172 & 1,271 & 1,186 & 1,221 & 1,186 & & 3,500 & 1,507 \\
\hline KNG1_HUMAN & MW & 1,182 & 1,028 & 1,181 & 1,076 & 1,117 & 6,659 & 0,711 & 0,956 & 0,832 & 0,918 & & 9,403 & 0,765 \\
\hline RET4_HUMAN & & 4,691 & 5,199 & 5,418 & 5,375 & 5,1 & 28,901 & 0,815 & 1,030 & 1,066 & 1,044 & 0,9 & 10,131 & 0,191 \\
\hline SAA_HUMAN & protein & 3,248 & 3,608 & 3,981 & 3,831 & 3,6 & 27,5 & 0,225 & 0,342 & 0,225 & 0,304 & & & 0,075 \\
\hline TRFE_HUMAN & in & 0,499 & 0,446 & 0,384 & 0,380 & 0,4 & 4,901 & 2,056 & 1,781 & 1,794 & 1,834 & 1,866 & 11,133 & 4,367 \\
\hline TTHY_HUMAN & & 0,916 & 0,889 & 0,822 & 0,835 & 0,8 & 3,860 & 1,1 & 1,119 & 1,167 & 1,158 & 1,1 & & 1,319 \\
\hline VTDB_HUMAN & & 1,415 & 1,335 & 1,206 & 1,215 & & & 3,1 & 2,900 & 2,961 & 2,991 & & 10 & 2,326 \\
\hline ZA2G_HUMAN & & 2,906 & 2,847 & 2,712 & 2,791 & & & 3,058 & 3,129 & 3,263 & 3,181 & & & 1,122 \\
\hline AACT_HUMAN & Alpha-1 antichymotrypsin & 1,480 & 1,247 & 1,620 & 1,459 & 1,451 & 13,333 & 0,407 & 0,764 & 0,542 & 0,626 & 0,585 & 12,966 & 0,403 \\
\hline
\end{tabular}

Tabelle 16: Spotquantitäten der 26 untersuchten Proteine des DIGE-Experimentes C. Vergleich von depletiertem Serum der Gruppe Rheuma (RA) mit dem der Gruppe Gesund (GES). (MW) Mittelwert; (SD) Standardabweichung, (Ratio) Quotient der Mittelwerte der Vergleichgruppen. Spotquantitäten sind in Volumen-Prozent angegeben.

\section{Auswertung DIGE-Experiment D}

\begin{tabular}{|c|c|c|c|c|c|c|c|c|c|c|c|c|}
\hline \multirow{2}{*}{ ID } & \multirow{2}{*}{ Protein } & \multicolumn{3}{|c|}{ DIGE-Gele } & \multirow{2}{*}{ MW } & \multirow{2}{*}{$\begin{array}{l}\text { SD } \\
{[\%]}\end{array}$} & \multicolumn{3}{|c|}{ DIGE-Gele } & \multirow{2}{*}{ MW } & \multirow{2}{*}{$\begin{array}{l}\text { SD } \\
{[\%]}\end{array}$} & \multirow{2}{*}{$\begin{array}{c}\text { Ratio } \\
{[-]}\end{array}$} \\
\hline & & RA 1 & RA 2 & RA 3 & & & G 1 & G 2 & G 3 & & & \\
\hline A1BG_HUMAN & Alpha-1B-gycoprotein & 1,276 & 1,104 & 1,262 & 1,214 & 7,790 & 0,796 & 0,863 & 0,818 & 0,826 & 2,768 & 0,680 \\
\hline A2GL HUMAN & Leucine alpha-2-glycoprotein & 1,261 & 1,240 & 1,093 & 1,198 & 7,491 & 0,647 & 0,803 & 0,851 & 0,767 & 8,714 & 0,640 \\
\hline A2MG_HUMAN & Alpha-2-macroglobulin & 0,838 & 1,183 & 1,124 & 1,048 & 15,059 & 1,215 & 0,756 & 0,876 & 0,949 & 19,442 & 0,905 \\
\hline ANT3_HUMAN & Antithrombin-III & 1,017 & 0,972 & 0,954 & 0,981 & 2,617 & 0,938 & 1,014 & 1,002 & 0,984 & 3,341 & 1,004 \\
\hline APOA1_HUMAN & Apolipqprotein A-I & 1,042 & 1,008 & 1,043 & 1,031 & 1,646 & 0,950 & 0,968 & 0,935 & 0,951 & 1,338 & 0,922 \\
\hline APOA4_HUMAN & Apolipoprotein A-IV & 1,355 & 1,572 & 1,330 & 1,419 & 10,873 & 0,567 & 0,607 & 0,634 & 0,603 & 2,752 & 0,425 \\
\hline APOH_HUMAN & Beta-2-glyøprotein 1 & 1,061 & 1,020 & 1,080 & 1,054 & 2,504 & 0,885 & 0,950 & 0,862 & 0,899 & 3,724 & 0,853 \\
\hline CFAB_HUMAN & Complement factor B & 1,089 & 1,071 & 1,145 & 1,102 & 3,169 & 0,868 & 0,930 & 0,782 & 0,860 & 6,089 & 0,780 \\
\hline CFAH_HUMAN & Complement factor $\mathrm{H}$ & 1,028 & 1,190 & 0,964 & 1,060 & 9,521 & 0,937 & 0,768 & 1,002 & 0,902 & 9,895 & 0,851 \\
\hline CLUS_HUMAN & Clusterin & 1,339 & 1,418 & 1,343 & 1,367 & 3,644 & 0,558 & 0,724 & 0,628 & 0,637 & 6,831 & 0,466 \\
\hline CO4A_HUMAN & Complement C4-A precursor & 0,857 & 0,977 & 0,828 & 0,887 & 6,468 & 1,077 & 1,009 & 1,113 & 1,066 & 4,321 & 1,202 \\
\hline CO6_HUMAN & Complement component C6 & 1,019 & 1,020 & 0,847 & 0,962 & 8,119 & 0,951 & 0,953 & 1,090 & 0,998 & 6,502 & 1,037 \\
\hline FETUA_HUMAN & Alpha-2-HSglycoprotein & 1,035 & 0,934 & 0,987 & 0,985 & 4,127 & 0,929 & 1,053 & 0,978 & 0,987 & 5,091 & 1,002 \\
\hline GELS_HUMAN & Gelsolin & 0,843 & 1,118 & 1,024 & 0,995 & 11,396 & 1,214 & 0,840 & 0,947 & 1,000 & 15,738 & 1,005 \\
\hline HEMO_HUMAN & Hemopexin & 0,908 & 1,035 & 1,129 & 1,024 & 9,044 & 1,110 & 0,941 & 0,883 & 0,978 & 9,662 & 0,955 \\
\hline HPT_HUMAN & Haptoglobin - LMW & 1,245 & 1,380 & 1,326 & 1,317 & 5,561 & 0,666 & 0,719 & 0,614 & 0,666 & 4,276 & 0,506 \\
\hline HPT_HUMAN & Haptoglobin - HMW & 1,624 & 2,009 & 1,464 & 1,6 & 22,875 & 0,295 & 0,423 & 0,478 & 0,399 & 7,669 & 0,235 \\
\hline IGHA1_HUMAN & Ig alpha- 1 chain $C$ region & 1,372 & 1,087 & 1,243 & 1,234 & 11,680 & 0,514 & 0,912 & 0,696 & 0,707 & 16,277 & 0,573 \\
\hline KNG1_HUMAN & Kininogen-1 LMW & 0,879 & 0,836 & 0,843 & 0,853 & 1,895 & 1,146 & 1,104 & 1,168 & 1,139 & 2,641 & 1,336 \\
\hline KNG1_HUMAN & Kininogen-1 HMW & 1,220 & 1,294 & 1,201 & 1,238 & 4,001 & 0,706 & 0,758 & 0,715 & 0,726 & 2,244 & 0,586 \\
\hline RET4_HUMAN & Retind-binding protein 4 & 1,862 & 2,549 & 1,971 & 2,127 & 30,167 & 0,166 & 0,219 & 0,155 & 0,180 & 2,786 & 0,085 \\
\hline SAA_HUMAN & Serum amyloid A protein & 1,663 & 2,274 & 1,691 & 1,876 & 28,179 & 0,192 & 0,303 & 0,228 & 0,241 & 4,627 & 0,128 \\
\hline TRFE_HUMAN & Serotransferrin & 0,719 & 0,609 & 0,756 & 0,695 & 6,237 & 1,413 & 1,357 & 1,296 & 1,356 & 4,788 & 1,951 \\
\hline TTHY_HUMAN & Transthyretin & 0,992 & 0,928 & 1,013 & 0,978 & 3,640 & 0,985 & 1,073 & 0,962 & 1,006 & 4,774 & 1,030 \\
\hline VTDB_HUMAN & Vitamin D-binding protein & 1,122 & 1,088 & 1,183 & 1,131 & 3,906 & 0,813 & 0,912 & 0,857 & 0,861 & 4,058 & 0,761 \\
\hline ZA2G_HUMAN & Zinc-alpha-2-glycoprotein & 0,860 & 0,883 & 0,806 & 0,850 & 3,215 & 1,075 & 1,137 & 1,140 & 1,117 & 2,982 & 1,315 \\
\hline AACT_HUMAN & Alpha-1-antichymotrypsn & 1,115 & 1,209 & 1,158 & 1,161 & 3,845 & 0,842 & 0,813 & 0,769 & 0,808 & 3,012 & 0,696 \\
\hline
\end{tabular}

Tabelle 17: Spotquantitäten der 26 untersuchten Proteine des DIGE-Experimentes D. Vergleich von depletiertem Serum der Gruppe Rheuma (RA) mit dem der Gruppe Gesund (GES). (MW) Mittelwert; (SD) Standardabweichung, (Ratio) Quotient der Mittelwerte der Vergleichgruppen. Spotquantitäten sind in Volumen-Prozent angegeben. 


\section{Abstract}

The rheumatoid arthritis (RA) is a chronic systematic inflammatory disorder that affects primarily the joints and will lead to a progressive destruction of the articular cartilage and ankylosis. Other clinical manifestations are inflammation in the lungs, pericardium, pleura, scleara and subcutanious nodular lesions. About $1 \%$ of the world's population is affected by RA whereas women are affected three times more often than man. The onset is most frequent in 40 to 50 years.

Although there are specific immunological blood tests and the diagnosis is fairly well categorized by the criteria for the classification of rheumatoid athritis the confirmation of the diagnosis strikes often too late for a matutinal therapy. This circumstance leads to an arising need for valid biomarkers in order to diagnose this disease as early as possible.

In this work human serum and activated synovial fibroblasts were analysed via a two step proteomic approach to discover a protein-based marker for the RA. In the first step activated synovial fibroblasts were obtained by digest with collagenase of human synovia, cultivated and analyzed by 2D-SDS-PAGE. Specific fragments of vimentin were significantly regulated and could only be detected in the fibroblasts of RA-patients. Vimentin is aspersed to be a mediator in the inhibition of the release of p53 and could modulate the resistence against apoptosis in these cells.

The second step human serum was analysed by DIGE. Prior to analysis the serum was depleted using a MARC (multiple affinity removal column) in oder to visualise low abundant proteins. Serum amyloid A protein (SAA) was significantly upregulated in the sera of RA compared to the sera of osteoarthritis (OA) patients. SAA is a key mediator in the release of matrix-metallo-proteases, modulates the release of inflammatory cytokines and could emerge to take an active part in the pathogenesis of the RA.

Furthermore a fractionation technique based on reverse-phase chromatography was developed to enhance the visualisation of low abundant proteins. 


\section{Danksagung}

Ich möchte mich hiermit ganz herzlich bei Prof. Dr. G.A. Müller für die Möglichkeit bedanken, dass ich meine Doktorarbeit in seinem Forschungslabor habe durchführen können und für die Bereitstellung des Themas.

Ich danke Frau Prof. Dr. Hoyer-Fender für die Betreuung meiner Doktorarbeit und für die anregenden Gespräche und Ideen. Prof. Dr. Groß danke ich für die freundliche Übernahme des Koreferats.

Ich danke Herrn PD Dr. Dihazi für seine engagierte und aufschlussreiche Betreuung meiner Arbeit. Für die Unterstützung im klinischen Bereich möchte ich Frau PD Dr. med. Blaschke danken. Ganz besonderer Dank geht an Dr. Mai von den Orthopädischen Kliniken Kassel gGmbH für die freundliche und kompetente Korrespondenz und die Bereitstellung der Synoviaproben, ohne die diese Arbeit kaum möglich gewesen wäre.

Ich danke dem Team der Proteomics Einheit, insbesondere Elke Brunst-Knoblich für die Unterstützung bei der Durchführung meiner Arbeit, sowie dem Team des Routinelabors unter der Leitung von Herrn Dr. Wessels für die Hilfe bei der Akquirierung der klinischen Daten. Dr. Nitin Argawal danke ich für die Einführung in den klinischen Laboralltag. Bei Rabi Raj Datta, Bettina Buchmaier, Moritz Hoffmann, Cosima Baumann und Souad Bazra möchte ich mich für die erfrischenden Momente im Alltag und das konstruktive freundschaftliche Arbeitsklima bedanken. Spezieller Dank geht an Hannes Vossfeld und Nadine Dannemann.

In der AG Klinische Chemie geht besonderer Dank an Dr. Streit für die Hilfe bei chromatographischen Fragestellungen und der freundlichen Bereitstellung des LC-Systems. Des Weiteren danke ich Dr. Asif für die Proteinidentifizierungsarbeiten.

Für die Einarbeitungszeit im Bereich LC danke ich ganz herzlich der AG Hanisch.

Dem Team der molekularen Gynäkologie danke ich für all die schöne Zeit, dabei insbesondere Martin Block, Dr. Stefanie Fister, Dr. Fadi Hussein und Antje Schubert.

Mein ganz besonderer herzlicher Dank gilt meinen Eltern für alles, was sie jemals für mich gemacht haben und noch tun werden.

Als letztes möchte ich Venita Daebel danken, die mir jeden Tag aufs Neue beweist, was Liebe, Geborgenheit und beispielloser Willen und Kraft bedeutet. Ohne sie wären die letzten Jahre sehr einsam, tier- und freudlos gewesen. 


\section{Lebenslauf}

$\begin{array}{ll}\text { Name } & \text { Streich } \\ \text { Vorname } & \text { Jan-Hendrik } \\ \text { Geburtsdatum } & \text { 15.Dezember } 1977 \\ \text { Geburtsort } & \text { Oldernburg i.O. } \\ \text { Familienstand } & \text { ledig } \\ \text { Staatsangehörigkeit } & \text { deutsch } \\ \text { Adresse } & \text { Neuer Kamp 16 } \\ & 25451 \text { Quickborn }\end{array}$

\section{Schulbildung}

1984 - 1988

Goethe-Schule, Quickborn

1988 - 1998

Elsensee-Gymnasium, Quickborn

$1995-1996$

South Fork High School, Stuart, FL 34997

Vereinigte Staaten von Amerika

\section{Ersatzdienst}

$1998-1999$

Herzchirurgische Intensivstation

Albertinen Krankenhaus, Hamburg

\section{Hochschulstudium}

$1999-2005$

Studium der Molekularen Biotechnologie

Universität Bielefeld

$05.2005-09.2005$

Abschluss: Diplom

Wissenschaftlicher Mitarbeiter im Bereich F\&E

Bibitec $\mathrm{GmbH}$

$11.2005-04.2006$

Promotion

Max Planck Institut für Biophysikalische Chemie

Göttingen

Seit 11.2005

Promotion

Nephrologie und Rheumatologie

Universitätsmedizin Göttingen 